\title{
Attention for Lyme prevention
}

Citation for published version (APA):

Beaujean, D. J. M. A. (2017). Attention for Lyme prevention: Educational tools to prevent tick bites and Lyme borreliosis. [Doctoral Thesis, Maastricht University]. GVO drukkers \& vormgevers B.V. https://doi.org/10.26481/dis.20170421db

Document status and date:

Published: 01/01/2017

DOI:

$10.26481 /$ dis.20170421db

Document Version:

Publisher's PDF, also known as Version of record

\section{Please check the document version of this publication:}

- A submitted manuscript is the version of the article upon submission and before peer-review. There can be important differences between the submitted version and the official published version of record.

People interested in the research are advised to contact the author for the final version of the publication, or visit the DOI to the publisher's website.

- The final author version and the galley proof are versions of the publication after peer review.

- The final published version features the final layout of the paper including the volume, issue and page numbers.

Link to publication

\footnotetext{
General rights rights.

- You may freely distribute the URL identifying the publication in the public portal. please follow below link for the End User Agreement:

www.umlib.nl/taverne-license

Take down policy

If you believe that this document breaches copyright please contact us at:

repository@maastrichtuniversity.nl

providing details and we will investigate your claim.
}

Copyright and moral rights for the publications made accessible in the public portal are retained by the authors and/or other copyright owners and it is a condition of accessing publications that users recognise and abide by the legal requirements associated with these

- Users may download and print one copy of any publication from the public portal for the purpose of private study or research.

- You may not further distribute the material or use it for any profit-making activity or commercial gain

If the publication is distributed under the terms of Article $25 \mathrm{fa}$ of the Dutch Copyright Act, indicated by the "Taverne" license above, 


\section{Attention for Lyme prevention}

Educational tools to prevent tick bites and Lyme borreliosis

Desirée Jacqueline Mathieu Angélique Beaujean 


\section{Colofon}

Copyright (C) 2017 by D.J.M.A. Beaujean. All rights reserved.

Cover illustration: Winkel van Sinke

Thesis layout: G. Meinsma

Printed by: GVO drukkers \& vormgevers B.V.

ISBN: 978-94-6332-137-2 


\title{
Attention for Lyme prevention
}

Educational tools to prevent tick bites and Lyme borreliosis

\author{
PROEFSCHRIFT
}

ter verkrijging van de graad van doctor aan de Universiteit Maastricht op gezag van de Rector Magnificus, Prof. dr. mr. R.M. Letschert volgens het besluit van het College van Decanen, in het openbaar te verdedigen op vrijdag 21 april 2017 om 10.00 uur

door

Desirée Jacqueline Mathieu Angélique Beaujean 


\section{Promotor}

Prof. dr. D. Ruwaard

\section{Co-promotores}

Dr. R. Crutzen

Dr. J.E. van Steenbergen (RIVM en Leids Universitair Medisch Centrum)

\section{Beoordelingscommissie}

Prof. dr. C.J.P.A. Hoebe (voorzitter)

Prof. dr. H.W. van den Borne

Prof. dr. J.W.R. Hovius (Academisch Medisch Centrum)

Prof. dr. ir. W. Takken (Wageningen University)

Prof. dr. N.K. de Vries

Reproduction of this thesis was financially supported by: DTT Multimedia, Flycatcher Internet Research, Ventoux producties, the National Institute for Public Health and the Environment (RIVM) and Maastricht University.

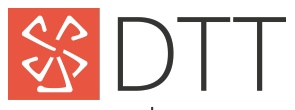

apps.web.games

\section{Fio FLYCATCHER}
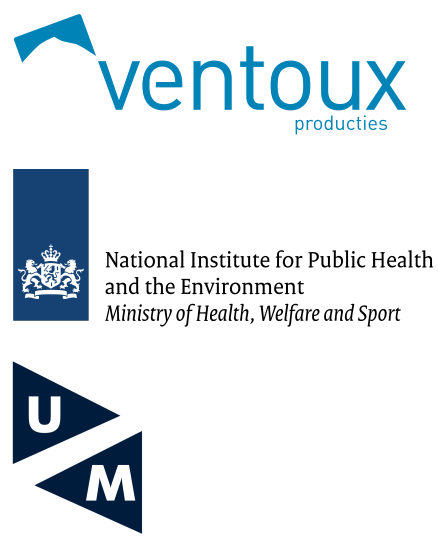


\section{Contents}

1 Introduction ....................... 1

I Inventory studies $\ldots \ldots \ldots \ldots \ldots \ldots \ldots \ldots$

2 Study on public perceptions and protective behaviors regarding Lyme disease among the general public in the Netherlands: implications for prevention programs $\ldots \ldots \ldots \ldots \ldots$

3 Determinants and protective behaviours regarding tick bites among schoolchildren in the Netherlands: a cross-sectional study . . . . . . . .

4 Using risk group profiles as a lightweight qualitative approach for intervention development: an example on prevention of tick bites and Lyme

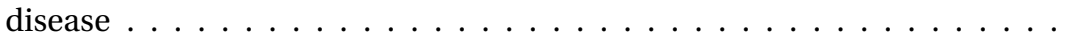

5 Developing requirements for a mobile app to support citizens in dealing with ticks and tick bites via end-user profiling ..........

II Evaluative studies $\ldots \ldots \ldots \ldots \ldots \ldots \ldots \ldots \ldots$

6 Comparing the effect of a leaflet and a movie in preventing tick bites and Lyme disease in The Netherlands . . . . . . . . . . . . . . . .

7 Education on tick bite and Lyme borreliosis prevention, aimed at schoolchildren in the Netherlands: comparing the effects of an online educational video game versus a leaflet or no intervention . . . . . . . 125

8 Prevention of tick bites: an evaluation of a smartphone app $\ldots \ldots$. . . 149 
9 Increase in ticks and Lyme borreliosis, yet research into its prevention on the wane . . . . . . . . . . . . . . . . . . 187

10 General discussion . . . . . . . . . . . . . . . . . . 191

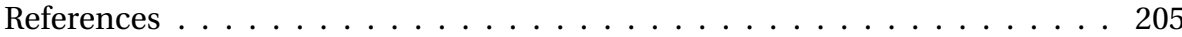

Valorization addendum . . . . . . . . . . . . . . . 221

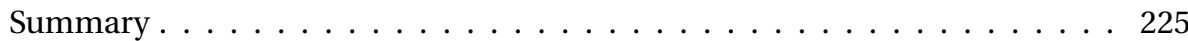

Samenvatting . . . . . . . . . . . . . . . . . . 229

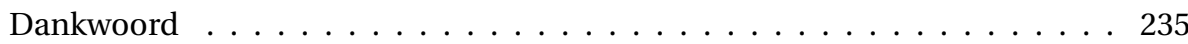

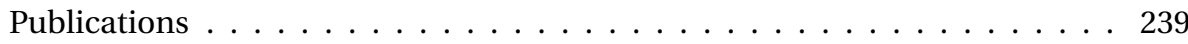

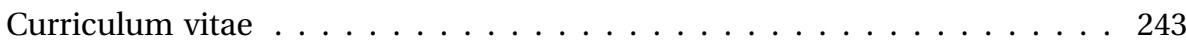




\section{Chapter 1}

\section{Introduction}

Partly published as book chapter:

D.J. Beaujean and H. Sprong. Evidence-based health promotion programmes and tools to prevent tick bites and Lyme borreliosis. In: M.A.H. Braks, S.E. van Wieren, W. Takken and H. Sprong editors, Ecology and prevention of Lyme borreliosis, Wageningen Academic Publishers, 2016. 


\section{The rising problem of tick bites and Lyme borreliosis in temperate climates}

Lyme disease, or Lyme borreliosis (LB), is now the most commonly reported tickborne disease in North Eastern USA and Europe [162]. This disease is named after the town Old Lyme, Connecticut, USA, where a link between tick-borne disease and a group of children, originally suspected of having juvenile arthritis, was noted in the mid 1970s [162]. Seven years later, Burgdorfer and colleagues were the first to culture the causative agent, Borrelia burgdorferi sensu stricto, from ticks in an endemic area [28]. In Europe, syndromes that have been reported in the past - as early as 1883 - can retrospectively be designated as being manifestations of $\mathrm{LB}[10]$. In this $\mathrm{PhD}$ thesis, the acronym $\mathrm{LB}$ will be used for Lyme borreliosis, also known as Lyme disease ${ }^{1}$.

\section{Vector}

Ticks are arachnids and can be divided into two families known as Ixodidae (hard ticks) and Argasidae (soft ticks). Hard ticks have a three-stage life-cycle, comprising larval, nymph, and adult stages, whereas soft ticks have two or more additional nymph stages (Figure 1.1). Larval hard ticks are typically $0.5 \mathrm{~mm}$ long (the size of a poppy seed) and have six legs. Nymphal ticks are about $1.5 \mathrm{~mm}$ long and adult unfed ticks about $3 \mathrm{~mm}$ long, although once they have fed they can enlarge to $11 \mathrm{~mm}$ in length. Both nymphs and adults have eight legs. Tick coloration varies between species, sexes, and different stages of engorgement. Unfed ticks can range from black to a red-brown color, but once engorged they can appear light pink, purple, dark red, or grey-blue.

LB is commonly transmitted to humans by Ixodes ricinus, a hard tick, known as the deer/sheep/castor bean tick. In general, uninfected tick larvae acquire the bacterium that causes LB by feeding on infected animals like small rodents, large mammals and birds. Ticks remain infected during their consecutive molting periods, enabling both nymphal and adult ticks to transmit the bacterium to other (larger) animals and humans. After their final blood meal, adult female ticks that have mated will usually lay uninfected eggs [47].

In the United States, Borrelia burgdorferi sensu stricto is the causative bacterium of LB and is mainly transmitted by the deer tick, Ixodes scapularis. By contrast, in Europe at least three major pathogenic Borrelia species, i.e. B. burgdorferi, B. garinii and B. afzelii are prevalent and able to cause LB and are primarily transmitted by the sheep ticks, Ixodes ricinus [172].

The most recent meta-analysis of surveillance data indicates that the overall mean prevalence of Borrelia infection in ticks in Europe is $13.7 \%$ (range $0-49.1 \%$ )

\footnotetext{
${ }^{1}$ Nevertheless, in some publications included in this thesis, Lyme disease (LD) was used for Lyme borreliosis. The choice of acronym depended on the scope and target audience of the relevant scientific journals. The publications are reproduced in an unmodified format in this thesis.
} 


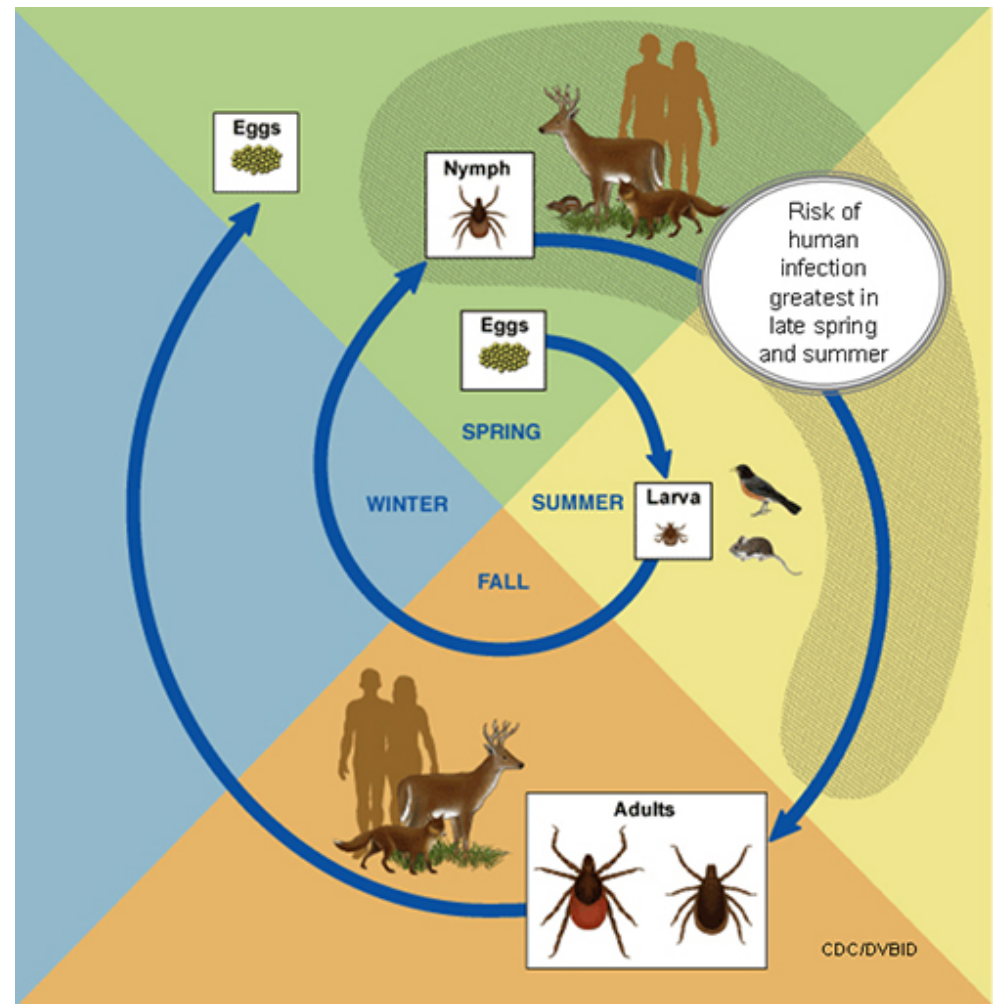

FIGURE 1.1: Lifecycle of ticks (source: http://www.cdc.gov/lyme/images/lifecycle . jpg, accessed June 1, 2016)

although the prevalence is higher in adults (18.6\%) than in nymphs $(10.1 \%)$ Central Europe (comprised of Austria, Czech Republic, Germany, Switzerland, Slovenia, and Slovakia) has by far the highest rates (nymphs $>11 \%$, adults $>20 \%$ ). Peak prevalence has recently been confirmed to be between $5^{\circ} \mathrm{E}$ and $25^{\circ}$ E longitude [136].

\section{Signs and symptoms}

Several days or weeks after a tick bite, in Borrelia-infected cases, early LB can occur. Although early infection can also be completely asymptomatic, typical of early LB include fever, headache, fatigue, and a characteristic skin rash called erythema migrans (EM). This is an expanding erythematous skin lesion with a central clearing located at the site of the tick bite. It typically appears after seven to 14 days, and can vary in size from 5 to $75 \mathrm{~cm}$ (median $15 \mathrm{~cm}$ ). Early LB symptoms can disappear spontaneously and respond well to antibiotic therapy. In Europe, $77 \%$ to $89 \%$ of all Lyme manifestations are EM [47]. If left untreated for 
several weeks or months, infection can spread and cause early disseminated LB with manifestations like early neuroborreliosis (3-16\% of Lyme manifestations), Lyme arthritis (5-7\%), and seldom a (myo)carditis with partial atrioventricular block $(<1 \%)$. If an infection is left untreated, after a period of several months or even years, late LB can occur. One could divide late Lyme manifestations into two groups: manifestations in which persistent Borrelia infection is causative for the ongoing symptoms, e.g., acrodermatitis chronica atrophicans (ACA), persistent (untreated) Lyme arthritis and neuroborreliosis; and manifestations in which other mechanisms, e.g., auto-immune phenomena or irreversible tissue damage, or unknown phenomena might play a role, leading to antibiotic-refractory Lyme arthritis, encephalopathy and dilated cardiomyopathy. Importantly, over half of the patients with late manifestations of LB do not remember having any EM symptoms [47].

\section{Diagnostics}

Clinical diagnosis of LB is based on the combination of symptoms (e.g., the typical EM rash), physical findings, and a history of possible exposure to infected ticks. Laboratory testing is helpful only if applied correctly and performed with validated methods in accredited laboratories, since laboratory testing of Borrelia is complicated. The best validated diagnostic tests are serological tests for the presence of Borrelia: a screening test (ELISA or enzyme immuno essay), followed by a confirmation test (immunoblot or PCR) on specific body fluids or tissues [32]. However, shortcomings of these tests need to be taken into account during diagnosis by health professionals. Furthermore, it is recommended to repeat this test after several weeks in patients with typical LB symptoms of short duration with negative results of serological Borrelia test. It is also worth pointing out that positive antibody tests may not differentiate between a previous infection and a present active infection. In this context, it is relevant to realize that the background seroprevalence (patients with a previous infection) is $4-8 \%$ in the Netherlands [86].

\section{Treatment}

Patients treated with appropriate antibiotics in the early stages of LB usually recover rapidly and completely. Oral antibiotics commonly prescribed include doxycycline, amoxicillin, or azithromycin. Patients with certain neurological or cardiac forms of illness may require intravenous treatment with drugs such as ceftriaxone or penicillin. Approximately 10 to $20 \%$ of patients who have received appropriate antibiotic treatment may still have persistent or recurrent symptoms; they are considered to have (PTLDS). However, it remains unclear if those symptoms are caused by a persistent Borrelia infection [32]. 


\section{Incidence}

In the USA, the number of people diagnosed with LB each year totals around 300,000 . Those LB cases are concentrated in the temperate Northeast and upper Midwest, with 14 states accounting for over $96 \%$ of cases reported [36]. This results in a mean incidence in these 14 states of 39.5 per 100,000 persons.

The endemic region in Europe runs from southern Scandinavia to central Spain and from Ireland to Russia [89]. Annual incidence rates in Europe seem to be lower in northern Europe compared to the southern parts of Central Europe, and range from less than 69 cases per 100,000 inhabitants in Sweden to about 350 per 100,000 inhabitants (e.g., parts of Slovenia, Germany and Austria, the Baltic coastline of southern Sweden, and some Estonian and Finnish islands) [136]. In many European countries, the incidence of the disease seems to be increasing in some areas. However, these trends are extremely heterogeneous and/or remain to be confirmed. Besides, all numbers are likely to be underestimates because case reporting is inconsistent and many infections go undiagnosed [58, 124]. Studies among Dutch general practitioners (GPs) have shown that the number of GP consultations for tick bites doubled between $1994(33,000)$ and $2001(65,000)$. The results of subsequent research in 2006 (population coverage 71\%) and 2009 (population coverage 65\%) again showed a strong increase in GP consultations for tick bites. According to these studies, in 2006 GPs assessed approximately 73,000 patients with tick bites, rising to 93,000 in 2009. It was not until 2014 that a decreased incidence in tick bite consultations was recorded: 82,000 patients [82, 81, 80, 79]. The number of cases of EM, the main hallmark manifestation of LB, has also steadily increased in recent years in the Netherlands (Figure 1.2). In 1994, EM was diagnosed in 6,500 patients (population coverage 88\%). By 2001 (population coverage 68\%) the number of cases of EM had doubled to 13,000 [172]. In subsequent recordings, the incidence had further increased to 17,000 in 2006, 22,000 in 2009, and 23,500 in 2014 [82, 81, 80, 79].

From these studies some risk areas emerged: South-Friesland, Achterhoek, Drenthe, Veluwe, Utrechtse Heuvelrug, dune areas and the West Frisian Islands. LB is endemic in the Netherlands.

This steady increase in EM cannot, or partly at best, be contributed to increased media attention or by improvements in EM recognition by GPs; according to experts in the Netherlands it is indicative of an actual increase of EM [86].

Until recently, no quantitative estimation of the actual disease burden of LB was available in order to utilize it for the prioritization of prevention and control efforts. Such an estimate can show which LB manifestations contribute most to LB burden, and makes it possible to compare its burden to the public health impact of other diseases. In the Netherlands, a recent study estimated the burden of LB expressed in Disability Adjusted Life Years (DALYs), a summary measure of disease burden that aggregates the impact of morbidity and mortality in one figure. Van den Wijngaard et al. found that LB has a substantial disease burden of 10.55 DALYs per 100,000 inhabitants. This is predominantly attributed to patients 

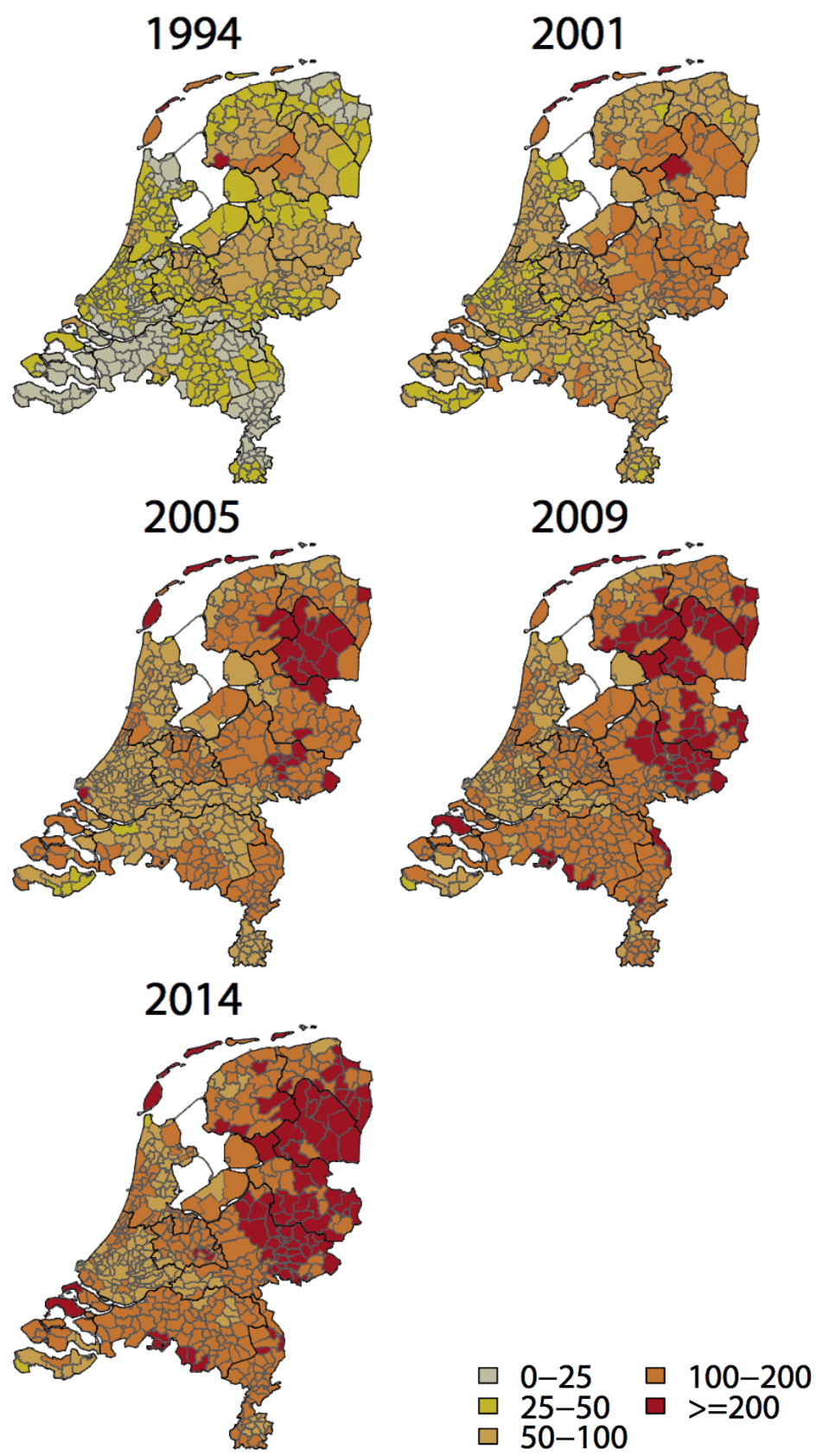

FigURE 1.2: Number of erythema migrans diagnoses per 100,000 inhabitants in the Netherlands in the period 1994-2014 (source: Nationale Atlas Volksgezondheid, version 4.18, 1 October 2014) 
with persisting symptoms attributed to LB (9.09 DALYs per 100,000 inhabitants), and to a lesser extent due to patients with EM (0.60 DALYs) and disseminated LB (0.86 DALYs). LB has the 12th highest disease burden when compared to the comprehensive DALY estimates for 32 other infectious diseases, largely based upon the 'Burden of Communicable Disease in Europe' (BCoDE)-project. This disease burden attributed to LB demonstrates the need for continued prevention and control efforts [173].

\section{Ways to prevent tick bites and Lyme borreliosis}

LB risk is specifically linked to tick abundance and exposure. Therefore higher risk is no longer considered to be associated with residency in rural areas, but with occupation (e.g., forestry work and farming) and especially with certain leisure activities (e.g., hiking, biking, camping, hunting, berry picking) in overgrown grass, bushes, and among leaf litter at trail edges. Risk is also stratified by age; children aged 5-14 years and adults aged 50-64 years are at highest risk of contracting LB [32]. For the record, in 1998 there was a promising and effective vaccine. This vaccine had an efficacy of $80 \%$ after three doses. However, high antibody titers did not persist long after vaccination and additional boosters would be necessary to maintain protective titers. Together with the suspicion that the vaccine had undesirable side effects, this contributed to the withdrawal of the vaccine from the market four years after its release [141].

Since there is currently no vaccine against LB, efforts are focused on other measures such as education of individuals and communities on how to prevent exposure to ticks (and therefore tick bites) and decrease the risk of LB in case of a tick bite. It has been suggested that individual or community measures could form extremely effective preventive methods [180, 67, 44]. For example, in order to decrease the risk of tick bites and Borrelia transmission, people living in or visiting tick-infested areas are advised to avoid tick habitats, to wear long, lightcolored trousers (and to tuck them into their socks) and to use insect repellent that contains permethrin (on clothes) or N,N-Diethyl-meta-toluamide (DEET) (on clothes or directly on skin). After visiting or working in such areas, taking a shower is recommended and a thorough check for ticks should be performed, including careful inspection of the neck, armpits and groin. Tick bites can also be avoided by carefully inspecting and removing ticks from pets [62].

Any attached tick should be removed immediately with tweezers if available, by seizing and pulling steadily on the mouth parts, without twisting, and the attachment site should subsequently be disinfected [128]. Since ticks do not have a high probability of transmitting Borrelia until 12-24 hours after they begin to feed on their host, immediate removal of ticks is one of the most effective ways of avoiding Borrelia infection. For 3 months after the bite, the site of the bite should be monitored for signs of EM and a person's overall health should be monitored for other possible symptoms. All these measures are set down in 
national and international Lyme prevention guidelines. In the United States, the recommendations on LB are issued by the Centers for Disease Control and Prevention (CDC) [38]. In the Netherlands there is the multidisciplinary CBO practice guideline on LB by the former Quality Institute for Health Care (CBO), aimed at health professionals involved in the diagnosis, treatment and care of patients suffering from LB. Based on the CBO guideline, there is a guideline for public health care workers produced by the RIVM's National Coordination Center for Communicable Disease Control (LCI) [32, 101]. According to these Dutch guidelines, the measures to prevent tick(s) (bites) and LB include:

1. avoiding tick areas;

2. wearing protective clothing;

3. using insect repellent;

4. removing ticks promptly;

5. applying pesticides;

6. reducing tick habitat.

While it is sensible to take preventive measures against ticks year-round, one should be extra vigilant in warmer months (spring and summer) when ticks are most active. Since applying pesticides and reducing tick habitat (measures 5 and 6) are measures which cannot be performed by an individual, these are not covered in this thesis. The first three abovementioned measures aim to prevent tick bites before they ever occur. This is classified as primary prevention. The fourth measure, removing ticks promptly, aims to improve early detection of a tick bite through checking the body of exposed persons, and can be classified as secondary prevention. In this thesis we focus on these primary and secondary prevention measures instead of treating patients who have become infected (tertiary prevention). Table 1.1 presents these four measures as outlined in the Dutch guidelines of CBO and LCI [32, 101].

\section{The need for health education on prevention of tick bites and Lyme borreliosis}

The preventive measures to reduce the risk of tick exposure (primary prevention measures) or checking the body for ticks (secondary prevention) are well-known, but universally the uptake is poor. Research in areas where LB is endemic has demonstrated that despite adequate knowledge about its symptoms and transmission, many people do not act in a way to reduce their risk of infection [46]. Daltroy and Malouin demonstrated that public education on ticks and LB decreases the chance to contract $[52,108]$. In other words, there is a need for 
TABLE 1.1: Selection of measures to prevent tick bites and LB according to the Dutch guidelines of CBO and LCI

\section{Avoiding tick areas}

During the 'tick season' (March to November), stay on the beaten paths and avoid contact with dense vegetation, wetlands with high grass, areas with leaf litter under trees, and shrubbery. Ticks are highly prevalent in the Netherlands, in wetlands on the ends of blades of grass, in bushy areas with high grass (up to 1.5 meter) and leaf litter. Depending on the ambient temperature and winter severity, in the Netherlands ticks are active from February/March to October/November [87]. There are two peaks in activity: a major spring peak in April/May, and a second in fall in September. Under favorable conditions for ticks, e.g., within a constantly moist humus layer in forests, both peaks may blend together. The tick density varies per season and per individual geographic area. If one avoids contact with vegetation, then one can assume that there is no chance of contact with ticks. There are no studies showing that avoiding certain areas prevents infection. A longitudinal study indicated that in the Netherlands the chance to get LB is greatest in dune areas, followed by forest areas, (city)parks and moorlands [184].

Wearing protective clothing

During the 'tick season' (March to November), wear protective clothing (long pants with pant legs into socks, closed shoes, and long sleeved tops). Ticks are more visible on lightcolored clothing. In case of potential occupational exposure to ticks, the employer must provide protective clothing to employees. A prospective study among a rural community in North-Western California in the USA showed that wearing protective clothes (long versus short sleeves and pants) during outdoors activities led to less cases of LB [99]. In addition, a case control study demonstrated that persons who wore protective clothing during outdoors activities were less likely to get LB than persons who did not wear protective clothing (corrected odds ratio $0.6,95 \%$ confidence interval [95\%-CI] 0.5-0.7) [180]. A study among soldiers showed that seropositivity against anti-tick salivary gland protein was higher among soldiers who did not wear pant legs in socks than among those who did (corrected odds ratio 2.8, 95\%-CI 1.17.1) [143]. A randomized cohort study demonstrated that Ixodes ricinus is more attracted to light-colored clothes than to dark-colored clothes [164]. Deciding whether or not to wear protective clothes is a personal responsibility. However, in the case of occupational risk of exposure to ticks, protective clothing should be provided to the employer.

\section{Using insect repellent}

During the 'tick season' (March to November), spray or grease your clothes or skin with a DEET-containing repellent. Wear permethrin impregnated clothing in case of occupational exposure to ticks. Permethrin is a synthetic pyretroid and is deadly to ticks. In the Netherlands, it is not permitted to sell permethrin as a separate product, but it is allowed to pre-treat clothes with it. Permethrin-treated clothes preserve their protective function through several washings.

\section{Removing ticks promptly}

Remove ticks promptly. Borrelia bacteria live in the intestines of the tick and whilst the tick sucks the host's blood, the bacteria move upwards to eventually come into contact with the host's blood. Animal studies have shown that transmission of Borrelia burgdorferi to the host starts 24 hours following attachment, sometimes sooner [127, 168]. Removing infected ticks more than 24 hours after attachment therefore means an increased risk of Borrelia bacteria transmission. There is no scientific evidence suggesting there is an increased risk of LB when the tick's head remains in the skin and only the tick's body is removed. 
educational interventions. In 2012 Mowbray published a systematic review, covering the period 1995-2010, of educational and communicational interventions to prevent tick-borne disease [113]. Nine studies were appraised, of which the most recent one was published in 2008. Based on the limited number and low quality of studies available at the time, they recommended that more research into education and communicational interventions should be conducted. Focus should be directed at improving evidence-based insights regarding the promotion of preventive behaviors among those members of the general public that exposed a greater risk of contracting LB. In 2015 we repeated Mowbray's review, covering the period January 1995-May 2015 [14]. Perhaps surprisingly, our study yielded exactly the same studies as already included in their review. This means no new studies on the topic of education and communication interventions to prevent tick borne diseases were published in the seven years following 2008.

\section{Objectives and research questions}

The studies in this thesis were conducted to gain insight into the effect of educational interventions on the prevention of tick bites and LB, in order to develop a theory- and evidence based health promotion program to decrease tick bites and LB in the Netherlands.

The citizens' initiative and the subsequent national expert consultation on tick bites and LB of the LCI in 2010 gave rise to the studies covered in this dissertatio [2]. The citizens' initiative requested, among other things, more education on ticks and LB and on a larger scale. One of the conclusions of the national expert consultation was that efforts concerning education on ticks and LB should be intensified and centrally coordinated by RIVM.

As first response to this request, the determinants of preventive behaviors of the Dutch public in relation to tick bites and LB needed to be studied. This then informed the framework of educational interventions.

Therefore, the first objective of this thesis was to gain insight into the determinants of preventive behaviors in relation to tick bites and LB of the general public in the Netherlands. School children are a distinct and vulnerable risk group for tick bites and LB. They are frequently active in bushy areas with high grass and, additionally, LB can be more difficult to identify in children because some of its symptoms are similar to those of other diseases that are quite common in the first years of life. Therefore, one of the interventional studies focused specifically on this group.

The second objective of this thesis was to evaluate the effects of four newly developed interventions (movie, leaflet, mobile app and a serious game) on the behavior and related determinants of the adult general public and schoolchildren in the Netherlands. 


\section{Research questions}

The following research questions were drawn up:

1. What are the determinants and protective behaviors in relation to tick bites and Lyme disease of the general public in the Netherlands?

2. What are the determinants and protective behaviors in relation to tick bites and Lyme disease of schoolchildren in the Netherlands?

3. What are the profiles of the risk groups, in order to develop an intervention on prevention of tick bites and Lyme disease?

4. What are requirements for developing a mobile app on the prevention of ticks and Lyme disease?

5. What are the effects of a leaflet and a movie on the determinants and protective behaviors in relation to tick bites and Lyme disease among the general public in the Netherlands?

6. What is the effect of the online educational video game 'Teekcontrol' on the determinants and protective behaviors in relation to tick bites and Lyme disease among schoolchildren in the Netherlands?

7. What is the effect of the mobile app 'Tekenbeet' on the determinants and protective behaviors in relation to tick bites and Lyme disease among the general public in the Netherlands?

\section{Outline}

Part I of this thesis focuses on behaviors and related determinants in relation to tick bites and LB among the general public (Chapter 2) and school children (Chapter 3). These studies are baseline measurements among the target groups and give guidance to the development of subsequent interventions.

Many public health campaigns use a one-size-fits-all strategy to achieve their desired effect. Public health campaigns for tick bites and LB in many countries convey all relevant preventive measures to all members of the public. Although preventing tick bites (e.g., by wearing protective clothing or using repellants) and checking for tick bites after visiting a risk area are effective and cost-efficient methods to prevent an individual from contracting a tick-borne disease, public compliance to these methods is poor. Therefore, in Chapter 4 we aimed to identify the group of individuals within the general Dutch population that are at high risk of being bitten by a tick or developing LB and to describe thoroughly their characteristics and behavioral determinants. These so called qualitative 'risk group profiles' can be used in addition to the quantitative results of the 
survey (Chapter 2) to determine the features and content of a targeted communication strategy about ticks and LD. In contrast to a leaflet or a movie, a mobile app is an interactive educational tool. Therefore, the development requires a thorough investigation of the needs of the designated end users and the context of its use. In Chapter 5 we discuss the development of requirements for a mobile app aimed at supporting the general public to deal with ticks and tick bites. With requirements is meant the specifications of what the technology should do, should look like, and how it should be implemented.

In Part II of this thesis, three evaluation studies (Chapters 6, 7, and 8) investigate the effects of four interventions on the prevention of tick bites and LB. Based on the results of previous public health studies (Chapter 2) and the riskgroup profiles (Chapter 4), a leaflet and a short movie on the prevention of tick bites and LB were developed and evaluated (see Chapter 6). Furthermore, based on the results of the studies among an adult population in Part I of this thesis (Chapters 2, 4, and 5), a smartphone app 'Tekenbeet' was developed and evaluated (Chapter 7). Since children are a distinct and vulnerable risk group for tick bites and LB, an intervention aimed specifically at children was deemed necessary. Based on the results of the study about knowledge, attitudes, beliefs and behaviors of school children (Chapter 3), an online serious video game 'Teekcontrol' was developed. Chapter 8 presents an evaluation study on the effects of this online educational video game.

Part III reflects on the findings in the individual studies and puts them into perspective. Before focusing on the main findings, the theoretical and methodological considerations and recommendations for public health practice, policy and research in Chapter 10, Chapter 9 highlights the impact of all published educational and/or behavioral interventions aimed at encouraging protective behaviors against tick-borne disease, covering the period 1998-2015 as published in an editorial. Table 1.2 shows an overview of studies included in this thesis and in Table 1.3 the interrelationship between all chapters is presented. 
TABLE 1.2: Overview of studies presented in this thesis

\begin{tabular}{|c|c|c|c|c|c|}
\hline Part & Chapter & Study subject & Study design & Participants & Sample size \\
\hline & 1 & Introduction & & & \\
\hline \multirow[t]{4}{*}{$\begin{array}{l}\text { I } \\
\text { Inventory } \\
\text { studies }\end{array}$} & 2 & $\begin{array}{l}\text { Determinants and } \\
\text { protective } \\
\text { behaviors among } \\
\text { adults in the } \\
\text { general public }\end{array}$ & $\begin{array}{l}\text { Cross- } \\
\text { sectional } \\
\text { study }\end{array}$ & $\begin{array}{l}\text { Members of a } \\
\text { representative } \\
\text { Internet panel } \\
\text { (adults } \geq 18 \text { years) }\end{array}$ & 550 \\
\hline & 3 & $\begin{array}{l}\text { Determinants and } \\
\text { protective } \\
\text { behaviors among } \\
\text { school children }\end{array}$ & $\begin{array}{l}\text { Cross- } \\
\text { sectional } \\
\text { study }\end{array}$ & $\begin{array}{l}\text { School children aged } \\
9-13 \text { years }\end{array}$ & $\begin{array}{l}1,447 \\
\text { children } \\
\text { from } 40 \\
\text { primary } \\
\text { schools }\end{array}$ \\
\hline & 4 & $\begin{array}{l}\text { Risk group } \\
\text { profiles }\end{array}$ & $\begin{array}{l}\text { In-depth semi- } \\
\text { structured } \\
\text { interviews }\end{array}$ & $\begin{array}{l}\text { Visitors of two } \\
\text { municipal health } \\
\text { services, travel health } \\
\text { clinics, and parents } \\
\text { of school children }\end{array}$ & 25 \\
\hline & 5 & $\begin{array}{l}\text { Requirements for } \\
\text { a mobile app }\end{array}$ & $\begin{array}{l}\text { In-depth semi- } \\
\text { structured } \\
\text { interviews }\end{array}$ & $\begin{array}{l}\text { Organizational } \\
\text { stakeholders and } \\
\text { designated end-users } \\
\text { of the app }\end{array}$ & 25 \\
\hline \multirow[t]{3}{*}{$\begin{array}{l}\text { II } \\
\text { Evaluative } \\
\text { studies }\end{array}$} & 6 & $\begin{array}{l}\text { Comparing the } \\
\text { effect of a leaflet } \\
\text { and a movie }\end{array}$ & $\begin{array}{l}\text { Randomized } \\
\text { controlled trial }\end{array}$ & $\begin{array}{l}\text { Members of a } \\
\text { representative } \\
\text { Internet panel } \\
\text { (adults } \geq 18 \text { years) }\end{array}$ & $\begin{array}{l}1,677 \text { at } \mathrm{t} 1 ; \\
361 \text { extra at } \\
\mathrm{t} 2\end{array}$ \\
\hline & 7 & $\begin{array}{l}\text { Comparing the } \\
\text { effect of an online } \\
\text { serious video } \\
\text { game and a leaflet }\end{array}$ & $\begin{array}{l}\text { Cluster- } \\
\text { randomized } \\
\text { controlled trial }\end{array}$ & $\begin{array}{l}\text { School children aged } \\
9-13 \text { years }\end{array}$ & $\begin{array}{l}887 \text { children } \\
\text { from } 25 \\
\text { primary } \\
\text { schools }\end{array}$ \\
\hline & 8 & $\begin{array}{l}\text { Evaluation of a } \\
\text { smartphone app }\end{array}$ & $\begin{array}{l}\text { Quasi- } \\
\text { experimental } \\
\text { study }\end{array}$ & $\begin{array}{l}\text { Visitors of the website } \\
\text { www.rivm.nl/tekenbeet }\end{array}$ & $\begin{array}{l}554 \text { on } \mathrm{t} 1 \\
238 \text { on } \mathrm{t} 2\end{array}$ \\
\hline \multirow[t]{2}{*}{$\begin{array}{l}\text { III } \\
\text { Reflections } \\
\text { and } \\
\text { current } \\
\text { thoughts }\end{array}$} & 9 & $\begin{array}{l}\text { Reflections based } \\
\text { on a review of } \\
\text { educational and } \\
\text { communicational } \\
\text { interventions to } \\
\text { prevent } \\
\text { tick-borne } \\
\text { diseases }\end{array}$ & $\begin{array}{l}\text { Systematic } \\
\text { review } \\
1998-2015\end{array}$ & & 9 studies \\
\hline & 10 & Discussion & & & \\
\hline
\end{tabular}


TABLE 1.3: Interrelationship between the chapters in Part I, II and III.

1. Introduction

\section{Part I Inventory studies}

2. Determinants adults

3. Determinants children

4. Risk group profiles

5. Requirements app

\section{Part II Evaluative studies}

$\Rightarrow \quad 6$. Effect movie and leaflet

$\Rightarrow \quad$ 8. Effect app

$\Rightarrow \quad 7$. Effect game

$\Rightarrow \quad 6$. Effect movie and leaflet

$\Rightarrow \quad 7$. Effect game

$\Rightarrow \quad$ 8. Effect app

$\Rightarrow \quad$ 8. Effect app

Part III Reflections and current thoughts

9. Reflections based on a systematic review

10. Discussion 


\section{Part I}

\section{Inventory studies}




\section{Chapter 2}

\section{Study on public perceptions and protective behaviors regarding Lyme disease among the general public in the Netherlands: implications for prevention programs}

Published as:

Beaujean DJ, Bults M, van Steenbergen JE, Voeten HA. Study on public perceptions and protective behaviors regarding Lyme disease among the general public in the Netherlands: implications for prevention programs. BMC Public Health 2013 Mar 15;13:225. 


\section{Abstract}

Background: Lyme disease (LD) is the most common tick-borne disease in the United States and in Europe. The aim of this study was to examine knowledge, perceived risk, feelings of anxiety, and behavioral responses of the general public in relation to tick bites and LD in the Netherlands.

Methods: From a representative Internet panel a random sample was drawn of 550 panel members aged 18 years and older (8-15 November 2010) who were invited to complete an online questionnaire.

Results: Response rate $(362 / 550,66 \%)$. This study demonstrates that knowledge, level of concern, and perceived efficacy are the main determinants of preventive behavior. $35 \%$ ( $n=125 / 362)$ of the respondents reported a good general knowledge of LD. While 95\% ( $n=344 / 362)$ perceived LD as severe or very severe, the minority ( $n=130 / 362,36 \%$ ) perceived their risk of LD to be high. Respondents were more likely to check their skin after being outdoors and remove ticks if necessary, than to wear protective clothing and/or use insect repellent skin products. The percentage of respondents taking preventive measures ranged from $6 \%$ for using insect repellent skin products, to $37 \%$ for wearing protective clothing. History of tick bites, higher levels of knowledge and moderate/high levels of worry were significant predictors of checking the skin. Significant predictors of wearing protective clothing were being unemployed/retired, higher knowledge levels, higher levels of worry about LD and higher levels of perceived efficacy of wearing protective clothing.

Conclusions: Prevention programs targeting tick bites and LD should aim at influencing people's perceptions and increasing their knowledge and perceived efficacy of protective behavior. This can be done by strengthening motivators (e.g. knowledge, concern about LD, perceived efficacy of wearing protective clothing) and removing barriers (e.g. low perceived personal risk, not knowing how to recognize a tick). The challenge is to take our study findings and translate them into appropriate prevention strategies.

\section{Background}

Lyme disease (LD) is the most common tick-borne disease in the United States and in Europe. In the Netherlands, the number of General Practitioner (GP) consultations for tick bites has increased from 191 per 100,000 in 1994 to 564 per 100,000 in 2009 [82]. In 1994, the incidence of patients visiting the GP for Erythema migrans (EM, an asociated symptom) was estimated at 39 per 100,000 inhabitants. This number increased to 134 per 100,000 in 2009 [82]. Similar trends have been observed in other European countries [152]. The emergence 
of Lyme borreliosis may have been partly caused by an increased awareness among citizens and medical personnel, and changes in pathogen and vector populations [77].

Transmission of LD requires the presence in the area of: (1) the spirochete Borrelia burgdorferii sensu lato (in Europe) in an animal reservoir that is capable of transmitting the spirochetes to feeding ticks; (2) the vector, in European ticks belonging to the Ixodes ricinus group; and (3) susceptible hosts, including humans. Forested areas and recreational sites such as parks and gardens are associated with a higher risk of tick bites [68].

In humans LD develops in three stages. In the first stage (the early localized infection), people may experience fever, headache, fatigue and depression. The most commonly recognized symptom at this stage (occurring in about $90 \%$ of patients) is a circular red skin rash around the place of the tick bite: erythema migrans. Antibiotics administered at this stage will prevent further stages developing. Untreated, the infection may spread from the site of the bite to other parts of the body, producing an array of distinct symptoms that may come and go, including: additional EM lesions in other areas of the body, facial or Bell's palsy (loss of muscle tone on one or both sides of the face), severe headaches and neck stiffness due to meningitis (inflammation of the spinal cord), pain and swelling in the large joints (such as knees), shooting pains that may interfere with sleep, heart palpitations and dizziness due to changes in the heartbeat. This is called the second stage (early disseminated stage). Many of these symptoms will resolve over a period of weeks to months, even without treatment. However, a lack of treatment can result in additional complications. Approximately $60 \%$ of patients with an untreated infection may begin to have intermittent bouts of arthritis, with severe joint pain and swelling. Without treatment, LD enters the third stage after several months. During this stage, the patients develop chronic symptoms that can affect a wide range of body parts, including the brain, nerves, joints and the heart [40].

Recommendations for first line treatment from most European countries and the USA specify doxycycline or amoxicillin, with minor differences in doses and treatment duration. Both agents have proven efficacy, but a small proportion of patients have persistent symptoms following appropriate treatment for LD [8]. Because no vaccine is available and effective measures for controlling tick populations are still in the experimental phase or insufficient, health education is considered the most important approach for preventing LD. The National Institute of Public Health and The Environment (RIVM) provides information on public health topics to professionals and to the general public. This includes a national guideline on the prevention and control of LD for professionals [101] and several brochures for the general public. In the Netherlands, the local public health services are responsible for sending out the guideline and brochures to professionals (e.g. GP's, camping holders) and to the public.

Preventive strategies include the avoidance of tick-infested areas, the use of protective clothing (e.g. wearing long-sleeved shirts and long trouserpants, which 
reduce the area of exposed skin), routine body checks for ticks after being outdoors, and the use of tick repellents on either the skin or clothing.

Despite the availability of Lyme prevention advice, public compliance with the LD-guidelines could be improved [129]. Surveillance of perceptions and behavioral responses of the general public to ticks and LD is required for improving health risk communication and achieving successful changes in public behavior $[75,67,24,3,31]$.

However, in the Netherlands very little is known about the perception and protective behavior of people in relation to the prevention of tick bites and LD [95]. In 2010 Maat and Konings found in their study among 600 residents in the Southwest of the Netherlands that many respondents lacked skills for recognizing and removing ticks, underestimated their personal risk for tick bites and found protective measures exaggerated [107]. They concluded that new prevention strategies should focus on self-efficacy, risk perception, and the presentation of alternative measures, e.g. skin check instead of wearing protective clothing. In the present study our aim was to examine the knowledge, perceived risk, feelings of anxiety, and behavioral responses of the Dutch general public related to ticks and LD. The questionnaire was based on an integrated model to explain health behavior, including constructs from the Protection Motivation Theory and the Health Belief Model [120, 42]. Protection Motivation theory has been used as a model for predicting health behavior. A threat appraisal is formed by an individual based on their perceived likelihood of a particular event occurring and their perceived severity of the event. The way in which an individual chooses to respond to a threatening situation is termed their coping appraisal, and is based on both the belief that uptake of a recommended behavior will resolve the threat (response efficacy), and an individual's belief in his/her own ability to effectively perform the behavior (selfefficacy).

In the Health Belief Model, perceptions of the individual are at the core of the model, which posits that the beliefs of individuals about their own susceptibility to a health threat, their perceptions about the severity of that threat, and their perceptions about the benefits and barriers associated with a particular protective action, will determine whether or not they adopt that action. Extensions to the model suggest that the 'self-efficacy' (their belief in their own ability to perform a given behavior) of an individual also plays a strong role in determining whether a behavior is adopted, as does the existence of cues to action that prompt or remind someone to engage in a particlar behavior.

The results will act as a guide for further development of effective LD prevention programs by identifying those measures most likely to be adopted by the general public in the Netherlands. 
TABLE 2.1: Perceptions regarding Lyme disease and preventive measures $(n=362)$

\begin{tabular}{|c|c|c|c|c|c|c|c|c|c|c|c|c|c|c|c|c|}
\hline \multirow{3}{*}{ Knowledge (5 statements) ${ }^{2}$} & \multicolumn{3}{|c|}{ Gender } & \multicolumn{4}{|l|}{ Age } & \multicolumn{4}{|c|}{ Education } & \multicolumn{3}{|c|}{ Employment status } & \multicolumn{2}{|c|}{ Overall } \\
\hline & \multirow[t]{2}{*}{$\begin{array}{l}\text { Male } \\
\text { (\%) }\end{array}$} & \multirow[t]{2}{*}{$\begin{array}{l}\text { Female } \\
\text { (\%) }\end{array}$} & $\begin{array}{l}p \text { - } \\
\text { value }\end{array}$ & $\begin{array}{l}\text { 18-29 } \\
\text { (\%) }\end{array}$ & $\begin{array}{l}30-49 \\
(\%)\end{array}$ & $\begin{array}{l}\geq 50 \\
(\%)\end{array}$ & $\begin{array}{l}p \text { - } \\
\text { value }\end{array}$ & $\begin{array}{l}\text { Low } \\
\text { (\%) }\end{array}$ & $\begin{array}{l}\text { Middl } \\
\text { (\%) }\end{array}$ & $\begin{array}{l}\text { High } \\
(\%)\end{array}$ & $\begin{array}{l}p- \\
\text { value }\end{array}$ & $\begin{array}{l}\text { Employed } \\
\text { (\%) }\end{array}$ & $\begin{array}{l}\text { Unemployed } \\
\text { retired (\%) }\end{array}$ & $\begin{array}{l}p \text { - } \\
\text { value }\end{array}$ & $\%$ & $n / n_{\text {total }}$ \\
\hline & & & & & & & & & & & & & & & & \\
\hline 4 or 5 correct & 31 & 38 & ns & 31 & 35 & 35 & ns & 33 & 35 & 36 & ns & 32 & 38 & ns & 35 & $(125 / 362)$ \\
\hline \multicolumn{17}{|c|}{ Perceived severity (scale 1-5; not at all-very severe/awful) } \\
\hline Seriousness of LD & & & & & & & & & & & & & & & & \\
\hline score 4-5 (severe/very severe) & 93 & 97 & 0.047 & 96 & 97 & 94 & ns & 94 & 97 & 93 & ns & 95 & 95 & ns & 95 & $(344 / 362)$ \\
\hline Severity being diagnosed with LD in the next $12 \mathrm{r}$ & months & & & & & & & & & & & & & & & \\
\hline score $4-5$ (awful/very awful) & 94 & 97 & ns & 100 & 96 & 94 & ns & 96 & 96 & 95 & ns & 95 & 95 & ns & 95 & $(345 / 362)$ \\
\hline Perceived vulnerability (scale 1-5; no & ry susc & ceptible/ & /likely) & & & & & & & & & & & & & \\
\hline Susceptibility to LD & & & & & & & & & & & & & & & & \\
\hline score $4-5$ (quite susceptible/very susceptible) & 38 & 34 & ns & 43 & 33 & 36 & ns & 31 & 35 & 44 & ns & 38 & 33 & ns & 36 & $(130 / 362)$ \\
\hline Likelihood being diagnosed with LD in the next 1 & $12 \mathrm{mon}$ & & & & & & & & & & & & & & & \\
\hline score 4-5 (likely/very likely) & 4 & 4 & ns & 2 & 4 & 5 & ns & 3 & 7 & 2 & ns & 5 & 3 & ns & 4 & $(15 / 362)$ \\
\hline Feelings of concern (scale $1-5$; not at all-very $u$ & vorried & & & & & & & & & & & & & & & \\
\hline score 3-5 (a bit worried/worried/very worried) & 51 & 55 & ns & 37 & 60 & 54 & 0.03 & 53 & 55 & 52 & ns & 56 & 50 & ns & 53 & $(193 / 362)$ \\
\hline Perceived efficacy (scale 1-5; certainly not-cert & tainly) & & & & & & & & & & & & & & & \\
\hline Wear protective clothing (score $4-5$ ) & 92 & 89 & ns & 78 & 91 & 94 & 0.005 & 90 & 91 & 90 & ns & 87 & 95 & 0.01 & 90 & $(327 / 362)$ \\
\hline Check your skin after being outdoors (score $4-5$ ) & 79 & 87 & 0.04 & 88 & 81 & 84 & ns & 82 & 85 & 84 & ns & 82 & 85 & ns & 83 & $(302 / 362)$ \\
\hline Remove tick from your skin (score $4-5$ ) & 73 & 71 & ns & 73 & 69 & 74 & ns & 68 & 79 & 67 & ns & 72 & 72 & ns & 72 & $(260 / 362)$ \\
\hline Use insect repellent skin products (score 4-5) & 31 & 37 & ns & 31 & 39 & 31 & ns & 31 & 39 & 31 & ns & 36 & 31 & ns & 34 & $(123 / 362)$ \\
\hline Perceived self-efficacy (scale 1-5; certainly not- & -certair & inly) & & & & & & & & & & & & & & \\
\hline Wear protective clothing (score 4-5) & 40 & 37 & ns & 35 & 31 & 45 & 0.04 & 44 & 33 & 39 & ns & 33 & 47 & 0.005 & 39 & $(140 / 362)$ \\
\hline Check your skin after being outdoors (score $4-5$ ) & 59 & 69 & 0.03 & 69 & 62 & 64 & ns & 67 & 68 & 54 & ns & 63 & 65 & ns & 64 & $(232 / 362)$ \\
\hline Remove tick from your skin (score $4-5$ ) & 77 & 72 & ns & 78 & 71 & 75 & ns & 69 & 77 & 79 & ns & 74 & 75 & ns & 74 & $(269 / 362)$ \\
\hline Use insect repellent skin products (score 4-5) & 21 & 38 & $<0.001$ & 26 & 33 & 29 & ns & 36 & 29 & 21 & 0.045 & 28 & 32 & ns & 30 & $(108 / 362)$ \\
\hline Intention (scale 1-5; certainly not-certainly) & & & & & & & & & & & & & & & & \\
\hline Wear protective clothing (score 4-5) & 39 & 38 & ns & 24 & 29 & 49 & $<0.001$ & 46 & 37 & 30 & 0.04 & 28 & 52 & $<0.001$ & 38 & $(139 / 362)$ \\
\hline Check your skin after being outdoors (score $4-5$ ) & 48 & 58 & ns & 53 & 54 & 52 & ns & 53 & 57 & 47 & ns & 53 & 54 & ns & 53 & $(192 / 362)$ \\
\hline Remove tick from your skin (score 4-5) & 92 & 93 & ns & 88 & 91 & 96 & ns & 93 & 92 & 93 & ns & 91 & 95 & ns & 93 & $(336 / 362)$ \\
\hline Use insect repellent skin products (score 4-5) & 17 & 27 & 0.03 & 20 & 25 & 21 & ns & 26 & 23 & 15 & ns & 22 & 23 & ns & 22 & $(80 / 362)$ \\
\hline Behavior (scale 1-4; never-always) & & & & & & & & & & & & & & & & \\
\hline Wear protective clothing (score 3-4) & 39 & 36 & ns & 28 & 33 & 43 & ns & 37 & 38 & 36 & ns & 31 & 46 & 0.002 & 37 & $(135 / 362)$ \\
\hline Check your skin after being outdoors (score 3-4) & 30 & 34 & ns & 39 & 31 & 30 & ns & 27 & 38 & 29 & ns & 32 & 31 & ns & 32 & $(115 / 362)$ \\
\hline Use insect repellent skin products (score $3-4$ ) & 7 & 6 & ns & 6 & 8 & 5 & ns & 7 & 4 & 8 & ns & 7 & 5 & ns & 6 & $(22 / 362)$ \\
\hline
\end{tabular}

LD = Lyme Disease; ${ }^{2}$ The five statements were: people can get Lyme disease after a tick bite; during the summer, the chance on tick bites is higher compared to the

winter; ticks mostly fall out of trees; about 1 in 15 people in the Netherlands are yearly bitten by ticks; using repellent skin products can protect against tick bites. 


\section{Methods}

\section{Participants}

For this study a representative Internet panel was used, named the Flycatcher panel (http://www.flycatcher.eu). This panel consists of members from the Dutch general public who volunteer to participate in online questionnaire surveys. The panel consists of 20.000 members with a representative distribution of demographic variables (gender, age, region, and level of education) for the general Dutch population. The panel meets high quality requirements and is ISO-certified. A random sample of 550 panel members aged 18 years and older was drawn. Panel members in this selection were invited to participate in this study by sending an email with a linking to an online questionnaire. The survey remained online from 8 to 15 November 2010. No reminders were sent out. To motivate enrollment, participants received 1.50 Euro in credits for completion of the survey, which could be exchanged for gift vouchers.

The nature of this general Internet-based survey among healthy volunteers from the general population does not require formal medical ethical approval according to Dutch law [33].

\section{Questionnaire}

The online questionnaire (45 questions) was developed based on an existing questionnaire used in studies on risk perception and precautionary behaviors of the general public during the $2009-\mathrm{H} 1 \mathrm{~N} 1 \mathrm{flu}$ pandemic and during outbreaks of SARS and avian Influenza [27, 26, 55]. To examine people's perceptions of $\mathrm{LD}$ and the preventive measures and the predictors of protective behavior we included the following constructs: knowledge, perceived severity of and vulnerability to LD, feelings of concern, perceived efficacy of preventive measures, a person's ability (self-efficacy) and intention to take measures, actual behaviors, and main motivators and barriers taking measures. Knowledge was examined according to five statements concerning modes of transmission, incidence of tick bites and preventive measures. For knowledge, a summary score was created based on the number of correct answers and dichotomized as 0 ( $\leq 3$ items correct) or 1 (4-5 items correct). Perceived severity was measured by two items, namely 'How serious do you think Lyme disease is?' and 'How awful would it be if you were diagnosed with LD in the next 12 months?'. Perceived vulnerability was also measured by two items, namely 'Do you think that you are susceptible getting LD, if you don't take preventive measures?' and 'How likely is it that you will be diagnosed with LD in the next 12 months?'. Feelings of concern were measured by asking respondents 'How worried are you about getting LD?'.

Participants were asked about four preventive measures for LD, namely: 'wearing protective clothing that cover the body (i.e. long trousers/sleeves)'; 'using insect repellent skin products'; 'checking the skin after being outdoors' and 
'removing ticks from the skin'. Perceived efficacy of these preventive measures was formulated as 'Do you think [measure X] helps to prevent Lyme disease?'; self-efficacy as 'Do you think you are able to perform [measure X]?'; intention as 'Do you intend to perform [measure X]?'; and behavior as 'How often do you perform [measure X]?'. People who indicated that they had never performed a certain preventive behavior were asked to tick a maximum of three barriers from a list of possible barriers (to which they could add their own barrier); people who indicated that they had sometimes/often/always performed a certain behavior were asked to tick a maximum of three motivators from a list of possible motivators (to which they could and their own motivator). Barriers and motivators were generated from the literature (including unpublished/grey literature) $[107,126,145,76]$.

\section{Analysis}

Descriptive statistics were performed. Due to skewed distributions, and to aid interpretation of the results, constructs were dichotomized into low and high scores (see Table 2.1), and the Chi-squared test was used to test the statistical significance of group differences (gender, age, educational level, and employment status) regarding knowledge, perceived severity, perceived vulnerability, feelings of concern, perceived efficacy of preventive measures, perceived self-efficacy, intention and preventive measures taken.

Univariate and multivariate logistic regression analyses were performed to identify factors significantly associated with 1) wearing protective clothing and 2) checking skin afterbeing outdoors. For the multivariate regression ana lyses, a backward 'elimination' procedure was employed, starting with all potential independent variables (all variables with a $p$-value $<0.1$ in the univariate analysis), and then with the least significant variable removed at each step (the one with the highest $p$-value), until only statistically significant predictors $(p<0.05)$ remained.

\section{Results}

A total of 550 panel members were invited to participate in this study, of whom 362 completed the questionnaire (response rate 66\%). Of the 362 respondents, $51 \%$ was female (data not shown). The age varied from $18-29$ years (14\%), 30 49 years $(35 \%)$ and $\geq 50$ years $(51 \%)$. Thirty-seven percent had a low educational level (i.e. primary education, lower general or lower vocational education or less), $38 \%$ an intermediate (i.e. secondary general or vocational education), and $25 \%$ a higher education (i.e. higher professionals education or university). More than half of the respondents were employed, and in $36 \%$ of the households there were one or more children. The overall majority were of Dutch origin. Most respondents lived in the middle (45\%) and the south $(46 \%)$ of the Netherlands. Twelve percent of the respondents had had a tick bite once and $9 \%$ had repeatedly had 
tick bites in the Netherlands. Around half of the respondents were regularly (every week/once a month) physically active in a garden, $37 \%$ visited the woods regularly and $21 \%$ visited open areas regularly.

TABLE 2.2: Predictors of wearing protective clothing to prevent tick bites

\begin{tabular}{|c|c|c|c|c|c|c|c|}
\hline \multirow[t]{3}{*}{ Characteristics } & \multicolumn{7}{|c|}{ Wearing protective clothing (often/always) } \\
\hline & \multicolumn{4}{|c|}{ Univariate } & \multicolumn{3}{|c|}{ Multivariate } \\
\hline & Row\% & OR & $95 \% \mathrm{CI}$ & $p$-value & $\overline{\mathbf{O R}}$ & $95 \% \mathrm{CI}$ & $p$-value \\
\hline \multicolumn{8}{|l|}{ Employment status } \\
\hline employed & 31 & 1.00 & & & 1.00 & & \\
\hline unemployed/retired & 46 & 1.96 & $1.27-3.03$ & 0.002 & 1.96 & $1.24-3.08$ & 0.004 \\
\hline \multicolumn{8}{|l|}{ Knowledge } \\
\hline $1-3$ statements correct & 33 & 1.00 & & & 1.00 & & \\
\hline $4-5$ statements correct & 46 & 1.80 & $1.15-2.81$ & 0.01 & 1.69 & $1.07-2.68$ & 0.03 \\
\hline \multicolumn{8}{|l|}{ Feelings of concern } \\
\hline not (at all) worried (1-2) & 28 & 1.00 & & & 1.00 & & \\
\hline a bit/(very) worried (3-5) & 45 & 2.07 & $1.34-3.21$ & 0.001 & 2.22 & $1.41-3.51$ & 0.001 \\
\hline \multicolumn{8}{|l|}{ Perceived efficacy } \\
\hline $\begin{array}{l}\text { certainly not, } \\
\text { probably not, even (1-3) }\end{array}$ & 17 & 1.00 & & & 1.00 & & \\
\hline certainly/probably (4-5) & 39 & 3.15 & $1.27-7.80$ & 0.01 & 2.97 & $1.17-7.54$ & 0.02 \\
\hline
\end{tabular}

Gender, age, education, children in household, ethnicity, region of residence in the Netherlands, experienced tick bites in past, frequency of visiting nature, perceived severity ( 2 items) and perceived vulnerability ( 2 items) were not univariately associated with wearing protective clothing.

\section{Knowledge}

Of the respondents, 125 (35\%) answered at least 4 out of 5 knowledge statements correctly (Table 2.1) and were categorized as having 'good general knowledge'. The statements 'people can get LD after a tick bite' and 'during the summer, the chance of tick bites is higher compared to the winter' were correctly answered by the majority of the respondents ( $98 \%$ and $90 \%$ respectively; data not shown). Remarkably, only $22 \%$ were aware that 'using repellent skin products can protect against tick bites'.

\section{Perceived severity and vulnerability}

Of the respondents, $95 \%$ perceived LD to be severe or very severe, significantly more often by female ( $n=179,97 \%)$ than by male respondents ( $n=165,93 \%$ ), ( $p=0.047$ ). Equally, ( $n=345$ ), 95\% reported that it would be awful or very awful if they were diagnosed with LD in the next 12 months, while $36 \%(n=130)$ perceived themselves as quite/very susceptible, and only $4 \%$ believed it was likely or very likely that they would be diagnosed with LD in the next 12 months. Around 
TABLE 2.3: Predictors of checking skin for the presence of ticks to prevent Lyme disease

\begin{tabular}{|c|c|c|c|c|c|c|c|}
\hline \multirow[t]{3}{*}{ Characteristics } & \multicolumn{7}{|c|}{ Checking skin (often/always) } \\
\hline & \multicolumn{4}{|c|}{ Univariate } & \multicolumn{3}{|c|}{ Multivariate } \\
\hline & Row\% & OR & $95 \% \mathrm{CI}$ & $p$-Value & $\overline{\text { OR }}$ & $95 \% \mathrm{CI}$ & $p$-Value \\
\hline \multicolumn{8}{|c|}{ Experienced tick bites in the past } \\
\hline no, never & 27 & 1.00 & & & 1.00 & & \\
\hline $\begin{array}{l}\text { yes, once / repeatedly / } \\
\text { outside NL }\end{array}$ & 48 & 2.48 & $1.48-4.14$ & 0.001 & 2.19 & $1.27-3.78$ & 0.005 \\
\hline \multicolumn{8}{|l|}{ Knowledge } \\
\hline 1-3 statements correct & 24 & 1.00 & & & 1.00 & & \\
\hline $4-5$ statements correct & 47 & 2.89 & $1.82-4.59$ & $<0.001$ & 2.83 & $1.74-4.58$ & $<0.001$ \\
\hline \multicolumn{8}{|l|}{ Perceived susceptibility } \\
\hline $\begin{array}{l}\text { not (at all) susceptible } \\
(1-3)\end{array}$ & 25 & 1.00 & & & & & \\
\hline (very) susceptible (4-5) & 44 & 2.34 & $1.48-3.70$ & $<0.001$ & & & \\
\hline \multicolumn{8}{|c|}{ Likelihood being diagnosed with Lyme disease in next 12 month } \\
\hline not (at all) likely (1-2) & 25 & 1.00 & & & & & \\
\hline a bit/(very) likely (3-5) & 39 & 1.92 & $1.23-3.01$ & 0.004 & & & \\
\hline \multicolumn{8}{|l|}{ Feelings of concern } \\
\hline not (at all) worried (1-2) & 20 & 1.00 & & & 1.00 & & \\
\hline a bit/(very) worried (3-5) & 43 & 3.04 & $1.89-4.90$ & $<0.001$ & 2.81 & $1.71-4.60$ & $<0.001$ \\
\hline
\end{tabular}

Gender, age, education, employment status, children in household, ethnicity, region of residence, frequency of visiting nature, perceived severity of Lyme disease (2 items) and perceived efficacy were not univariately associated with checking skin.

half of the respondents reported feelings of concern about getting LD, significantly less frequently in respondents aged $18-29$ years $(n=19,37 \%)$ compared to the other age groups $(n=176,57 \%)(p=0.03)$.

\section{Self-efficacy, response efficacy and intention}

Wearing protective clothing and checking the skin after being outdoors were perceived as the most effective measures for preventing tick bites. Respondents aged 18-29 and those employed reported high perceived efficacy of wearing protective clothing less often ( $p=0.005$ and $p=0.01$ respectively), whereas male respondents reported high perceived efficacy of checking the skin $(p=0.04$ ) less often. Almost three quarters reported high perceived efficacy of removing a tick from their skin, and only a minority of the respondents (34\%) reported high perceived efficacy of using repellent skin products. The majority of respondents reported high perceived self-efficacy for removing ticks from their skin $(74 \%)$ and checking their skin after being outdoors $(64 \%)$. Female respondents $(p=0.03)$ reported high perceived self- efficacy of checking their skin after being outdoors more often. Only 39\% reported high perceived self-efficacy of wearing protective clothing, which was more often reported by respondents aged 50 years and older and 
those unemployed/retired (resp. $p=0.04$ and $p=0.005$ respectively). High perceived self-efficacy of using repellent skin products was reported by $30 \%$ of the respondents. Female respondents $(p<0.001)$ and lower educated $(p=0.045)$ reported high perceived self-efficacy for using repellent skin products more often.

The overall majority (93\%) reported a high intention to remove a tick from their skin, if necessary, and 53\% reported high intention for checking their skin. High intention to wear protective clothing was observed in $38 \%$ of the respondents. Respondents aged 50 years and older $(p<0.001)$, those with a lower education $(p=0.04)$ and unemployed/retired $(p<0.001)$ reported high intention to wear protective clothing more often. Twenty-two percent of the respondents reported high intention for using insect repellent skin products. Female respondents reported high intention to use repellent skin products more often ( $p=0.03)$.

\section{Preventive measures taken}

Thirty-seven percent of the respondents reported wearing protective clothing when going into nature areas $(30 \%$ who reported this behavior often and $8 \%$ always; data not shown). Unemployed/retired respondents reported to wear protective clothing more often compared to those employed $(p=0.002)$. Thirtytwo percent of the respondents reported checking their skin after they had been outdoors ( $21 \%$ often and $11 \%$ always). A minority $(6 \%)$ reported to use insect repellent skin products ( $5 \%$ often and $1 \%$ always).

\section{Determinants of preventive behavior}

Univariate and multivariate logistic regression analyses were performed to identify factors significantly associated with 1) wearing protective clothing and 2) checking the skin after being outdoors. Table 2.2 shows significant predictors of wearing protective clothing that were selected using the univariate logistic regression. From the multivariate logistic regression analysis, predictors of wearing protective clothing were: being unemployed/retired (OR 1.96; 95\% CI 1.24-3.08), higher knowledge levels (OR 1.69; 95\% CI 1.07-2.68), higher levels of concern about LD (OR 2.22; 95\% CI 1.41-3.51) and higher levels of perceived efficacy of wearing protective clothing (OR 2.97; 95\% CI 1.17-7.54). Table 3.3 shows significant predictors of checking the skin for the presence of ticks. From the multivariate logistic regression analysis, predictors of checking the skin were: experienced tick bites in the past (OR 2.19; 95\% CI 1.27-3.78), higher knowledge levels (OR 2.83; 95\% CI 1.74-4.58) and higher levels of concern about LD (OR 2.81; 95\% CI $1.71-4.60)$. 
TABLE 2.4: Main motivators and barriers for measures to prevent tick bites

$\begin{array}{lr}\text { Wearing protective clothing } & \text { \% } \\ \text { Motivators ( } n=284) & 53 \\ \text { 'wearing protective clothing is effective' } & 47 \\ \text { 'high perceived chance of tick bites' } & 37 \\ \text { 'Lyme disease can be severe' } & 33 \\ \text { 'feel responsible for my health' } & 19 \\ \text { 'I follow the advice' } & 81 \\ \text { Barriers ( } n=78 \text { ) } & 30 \\ \text { 'wearing protective clothing during summer is too warm' } & 23 \\ \text { 'low perceived chance of tick bites' } & 19\end{array}$

\section{Using insect repellent skin products}

Motivators $(n=86)$

'Lyme disease can be severe'

'feel responsible for my health'

'high perceived chance of tick bites'

'using repellent skin products is effective' $\quad 34$

'I follow the advice'

Barriers $(n=276)$

'do not belief it is effective'

' do not like to use insect repellent products for my skin' 32

'too little information is provided' 27

'low perceived chance of tick bites' 23

'using insect repellent skin products is overdone' 22

$\begin{array}{ll}\text { 'I am not familiar with insect repellent skin products' } & 19\end{array}$

Checking skin after being outdoors/remove tick

Motivators $(n=353)$

$\begin{array}{lr}\text { 'Lyme disease be severe' } & 64\end{array}$

'checking skin/remove tick is effective' 48

'feel responsible for my health' 44

'I follow the advice' $\quad 25$

'high perceived chance of tick bites' $\quad 18$

'high perceived chance of Lyme disease' 16

Barriers $(n=108)$

'low perceived chance of tick bites' 35

'do not know how to recognize a tick' 19

'check my skin after being is overdone' 19

'do not know how to remove a tick' 16

'too little information is provided' 16

Reasons reported by $<15 \%$ of the respondents are not included in this table. 


\section{Main motivators and barriers}

Respondents were asked to identify the main motivators and barriers for wearing protective clothing, using insect repellent skin products and checking skin / removing ticks from their skin (Table 2.4). Overall, the main motivators that were mentioned were: the perceptions that LD can be severe, the perception that the preventive measure is effective in preventing tick bite/LD, a person's feeling of responsibility regarding his/her health and the perception that there is a high chance of tick bites. Among the 78 respondents who did not wear protective clothing, $81 \%$ reported that as a barrier, wearing protective clothing in summer is too warm; $30 \%$ reported a low risk of tick bites and $23 \%$ perceived that wearing protective clothing in nature areas is overdone. Of the 276 respondents who did not use insect repellent skin products, $34 \%$ did not believe these products to be effective, $32 \%$ did not like to use insect repellent products on their skin and $27 \%$ reported that too little information is provided about preventing tick bites through insect repellent skin products. Of the 108 respondents who did not check their skin/remove tick, 35\% perceived low risk of tick bites, $19 \%$ did not know how to recognize a tick, 19\% thought checking the skin after being outdoors is overdone, and $16 \%$ did not know how to remove a tick or reported that too little information is provided.

\section{Discussion}

In this study we identified the main predictors and motivators that influence protective behavior for preventing tick bites and LD. We did this by investigating the knowledge, perceptions and efficacy beliefs of healthy people in the general population in the Netherlands, a country in which the incidence of LD has increased sharply throughout the past two decades.

Insight into public perceptions and protective behavior regarding LD is crucial in order to develop a successful prevention program [75]. We conclude that good general knowledge about preventing tick bites and LD is scarce, while the perception of risks and self-efficacy of the measures varies greatly among the respondents.

Only $35 \%$ of the respondents reported a good general knowledge of LD, and only a quarter were aware that using repellent skin products can protect against tick bites. Suboptimal public knowledge regarding LD was also found in other studies in endemic areas. For example, Heller et al. conducted a questionnaire study among 103 Brazilian residents -living in a Lyme disease endemic area in the United States-, and reported that $36 \%$ of the respondents had never heard of the disease and $62 \%$ were not certain they could recognize the symptoms [75]. Higher levels of knowledge seem to positively influence protective behavior as demonstrated by Gould et al. [67]. However, research in areas where LD is endemic has demonstrated that despite adequate knowledge about its symptoms and transmission, many people do not perform behaviors to reduce their risk of 
infection [46]. These findings suggest that a lack of knowledge is not the only reason for poor uptake of protective behavior.

Nearly all respondents perceived high severity of LD, but perceived vulnerability and feelings of anxiety were lower. The fact that the majority of the respondents perceived low personal risk of LD, implicates some public underestimation, especially, given the fact that people in the Netherlands, in particular those who often visit woodland areas, have a real risk of getting tick bites and developing LD [53]. The underestimation of risk is found to have been caused by factors such as lack of knowledge. Furthermore, if people underestimate their personal risk they will be less willing to engage in preventive behavior [31, 150].

Higher levels of self-efficacy, respons efficacy and intention were observed for checking the skin after being outdoors and removing ticks if necessary. However, lower levels of (self-)efficacy and intention were observed for wearing protective clothing and using insect repellent skin products. The fact that most respondents in our study were unaware that using repellent skin products can protect against tick bites, might also be related to the lower levels of intention to use these products.

The percentage of respondents taking preventive measures ranged from $6 \%$ for using insect repellent skin products, to $40 \%$ for wearing protective clothing. These percentages are rather low, compared to other studies. Studies in the US reported that $66 \%-99 \%$ of the respondents took measures to prevent LD [67, 126, 145]. Furthermore, Heller et al found that the majority (78\%) of the Brazilian respondents wore long trousers when outdoors and Herrington reported that one-half of the US respondents also did this [75, 76]. The lower levels of wearing protective clothing in the Netherlands, especially in the summer, could be caused by the climate. The Netherlands has a maritime climate, with cool summers and an average temperature of $19^{\circ} \mathrm{C}$ in July. People in the Netherlands like wearing (light) clothing, such as shorts and short sleeved shirts, if the temperature increases. Also the fact that people believe that wearing protective clothing in nature areas is overdone, as reported in this study, might be a reason for the low levels of wearing protective clothing as reported by Cartter et al. [31].

One-third of the respondents in our study reported checking their skin after being outdoors. This is comparable with other studies; i.e. Heller et al. who described that only $28 \%$ of the Brazilian population check their skins for ticks [75]. The main barriers for checking skin for ticks reported in our study were low perceived personal risk and not knowing how to recognize a tick.

Only $6 \%$ of our respondents reported using repellent skin products. The low use of insect repellent skin products was also been found in other studies. For example, in Brazil and the US $66 \%$ and $69 \%$ of the respondents respectively never used insect repellent skin products for protection against LD [75]. In our study a barrier for using repellent skin products is that people are not convinced about their efficacy or do not like to use these products. Herrington investigated barriers for using insect repellent skin products, and found that a substantial proportion of US respondents believed that using insect repellent could make 
them ill [76]. This underlines the need for people to 'believe' in the effectiveness of a recommended behavior as well as they should have appropriate knowledge on the subject.

There were some differences in public perceptions regarding LD among socio-demographic subgroups. For example, females reported higher levels of perceived efficacy and self-efficacy to check their skin after being outdoors, whereas older respondents ( $\geq 50$ yrs) reported higher levels of perceived efficacy, self-efficacy and an intention to wear protective clothing. However, in multivariate analysis, of all socio-demographic variables only employment status remained a significant predictor for wearing protective clothing for preventing tick bites.

As reported in our study, having had tick bites in the past, higher levels of knowledge and moderate/high levels of concern were significant predictors for checking the skin. Significant predictors of wearing protective clothing were being unemployed/retired, higher knowledge levels, higher levels of concern about LD and higher levels of perceived efficacy of wearing protective clothing. These findings are in accordance with Herrington [76], reporting that having seen ticks, being concerned about being bitten, having heard about LD and knowing someone who had LD are the factors most predictive of specific tick-bite protective behavior. Mowbray et al. showed in his review that both knowledge and attitudes towards tick-borne disease are amenable to change via an education campaign [113]. Unfortunately, in his systematic review of all previous studies that assessed the impact of education or behavioral interventions on the uptake of behaviors intended to protect against tick-borne diseases he could find only nine studies, of which only three took the form of a randomized controlled trial (RCT) [113]. One RCT studied the willingness to the uptake of a vaccine for LD and two focussed on other protective measures. Lawless et al. used an instructional video with a mock horror movie theme to improve knowledge, attitudes, and behaviors towards LD prevention in 13-to 16-year-olds from four Connecticut towns [100]. One month and six months after seeing the video, knowledge, attitudes and behavior had increased significantly in the intervention group. Another study investigating the effectiveness of an educational intervention was performed by Daltroy et al. In over 30000 passengers on ferry boats to a Lymeendemic area of Nantucket Island. In this study controls received education about bike safety, while intervention participants received information on preventing tick- borne disease, particularly LD. Information was delivered on board by entertainers to make the messages more compelling. Two months after the intervention, experimental participants were more likely than controls to adopt precautionary behaviors, as well as to check themselves daily for ticks. In conclusion, future prevention programs for LD should focus on improving public knowledge, i.e. with regard to disease severity and vulnerability, efficacy of measures and on how to take preventive measures.

This is the first national study to evaluate the perceived LD-risk and protective behavior for LD in the general public in the Netherlands. Nevertheless, 
there are a number of limitations to our study. The majority of respondents (51\%) was older than 50 years. This may have limited the generalizability of the results, although older age has not been found to be a distinct factor associated with compliance to preventive measures for LD found in previous studies. Furthermore, potential selection bias may have been introduced in that only respondents with a computer were interviewed by this online survey. Finally, cross sectional studies can prove a rich baseline of data points but should not be used to make causal statements, given the lack of a temporal sequence of events.

\section{Conclusion}

Our study has several implications for the development of LD prevention programs. It demonstrates that knowledge, level of concern and perceived efficacy of measures are the main determinants of preventive behavior. Therefore future prevention programs should focus on these determinants, for example, by providing facts and raising awareness about LD and protective measures that can be taken. Since protective measures like wearing protective clothing and using insect repellents are not 'popular', it is important that prevention programs focus on removing any barriers for complying with these protective measures, especially in people who have never had tick bites and those who are less concerned about the risks. Furthermore, it is important to tailor the information to specific socio-demographic subgroups and high risk groups.

Promoting preventive measures for LD is really important since reducing the tick population and developing a vaccine can only be seen as long-term solutions for the problems. The results of this study can be used as a base for developing effective prevention programs that connect with the needs of the target group, with the main goal to increase compliance with recommended measures.

The challenge is to take the principles demonstrated in this study and apply them to prevention programs. Some work in this area has already been done. Last year the Netherlands National Institute of Public Health and The Environment redesigned the national public information campaign on ticks and LD in the Netherlands. In this campaign the focus was shifted. First, not all possible evidence based preventive measures on LD were presented in the communication, instead the focus was placed on checking the skin and removing ticks. Also a educational game was developed, called in Dutch: 'Teekcontrol.nl', to teach children playfully about ticks and LD. In this online game children can discover where ticks are most likely to be found and why it is important to check the skin after playing outdoors. Within 8 months of launching over 30.000 children had played this game. The learning effect of the game will be evaluated in 2012 . Furthermore, a mobile phone app on ticks and LD is currently being developed. This will be based on a user-centered design. This means that the public will determine the features of this application. 


\section{Chapter 3}

\section{Determinants}

and protective behaviours

regarding tick bites

among school children

in the Netherlands:

a cross-sectional study

Published as:

Beaujean DJ, Gassner F, Wong A, van Steenbergen JE, Crutzen R, Ruwaard R. Determinants and protective behaviours regarding tick bites among school children in the Netherlands: a cross-sectional study. BMC Public Health 2013 Dec 9;13:1148. 


\section{Abstract}

Background: Lyme borreliosis (LB) is the most common tick-borne disease in the United States and Europe. The incidence is 13.4 per 100,000 inhabitants in the United States and more than 300 per 100,000 inhabitants in Europe. Children are at highest risk of LB. In the Netherlands in 2007, the incidence of tick bites in children between 10-14 years varied from 7,000-11,000 per 100,000, depending on age. This study among Dutch school children aimed to examine the knowledge, perceived threat, and perceived importance of protective behaviour in relation to tick bites and their potential consequences.

Methods: In April 2012, the municipal health services (MHS) contacted primary schools to recruit children 9-13 years by telephone, e-mail, or advertisement in MHS newsletters. In total, 1,447 children from 40 schools participated in this study by completing a specifically developed and pretested compact paper questionnaire. Regression models were used to determine which covariates (e.g. forest cover, previous education, knowledge) are associated with our response variables.

Results: $70 \%(n=1,015)$ of the children answered at least six out of seven knowledge questions correctly. The vast majority $(93 \% ; n=1345)$ regarded body checks as very or somewhat important, $18 \%(n=260)$ was routinely checked by their parents. More frequent body checks were associated with good knowledge about ticks and tick-borne diseases and knowing persons who got ill after tick bite. Children in areas with a higher forest cover were more likely to be checked frequently.

Conclusions: Most children have a good knowledge of ticks and the potential consequences of tick bites. Knowing persons who personally got ill after tick-bite is associated with a good knowledge score and leads to higher susceptibility and better appreciation of the need for body checks. Perceived severity is associated with a good knowledge score and with knowing persons who got ill after tickbite. Is seems to be useful to additionally address children in health education regarding ticks and tick-borne diseases. The relationship between health education programs for children (and their parents) about ticks and their possible consequences and prevention of these deserves further study.

\section{Background}

Lyme borreliosis (LB) is the most common tick-borne disease in the United States (USA) and Europe. From 1992 through 2006, a total of 248,074 cases of LB were reported to the U.S. Centers of Disease Control and Prevention, with 
a nationwide incidence of 13.4 per 100,000 inhabitants. The annual count increased $101 \%$, from 9,908 cases in 1992 to 19,931 cases in 2006. Incidence was highest among children aged 5-4 years [9]. In Europe, where the main endemic areas are located in Scandinavia and the south central areas of Germany, Austria, north-east Italy, and Slovenia, the reported incidence is more than 300 cases per 100,000 inhabitants. In the Netherlands, the rate of general practitioner (GP) consultations for tick bites increased from 191 per 100,000 persons in 1994 to 564 per 100,000 persons in 2009 [82]. In 1994, patients visiting the GP for erythema migrans (EM), a circular red skin rash around the place of the tick bite, was estimated at 39 per 100,000 inhabitants. This rate increased to 134 per 100,000 in 2009 [82], and similar rises occurred in other European countries as well [152].

Children are at highest risk of $\mathrm{LB}$, with a peak incidence rate among boys aged 5-9 years [37, 157]. In the Netherlands, a repeated retrospective study among general practitioners has shown a continuing and strong increase in consultations for tick bites and for EM between 1994 and 2009 [82, 53, 83]. The increasing numbers of tick bites, adding up to 1.5 million people with a tick bite in 2009 [9], poses a progressive threat to public health. As these data was derived from general practices, the incidence of tick bites is probably higher in the wider population, which includes people not routinely visiting a GP. The Dutch data accords with findings of an LB seroprevalence survey conducted in children throughout Germany [56] that point to children as a distinct and vulnerable risk group [94]. Another study found that children aged 5-14 years are at higher risk for LB in Europe. As in the Netherlands, EM is the most reported manifestation of LB (77-89\%) in children across Europe [136].

This complex infection has a number of objective manifestations, including a characteristic skin lesion called erythema migrans (the most common presentation of early Lyme disease), certain neurologic and cardiac manifestations, and pauciarticular arthritis (the most common presentation of late Lyme disease), all of which usually respond well to conventional antibiotic therapy. Despite resolution of the objective manifestations of infection after antibiotic treatment, a minority of patients have fatigue, musculoskeletal pain, difficulties with concentration or short-term memory, or all of these symptoms [60].

In addition, there is an extensive range of rare manifestations $[43,21,25$, $71,148]$. The increase of LB might be caused by changes in pathogen and vector populations but could also reflect increased awareness. Indeed, the more citizens and medical personnel are aware of LB, the more LB is diagnosed [77]. However, LB can be significantly more difficult to identify in children, because half of all EM is situated in head and neck and can go unnoticed and late manifestations can present with nonspecific chronic complaints [25].

Health education is considered the most important approach for preventing LB, because no vaccine is available and effective measures for controlling tick populations are experimental or insufficient [59]. In the Netherlands, health education materials focus on personal behaviours [101]: avoiding tick-infested areas, wearing protective clothing (e.g. long-sleeved shirts and long trouser pants 
to minimise exposed skin), using tick repellents on skin or clothing, doing body checks after being outdoors. Except for body checks, these measures are not well accepted by the general public in the Netherlands $[54,17]$.

At present, health education materials and LB prevention research are mainly aimed at adults. Although parents are the designated persons to check children for ticks, the need for checking should be communicated directly to children as well [54]. Teaching them to recognise the tiny nymphal stage of ticks and the features of tick habitats can encourage them to urge parents to do timely body checks [59]. Therefore it seems logical to develop education materials aimed at both children and their parents. To develop tailored education materials it is necessary to determine the determinants associated with the risk behaviours. This study among Dutch school children aimed to examine the response variables of knowledge, perceived threat, and perceived importance of protective behavior in relation to tick bites and their possible consequences. The study is based on the Protection Motivation theory [120]. This theory posits that a 'threat appraisal' is formed by an individual based on the perceived likelihood of a particular event (denominated here as 'perceived susceptibility') and its perceived severity. The way in which individuals choose to respond to a threatening situation is termed their 'coping appraisal'. It is based on their belief that a recommended behaviour will resolve the threat 'response efficacy') and their belief that they are able to perform the behaviour ('self-efficacy'). The latter belief is less important in the current study, because parents must perform the behaviour (e.g. tick checks). Furthermore, since our subjects are primary school children, the questions must be limited in number and easily understood by children.

\section{Methods}

\section{Participants}

This study was performed in April 2012 among Dutch school children aged 9-13 years, attending the two highest grades of primary school. To request voluntary participation, municipal health service (MHS) workers contacted schools in their region by telephone, e-mail, or advertisement in MHS newsletters. The schools could participate voluntarily. School children were recruited at school-level; all children in the targeted age-group in these schools participated in the study (except in case of illness or absence). Approximately 1,100 schools were reached, resulting in a convenience sample of 40 schools nationwide. The study included 1,447 children. Being a general survey among healthy volunteers from the general population, it did not require formal medical ethical approval, according to Dutch law [33]. 


\section{Questionnaire}

A concise two-sided paper questionnaire with 12 questions was developed and pretested to make it accessible for primary school children of varying education levels (see questions in Annex 1. Answer categories were minimised to a threepoint scale; text was limited to short sentences, and images were used when possible. We included the following constructs: knowledge (assessed by asking 7 questions on tick ecology, basic prevention, and tick bites); perceived severity (asking about the possible consequences of a tick bite); perceived susceptibility (asking whether the child thinks he/ she could personally become ill after a tick bite); an additional proxy for perceived susceptibility (asking whether the child personally knows someone who became ill after a tick bite); perceived importance of protective behaviour as a proxy for response efficacy (asking whether the child thinks tick-checks are important), and actual protective behaviour (asking for the frequency of tick checks performed by his/her parents). Finally children were asked if they had had previous classroom lectures on ticks. Teachers handed out the questionnaires, which were completed in the classroom, and sent them back by regular mail.

\section{Analysis}

For each construct we used a set of covariates which were selected based on proven or plausible effects of covariates on an outcome category, as described below and in Table 3.1. Most covariates were obtained through the questionnaire, but two additional covariates were collected as a measure of tick habitat exposure: the level of urbanisation and the level of forestation.

In the Unites States, knowledge and behaviour on LB prevention has been associated with the level of urbanisation [13]. Therefore, data on the extent of urbanisation based on a 1-5 ordinal scale of household density per postal code area was extracted from the Dutch National Atlas of Public Health [186]. Here, level 1 represents a highly urbanised area and level 5 represents the lowest population density (i.e. rural). The public perception of tick-risk areas is mostly related to woodlands [126], as is LB risk [69]. Therefore, a variable to estimate the children's perception of tick exposure was constructed by assessing the percentage of forest cover (deciduous and evergreen) in a radius of $10 \mathrm{~km}$ around each studied school, according to the Dutch land use database 2007-2008 [73]. These distances reflect the fact that children live close to their primary school, which on average is $0.6 \mathrm{~km}$ in the Netherlands [161].

The class of generalised linear mixed models (GLMM) was used to explore the relationship between the constructs assessed in the questionnaire and the sets of covariates, whilst accounting for the cluster structure in our data [110]. Children attending the same school are likely to score similarly on the constructs, and can therefore be considered as a cluster. GLMMs adjust for this correlation within clusters by introducing a random effect; more specifically, we used a random 
TABLE 3.1: Overview of model per domain

\begin{tabular}{|c|c|c|c|c|}
\hline $\begin{array}{l}\text { Response } \\
\text { variate }\end{array}$ & $\begin{array}{l}\text { Outcome } \\
\text { variable } Y\end{array}$ & $\begin{array}{l}\text { Outcome } \\
\text { categories } j\end{array}$ & Model type & Covariates \\
\hline Knowledge & $\begin{array}{l}\text { Knowledge } \\
\text { sufficiency } \\
\text { (based on } \\
\text { Q2-8) }\end{array}$ & $\begin{array}{l}j=1 \\
\text { ('Sufficient') if at } \\
\text { least } 6 \text { out of } 7 \\
\text { questions have } \\
\text { been answered } \\
\text { correctly, } \\
j=0 \\
\text { 'Insufficient' }\end{array}$ & $\begin{array}{l}\text { Logistic } \\
\text { regression with } \\
\text { random effects }\end{array}$ & $\begin{array}{l}\text { Forest cover (\%), Urbanisation } \\
\text { level (scale 1-5); Previous } \\
\text { education; Perceived } \\
\text { susceptibility (knowing persons } \\
\text { with LB) }\end{array}$ \\
\hline $\begin{array}{l}\text { Perceived } \\
\text { severity }\end{array}$ & $\begin{array}{l}\text { Consequence } \\
\text { of tick bite: } \\
\text { disease or } \\
\text { itch (based } \\
\text { on Q5) }\end{array}$ & $\begin{array}{l}j=1 \text { ('Disease'), } \\
j=0 \text { ('Itch' or } \\
\text { 'Not sure') }\end{array}$ & $\begin{array}{l}\text { Logistic } \\
\text { regression with } \\
\text { random effects }\end{array}$ & $\begin{array}{l}\text { Forest cover (\%), Urbanisation } \\
\text { level (scale } 1-5 \text { ); Previous } \\
\text { education; Knowledge score } \geq 5 \text {; } \\
\text { Perceived susceptibility (knowing } \\
\text { persons with LB) }\end{array}$ \\
\hline $\begin{array}{l}\text { Perceived } \\
\text { susceptib- } \\
\text { ility }\end{array}$ & $\begin{array}{l}\text { Can you get } \\
\text { ill? (based } \\
\text { on Q9) }\end{array}$ & $\begin{array}{l}j=2 \text { ('Yes'), } \\
j=1 \text { ('Not } \\
\text { sure'), } \\
j=0 \text { ('No') }\end{array}$ & $\begin{array}{l}\text { Ordered logit } \\
\text { with random } \\
\text { effects }\end{array}$ & $\begin{array}{l}\text { Forest cover (\%), Urbanisation } \\
\text { level (scale 1-5); Previous } \\
\text { education; Knowledge score } \geq 6 \text {; } \\
\text { perceived severity; Perceived } \\
\text { susceptibility (knowing persons } \\
\text { with LB); Protective behaviour }\end{array}$ \\
\hline $\begin{array}{l}\text { Perceived } \\
\text { import- } \\
\text { ance }\end{array}$ & $\begin{array}{l}\text { Body checks } \\
\text { important? } \\
\text { (based on } \\
\text { Q10) }\end{array}$ & $\begin{array}{l}j=2 \text { ('Very } \\
\text { important'), } \\
j= \\
1 \text { ('Somewhat } \\
\text { important'), } \\
j=0 \text { ('Not } \\
\text { important') }\end{array}$ & $\begin{array}{l}\text { Ordered logit } \\
\text { with random } \\
\text { effects }\end{array}$ & $\begin{array}{l}\text { Forest cover (\%), Urbanisation } \\
\text { level (scale 1-5); Previous } \\
\text { education; Knowledge score } \geq 6 \text {; } \\
\text { Perceived severity; Perceived } \\
\text { susceptibility (Can you get ill and } \\
\text { Knowing persons with LB) }\end{array}$ \\
\hline $\begin{array}{l}\text { Protective } \\
\text { behaviour }\end{array}$ & $\begin{array}{l}\text { Body check } \\
\text { frequency } \\
\text { (based on } \\
\text { Q12) }\end{array}$ & $\begin{array}{l}j=2 \text { ('Often'), } \\
j=1 \\
\text { ('Sometimes'), } \\
j=0 \text { ('Never') }\end{array}$ & $\begin{array}{l}\text { Ordered logit } \\
\text { with random } \\
\text { effects }\end{array}$ & $\begin{array}{l}\text { Forest cover (\%), Urbanisation } \\
\text { level (scale 1-5); Previous } \\
\text { education; Knowledge score } \geq 6 \text {; } \\
\text { Perceived severity; Perceived } \\
\text { susceptibility (Can you get ill and } \\
\text { Knowing persons with LB); } \\
\text { Perceived importance. }\end{array}$ \\
\hline
\end{tabular}

All $j=0$ are considered reference categories in each model. 
intercept for schools. We observed a clear subdivision where a group of respondents answered 6 or 7 out of 7 knowledge questions correctly, or answered 5 or fewer questions correctly (Figure 3.1). The knowledge construct was therefore operationalised as a binary variable, with 6-7 of 7 questions correct was considered Sufficient (i.e. good) and 5 or fewer as Insufficient. For this construct, we used a GLMM assuming a Bernoulli distribution and logit link (i.e. logistic regression with random effects). Note that we could have also operationalised the construct as Sufficient, Somewhat sufficient, and Insufficient; but as shown in the results section, most children answered most questions right, making a such a detailed categorisation less appropriate.

The other constructs were operationalised by ordered outcome variables with three outcome categories; for these constructs, we considered ordered logit / cumulative logit models with random effects [5], in which the probability of each category is assumed to be dependent on a set of covariates. Note that we assume 'No', 'Don't know' and 'Yes' to be ordered, with 'Don't know' falling between 'No' and 'Yes', as it indicates doubt between them ${ }^{1}$. These models assume 'proportional odds', which implies that only one set of regression coefficients, is applicable for all outcome categories (with the exception of the intercept). Using the Likelihood Ratio test, we found that this assumption was not violated, except for the protective behaviour construct. For this construct we considered a GLMM with multinomial distribution, but found that it led to convergence problems, presumably due to model complexity. We therefore retained the ordered logit model for this construct in order to adjust for the cluster structure. The specific model characteristics (model type, distribution, covariates, outcome categories) used per construct are summarised in Table 3.1.

A difficulty arises in the interpretation of the effect sizes for each covariate, as our GLMM models are nonlinear. To facilitate interpretation, we make multiple predictions with our estimated models. For instance, if we are interested in the effect size of one covariate, we first make a prediction of the probability of a given response category for a baseline value of this covariate while assuming all other covariates assume their mean or modus values. Then we change the value of the covariate and make a new prediction while assuming all other covariates remain constant (ceteris paribus). The change in the predictions can be interpreted as the difference in risk that is associated with a change in the covariate, indicating the effect size under the ceteris paribus assumption. In the remainder of this article we will therefore refer to this risk difference as the 'effect size'. The absolute value of an effect size can vary between zero and one. Whether or not an effect is considered large depends strongly on context, as will be illustrated in the next section. The statistical software R [167] was used for our analyses.

\footnotetext{
${ }^{1}$ If we do not make this assumption, and fit a logistic regression model with random effects (with only 'no' and 'yes' as outcome categories, and 'don't know' omitted), we find that the results are very similar.
} 


\section{Results}

The study included 1,447 children from 40 primary schools, with an average of 36 (range: 10 to 106) participating from each school. The schools were geographically dispersed across the country, there being 14 with 420 children in the Northern part of the country, 21 with 814 children in the Middle, and 5 with 213 children in the Southern part. In general, response rates to the questions were high, with $96.7 \%(n=1,403)$ of children completing the questionnaire without skipping any questions; $2.9 \%(n=42)$ skipping one question, and $0.14 \%(n=2)$ skipping 5 out of 12 questions (Table 3.1). Data of all respondents were included in the dataset; missing data (e.g. where a participant skipped a question) were not imputed.

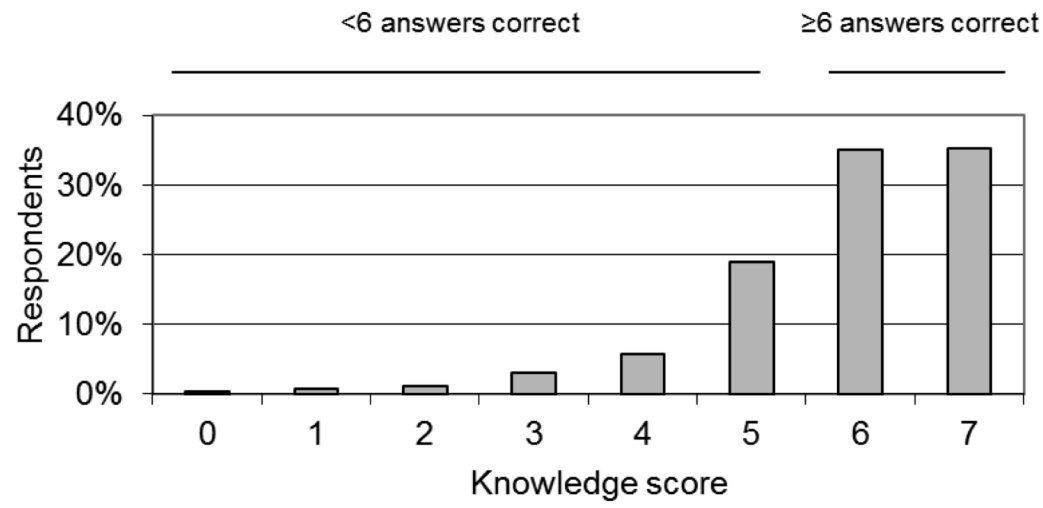

FIGURE 3.1: Knowledge level in Dutch primary school children aged 9-13 years ( $n=1447)$. The 'knowledge score' on the $\mathrm{x}$-axis represents the number of correct answers out of seven knowledge questions.

\section{Knowledge and perceived severity}

Of the respondents, $78 \%(n=1,131)$ indicated that they never had classroom education about ticks (Table 3.2). The vast majority, $70 \%(n=1,015)$ nevertheless had a sufficient knowledge, as they answered at least six out of seven knowledge questions correctly (Figure 3.1). The favorite habitat of ticks, whether one can become ill after a tick bite (also interpreted as perceived severity), and the shape of unfed ticks were the three questions most often answered correctly (98\%, $n=1,419$; 94\%, $n=1,353$ and 87\%, $n=1,255$, respectively). Our logistic regression model with random effects indicates that the variation in knowledge among schools was considerable (see Figure 3.2). Prior tick-related education is significantly associated with a higher probability of answering at least six questions correctly $(p<0.01)$. As the corresponding estimated effect size is 0.096 , the 
probability of answering at least six questions correctly is 0.096 higher when having prior education, assuming all other covariates remain at their mean or modus level. Also, knowing persons with LB, here used as proxy for perceived susceptibility, was significantly associated with a higher knowledge level ( $p<0.001$, effect size 0.117), but forest cover and level of urbanisation were not (Table 3.3). Perceived severity, i.e. being aware of possible consequences of tick bites, was associated with a good knowledge score (answering $\geq 5$ questions correctly, $p<0.001$, effect size 0.076$)$ and with knowing persons with LB ( $p=0.003$, effect size 0.087 .

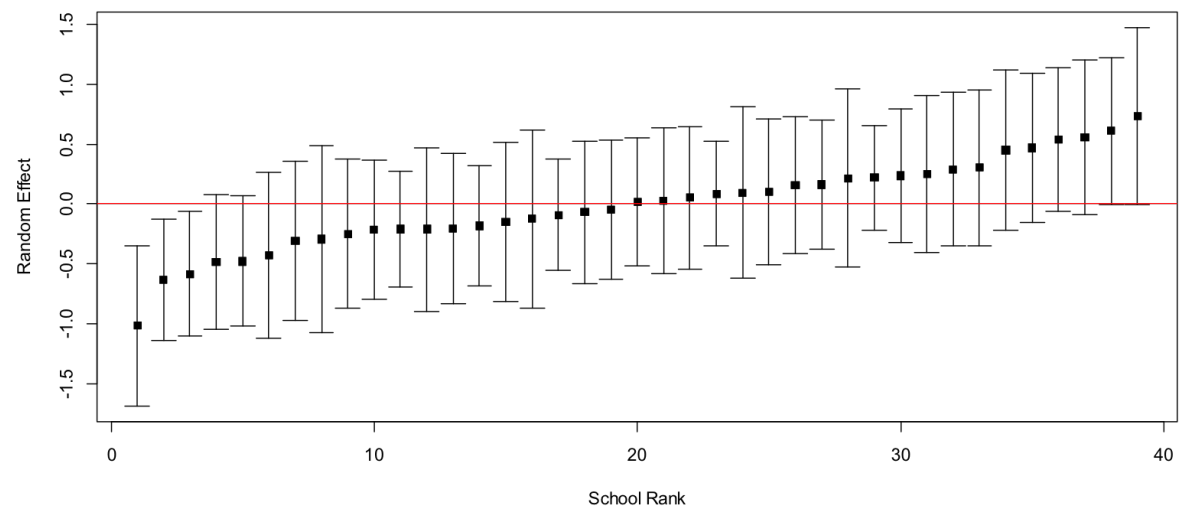

FIGURE 3.2: Variation in knowledge by school, illustrated by the posterior empirical bayes estimates of the random effects for each school rank (squares), with their 95\% confidence intervals. Red horizontal line indicates the level for the average school; if an interval does not intersect with the red line, the corresponding school differs significantly from the average.

\section{Perceived susceptibility}

Of the respondents, $69 \%$ ( $n=992)$ believed they were susceptible to illness due to a tick bite. Children aware of possible consequences of a tick bite (perceived severity) are more likely to think that they could personally get ill after a tick bite $(p<0.001)$. Given the effect size of 0.116 , the probability of perceiving oneself as susceptible increases by 0.116 when being aware of the possible consequences. In line with knowledge score, the proxy for perceived susceptibility (knowing persons with LB) was positively associated with the perceived susceptibility of personally becoming ill after a tick bite $(p<0.001$, effect size 0.117$)$. A quarter of the respondents $(27 \%, n=386)$, indicated knowing persons with a past or present episode of LB, a secondary measure of perceived susceptibility (Table 3.2). However, forest cover, level of urbanisation, and the frequency of body checks were not associated with perceived susceptibility (Table 3.3). 
TABLE 3.2: Questionnaire responses of 1,447 respondents

\begin{tabular}{|c|c|c|c|c|c|}
\hline $\begin{array}{l}\text { Question } \\
\text { (determinant) }\end{array}$ & Abbreviated question & $\begin{array}{l}\text { Correct } \\
\text { answer/yes }\end{array}$ & $\begin{array}{l}\text { Incorrect } \\
\text { answer/no }\end{array}$ & $\begin{array}{l}\text { Don't } \\
\text { know }^{*}\end{array}$ & $\begin{array}{l}\text { No } \\
\text { response } \\
(n)\end{array}$ \\
\hline 1 & $\begin{array}{l}\text { Previously educated on } \\
\text { ticks at school }\end{array}$ & $21.4 \%$ & $78.2 \%$ & n.a. & $0.4 \%(6)$ \\
\hline $2(\mathrm{~K})$ & $\begin{array}{l}\text { How to recognise an unfed } \\
\text { tick (Image: tick shape or } \\
\text { ant shape) }\end{array}$ & $86.7 \%$ & $6.6 \%$ & $6.4 \%$ & $0.2 \%(3)$ \\
\hline $3(\mathrm{~K})$ & $\begin{array}{l}\text { Unfed tick size estimation } \\
\text { (Image: } 1 \mathrm{~mm} \text { dot or } 10 \\
\text { mm dot) }\end{array}$ & $82.2 \%$ & $9.3 \%$ & $7.5 \%$ & $1.0 \%(14)$ \\
\hline $4(\mathrm{~K})$ & $\begin{array}{l}\text { Tick habitat (Image: forest } \\
\text { or playground) }\end{array}$ & $98.1 \%$ & $0.7 \%$ & $0.7 \%$ & $0.6 \%(8)$ \\
\hline 5 (K;PV) & $\begin{array}{l}\text { Consequence of tick bite } \\
\text { (disease or itch) }\end{array}$ & $93.5 \%$ & $4.1 \%$ & $2.4 \%$ & $0.1 \%(1)$ \\
\hline $6(\mathrm{~K})$ & $\begin{array}{l}\text { Where ticks reside (near } \\
\text { ground or up in trees) }\end{array}$ & $64.2 \%$ & $29.1 \%$ & $6.6 \%$ & $0.1 \%(1)$ \\
\hline $7(\mathrm{~K})$ & $\begin{array}{l}\text { How to prevent tick bite } \\
\text { (tick check or washing) }\end{array}$ & $86.1 \%$ & $8.5 \%$ & $5.3 \%$ & $0.1 \%(2)$ \\
\hline $8(\mathrm{~K})$ & $\begin{array}{l}\text { Main bite sites on the } \\
\text { body (image: hairline, } \\
\text { armpits, groin and knees; } \\
\text { or mouth, chest, fingers } \\
\text { and toes) }\end{array}$ & $75.2 \%$ & $16.9 \%$ & $7.7 \%$ & $0.2 \%(3)$ \\
\hline 9 (PS) & $\begin{array}{l}\text { Perceived susceptibility for } \\
\text { LB (can you personally get } \\
\text { ill after tick-bite?) }\end{array}$ & $68.6 \%$ & $16.7 \%$ & $14.4 \%$ & $0.3 \%(4)$ \\
\hline $10(\mathrm{PI})$ & $\begin{array}{l}\text { Importance of check (not, } \\
\text { somewhat, or very } \\
\text { important) }\end{array}$ & $* 7.0 \%$ & ${ }^{*} 52.5 \%$ & ${ }^{*} 40.4 \%$ & $0.2 \%(3)$ \\
\hline 11 (PSK) & $\begin{array}{l}\text { Perceived susceptibility } \\
\text { (knowing persons with } \\
\text { illness after tick bite) }\end{array}$ & $26.7 \%$ & $66.6 \%$ & $6.4 \%$ & $0.3 \%(4)$ \\
\hline $12(\mathrm{~PB})$ & $\begin{array}{l}\text { Checked for tick bites to } \\
\text { date? (never, occasionally, } \\
\text { every time) }\end{array}$ & $* 30.1 \%$ & $* 51.8 \%$ & ${ }^{*} 17.9 \%$ & $0.2 \%(3)$ \\
\hline
\end{tabular}

Behavioural determinants are given where relevant by abbreviations:

n.a. not available; K knowledge; PV perceived severity; PS perceived susceptibility;

PSK perceived susceptibility due to knowing persons with LB; PI perceived

importance, and PB protective behaviour.

${ }^{*}$ See abbreviated question for answer category. 
TABLE 3.3: Model coefficients $\beta$ and $p$-value for each determinant and response variable

\begin{tabular}{|c|c|c|c|c|c|}
\hline Covariate & $\begin{array}{l}\text { Knowledge } \\
\text { score }\end{array}$ & $\begin{array}{l}\text { Perceived } \\
\text { severity } \\
\text { (Q5) }\end{array}$ & $\begin{array}{l}\text { Perceived } \\
\text { susceptibility }\end{array}$ & $\begin{array}{l}\text { Perceived } \\
\text { importance }\end{array}$ & $\begin{array}{l}\text { Protective } \\
\text { behaviour }\end{array}$ \\
\hline$\%$ Forest cover & $2.50(0.20)$ & $0.15(0.96)$ & $0.68(0.60)$ & $-2.63(*)$ & $4.54\left(^{* *}\right)$ \\
\hline Urbanisation level 2 & $0.11(0.82)$ & $-0,34(0.62)$ & $-0.61(0.08)$ & $0.39(0.26)$ & $-0.33(0.34)$ \\
\hline Urbanisation level 3 & $0.12(0.82)$ & $-0.12(0.88)$ & $-0.25(0.6)$ & $-0.05(0.87)$ & $0.40(0.24)$ \\
\hline Urbanisation level 4 & $0.12(0.82)$ & $0.49(0.60)$ & $-0.39(0.28)$ & $-0.98(*)$ & $-0.32(0.38)$ \\
\hline Urbanisation level 5 & $0.12(0.78)$ & $-0,30(0.67)$ & $-0.60(0.06)$ & $-0.53(0.09)$ & $0.36(0.25)$ \\
\hline Previous education & $0.45\left(^{*}\right)$ & $-0.04(0.90)$ & $0.02(0.91)$ & $0.13(0.34)$ & $0.13(0.35)$ \\
\hline Knowledge score $\geq 6$ & nd & $1.78(* *) \dagger$ & $0.13(0.37)$ & $0.42(* *)$ & $\left.0.61{ }^{(* *}\right)$ \\
\hline $\begin{array}{l}\text { Perceived severity (is aware } \\
\text { of tick consequence) }\end{array}$ & nd & nd & $(0.69)(*)$ & $-0.08(0.74)$ & $0.31(0.21)$ \\
\hline $\begin{array}{l}\text { Perceived susceptibility } \\
\text { (doesn't know) }\end{array}$ & nd & nd & nd & $0.28(0.16)$ & $-0.45\left(^{*}\right)$ \\
\hline $\begin{array}{l}\text { Perceived susceptibility } \\
\text { (can get ill) }\end{array}$ & nd & nd & nd & $0.55\left(^{* *}\right)$ & $-0.08(0.58)$ \\
\hline $\begin{array}{l}\text { Perceived importance } \\
\text { (a bit important) }\end{array}$ & nd & nd & nd & nd & $\left.0.99{ }^{(* *}\right)$ \\
\hline $\begin{array}{l}\text { Perceived importance } \\
\text { (very important) }\end{array}$ & nd & nd & nd & nd & $2.16(* *)$ \\
\hline $\begin{array}{l}\text { Perceived susceptibility } \\
\text { (not person with LB) }\end{array}$ & $-0.23(0.35)$ & $-0.67(0.07)$ & $-0.04(0.85)$ & $-0.36(0.12)$ & $-0.39(0.10)$ \\
\hline $\begin{array}{l}\text { Perceived susceptibility } \\
\text { (knowing person with LB) }\end{array}$ & $0.57(* *)$ & $1.17(*)$ & $0.58{ }^{(* *)}$ & $0.45\left(^{* *}\right)$ & $0.37\left(^{*}\right)$ \\
\hline $\begin{array}{l}\text { Protective behaviour } \\
\text { (sometimes) }\end{array}$ & nd & nd & $0.17(0.21)$ & nd & nd \\
\hline $\begin{array}{l}\text { Protective behaviour } \\
\text { (frequently) }\end{array}$ & nd & nd & $0.29(0.13)$ & nd & nd \\
\hline
\end{tabular}

An $\left(^{*}\right)$ indicates $p \leq 0.05$, and $\left({ }^{* *}\right)$ indicates $p \leq 0.001$. Those variables that were not included in analyses per domain are indicated with 'nd'.

$\dagger$ This model was run with an adjusted knowledge score, where Question 5 was excluded and the criterion was set at $\geq 5$ questions correct. 


\section{Perceived importance of protective and actual practice of protect- ive behaviour}

The vast majority ( $92 \% n=1,343$ ) of the respondents regarded body checks as very or somewhat important $(40 \%$ and $52 \%$, respectively). This finding was associated with a good knowledge level ( $p=0.001$, effect size 0.098 , which suggests that the probability of finding body checks very important increases by 0.098 with a good knowledge level). Additionally, a high perceived susceptibility $(p<0.001$, effect size 0.124$)$ and a high proxy for perceived susceptibility through knowing persons with LB ( $p<0.001$, effect size 0.112 ) were associated with finding body checks very or somewhat important. Surprisingly, respondents from areas with a high forest cover within a $10 \mathrm{~km}$ radius around the school were less likely to find tick checks important ( $p=0.049$, with a large effect size of -0.392) than children from less forested areas. In line with this observation, but with smaller effect size: the less urbanised area level 4 also shows this effect (significant at $p=0.02$, effect size -0.191). The least urbanized level 5 was not significant $(p=0.09$, effect size -0.134$)$.

Half of the children $(52 \%, n=749)$ reported being inspected occasionally for tick bites after having been outside. Nearly one third of the total respondents (30\%, $n=436$ ) had never had a body check, and only $18 \%$ of the respondents indicated they were checked after every visit to nature. Children with a good knowledge score $(p<0.001$, effect size 0.053$)$ and those knowing persons with LB (proxy for perceived susceptibility, $p=0.004$, effect size 0.046 ) were more likely to be checked often. Likewise, those who considered body checks somewhat or very important were checked more frequently (both $p<0.001$, effect size 0.075 and 0.429 , respectively). Respondents in areas with a higher forest cover were more likely to be often checked for ticks $(p<0.001$, effect size 0.810$)$, which implies that their parents perceived susceptibility even if the children did not.

\section{Discussion}

We studied school children's knowledge, perceived severity, perceived susceptibility, and protective behaviour in relation to ticks and their possible consequences in the Netherlands, where LB incidence has increased sharply throughout the past two decades. We conclude that most Dutch children have very good general knowledge about ticks and their possible consequences, although three-quarters of them never had classroom lectures about ticks. Seventy percent answered at least six out of seven knowledge questions correctly. This percentage is higher than among adults studied in tick- and LB-endemic areas [17, 74] and may reflect discussion of ticks and their possible consequences by children's television programs in recent years.

An exception to the good general knowledge was that most children incorrectly believe that ticks live in trees and that headgear therefore offers some pro- 
tection. This common misunderstanding exists also among adults [17] and must be addressed in education programs for all age groups. Awareness that ticks occur in lower vegetation is essential for understanding why protective clothing includes long trousers and shoes with socks, not caps. Such awareness also enables more effective body checks.

Knowing persons who personally got ill after tick bite was significantly associated with a higher knowledge level. Knowing such persons was found by others to predict specific tick-bite protective behaviour [76]. Perceived severity (based on Q5: being aware of tick bite consequences) was likewise associated with higher knowledge scores. Sixty-nine percent of the children perceived themselves as susceptible for illness due to a tick bite. They were aware of the possible consequences of a tick bite, and such awareness is crucial to a realistic perception of personal risk. People with a realistic perception of risk are more likely to be motivated to engage in preventive behaviour [76, 31].

The evidence base for checking for ticks to prevent LB is still limited, but there is some evidence. Smith and Jacobs showed in their studies that checking the skin for ticks during outdoor activities and removing them within 24 hours, reduced the chance of getting Lyme disease (odds ratio $0.59 ; 90 \%$ CI $0.48-0.72$, respectively $0.6 \%, 95 \%$ CI: $0.0003-0.029$ ) [151, 91]. The vast majority (93\%) of children regarded body checks as somewhat or very important. Children with a sufficient knowledge level, a high perceived susceptibility, or knowing persons who got ill after tick bite were more likely to find body checks very or somewhat important and were also checked by their parents more frequently. Whereas nearly $18 \%$ of the children indicated being inspected after every nature visit, the rest $(82 \%)$ were checked occasionally $(n=749,52 \%)$ or never $(n=436,30 \%)$. In comparison, $28 \%$ of the Brazilian population on the Massachusetts idland of Martha's Vineyard checks their skins for ticks routinely [74]. Dutch children in the least urbanised and most forested areas regarded tick checks as less important, but were nevertheless checked for tick bites more frequently than more urban children. Clearly the less urbanised parents are more vigilant, but their children may be so accustomed to having the checks (habitual behavior) that they give them less notice than do urban children, for whom they are less routine.

Our findings suggest that it is useful to focus on children in health education regarding ticks and tick-borne diseases. Although the parents must perform body checks on children, the knowledge, perceived susceptibility, and perceived importance of protective behaviours among children is related to the desired behaviour of the parents: performing body checks.

This is the first study to evaluate the knowledge, perceived severity and susceptibility, and protective behaviour of school children in relation to ticks and their possible consequences. As to possible limitations, selection bias may have occurred because primary schools in the southern Netherlands had holiday during the study period. However, with no reason to believe that those schools differ in tick-related knowledge from the schools that did participate, we think this will not affect the generalisability of the results. 
It could be a limitation that our questionnaire-based approach kept the number of questions to 12 . Additional questions on the studied constructs and on the protective measures taken by the respondents to prevent tick bites may have been beneficial in terms of validity, but was deemed less feasible for primary school children. Since this is the first study among school children we developed and pretested a new questionnaire. This questionnaire needs to be validated in future studies (e.g., in terms of the accuracy of the reported behaviors).

The question: 'Do you know someone who has become ill after a tick bite?' might be interpreted as if a tick bite preceding development of Lyme disease will always be recognized. However, the majority of patients who develop Lyme disease do not report a preceding tick bite. Therefore, this question might be ambiguous. Since we used this question too as a proxy for the perceived severity of the children, we think this ambiguity is acceptable.

Finally, this cross-sectional study could not demonstrate a cause-effect relationship between the determinants in the children and the behaviour of the parents. For example, it may be that body checks by parents lead to higher knowledge, perceived severity and susceptibility among children, but equally it may be that these factors in children lead to parents' performing body checks. Ideally we might have included both the school children and their parents, performing repeated measurements to analyse differences in the knowledge, perceived threat, and behaviours regarding ticks and their possible consequences within the family, showing a more plausible cause-effect relationship. Since the children in this study were contacted through their schools and not through families, it was complicated to include their parents.

\section{Conclusion}

The previous studies on knowledge, perceived severity and susceptibility, and protective behaviour regarding ticks and their possible consequences have focussed on adults or the general population. As the first to focus solely on primary school children, our study can assist in development of education programs on ticks for children, a high risk group in Western Europe and the USA. Such programs should reflect our findings that good knowledge of ticks and knowing someone who got ill after tick bite lead to more body checks. Programs should take into account that children in forested areas view checks as less important, but are checked more frequently by parents. Further research on the relationship between health education programs about ticks aimed at children (and their parents) in order to prevent LB is needed. 


\section{Annex 1: Questionaire}

What age are you?

Multiple choice questions (Instruction to tick one box in each question):

1. Did you ever receive classroom lectures about ticks?
(a) Yes
(b) No

2. What does a tick look like?

(a) Image: Silhouette of an ant

(b) Image: Silhouette of a tick

(c) I don't know

3. What is the real size of a tick that could bite you?

(a) Image: poppy-seed size black dot

(b) Image: pea size black dot

(c) I don't know

4. At what sort of place would you expect to encounter ticks?

(a) Color image of path in a forest

(b) Color image of sand-covered playground

(c) I don't know

5. Why should you watch out for ticks?

(a) Ticks make you itch

(b) Ticks can make you ill

(c) I don't know

6. At what place do ticks prefer to live?

(a) Up in the trees

(b) Near the ground in brushes and tall grass

(c) I don't know

7. What can you do to prevent tick bites?

(a) Wash carefully to rinse off ticks

(b) Check your clothes and body with an adult and pull out attached ticks

(c) I don't know 
8. Which picture shows best where ticks prefer to bite?
(a) Image: child body contours with arrows pointing at nose, chest, hands and toes
(b) Image: child body contours with a rows pointing at ears, armpits crotch and knees
(c) I don't know

9. Do you think that you could personally become ill after a tick bite?
(a) Yes
(b) No
(c) I don't know

10. Do you consider it important to be checked for tick bites after playing in an area where ticks may live?
(a) Not important
(b) Somewhat important
(c) Very important

11. Do you know someone who has become ill after a tick bite?
(a) Yes
(b) No
(c) I don't know

12. Did you ever do a body inspection for tick bites with your parent or carer?
(a) Never
(b) Occasionally
(c) Every time after a visit to an area where ticks may live 


\section{Chapter 4}

\section{Using risk group profiles as a lightweight qualitative approach for intervention development: an example on prevention of tick bites and Lyme disease}

Published as:

Beaujean DJ, van Velsen L, van Gemert-Pijnen JE, Maat A, van Steenbergen JE, Crutzen R. Using Risk Group Profiles as a Lightweight Qualitative Approach for Intervention Development: An Example of Prevention of Tick Bites and Lyme Disease. JMIR Res Protoc, 2013 Oct 30; 2(2):e45. 


\section{Abstract}

Background: Many public health campaigns use a one-size-fits-all strategy to achieve their desired effect. Public health campaigns for tick bites and Lyme disease (LD) in many countries convey all relevant preventive measures to all members of the public. Although preventing tick bites (e.g., by wearing protective clothing or using repellants) and checking for tick bites after visitinga risk area are effective and cost-efficient methods to prevent an individual from contracting a tick-borne disease, public compliance to these methods is low.

Objective: We aimed to identify the group of individuals within the general Dutch population that are at high risk of being bitten by a tick or developing $\mathrm{LD}$ and to describe their characteristics, knowledge, and perceptions. The incidence of patients visiting their general practitioner for tick bites and erythema migrans (the first sign of LD) has increased tremendously in the last decades in the Netherlands and other European countries; therefore, our efforts can be used to counter this troubling trend.

Methods: We conducted in-depth semi-structured interviews to identify individuals belonging to the average risk group. Participants were recruited in two ways. Patients who visited two municipal health services travel health clinics (one in a high-endemic area and one in a low-endemic area) were asked to participate. This resulted in 18 interviews. Further, parents were recruited using the convenience sampling method, which resulted in 7 interviews. We discontinued interviewing when the point of data saturation was reached. We analyzed the results immediately after each interview to identify the point of data saturation. Data saturation is when the new interviews provided no new information compared to the previous interviews. The interviews were transcribed and analyzed using inductive thematic analysis.

Results: We identified four groups at risk of being bitten by ticks and developing LD among the general Dutch population. The groups were as follows: (1) outdoor people that check for tick bites, (2) outdoor people that do not check for tick bites, (3) parents that check their children for tick bites, and (4) parents that do not check their children for tick bites. Previous experience with ticks or LD was the main denominator between the groups. Checking for tick bites is a more easily adopted measure than preventing tick bites. Therefore, for all groups, public health efforts in the future should primarily emphasize on the importance of checking for tick bites. 
Conclusions: The lightweight qualitative approach presented in this paper is highly relevant in tailoring public health efforts toward specific groups. The profiles of members in each risk group and the motivations underlying the behaviors of the members in each risk group can be used to determine the features and content of a targeted communication strategy about ticks and LD.

\section{Introduction}

Many public health campaigns use a one-size-fits-all strategy to achieve their desired effect. In the context of controlling infectious diseases, a single mode of communication (e.g., a leaflet or a television commercial) is often used to convey allrelevant evidence-based precautions for a single disease. For example, a Dutch leaflet on preventing food-borne infections advices people to wash their hands with soap before preparing food, after touching raw meat, before eating, and after visiting the toilet or changing diapers; to use a separate cutting board for raw meat and vegetables; to use clean knives for different products; to keep salads and meat cooled during barbeques; not to drink raw milk, etc. Dividing a heterogeneous audience into homogeneous audience segments and subsequently targeting health communication toward these audience segments is a more fruitful approach than distributing a one-size-fits-all message [149]. In the past, many audiences have been successfully segmented for health campaigns such as healthy eating campaigns [92] and promoting physical activity [158]. Segmentation is often based upon demographic, behavioral, and/or psychosocial data and involves the analysis of very large volumes of quantitative data [22].

Lyme disease (LD) is the most common tick-borne disease in the United States and in Europe. In the Netherlands, 564 per 100,000 inhabitants consulted their general practitioner (GP) about tick bites [82]. In 1994, about 39 per 100,000 inhabitants visited their GP for erythema migrans (EM, an associated symptom of LD). This number increased to 134 per 100,000 inhabitants in 2009 [82]. In humans, LD develops in three stages, starting with a circular red skin rash (EM) with fever, headache, fatigue, and depression to a chronic stage that can affect a wide range of body parts, including the brain, nerves, joints, and heart.

Public campaigns in many countries aimed at preventing tick bites and LD use the strategy of providing every member of the public with all the relevant preventive measures [132]. Although preventing tick bites (e.g., by wearing protective clothing or using repellants) and checking for tick bites after visiting a risk area are effective and cost-efficient methods to prevent an individual from contracting a tick-borne disease [52], public compliance to these methods is low. According to Marcu et al. [109] and Beaujean et al. [17], people do not comply with precautions because of the following reasons: people believe that these precautions interfere with how they want to enjoy nature (e.g., they refuse to wear long clothes on a hot day), people assume that the risk of tick bites is low, people do not believe that the precautions are effective (e.g., they refuse 
to apply insect repellent products), and people do not know how to identify a tick bite (e.g., recognizing and removing a tick). Although it is not impossible to change the knowledge and perceptions of the people about precautions, Mowbray et al. [113] recently reported a finding for segmenting the general audience in relation to tick bites and LD.

They claim that communication about preventive measures should be tailored toward the knowledge and perceptions of an audience segment about the disease and possible precautions. Thus, it will be more rewarding to provide an audience segment with the advice that they are likely to adopt only. For example, preventive measures that are realistic and fit within the perception of the audience (segment). The measures for preventing LD include checking for tick bites and removing them. Previous studies showed that to match the needs of the target users and to maintain their interest, user involvement is critical in planning and designing the intervention [98, 85]. An assessment of mobile-based interventions for management and prevention of human immunodeficiency virus (HIV) infection showed that majority of the interventions failed to attract the attention of their users [115], and users criticized a computertailored program for chronic obstructive pulmonary disease (COPD) because the feedback was not tailored to the severity of the disease and could not be used for patients with severe COPD [181]. To develop an intervention that is likely to be used by its target users, it is crucial to gain insight into the perception of the audience segments.

To date, segmentation of the audience has not been performed for providing information about tick bites and LD. In this study, we identified the group of individuals among the general Dutch population that are at high risk of being bitten by ticks or developing LD, and we have described their characteristics, knowledge, and perceptions. The incidence of patients visiting their GP for tick bites and EM has increased tremendously in the last decades in the Netherlands and other European countries [82, 77]; therefore, our efforts can be used to counter a troubling trend. Furthermore, to identify audience segments, we will usea lightweight qualitative approach that can be used whenever one does not have access to a large body of information about an audience, or is not in a position to create one, as is often the case in clinical practice. This is especially relevant within the sector of public health, because despite its importance at the societal level, the sector faces critical challenges, including substantial decreases in funding [64, 111]. In recent years, public health organizations have been hit hard with cutbacks and layoffs, while more is expected of public health professionals $[170,41]$. In this study, we take a first step in identifying risk groups on the basis of the previous studies and attempt to understand the differences between the groups based on interview results. In the following sections, we describe the set-up of our methods and present the results for prevention of tick bites and LD. Finally, we discuss the risk groups that we identified and how our method can be used for targeting health communication about the prevention of tick bites and LD. 


\section{Methods}

\section{Overview}

The approach of this study consists of two steps: (1) identification of a risk group on the basis of results from previous studies, and (2) in-depth interviews with members of the identified risk group(s) to describe the characteristics of the identified groups. We used a lightweight qualitative approach (small sample of respondents) as a first step in identifying risk groups among the general Dutch population.

\section{Risk group identification}

The first step in targeting health communication is to identify groups at high risk for a condition. In the case of tick bites and LD, two high-risk groups are observed among the general Dutch population [34]. The first risk group consists of people that spend a lot of time outdoors (outdoor people), such as hikers, campers, and dog owners. The number of hours spent outdoors per week is related to the risk of tick bites; the greater the number of hours spent outdoors, the higher the incidence of tick bites [163, 78]. The second risk group includes children aged from 5 to19 years because of their increased contact with tick habitats, for example, because they play outside $[82,94,56]$. Since parents are responsible for the health and tick checks of their children, we interviewed parents about their children and tick bites and LD.

\section{Profiling risk group members: in-depth interviews}

To profile the members belonging to an average risk group, conducting in-depth semi-structured interviews is an effective approach. These interviews allow for exploring a range of topics and subsequently pursuing a topic in-depth when it appears to be important [130]. This method was also suggested by Mowbray et al. [113] to create a basis for designing targeted interventions against tick bites and LD.

Participants were recruited in two ways. People who visited two municipal health services (MHS) travel health clinics (one in a high-endemic area and one in a low-endemic area) for traveler's vaccination were asked to participate in an interview by a nurse in the infectious disease control department. We opted for this group, because they often recreate outdoors. This resulted in 15 interviews with people who spend time outdoors and 3 with parents. Further, we recruited parents via a convenience sampling method, which resulted in 7 interviews.

We created an interview scheme based on an overview of citizen characteristics that need to be taken into account when developing health interventions [104]. The interview scheme addressed (1) demographics, (2) frequency of visits to high-risk areas, (3) knowledge of ticks and LD (i.e., using five statements 
about recognition of ticks, tick habitats, mode of transmission, and symptoms of LD), (4) experience with ticks and LD, (5) perception and behavior about LD prevention measures (e.g., 'How severe do you perceive LD?' and 'What would you do in the case of a tick bite?'), and (6) tick- and LD-related information seeking behavior (e.g., 'Where would you seek for information on ticks and LD?'). Interview schemes can be found in Annex 1. An experienced qualitative researcher conducted all the interviews.

Each interview started with a short introduction of its goal, after which the interviewees were guaranteed anonymity. Then, the interviewees provided informed consent and permission for audio recording. Subsequently, the interviewees received a gift voucher as an incentive.

We stopped the interview when all pre-determined themes were discussed, and the interviewee added no new themes. We analyzed the results immediately after each interview to identify the point of data saturation. Data saturation occurred when the interviewer concluded that, compared to the previous interviews, the new interviews provided no new information.

\section{Analyses}

The interviews were transcribed and analyzed using inductive thematic analysis according to the six steps suggested by Braun and Clarke [23]. Inductive thematic analysis focuses on identification and description of themes both implicit and explicit ideas within the interview data. An experienced analyst of qualitative data analyzed the interviews. Step 1 was familiarizing with the data. This involved transcribing the data and reading and re-reading the data in an active manner; searching for meanings, patterns, and writing down initial ideas. This phase was time consuming, but is the bedrock for the rest of the analysis. The formal coding process began after completion of this step. Step 2 was generating initial codes from the data. Codes identify a feature of the data (semantic contentor latent) that appears interesting for the analysis and refer to 'the most basic element of the raw information that can be assessed in a meaningful manner about the phenomenon.' In this phase, it was important to ensure that all actual information was coded. Step 3 began when all information was coded and a long list of the different codes was identified across the dataset. Now, the codes require to be ordered into potential themes. Step 4 included reviewing and refining the themes. Some themes collapsed into each other and some themes were not really themes (the data were too diverse). At the end of this step, we had a good idea of what the different themes were, how they fit together, and the overall story they told about the data. In step 5, we defined and named the themes. Finally, step 6 involved the final analysis and writing up of the results. We will provide an example to make this process more transparent. One interviewee said when we asked him how quickly a tick that has bitten should be removed from the body "I don't know; I only know that it is in its saliva. So, you should never use detergent or alcohol. Because if it has contaminated saliva, it will spit." A 
second interviewee said, "I don't know. I don't think it matters because either the beast has Lyme or it doesnot." Finally, a third interviewee said, "I think directly." Initially, the interview segments were coded as "knowledge about how soon to remove ticks." Next, the first two interviewees were coded as "not knowing how quickly to remove a tick", and the third response was coded as "knowing when to remove a tick." An overview was finally made when all interviewees were coded according to whether or not they knew how soon to remove a tick.

\section{Results}

\section{Profiles of risk group members}

The responses of the interviewees to the open question about checking for ticks led us primarily to divide both risk groups into the following two subgroups:

1. Outdoor people that do not care about being bitten by a tick and the risks involved (those that do not check) and people that do care and therefore check for ticks when they have visited a high-endemic area (those that check).

2. Parents that check their children for tick bites, and those that do not.

Each subgroup had its own view toward ticks, LD, and preventive behavior, and therefore, we analyzed their responses separately.

Outdoor people that do not check ("I never check for ticks after being outdoors") constituted a large group (men: $7 / 14,50 \%$ and women: $7 / 14,50 \%$; mean age 43 years). People in this group are often in their backyards and frequently visit a forest. The group of those that check ("I sometimes or always check for ticks after being outdoors") is relatively small (women: $3 / 3,100 \%$; mean age 42 years), and people belonging to this group spend a lot of time in their backyard and can frequently be found in forests, heathland, dunes, and city parks.

Parents that check ("I sometimes or always check my child/children for ticks after they have been outdoors"; men: 2/8, 25\% and women: 6/8, 75\%; mean age 41 years) accounted for the majority of parents. Their children very often play in the backyards and some of the children of these parents regularly play in forests. Parents that do not check ("I never check my child/children after they have been outdoors"; men: 1/2, 50\% and women: 1/2, 50\%; mean age 42 years) were a small group, whose children often play in the backyards. 
TABLE 4.1: Characteristics of outdoor people

\begin{tabular}{|c|c|c|}
\hline & Those that do not check & Those that check \\
\hline Age & widespread & widespread \\
\hline Family situation & $\begin{array}{l}\text { either living alone, living } \\
\text { together without children, } \\
\text { or living together with } \\
\text { grown-up children }\end{array}$ & $\begin{array}{l}\text { either living alone, living } \\
\text { together without children, } \\
\text { or living together with } \\
\text { grown-up children }\end{array}$ \\
\hline Education & widespread & widespread \\
\hline Pet ownership & $\begin{array}{l}\text { about half of the people } \\
\text { has a pet }\end{array}$ & about half of them has a pet \\
\hline $\begin{array}{l}\text { Direct experience with } \\
\text { ticks / LD }\end{array}$ & $\begin{array}{l}\text { the majority of people has } \\
\text { not been bitten by a tick }\end{array}$ & $\begin{array}{l}\text { most of the people have } \\
\text { been bitten by a tick or } \\
\text { noticed a tick on their body } \\
\text { once }\end{array}$ \\
\hline Knowledge of ticks / LD & $\begin{array}{l}\text { widespread; some people } \\
\text { know nothing, some } \\
\text { people know a lot }\end{array}$ & medium to high \\
\hline
\end{tabular}

\section{Outdoor people}

\section{Overview}

The main characteristics of the two subgroups within the outdoor people are shown in Table 4.1. The results indicate that experience with tick bites or LD is the great denominator between the groups and the main reason for a person to shift from checking to not checking for tick bites.

\section{Knowledge of ticks and Lyme disease}

Outdoor people that do not check for tick bites had a widespread knowledge of ticks and LD. Most of them knew that a tick is a little animal. Almost all the participants thought they could get a tick bite in a forest and falsely believed that ticks let themselves fall from trees. About half of our participants also said that ticks can be found in high grass or shrubs. Only few people knew that ticks live in dunes.

"I would say only in the forest. And, when you standunder a tree, that's what you hear often, that they fallout of the tree. That's all I know." (Woman; age, 18 years)

Most interviewees did not think that a tick bite always resulted in LD. Some thought there were individual differences in terms of susceptibility. Most participants thought that a tick should be removed as soon as possible. When asked how they could know whether they have LD, about half of the people mentioned 'the red spot' (referring to EM). The remaining participants had no idea. Participants who do check for tick bites had medium to high knowledge of ticks and 
LD. They knew the size of the ticks, but were not completely informed of their habitat, because they mainly mentioned grassland and forests, and the possibility of ticks falling from trees. According to this group, whether or not a tick bite leads to LD is dependent on the tick being infected or not or how long it is attached to the skin. Finally, they mentioned 'the red spot' as a first sign of LD.

\section{Experience with ticks}

Several outdoor people that do not check for tick bites told us they had seen a tick mostly on pets. On the other hand, those who checked for tick bites had direct or indirect experience with ticks or LD; they had pets with ticks, friends with LD, or experienced a tick bite followed by an EM.

\section{Dealing with tick bites}

About half of the people that 'do not care' would remove a tick using (tick) pliers themselves. However, some erroneous strategies were mentioned, such as burning it off with a cigarette, waiting for the tick to grow big so it can be removed more easily, and twisting the tick when removing it. Some people foresaw negative consequences of using tick pliers, like pain, difficulty in removing the tick, not removing the tick's head, and finally, the unpleasant feeling of 'operating' on yourself. The other half would go to their GP after encountering a tick bite, mostly because they thought they were unable to properly remove a tick by themselves. Participants who check were more confident about their abilities and said they would remove ticks themselves when bitten using (tick) pliers.

\section{Preventive measures}

Participants of the group that do not check did not take preventive measures against tick bites when visiting a high-endemic area. They regard staying on paths and using an insect repellent spray on their skin as a viable option to guard themselves against ticks. Several of these people did indicate,however, that if something caught their interest in the forest,they would stray from the paths. Wearing clothes that cover the body was not a viable option according to the respondents as it was uncomfortable or 'looks stupid.' After visiting a highendemic area, people that 'did not care' never checked for tick bites. They did not know that they were in a high-endemic area (like dunes), forgot to check, or expected a tick bite to itch. Those that check thought that staying on the paths in the forest could be a viable preventive measure, but they also indicated that they would not comply whenever they wanted to explore the forest off the beaten path. Normally, these participants did not consider wearing clothes that cover the body as a good preventive measure, especially in warm weather. However, the participants also indicated that when the risk of being bitten is high (e.g., when being in a high-endemic area), they would comply with this measure. 
"When it's $35^{\circ} \mathrm{C}$ outside, you walk in short pants anyway. And then, you check yourself properly in the evening. But, when the number of ticks runs out of hand, you do put on long thin pants." (Woman; age, 53 years)

Finally, for most interviewees, using an insect repellent skin spray was a reasonable measure; it allowed them to wear short pants. All of those that check, stated they checked themselves for tick bites when they were outdoors.

\section{Information seeking behavior}

Outdoor people that do not check for tick bites indicated they would consult a wide range of sources when seeking information on ticks or LD. Most popular resources when searching for information on how to prevent tick bites are the Internet and the MHS, or when bitten by a tick, their GP, the Internet, or the MHS. When searching on the Internet, practically all interviewees would start with a Google search. Those that check expected their MHS to provide them with information on tick sand LD. When searching for information on how to prevent tick bites, they mentioned pharmacies and an online Google search. For information on how to remove ticks, they would resort to their GP or the Internet (with no specific website in mind).

\section{Parents}

\section{Overview}

Checking for ticks is determined by previous experience with ticks and LD (Table 4.2). Children of parents that check spend more time in high-endemic areas.

\section{Knowledge of ticks and LD}

Parents that do not check had little knowledge of ticks and LD but thought that LD was a dangerous disease. The forest was the main location where they thought a child could be bitten. According to them, not all tick bites lead to LD. They did not know the first signs of LD or how fast a tick should be removed. Parents that check had medium knowledge of ticks and LD. They knew what a tick was and that they are very small. In addition, all of them knew about LD and thought it is a serious condition. All participants thought one could be bitten in a forest or in places with shrubs or grass. It was not clear to them that ticks also reside in dunes. None of the interviewees thought a tick bite always leads to LD. Most of them thought a tick should be removed within 24 hours after being bitten. Parents that check knew that EM occurs after an LD infection. A few also mentioned flu-like symptoms as a first sign of LD. 


\section{Experience with ticks}

Parents that do not check their children for tick bites had no experience with ticks or LD, while all of the parents that check their children for tick bites had previous experience. The latter were once bitten themselves, had one or more children or pets were bitten at least once, or they knew someone with LD.

\section{Dealing with tick bites}

Parents that do not check their children for tick bites have two strategies for removing ticks: using (tick) pliers or visiting their GP. They were unsure about their own abilities to remove ticks because they were afraid they could not remove the tick in its entirety. Most parents that check would remove a tick themselves if one of their children were bitten. However, they anticipated difficulties in the removal. They were afraid they would do it wrong, because they received different kinds of instructions (twisting when removing, pulling upward), or they were afraid that they would also remove the skin or would leave (a part of) the tick's head behind.

"I think I will have it removed by the family doctor. I don't mind with my own cat... but, in the case of my own child, I want to have it done properly. It's not that I won't dare to do it, but I think I will notify the family doctor or will discuss with him what to do. I have one of those tick pliers. But, the last time the cat had a tick, it didn't go as I wanted it to. So, I would go to the family doctor." (Woman; age, 32 years)

\section{Preventive measures}

All parents agreed about the issue of tick bite prevention. They knew they could prevent their children from being bitten by a tick by wearing the right kind of clothing. When prompted about the different precautions they could take, parents were not enthusiastic. They did not want to keep their child on paths inforests or parks, because they thought the children should be allowed to run freely. Wearing clothes that cover the body was not seen as a practical option when it was warm outside.Wearing a cap was not seen as an option, because the parents expected their child to remove it. Parents disliked the use of insect repellent sprays, because they contain diethyltoluamide (DEET), or the parents did not want to spray in their child or their clothes every day. Parents that do not check their children for tick bites do so because they think the chance of their child being bitten by a tick is very small or expect their child to notice a tick bite; they assumed that the children would 'feel it.' Parents that do check their children do this when they thought their child was at risk of tick bite, for example, by having spent time in the forest. When they check their children, they mostly look at their armpits, neck, ears, groin, back of the knee, or 'warm creases.' 


\section{Information seeking behavior}

Parents that do not check indicated that they would search the Internet when they wanted information on how to prevent tick bites or how to remove ticks. Parents that do check expected the national government or the MHS to inform them about preventing tick bites and LD. When they need information on how to prevent tick bites, they would perform an Internet search using Google. To find information on how to remove ticks, they would perform a Google search or would consult their GP.

"I think I would go to the family doctor if I don't trust the situation [a child with a tick bite]. I would Google. That would be the way for me. Just type in 'tick bite' and see where it gets me.' (Woman; age, 47 years)

All children of the parents we interviewed went into high-endemic areas with clubs or schools. Both groups of parents thought that checking for tick bites was their own responsibility when possible although they would like to be reminded to do so. When children are away overnight, the parents thought that it was the responsibility of the club or school to control for tick bites.

TABLE 4.2: Characteristics of parents and their children

\begin{tabular}{lll} 
Age & Parents that do not check & Parents that check \\
$\begin{array}{l}\text { Family situation } \\
\text { Education }\end{array}$ & $\begin{array}{l}\text { married; } 1 \text { to } 3 \text { children } \\
\text { widespread }\end{array}$ & $\begin{array}{l}\text { 30 to } 50 \text { years old } \\
\text { married; } 1 \text { to } 3 \text { children } \\
\text { widespread }\end{array}$ \\
$\begin{array}{ll}\text { Pet ownership } \\
\begin{array}{l}\text { Direct experience } \\
\text { with ticks / Lyme }\end{array}\end{array}$ & low & $\begin{array}{l}\text { none } \\
\text { about half of them has a pet }\end{array}$ \\
$\begin{array}{l}\text { Knowledge of } \\
\text { ticks / Lyme }\end{array}$ & low & $\begin{array}{l}\text { all parents have experience with } \\
\text { ticks or LD, either being bitten } \\
\text { themselves, via a child, or via a pet }\end{array}$ \\
\hline
\end{tabular}

\section{Discussion}

\section{Overview}

In this paper, we have shown a lightweight qualitative approach by identifying risk groups and conducting in-depth interviews to create risk group profiles that can be used as inputs for targeting health communication. Such health communication is geared toward the characteristics and contexts of specific groups within a population and is generally more effective than one-size-fits-all communication [149]. To our knowledge, this is the first study in which this approach 
has been used providing information about tick bites and LD to the general Dutch population.

\section{Identifying risk groups}

We identified four groups at a risk of being bitten by ticks bites and developing LD among the general Dutch population. The four groups were as follows: (1) outdoor people that check for tick bites, (2) outdoor people that do not check for tick bites, (3) parents that check their children for tick bites, (4) and parents that do not check their children for tick bites. Previous experience with tick bites or LD appeared to be the main denominator between the groups. Herrington [76] also identified previous experience with tick bites as one of the main factors governing compliance with preventive measures. The willingness to adopt measures that prevent tick bites (e.g., wearing protective clothing) was low for all risk groups.

\section{Communicating targeted precautions}

Our results were consistent with those reported by Gould et al. [67], Marcu et al. [52], and Beaujean et al. [109], in that we found that checking for tick bites is a measure that is more easily adopted than preventing tick bites. Therefore, for all groups,the advice should primarily stress the importance of checking for tick bites. Moreover, we identified differences among groups, and therefore, health organizations should shift their focus from communicating expert-driven guidelines (promoting all precautions that can help) to communicating targeted precautions (those that members of a risk group are likely to adopt and/or fit with their perceptions). Using the profile of each risk group (Tables 4.1 and 4.2) and the motivations behind their behavior, health organizations can attune their informative and persuasive communication efforts. For example, outdoor people that do not check need to be educated about ticks and LD from scratch; they must be encouraged to check for tick bites after visiting arisk area; and they must be encouraged to remove ticks themselves instead of visiting their GP. However, outdoor people that do check already know the basics about ticks and LD and will remove ticks. These people should be provided with detailed information about the habitat of ticks. An approach similar to that mentioned above should be used in the case of parents. Parents that do not check their children for tick bites should be educated about the topic and should be motivated to check their children for tick bites and to independently remove the ticks that have bitten their children. Parents that do check are more willing to remove ticks that have bitten their child themselves but are afraid to do this wrong. Therefore, they do not need to be persuaded to remove the tick, but they require appropriate instructions. 


\section{A targeted communication strategy}

Currently, we are developing a mobile app for ticks and LD asan example of a targeted communication strategy using a multidisciplinary requirements development approach [179]. We are using the profiles of each risk group (Tables 4.1 and 4.2) and the motivations underlying the behavior of the members of each risk group to determine the features and content of the app. A mobile app provides real-time up-to-date instructions and information and can be targeted to specific groups. Van Velsen et al. showed that users need a video with information on how to remove a tick, a tick radar that indicates the actual tick activity on the basis of location and seasonality, and an alert that reminds people to check for tick bites at the end of the day when they have been in an endemic area. Finally, users expressed the need to document tick bites. A mobile app can provide these requirements identified by the users [177]. The app will offer only the selected information that is required according to the risk group. For example, for people that do not check (themselves or their children), information encouraging these people to check for tick bites after visiting a risk area will be included in the app. For people that do check, instructions on how to properly remove ticks will be added. Thus, the communication about ticks and LD will be targeted to great extent. Further studies are required to determine whether this method of communication is a more fruitful approach than communicating a one-size-fits-all message.

\section{Limitations}

The main limitation of our study is the small sample size inherent to qualitative research and the approach used. Our study is a first step in identifying risk groups and understanding the differences between the risk groups used for the development of an intervention for the prevention of tick bites and LD. A larger number of respondents are required to draw more definite conclusions, for example, about the size of certain risk groups. However, the aim of this study and of creating a basis for targeted health communication is not to quantify conclusions (e.g., give a certain percentage) that hold for a total population(and for which a quantitative study with a large sample would be most suited) but to identify risk groups, and most importantly, to understand the differences between the risk groups. Because we reached the point of data saturation, we were confident that we understand the differences between the risk groups (without actually quantifying these risk groups, which was not the aim of this study). Furthermore, we have presented an approach toward targeting health communication for situations in which access to large sets of data about a population is not available. When one wants to understand people's behavior, or when largesets of data about a population are not available (as is often thecae in public health), qualitative research is the only feasible means to elicit the necessary information (with limited budgets). 
Another limitation relates to the defined risk groups. The distinction between outdoor people and parents with children might be somewhat confusing because some people might belong to both, for example, outdoor people with children. For these people, both targeted strategies would apply; one strategy for checking themselves and one strategy for checking their children. Although children can also be outdoor people, they do not belong to the outdoors group because they cannot be held responsible for checking themselves for ticks; this is the responsibility of parents.

\section{Conclusions}

Finally, the extreme form of targeting is tailoring, that is, tuning health communication toward the characteristics and context of the individual. This holds the potential to increase a person's attention or motivation about a specific health issue or healthy behavior [72, 97]. Further, with the development of new technologies in the last decade, health organizations have gained a wide range of possibilities for gearing messages toward the individual user. However, although often effective [118], tailoring is not always preferred over targeting, because this choice depends on the complexity of the targeted behavior, the available budget, the variability of behavioral determinants among individuals, and the availability of mechanisms for assessing an individual's characteristics and context [139]. Moreover, in many cases, a combination of a targeted and tailored approach is the optimal health communication strategy [139]. Therefore, identifying differences among risk groups is and remains an important facet of tailoring health advice be it toward groups or individuals. The lightweight qualitative approach presented in this paper is highly relevant in achieving this objective. 


\section{Annex 1: Interview guide}

\begin{tabular}{|c|c|c|c|}
\hline & OUTDOOR PEOPLE & & PARENTS \\
\hline & Demographics & & Demographics \\
\hline 1 & What is your age? & 1 & What is your age? \\
\hline 2 & In what country are you born? & 2 & In what country are you born? \\
\hline 3 & $\begin{array}{l}\text { If relevant, how well do you speak } \\
\text { Dutch? }\end{array}$ & 3 & $\begin{array}{l}\text { If relevant, how well do you speak } \\
\text { Dutch? }\end{array}$ \\
\hline 4 & What is your family situation like? & 4 & What is your family situation like? \\
\hline 5 & What do you do for a living? & 5 & What do you do for a living? \\
\hline 6 & $\begin{array}{l}\text { What is the highest education you have } \\
\text { completed? }\end{array}$ & 6 & $\begin{array}{l}\text { What is the highest education you have } \\
\text { completed? }\end{array}$ \\
\hline & Ticks and Lyme disease & & Ticks and Lyme disease \\
\hline 7 & Do you know what a tick is? & 7 & Do you know what a tick is? \\
\hline 8 & $\begin{array}{l}\text { Have you ever seen a tick? } \\
\text { If so, when and where? }\end{array}$ & 8 & $\begin{array}{l}\text { Have you ever seen a tick? } \\
\text { If so, when and where? }\end{array}$ \\
\hline 9 & How large do you think ticks are? & 9 & How large do you think ticks are? \\
\hline 10 & $\begin{array}{l}\text { Have you ever heard of Lyme disease? } \\
\text { If so, can you tell me what you know } \\
\text { about it? }\end{array}$ & 10 & $\begin{array}{l}\text { Have you ever heard of Lyme disease? } \\
\text { If so, can you tell me what you know } \\
\text { about it? }\end{array}$ \\
\hline 11 & $\begin{array}{l}\text { How do you think you can get Lyme } \\
\text { disease? }\end{array}$ & 11 & $\begin{array}{l}\text { How do you think you can get Lyme } \\
\text { disease? }\end{array}$ \\
\hline 12 & $\begin{array}{l}\text { Does a tick bite always lead to Lyme } \\
\text { disease? }\end{array}$ & 12 & $\begin{array}{l}\text { Does a tick bite always lead to Lyme } \\
\text { disease? }\end{array}$ \\
\hline 13 & $\begin{array}{l}\text { How fast do you think you should } \\
\text { remove a tick? }\end{array}$ & 13 & $\begin{array}{l}\text { How fast do you think you should } \\
\text { remove a tick? }\end{array}$ \\
\hline 14 & $\begin{array}{l}\text { Do you know how you can see or notice } \\
\text { you have Lyme disease? }\end{array}$ & 14 & $\begin{array}{l}\text { Do you know how you can see or notice } \\
\text { you have Lyme disease? }\end{array}$ \\
\hline 15 & $\begin{array}{l}\text { Do you think Lyme disease is a } \\
\text { dangerous disease? }\end{array}$ & 15 & $\begin{array}{l}\text { Do you think Lyme disease is a } \\
\text { dangerous disease? }\end{array}$ \\
\hline 16 & $\begin{array}{l}\text { Can you remember where and when you } \\
\text { first heard of Lyme disease? }\end{array}$ & 16 & $\begin{array}{l}\text { Can you remember where and when you } \\
\text { first heard of Lyme disease? }\end{array}$ \\
\hline 17 & $\begin{array}{l}\text { At which places in nature do you think } \\
\text { you can get a tick bite? }\end{array}$ & 17 & $\begin{array}{l}\text { At which places in nature do you think } \\
\text { your child can get a tick bite? }\end{array}$ \\
\hline 18 & $\begin{array}{l}\text { Have you ever been bitten by a tick? Or } \\
\text { have you ever had one on your body? If } \\
\text { so, what did you do then? If so, would } \\
\text { you do the same now to get rid of it? If } \\
\text { not, what would you do when you would } \\
\text { find out you were bitten by a tick? }\end{array}$ & 18 & $\begin{array}{l}\text { Has your child ever been bitten by a } \\
\text { tick? Or has s/he ever had one on } \\
\text { his/her body? If so, what did you do } \\
\text { then? If so, would you do the same now } \\
\text { to get rid of it? If not, what would you } \\
\text { do when you would find out your child } \\
\text { was bitten by a tick? }\end{array}$ \\
\hline
\end{tabular}


19 Imagine you would like to know more about removing a tick, where would you search? Who would you ask?

20 Do you know what you can do to prevent a tick bite? If so, can you tell me what you can do? If so, imagine you would like to know more about this, where would you search? Who would you ask? If not, imagine you would like to know more about this, where would you search? Who would you ask?

21 Do you expect difficulties when searching for information on ticks, tick bites and Lyme disease? If so, which ones?

22 From whom do you expect to receive information about the prevention of tick bites and Lyme disease? And why?

23 What do you think of the way in which you are currently informed about ticks and Lyme disease?

24 What would you like to know or be able to do in order to deal with ticks and Lyme disease?

25 Do you expect difficulties when preventing or treating tick bites? If so, which ones?

26 What do you think of the following parties that can inform you about ticks and Lyme disease? Are they suited? Do you trust them?

- the Municipal Health Service

- the National Center for Disease Control - your municipality

- intermediaries like sports clubs or tourist information offices your general practitioner

- the patient association for Lyme disease
19 Imagine you would like to know more about removing a tick from your child, where would you search? Who would you ask?

20 Do you know what you can do to prevent a tick bite on your child? If so, can you tell me what you can do? If so, imagine you would like to know more about this, where would you search? Who would you ask? If not, imagine you would like to know more about this, where would you search? Who would you ask?

21 Do you expect difficulties when searching for information on ticks, tick bites, Lyme disease and your child? If so, which ones?

22 From whom do you expect to receive information about the prevention of tick bites and Lyme disease for your child? And why?

23 What do you think of the way in which you are currently informed about your child and ticks and Lyme disease?

24 What would you like to know or be able to do in order to deal with ticks and Lyme disease and your child?

25 Do you expect difficulties when preventing or treating tick bites on your child? If so, which ones?

26 What do you think of the following parties that can inform you about your child, ticks and Lyme disease? Are they suited? Do you trust them?

- the Municipal Health Service

- the National Center for Disease Control

- your municipality

- intermediaries like sports clubs or tourist information offices your general practitioner - the patient association for Lyme disease 
Inventarisation of outdoor activities with risk for a tick bite

27 We already talked about the places where you thought you could get a tick bite. Can you tell me how often you go to the following kinds of places to relax, walk or exercise?

- your backyard of the one of friends or family

- forests

- heath area

- dunes

- city parks
Attitude and behaviour regarding checking for, and preventing tick bites Do you ever check whether you have been bitten by a tick?

If so, when?

If so, do you always do this when you have been in [name risk areas that interviewee mentioned at question 17]? If so, which parts of your body do you check?

If so, how do you check those parts of your body?

If not, or not always, why not?

29 There are several things you can do to prevent a tick bite. Could you tell us what you think about the following precautions? Do you think they are practical?

- staying on the paths in the forest or city park

- wear clothes that cover your body, like long trousers, putting trouser legs in socks and wearing closed shoes

- use insect repellant sprays on your body

- use insect repellant sprays on your clothes
Inventarisation of outdoor activities with risk for a tick bite

27 We already talked about the places where you thought your child could get a tick bite. Can you tell me how often your child plays at the following kinds of places?

- your backyard of the one of friends or family

- forests

- heath area

- dunes

- city parks

28 Does your child ever go on camp or into the forest with school or a club (e.g., scouting, sports club)? If so, do you think it is important that your child is checked for tick bites afterwards? Who do you think is responsible for checking your child for tick bites in this situation? Attitude and behaviour regarding checking for, and preventing tick bites

29 Do you ever check whether your child has been bitten by a tick?

If so, when?

If so, do you always do this when your child has been in [name risk areas that interviewee mentioned at question 17]? If so, which parts of your child's body do you check?

If so, how do you check those parts of your child's body?

If not, or not always, why not?

30 There are several things you can do to prevent your child from getting a tick bite. Could you tell us what you think about the following precautions? Do you think they are practical?

- keeping your child on the paths in the forest or city park

- make you child wear clothes that cover his/her body, like long trousers, putting trouser legs in socks and wearing closed shoes

- make your child wear a cap

- use insect repellant sprays on your child's body

- use insect repellant sprays on your child's clothes 


\section{Closing}

30 Are there any final comments you would like to make? Do you have any questions?

\section{Closing}

31 Are there any final comments you would like to make? Do you have any questions? 


\section{Chapter 5}

\section{Developing requirements for a mobile app to support citizens in dealing with ticks and tick bites}

\section{via end-user profiling}

Published as:

van Velsen L, Beaujean DJ, Wentzel J, van Steenbergen JE, van Gemert-Pijnen JE. Developing requirements for a mobile app to support citizens in dealing with ticks and tick bites via end-user profiling. Health Informatics J 2015 Mar;21(1):24-35. 


\section{Abstract}

Tick bites and tick-borne infections are an increasingly large problem. There is a wide range of precautions that citizens can take, but compliance is low. Mobile technology can offer a solution here, as they allow citizens to access health information in context. In this article, we discuss the development of requirements for a mobile app to support citizens in dealing with ticks and tick bites. First, we identified organizational stakeholders based on relevant protocols, and primary end-users via a systematic risk determination procedure. Then, we profiled endusers based on 25 in-depth interviews. We consulted organizational stakeholders via a focus group. The mobile app should primarily motivate citizens to check themselves for tick bites after visiting a risk area. The app should also include a tick radar, alerts to remind people to check for tick bites, and the possibility to document tick bites. Our experiences underline the necessity of thoroughly investigating the designated end-users and their context of use in order to tailor preventive health advice, and we demonstrate how this can be done. Finally, this case shows the need to create persuasive health technology in order to maximize citizen compliance.

\section{Introduction}

Ticks are small insects that feed on animal and human blood. In the Netherlands, the tick species Ixodes ricinus can infect the host with an infection called Lyme borreliosis or Lyme disease (LD) during the process of feeding. LD often starts with a relatively innocent skin lesion called erythema migrans (EM), sometimes accompanied by flu-like symptoms. When left untreated, LD can evolve into a serious chronic condition with symptoms like joint inflammations and neurologic complications [162]. In the Netherlands, and Europe in general, the number of General Practitioner consults for tick bites and cases of an EM has increased rapidly in the last decade $[82,77]$. Preventing tick bites (e.g. by wearing protective clothing or using repellents) and checking for tick bites after spending time in tick habitats have been found to be effective and cost-efficient methods to prevent LD [52]. As a result, they have been propagated by health organizations as measures citizens should take, regardless of whether or not they fit in with the way citizens want to enjoy nature and how they want to deal with the risks involved. However, in order to achieve behavior change, and to make people comply with preventive measures for LD, advice needs to align with the needs and wishes of the target group [107]. In other words, one should only present those preventive measures to citizens that they are likely to adopt. One of the tools that can be used to tailor this preventive advice is mobile health (mHealth) technology.

mHealth technology is a new phenomenon that will change the way in which citizens consume health information and communicate with health organiza- 
tions and health professionals. It allows citizens to access a health service where they need it and when they need it [103]. For the context of public health, mHealth is particularly suited for patient education, disease self-management, and remote monitoring of patients [112]. But in order to know how to design mHealth technology and to reap its benefits, experiences with the development and evaluation of these interventions need to be shared, something which is rarely done yet [183].

This article discusses the development of requirements for an mHealth intervention aimed at supporting citizens to deal with ticks and tick bites and persuading them to comply with preventive advice. When we talk about requirements, we mean specifications of what a technology should do, should look like, and how it should be implemented. The development process we applied is centered on the profiling of the designated end-user, and we show how one can derive end-user profiles for mHealth interventions and which requirements and benefits can be derived from them. This is one of the first articles to discuss in detail how one can design an electronic health intervention via end-user profiling and value-based design. The result of this process is a set of requirements that not only specifies what the technology should do (functionalities) but also how it should be implemented. A focus on the latter ensures that an mHealth technology not only has an added value to the user but will also be used and promoted by organizational stakeholders (such as Municipal Health Services (MHSs)).

In the next sections, we will discuss the foundation of our design approach and then chronologically discuss the different activities (such as brainstorms, interviews, and a focus group) we undertook in order to come to end-user profiles and requirements for a mobile tick app. At the end of the article, we discuss how such an app should be designed and reflect on the merits of applying an mHealth design approach that utilizes end-user profiles.

\section{Design approach}

The development of requirements was guided by the Center for eHealth Research (CeHRes) roadmap [117, 174, 179], which focuses on creating electronic health interventions that are in line with citizens' contexts and characteristics (following the principles of human-centered design [66]) and the creation of an implementation plan and business model. It consists of five phases, which are depicted in Figure 5.1 and, in all phases, formative evaluations improve the quality of design.

1. Contextual inquiry. Primary end-users and stakeholders are identified and the designated context of use is mapped;

2. Value specification. Stakeholder values and requirements are formulated based on input from the contextual inquiry;

3. Design. Requirements guide the creation of prototypical versions of the technology, which is evaluated continuously; 


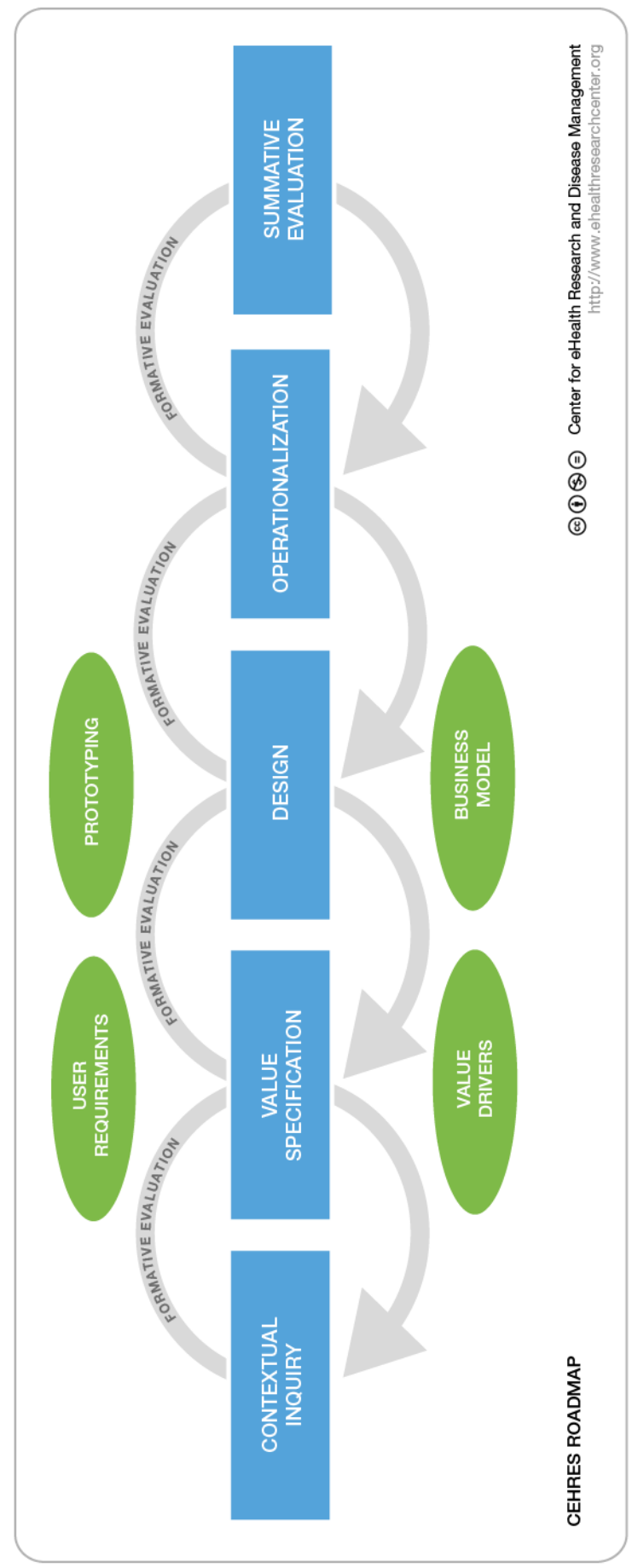

FIgURE 5.1: CeHRes roadmap 
4. Operationalization. The eHealth intervention is launched and the implementation plan is set into motion;

5. Summative evaluation. The uptake and effect of the eHealth intervention is assessed.

Table 5.1 shows the activities we deployed during the development of requirements and how they match with the main phases of the CeHRes roadmap. In this article, we will focus on the development of requirements and will therefore restrict ourselves to the first three phases: contextual inquiry, value specification, and design.

TABLE 5.1: Phases, activities, and products in the requirements development process

\begin{tabular}{|c|c|c|c|}
\hline $\begin{array}{l}\text { CeHRes } \\
\text { roadmap } \\
\text { phase }\end{array}$ & $\begin{array}{l}\text { Requirements } \\
\text { development } \\
\text { phase }\end{array}$ & Main activities & Products \\
\hline $\begin{array}{l}\text { Contextual } \\
\text { inquiry }\end{array}$ & Preparation & $\begin{array}{l}\text { - Composing the project team } \\
\text { - Deciding upon the overall } \\
\text { goal(s) }\end{array}$ & \\
\hline $\begin{array}{l}\text { Contextual } \\
\text { inquiry }\end{array}$ & $\begin{array}{l}\text { Stakeholder and } \\
\text { primary end-user } \\
\text { identification }\end{array}$ & $\begin{array}{l}\text { - Audience segmentation } \\
\text { - Stakeholder elicitation }\end{array}$ & $\begin{array}{l}\text { List of primary } \\
\text { end-users and } \\
\text { stakeholders }\end{array}$ \\
\hline $\begin{array}{l}\text { Contextual } \\
\text { inquiry }\end{array}$ & $\begin{array}{l}\text { Requirements } \\
\text { elicitation }\end{array}$ & $\begin{array}{l}\text { - End-user interviews } \\
\text { - Stakeholder focus group }\end{array}$ & Transcripts \\
\hline $\begin{array}{l}\text { Value spe- } \\
\text { cification }\end{array}$ & $\begin{array}{l}\text { Requirements } \\
\text { analysis }\end{array}$ & $\begin{array}{l}\text { - Determining values and } \\
\text { requirements } \\
\text { - Profiling primary end-user }\end{array}$ & $\begin{array}{l}\text { - Values and } \\
\text { requirements } \\
\text { - Personas }\end{array}$ \\
\hline Design & $\begin{array}{l}\text { Communicating } \\
\text { requirements }\end{array}$ & $\begin{array}{l}\text { - Completing requirement } \\
\text { notation templates } \\
\text { - Creating the design } \\
\text { document }\end{array}$ & $\begin{array}{l}\text { Design } \\
\text { document }\end{array}$ \\
\hline
\end{tabular}

\section{Project team and project goals}

The first step was to compile the project team: those who would lead requirements elicitation activities, interpret results, and translate those results into requirements. The team consisted of one eHealth expert (working in academia), one mHealth expert (working in academia and for the Dutch National Institute for Public Health and the Environment (RIVM)), one public health policy advisor with an expertise in infectious disease control (working for the RIVM), and finally, one public health infectious disease nurse (working at a MHS). When the situation called for it, external expertise was consulted. For example, a biologist checked the correctness of information on ticks, and technical advisors provided advice on the technical feasibility of our plans. 
Next, the project team set the overall goals of the app: to prevent people from contracting a tick bite, to remind them to check for tick bites, to teach them to properly remove ticks, and finally, to assist them in making the decision on when to visit their general practitioner after a tick bite. Mobile technology was introduced as a technology push. The adoption rate of this technology is estimated to be very high in a few years' time, and it is likely that mobile technology will become the preferred medium for many citizens, instead of websites that should be viewed on a desktop computer. Furthermore, mHealth technology provides many opportunities for communicating with citizens at a time when it matters most (i.e. immediately when they notice a tick bite). The project team then set out to identifying stakeholders and primary end-users.

\section{Stakeholder and primary end-user identification}

Stakeholders (every party or person affected by the mHealth intervention [175]) were first identified by the mHealth expert, the public health policy advisor, the public health infectious disease nurse, and additionally, the manager of a tick prevention project of a MHS. Stakeholders were identified by scrutinizing the Lyme borreliosis protocol of the RIVM. Then, a brainstorm was held to identify additional stakeholders. The following list with the most important stakeholders was the result:

1. Patients. They have to deal with a tick bite or first signs of LD.

2. RIVM. They provide the Lyme borreliosis protocol and toolkits with information and instructions for patients, which MHSs can reuse.

3. General Practitioners. They have to help or treat people with a (suspected) LD infection.

4. Patients' association for $L D$. They provide public education and counseling about ticks, tick bites, and LD.

5. Intermediaries. They facilitate outdoor recreation, like scouting groups and campsites. It is on their property or while in their care that many people are bitten by a tick.

6. Schools. They are responsible for dealing properly with ticks and tick bites on children during school outings.

7. Manufacturers of tick repellents and tick removal devices. They provide the tools to deal with tick bites.

8. MHS. They provide public education about ticks, tick bites, and LD.

9. Municipalities. They provide public education about ticks, ticks bites, and $\mathrm{LD}$; often they leave this task to the MHS. 
Primary end-users were identified with the help of four MHSs that segmented the general population of citizens by conducting a risk analysis. They identified distinctive subpopulations that are most at risk of contracting LD, using a systematic procedure for risk determination for infection prevention [96]. For different groups of people, the following factors were determined: their size, chance of infection, influenceability, chance of comorbidity, information need, quality and amount of current preventive efforts, availability of effective interventions for this risk group, and finally, the social desirability that this group is catered for. A combination of scores for these assets resulted in three audience segments that were most important: Outdoor people, Parents \& children, and Professionals in the green sector (e.g. gardeners and foresters). Catering for the specific contexts and characteristics of these audience segments would be most likely to result in a maximum effectiveness of the mHealth intervention [149]. Therefore, we decided to create one app for Outdoor people and Parents \& children, as these groups partly overlap, while for professionals in the green sector, a separate mHealth intervention would be developed. In this article, we will focus on the development of the app for Outdoor people and Parents \& children. These groups were taken as a focal point for design. Therefore, the next step was to profile them.

\section{Profiling primary end-users}

In order to profile Outdoor people and Parents \& children, we conducted semistructured, in-depth interviews. Interview schemes were based upon an overview of end-user characteristics that need to be mapped in order to profile primary end-users of an eHealth technology [104]. The following aspects were addressed:

1. Demographics;

2. Frequency of visits to high-risk areas;

3. Knowledge of ticks and LD;

4. Experience with ticks and LD;

5. Attitude and behavior regarding LD prevention measures;

6. Tick and LD-related information seeking behavior;

7. Technology skills and use.

We recruited interviewees via the travel clinics of two MHSs. Visitors were asked to participate, as they often take part in outdoor recreation. As it turned out to be difficult to find parents with young children, we recruited an additional seven parents via a convenience sample (i.e. they were friends of colleagues). In total, we conducted 15 interviews with Outdoor people and 10 with parents. 
Although this number might seem small, the goal of our research was to support technology design and not to generate an overview of citizen's attitudes and behavior with regard to ticks and tick bites upon which statistical tests can be run. Therefore, we stopped interviewing when we reached the point of data saturation (i.e. additional interviews did not generate new insights). After a short introduction, interviewees were guaranteed anonymity. Next, they provided informed consent and gave permission for an audio-recording. We questioned parents about their children, ticks, and LD. The interview protocol can be found in Annex 1. Audio recordings were transcribed in ATLAS.ti and coded by using the categories for persona attributes from LeRouge et al. [104]. Next, we made an overview of each interviewee's response to the most important attributes.

\section{Personas}

As we stated before, communicating preventive health advice is most effective when advice is tailored toward the needs and wishes of a person. Therefore, we created an overview of the primary end-user's needs and wishes, upon which we could consequently tailor preventive advice.

The interview results made it clear that the two primary end-user groups should be split further. Although all persons in these groups ran the risk of contracting a tick bite at one time or another, distinctive sets of behavior and attitudes toward tick bites and tick bite prevention measures were found for Outdoor people who do or do not check for tick bites, as well as for Parents who do or do not check their children for tick bites. For each of these four groups, we created a persona. Personas are descriptions of fictitious persons who resemble an end-user group [45]. The advantage of using personas is that they are easy to understand and are a good means to inspire eHealth design and its implementation and to engage the design team [131]. The personas were created by following a procedure set out in van Velsen et al. [178].

The characteristics of Outdoor people who do not check for tick bites corresponded with the answers of 12 interviewees, making it a primary persona. This persona does not really care about ticks or LD, does not visit risk areas often, does not check for ticks, and intends to use an app only when noticing a tick bite. Outdoor people who do check were represented by three interviewees, making it a secondary persona. This persona has experience with tick bites, often visits risk areas, (almost) always checks for ticks, and will use an app to read about ticks out of curiosity.

Parents who check their children for tick bites were in the majority (eight interviewees), making it another primary persona. They are concerned about ticks and the risks involved, their children often play in backyards and forests, and they (almost) always check their children for tick bites when they have been in an endemic area. Finally, they would use the app when noticing a tick bite. Parents who do not check were represented by two interviewees, making it an- 
other secondary persona. They do not think the risks involved are high, and consequently, they never check for tick bites. Their children often play in backyards, and they would rather consult a mobile website when noticing a tick bite on their child.

Figure 5.2 shows the persona for Outdoor people who do not check. All personas can be found in Annex 2.

\section{Consulting stakeholders}

In order to get input from the identified stakeholders about our plans for a mobile app, we conducted a focus group. We invited representatives of each stakeholder group, except for patients who were already catered for by means of the interviews and personas. The intermediaries were represented by persons working for scouting groups and the National Forest Service. Additionally, we conducted a separate interview (with the same setup as the focus group) with the trade organization for entrepreneurs in the recreation branch (e.g. camp site owners), as they were unable to join the focus group.

As a preparation, the participants were asked to read the personas and scenarios we created on the basis of the personas (stories of encounters with ticks, demonstrating the current prevention and care path). This was done in order to spark the discussion. During the focus group, we mapped each stakeholder's role in the prevention and care path of LD, we identified bottlenecks, and finally, we asked feedback about preliminary design ideas (e.g. a tick radar, demonstrated by showing a German tick radar: http://www.zeckenwetter.de). The focus group lasted $2 \mathrm{~h}$. Spoken text was transcribed in a Word document to serve as input for requirements specifying the implementation of the app.

\section{Guidelines for designing a mobile tick app}

In order to come to design guidelines, we first determined the values end-users and stakeholders have. Values are ideals or interests a (future) end-user or stakeholder aspires to or has [179]. They are important directives for the design of the mobile tick app as they indicate what general goals it must absolutely serve, or which (personal) principles it should not violate. Then, we identified requirements. Requirements are technical directives, specifying how the mHealth intervention should be designed. Following a procedure devised by van Velsen et al. [179], one project team member and an external eHealth expert identified values and requirements for the system. Sources for values and requirements were the transcribed interviews, the focus group, and the personas. 
Mark is 54 years old and planning engineer for a construction company. He lives together with his wife. Together, they have two children (21 and 19 years old) that live on their own by now. They don't live completely alone though, together they take care for their dog: Tommy.

Fortunately, Mark has never been bitten by tick. But he does know some things about the bug. $\mathrm{He}$ knows that it's an insect that bites and sucks your blood. He

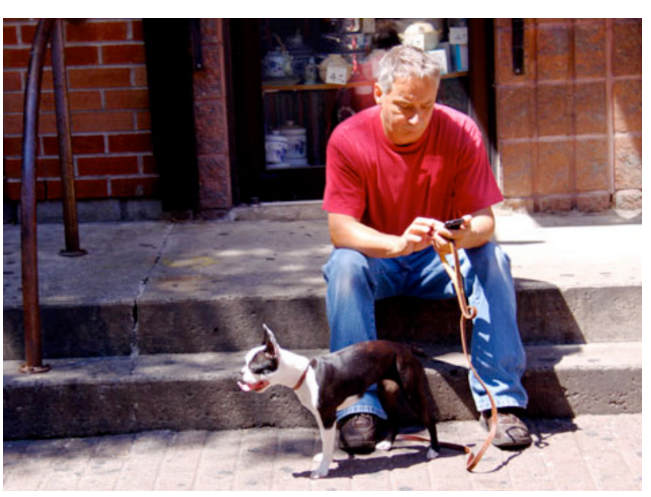

Photo: ChrisGoldNY, used under creative commons license also knows it can give you Lyme disease. Finally, he thinks that ticks fall down on you from trees, and that if you're bitten you should visit your GP to get the tick removed. Mark has seen ticks before, Tommy takes them home now and again. Then, Mark or his wife remove them with tick pliers.

Mark does not visit nature very often. In the summer he likes to sit in his backyard, and when they go on vacation he and his wife like to make long walks through the forests or the mountains. He does not take preventive measures to prevent a tick bite then. He also doesn't check for tick bites afterwards. It simply does not cross his mind.

His digital skills are perfectly fine, Mark thinks. After all, he thinks it's fun to try out new technology and he has numerous apps on his iPhone 4G. He takes his phone everywhere and never turns it off. Mark will only start to search for information about ticks on the Internet or on his iPhone when he notices he's been bitten by a tick. In that case, he will Google first, but will also check out the website of his Local Health Authority.

FIGURE 5.2: Mark: the persona for Outdoor people who do not check 
In total, we identified five values, of which three hold for the potential endusers:

- Being well informed;

- Enjoying nature in a carefree manner;

- Easy to use.

The designated end-users (Outdoor people and Parents) want to be informed of the risks ticks pose and how they should deal with them. Second, these citizens want to enjoy nature in a carefree manner. This is their first priority when they go outdoors, and they do not allow the risk of a tick bite to interfere. Relatedly, they want an intervention aimed at supporting them in dealing with ticks and tick bites to be easy to use.

Four values hold for professional stakeholders:

- Being well informed;

- Easy to use;

- Receiving information on time;

- Explicitly presenting the stakeholder organization as a source.

First of all, stakeholders want to be well informed of the risks ticks bring with them and how their organization should deal with them. Second, interventions aimed at supporting them should be easy to use; they should fit easily in existing working routines. Furthermore, an intervention should be provided to them on time, and it is important for them that they can promote their own identity or organization name.

Next, we identified requirements. We will summarize those with a high priority (i.e. those requirements that are crucial for an effective mHealth intervention that is adopted both by end-users and other stakeholders).

\section{Functionality}

In order to enable end-users to properly estimate the risk of contracting a tick bite, to stimulate tick control, and to aid end-users in dealing with one, the mHealth intervention should provide information at the appropriate time and place. Users should be provided with a risk estimation of their current location and should be motivated to check for tick bites at the end of days in which they have been in an endemic area, so that they do not forget to. The latter might easily happen with parents who are busy with their children and chores. Translated into app functionality, this results in the following:

- A tick radar that indicates the risk of contracting a tick bite based on location (using global positioning system (GPS) coordinates) and seasonality; 
- An alert that reminds people to check for tick bites at the end of the day when they have been in an endemic area. The alert should only appear when the end-user explicitly agrees;

- The possibility to document tick bites. For each tick bite, end-users should be able to log the name of the person, date of the bite, date of removal, location of the bite (to be 'ticked' on the picture of a body), a picture of the tick, and a picture of an eventual EM. It should be possible to email each log (e.g. to a General Practitioner, or in the case of a scouting club, to parents of a child who has been bitten).

Finally, from the interviews with the end-users, it became clear that citizens are hesitant to install a lot of mobile apps and experience a medical app overload (even while the field of mHealth is still very young). Therefore, it should be possible to integrate the functionality and content of the tick app into popular, general health apps. This means that the app should be open source.

\section{Promoting the app}

Three high-priority requirements were formulated that specified how the app should be promoted to end-users. First, the app should be promoted at the entrances and exits of endemic areas (e.g. forests and dunes). An on-the-spot download should be facilitated by a quick response (QR) code. This issue was discussed with a representative from the National Forest Service during the focus group, who indicated that they would be willing to facilitate this. Second, the website of the MHS on ticks and tick bites, including a link to a download location for the app, should appear in the top five of Google search results when sought for terms like 'ticks' and 'remove tick.' End-user interviews indicated that this is an often-used strategy for finding information. Additionally, citizens are more familiar with their MHS than with the RIVM and are more likely to consult this source. Their higher familiarity with their MHS may also result in a higher trust in this source. Finally, promotion material for the app that is to be sent to intermediaries, such as campsites, should be delivered well before the start of the new recreation and tick season, which starts in March.

\section{Content}

The information provided via the mobile app, and the information provided via the websites of the RIVM and the MHSs should be reinforce one another. Interviewees indicated that they would consult an app predominantly in case of a tick bite and that they are not willing to take measures to prevent tick bites (such as staying on paths in the forest). This interferes with one of their values: enjoying nature in a carefree manner. Therefore, the app should promote checking for tick bites after visiting an endemic area and should instruct people on what to do in case of a tick bite and when to visit their General Practitioner. Communicating 
preventive measures (like using insect repellent and wearing protective clothes) is better left to the website, as it serves a relatively small population who are likely to search actively for this information.

The mobile app should inform users of the following:

- What ticks look like and how large they are;

- How to remove a small and large tick with tweezers. Interviewees indicated they do not have confidence in their ability to remove a nymph, or do not know how they should do this. This instruction should be conveyed by video;

- What an EM looks like, including examples that are less clear;

- To visit their General Practitioner when an EM and/or flu-like symptoms appear.

Finally, promotion material for the app for intermediaries should include white space so that these organizations can insert their logo or organization name (in line with their value 'Communicating one's own identity').

\section{User experience}

The app should create an experience that does not create anxiety. The app should therefore not worry users by only telling them what the risks are and how they should prevent them, but should offer solutions that are in line with the way in which they enjoy nature. This is also reflected in the content requirement not to communicate precautions, but to primarily promote checking for tick bites. Finally, the app should display the logo of the RIVM and the MHSs. Interviewees indicated they want to receive information from an expert health source, but not everybody knows the RIVM. The MHS is familiar to most, is considered to be easily approachable, and is their preferred source of information.

\section{Conclusion}

In this article, we have discussed the development of requirements for an mHealth intervention aimed at supporting citizens to deal with ticks and tick bites and have listed high-priority requirements. Our development process was centered around the profiling of the prospective end-user and has made three things clear. First, it underlined the necessity of thoroughly investigating the designated end-users and their context of use. Each primary end-user group (or persona) has a different set of characteristics and context, which must be catered for in the mHealth intervention. For example, one of the end-users' values was 'enjoying nature in a carefree manner,' and therefore, promoting checking for tick bites is most likely to have a higher return on investment than advertising 
other preventive measures such as wearing clothes that cover the body. The latter would be medically correct and complete but will have a poor fit with the context in which it is to be used. In this case, the adoption and impact of the intervention will be low. Such a tactic does imply a shift in developing communication strategies by public health organizations. Traditionally, they communicate all preventive measures for a given condition to the public that have proven their worth in scientific studies. Instead, they should make a selection of measures that work and that will be easily adopted by the target group. This tactic should also work for situations besides tick bites, unless omitting a precaution leads to great risk for the citizen. For example, prevention of food-borne infections may benefit from this approach: there are many possible precautions (not consuming raw milk, boiling food, preventing cross-contamination via cutting boards, etc.), of which some will be more easily accepted than others. In order to simplify the message and make it more actionable, only easily adoptable precautions should be communicated. Second, this case demonstrated that public eHealth technology that aims to increase healthy behavior (such as checking for tick bites) is per definition also persuasive technology. Persuasive health technology has the goal to form, alter, or reinforce attitudes or behaviors in order to improve health without coercion [93]. Several requirements that resulted from our contextual inquiry (reminders, tailored information, and the inclusion of an authoritative source) aligned with persuasive system features that have proven their worth in the past [122]. It is therefore of high importance for eHealth designers to be aware of the features that improve eHealth persuasiveness, and when and how to implement them. Third, and finally, we have elicited and formulated several requirements that were not focused on the technical device itself, but on its implementation (e.g. when to send promotion material to campsites and to leave white space on this promotion material so they can include their own logo). From the focus group, it became clear that these stakeholder demands were extremely important. If we would not take these wishes into account, organizations would not be willing to promote the app, regardless of the app's proven worth or value to end-users. Developers of mHealth technologies should therefore be not only great technology creators but also connoisseurs of the organizational context in which they are embedding their technology and how to serve the actors within this organizational context.

Designers should take into account that when they take our findings as input for their own mobile tick app, these requirements are partly a product of the Dutch situation. There may be a difference in information needs, attitudes toward the risk of a tick bite, and attitudes toward preventive measures between endemic and non-endemic countries. Furthermore, different countries or regions can have different tick species that spread different diseases, may have a different set of organizations that are involved in preventing and dealing with tick bites, or may have different technical possibilities (e.g. the number of locations with no reception for mobile data traffic). In order to deal with these issues, the project team should consult a biologist, and they can replicate our requirements 
development activities in order to identify and profile primary end-users and to consult stakeholders.

The requirements we have discussed in this article will allow us to design an mHealth intervention that has the capacity to persuade the target group to conduct healthy behavior with regard to tick bites while respecting their values (such as enjoying nature in a carefree manner). In the next phase of the project, we will come to a design by several rounds of prototyping. Finally, we will assess the uptake and effect (assessed in terms like 'increase in checking for tick bites' and 'confidence in one's ability to remove a tick') in a trial.

\section{Annex 1: Interview protocol - Outdoor people}

\section{Demographics}

1. Are you male or female?

2. How old are you?

3. In what country were you born? If relevant: How well do you speak Dutch?

4. What is your family situation like?

5. What do you do for a living?

6. What is the highest education you have completed?

\section{Knowledge about ticks and Lyme disease}

7. Do you know what a tick is?

8. Have you ever seen a tick? If so: Where and when?

9. How large do you think ticks are approximately?

10. Have you ever heard of Lyme disease?

If so: Can you tell me what you know about that?

How do you think you can contract Lyme disease?

Do you think a tick bite always leads to Lyme disease?

How fast do you think you have to remove a tick, once it has bitten?

Do you know how you can see or notice that you have Lyme disease?

11. Can you remember where you first heard about ticks and/or Lyme disease?

12. At which places in nature do you think you can get a tick bite? 
13. Have you ever been bitten by a tick? Or did you ever see one on your body? If so: What did you do then?

Would you do the same now, as you did then?

If not: what would you do when you notice that you have been bitten by a tick?

14. Do you know what you can do to prevent yourself from getting a tick bite? Can you name these precautions?

If so: Imagine you wanted to know more about this, where would you search for information?

Who would you ask?

If not: Image you wanted to know what you can do to prevent yourself from getting a tick bite, where would you search for information? Who would you ask?

15. Do you expect any difficulties while searching for information about ticks, tick bites and Lyme disease?

If so: which ones?

16. Who do you expect to inform you about preventing tick bites and Lyme disease? And who would you consult preferably?

17. What do you think about the way you are currently informed about ticks and Lyme disease?

18. Is there something you would like to know about ticks or Lyme disease, or would like to be able to do better?

19. Do you expect any problems while preventing or treating tick bites? And if so, which ones?

20. What do you think about the following parties that can inform you about ticks and Lyme disease? Do you think they are suitable and trustworthy?

- Your local Municipal Health Service

- The national Institute for Public Health and the Environment

- Your municipality

- Intermediaries, such as sporting clubs and tourist offices

- Your General Practitioner

- The patients' association for Lyme disease 


\section{Inventory of visits to high-risk areas}

21. Can you indicate how often you visit the following places to relax, take a walk, or to work out?

- Your backyard or that of family or friends

- Forests

- Heath

- Dunes

- City parks

\section{Attitude and behavior with respect to tick bites}

22. Do you ever check for tick bites?

If so: when?

Do you always check for tick bites after you have visited nature?

Which parts of your body do you check?

How do you check these parts of your body?

If not: Why don't you?

23. There are several things you can do to prevent a tick bite. Could you tell me what you think about the following precautions? Do you think they are practical?

- Staying on paths on forests or city parks

- Wear clothes that cover your body, such as trousers with long legs, putting trouser legs in socks, and wearing closed shoes

- Rubbing uncovered skin with insect-repellents

- Spraying in clothes with DEET

\section{Knowledge and use mobile technology}

24. Do you think you are handy with new technology, such as the Internet and mobile phones?

25. Do you like to use new technology, such as the Internet and mobile phones?

26. Do you know what a smartphone is? Or do you know, for example, the iPhone?

27. Do you own a smartphone?

If so: Do you always take your smartphone with you when you go into nature? 
28. I will now show you a picture of a so-called QR code. Do you know what you can do with such a code?

\section{Using a tick and Lyme app or website}

At the moment, we are making a program for a smartphone to inform people about ticks and Lyme Disease. This is also called an app. Then, we are also creating a website about ticks and Lyme disease. They should inform people, and instruct people on how to deal with ticks. How do you recognize a tick? How do you prevent getting a tick bite? When to visit your General Practitioner in case of a tick bite?

29. What kind of information would you like to see on the website? What should you be able to do there?

30. What kind of information would you like to see on the smartphone app? What should you be able to do there?

31. Do you think you would consult such a website? Why (not)?

32. Do you think you would install such an app? Why (not)?

33. Are there other means which you would prefer for getting this kind of information? For example, via Twitter?

\section{Closing}

34. Do you have any remarks or questions? 


\section{Annex 2: Personas}

Anouk is 29 jaar old and works as an intermediary at an employment agency. Since a weeks, she lives together with her friend Patrick in an apartment in The Hague. They don't have any children yet. They think it's a bit too early for that.

Anouk has been bitten by a tick once, but she never noticed. She thought she had some eczema on her arm. After a days, she consulted her General Practitioner about this, as it itched quite a lot. Her General Practitioner stated this was an Erythema Migrans and prescribed a sixweeks Antibiotics cure. Anouk thought this was all quite disturbing. She even had to set her alarm clock in the morning so she could take her medication on time! Fortunately, this cure has prevented a progression of Lyme disease. Anouk has learned quite a bit about ticks in that period. She knows you can get a tick bite in a forest and that it can make you very ill. So she thinks it's

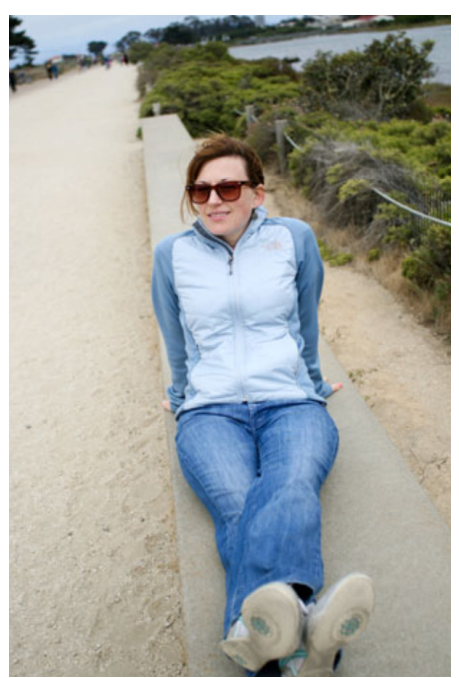

Photo: ChrisGoldNY, used under creative commons license very important that you notice a tick bite as soon as possible.

Anouk visits nature quite regularly. Together with Patrick she walks through forests, and she can also be found in the dunes now and then. She knows that you should stay on pathways in the forest to prevent tick bites, but she doesn't really adhere to this precaution. She does check herself thoroughly for tick bites when she has visited a forest: she looks at her arms, knee pits, arm pits, and she asks her boyfriend to check the places she can't see herself. Should she find a tick, then she would remove it herself with tick pliers.

Finally, Anouk thinks she is quite good with computers and mobile phones. She doesn't really enjoy using them, but the simple fact is she has to. She has a Samsung Galaxy that she always takes along with her: she wants to be reachable at all times. After her previous experience, she is interested in ticks and Lyme disease. So when the new tick season starts, she would like to be informed about tick-related news. For this information she refers to the Internet, but prefers reliable websites, such as the website of her Municipal Health Service. 
Chantal is 41 years old and works three days a week as a dentist's assistant. Together with her husband, she has two children: Jeroen (nine years old) and Benthe (six years old). The four of them live in one of Utrecht's suburbs.

Jeroen has been bitten a few times by a tick while playing in the forest. Chantal removed these ticks with tick pliers. Then, she kept an eye on the exact spots to see whether or not a red circle would appear. Because Chantal

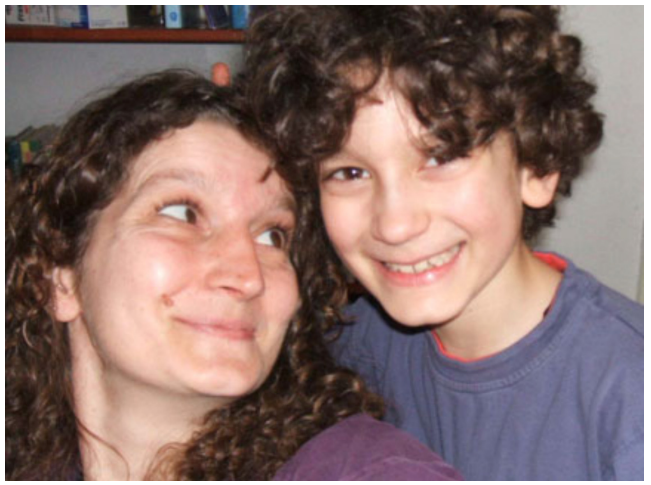

Photo: Missgien, used under creative commons license has had some experiences with tick bites, she also knows a bit about the insects and Lyme disease: you can contract a tick bite in a forest, after which you can get Lyme disease if the bug sucks your blood. According to her, Lyme disease is an unpleasant and dangerous disease.

Jeroen and Benthe play in their backyard on an almost daily basis, and they also play in the forest regularly. Chantal is not very concerned about preventing tick bites. Although she knows it's wise to make her children wear clothes that cover their bodies, she doesn't insist on this. She wants her children to be able to play an move freely, and also thinks it's quite a hassle to take care of this. However, she does check her children for tick bites after they have played in the forest. Then, she looks at the 'warm places', like the armpits and between the buttocks. Jeroen is a boy scout, and with the boy scouts he visits the forest regularly. In that case, Chantal thinks checking for tick bites is a shared responsibility. She has to do the actual checking, but the scouting should remind her to do this. When Jeroen goes on an overnight trip with the boy scouts, she thinks checking for tick bites and removing ticks is a responsibility of the scout leaders.

Chantal thinks she is pretty good with computers and mobile phones, and she also likes to try out these new technologies. She herself has an iPhone 4, which she always takes with her. She will use her iPhone to search for information on ticks and tick bites in case of an emergency: when one of her children is bitten. In that case, she wants to know exactly what to do. General information, such as precautions, she can also search for at home, when she is more comfortable. She will search the Internet, or look at the website of the National Institute for Public Health and the Environment, or her local Municipal Health Service. 
Chaouki is 45 years old has a shop with Moroccan food. Before he opened this shop, he completed the vocational school for intermediate business education. $\mathrm{He}$ is married, and has a son, Yanick, who is seven years old. The three of them live in the city center of Utrecht.

No one in his family has ever been in contact with ticks or Lyme disease. Chaouki has vaguely heard of ticks and Lyme disease somewhere, but he doesn't know what it entails ex-

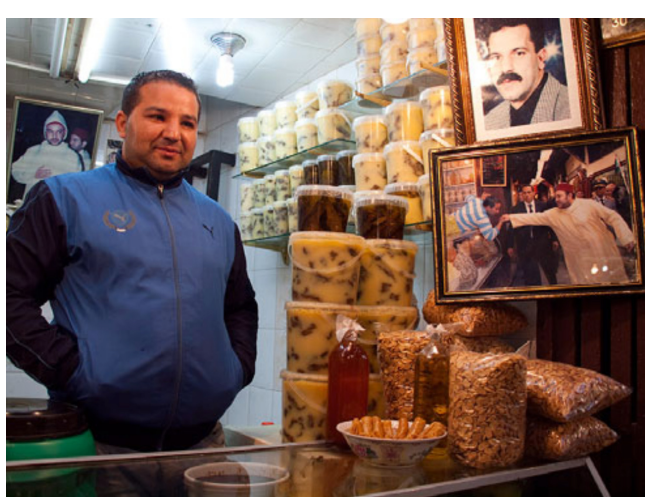

Photo by zz77, used under creative commons license (http://ww.flickr.com/photos/zz77/5745332745/) actly. He does think Lyme disease is a dangerous disease.

Yanick often plays in the backyard of their home. En although Chaouki knows that wearing clothes that cover the body protects against tick bites, he doesn't insist on this. This is only annoying for children when it's warm for example. He also doesn't check for tick bites when Yanick has been in the backyard or the forest. He doesn't really know why exactly. And doesn't it itch when you're bitten by a tick? During school outings, Yanick visits forests or heath land now and then. Chaouki thinks he is himself responsible for checking for tick bites in these case, but it would be handy if the school reminds him of this. Should he find a tick on Yanick's body, then he would try to remove it himself with tick pliers. But he is a bit unsure whether or not he would succeed. Doesn't the tick break, and wouldn't this leave parts of the tick attached? Because of this, he would also think about visiting their General Practitioner.

Chaouki thinks he is good with computers and mobile phones. He is also always curious about the newest apps he can download for his HTC one. He takes this phone everywhere and always leaves it turned on. Should he find out that Yanick has been bitten by a tick, then Chaouki will go search for information on what to do on his smartphone. He would be willing to install an app for this goal, but he'd be just as willing to visit a mobile website. If he wants general information, then he will Google the Internet at home on his PC. 


\section{Part II}

\section{Evaluative studies}


or 


\section{Chapter 6}

\section{Comparing the effect of a leaflet and a movie in preventing tick bites and Lyme disease in the Netherlands}

Published as:

Beaujean DJ, Crutzen R, Gassner F, Ameling C, Wong A, van Steenbergen JE, Ruwaard D. Comparing the effect of a leaflet and a movie in preventing tick bites and Lyme disease in the Netherlands. BMC Public Health 2016 Jun 10;16:495. 


\section{Abstract}

Background: Lyme disease (LD) has become the most common vector borne illness in the Northern hemisphere. Prevention relies predominantly on fostering protective behaviors (e.g., avoiding tick areas, using protective clothing and repellent, and doing routine tick checks post-exposure). The objective of this study was to evaluate the effectiveness (in terms of knowledge, perceived severity and susceptibility, self-efficacy, response efficacy, intention, and behavior over time) and appreciation of a leaflet and a movie as tools for informing the public in the Netherlands about ticks and LD protective behaviors.

Methods: Participants (1,677 at $t 1$ and 361 extra at $t 2)$ were members of a representative Internet panel (adults aged 18 years and above). A four group randomized controlled design was used to test the effect of an information leaflet and a movie (two intervention groups), compared to a control group and a follow-up only control group. Data were collected over two periods: July 15-29, $2013(t 1)$ and at follow-up 4 weeks later, August 16-31, $2013(t 2)$

Results: Post-intervention results show all respondents in all groups possess good general basic knowledge of ticks and LD. Respondents in both the leaflet and movie groups knew more than respondents in the control group, and had greater awareness of best practices after a tick bite. Intention to perform protective behavior in future was stronger among respondents in the intervention groups. While respondents generally appreciated both the movie and the leaflet, they found the movie ran too long. Follow-up revealed no lasting positive effects from either the leaflet or the movie.

Conclusions: Our results suggest that both the movie and the leaflet are valued and effective intervention tools for improving knowledge about tick bites and strengthening self-efficacy and intentions to perform protective behavior against ticks and LD . Achieving lasting effects, however, calls for more action.

\section{Background}

Lyme disease (LD) is the most common tick borne disease in the United States and Europe. In the Netherlands, where LD is also endemic. The number of general practitioner (GP) consultations for tick bites has increased from 191 per 100,000 in 1994 to 564 per 100,000 in 2009 [81]. In 1994, the incidence of patients visiting the GP for erythema migrans (EM, an associated symptom) was estimated at 39 per 100,000 inhabitants. This number increased to 134 per 100,000 in 2009 [81]. Similar trends have been observed in other European countries [152]. More than one million people in the Netherlands ( $8 \%$ of the total population) suffered from a tick bite each year, making LD a serious and increasing threat 
to public health $[81,57]$. Sustainable solutions, such as vaccination, are not yet available [153]. Public health intervention therefore relies predominantly on education, focusing on behavioral measures for tick bite prevention (e.g., tick area avoidance, clothing, and repellent use) and Borrelia species transmission prevention post-bite (e.g., checking for ticks and tick-borne pathogen transmission and removing ticks). Despite the availability of public LD-prevention programs, adoption of protective behavior could be improved [129, 76, 126]. Beaujean and colleagues found low levels of wearing protective clothing and using repellent in 2013 in the Netherlands. Checking for and removing of ticks were the most adopted measures [17]. Gould, concluded in her study that sustainable LD prevention programs should focus on promoting measures most likely to be adopted. Therefore the Dutch National Institute for Public Health and the Environment (RIVM) focuses in the education materials mainly on 2 measures: checking for and removing of ticks. Since over 10 years the RIVM develops education materials like leaflets and posters on ticks and LD and makes these public available through the internet. Recently the RIVM added an educational movie on ticks and LD to these online materials.

With this study we respond to the call of Mowbray et al. to perform more evaluation studies, since they could find only nine studies in their systematic review that had been undertaken to assess the effectiveness of educational interventions regarding protection against tick-borne disease [113]. This study aims to examine the differences in effectiveness between a leaflet and a movie for several outcomes among the Dutch general public: knowledge, perceived severity and susceptibility, self-efficacy, response efficacy, intention, and behavior over time, as well as subjects appreciation of both educational tools. Using study results, we provide advice on how to improve current tick bite and LD health education tools.

\section{Methods}

Our randomized, controlled experiment involved four groups (two intervention groups [IGs] and two control groups [CG]) and two measurement moments ( $t 1$ and $t 2$ ). No prior (pre-test) measurements were taken, but one was done immediately afterwards ( $t 1$; post-test) and another at 4 week follow-up ( $t 2)$, since both interventions were of brief duration ( $5 \mathrm{~min}$ ). At $t 1$ (July 15-28, 2013), respondents were randomly assigned to three groups (Fig. 6.1): leaflet group (IG1), movie group (IG2), and Control group 1 (C1). All respondents proceeded to fill out questions on outcome variables. To assess lasting effects of the leaflet and movie, all respondents were asked to participate in $t 2$ (August 12-31, 2013) 4 weeks after the first measurement. The respondents in the IGs were not re-exposed to the interventions at $t 2$. The difference in outcome variables between $t 1$ and $t 2$ for each group can be evaluated after adjusting for confounding (see the section on statistical analysis below). A difference in group C1 indicates whether a learning 
effect is achieved through repeated completion of the questionnaire; this learning effect is assumed to be equally high in all three groups. The null hypothesis (no intervention effect) will therefore hold if differences within intervention groups are equal to that within $C 1$. If the difference is greater, the null hypothesis can be rejected in favor of the alternative hypothesis that confirms the presence of an intervention effect.

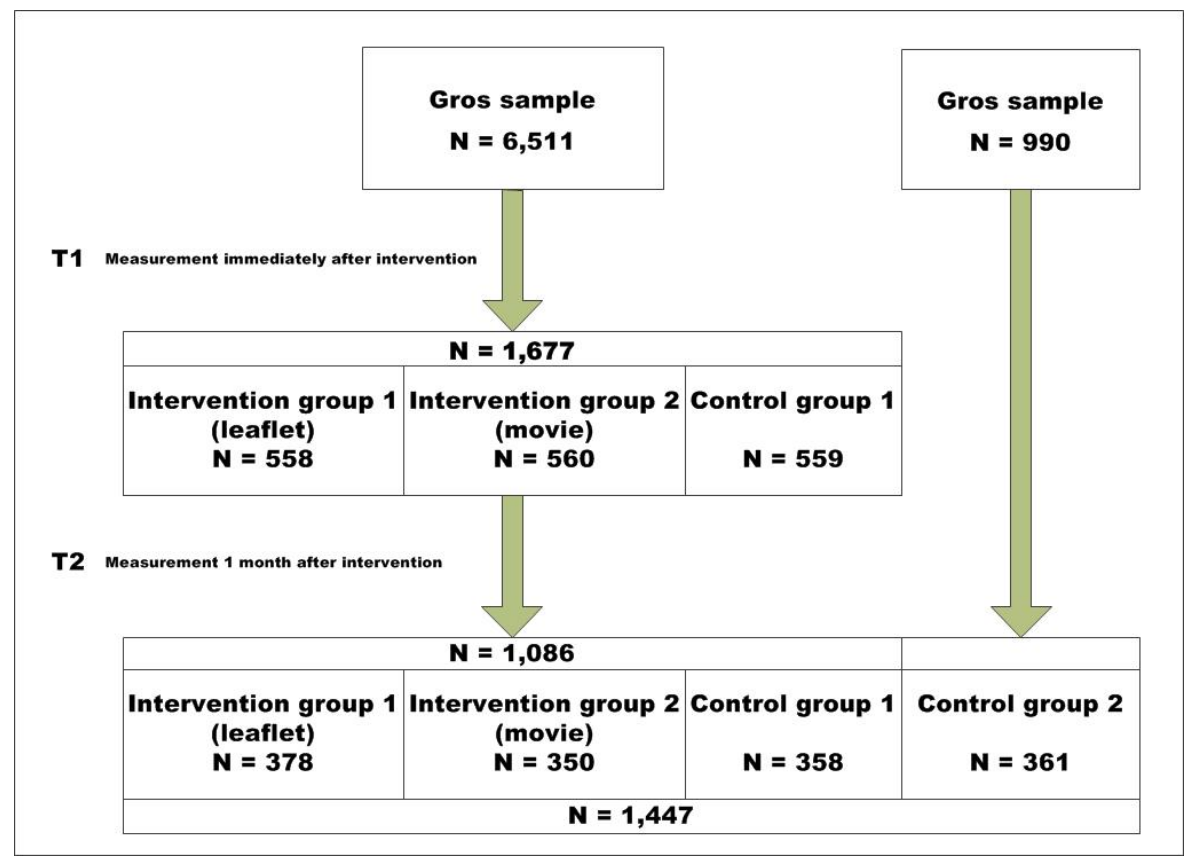

FIGURE 6.1: Study design

Outcome variables between $t 1$ and $t 2$ may have been influenced by an exogenous factor such as exposure to newspaper articles or television programs on ticks or LD. A new control group (C2) was recruited at $t 2$, in order to distinguish between the learning effect and exogenous exposure to public information on ticks and LD via mass media or social network or family.

\section{Participants}

Out of a representative Internet panel consisting of 20,000 members set up by Market Response Nederland BV, we invited at $t 1$ 6,511 members and at $t 2990$ additional persons, to complete the online study. A total of 1,677 respondents participated at $t 1$ and 1,086 of this group participated at $t 2$. From the 990 members invited at $t 2,361$ respondents participated as an extra control group (Fig. 6.1). Panel members were volunteers drawn from the Dutch general public, 
willing to participate in online studies. Participants received no reward for study completion. The 20,000 member panel shows a representative distribution of demographic variables (gender, age, region, and level of education) in the Dutch general population. The panel meets high quality requirements and is ISO certified. Participants were invited via email, with a link to the online questionnaire. According to Dutch law [33], this general Internet-based survey involving healthy volunteers from the general population requires no formal medical ethical approval.

\section{Questionnaire}

A questionnaire, developed from a version used in a previous study [17] and expanded to include leaflet and movie appreciation questions, was based on factors derived from the Protection Motivation Theory (PMT) and the Health Belief Model (HBM) [120, 42]. The questionnaire, administered online, began with general questions about activities in green space and personal experiences with tick bites and LD. The groups were then exposed to their allocated intervention or to the control group: IG respondents were presented with the movie or leaflet, while $C 1$ respondents received no information on ticks and LD. In the second questionnaire at $t 2$ the general questions about activities in green space, personal experiences with tick bites and LD and the questions about the interventions were removed. Moreover, the time frames of the questions about behaviour in the questionnaires differed: the first questionnaire concerned 'behavior during the last year', and the same question in the second questionnaire concerned 'behavior during the last month'. It served to assess level of knowledge (4 questions), perceived severity (6 questions), perceived susceptibility (1 question), self-efficacy (5 questions), efficacy of measures (5 questions), intention (4 questions), behavior (4 questions), appreciation of interventions (5 questions), and activities in green space and experience with tick bites and LD (7 questions) (see Annex 1 for full questionnaire). All questions, except for true/false knowledge statements, were rated on 7-point Likert scales; responses ranged from 'strongly disagree' (1) to 'strongly agree' (7).

\section{Materials}

We used the existing paper leaflet created by the National Institute for Public Health and the Environment, and a newly developed online 5-min movie titled A Tick? Take it! Both the leaflet and the movie show what ticks look like, where and how they live, how they can make people ill, and how to identify the (early) symptoms of LD. They also explain the reasons, methods, and importance of checking for and removing ticks, when to consult a GP, and how to treat LD. For analogous comparison between the effects of both tools, the leaflet was presented online to ensure any variances in effect would be due to differences in mode rather than offline versus online presentation. 


\section{Statistical analysis}

Only respondents who participated in both measurements were included in the analysis (except $\mathrm{C} 2$, which did not participate at $t 1$ ). Differences in inter-group participant characteristics can still differ despite randomization, and may lead to bias in estimates of effects. This problem was addressed by applying nearest neighbor matching based on propensity scores [138] estimated using random forests, which can outperform logistic regression when the 'true' model (i.e., the model from which the data is generated) is highly non-linear [102]. For the propensity score model we choose all variables that we suspect may be correlated with the outcome. We follow the advice by Stuart, by being liberal in our choice of confounders [165]. The loss of efficiency due to the inclusion of too many non-relevant variables is a lesser problem than the exclusion of potentially relevant confounders, as the latter would violate the strongly ignorable treatment assignment assumption that is essential in propensity score matching. Our chosen confounders fall into the following categories. First, basic participant characteristics may affect the outcome variables (age, gender, education,household size, urbanization category for area of residence, geographic region. daily Internet use, and dog or cat ownership); these characteristics were available post-randomization / pre-intervention. Second, characteristics that describe activities or events that are likely to influence the outcomes were also considered. These include frequency of walking/running or mountain biking in green spaces, frequency of gardening, frequency of camping, job requiring work in green spaces, tick bite already contracted by self or anyone in direct social network, LD contracted by self or anyone in direct social network, and previous exposure to the movie or leaflet (for IGs);these variables became available post intervention.

Sum scores for number of correctly answered items were calculated for multiple item questions on knowledge (Q8.1-Q8.7 (7 true/false statements), Q9 (4 preventive measures in 2 situations), and Q11 (6 symptoms) in questionnaire, Tables 6.1 and 6.2). Mean (Likert) scores were calculated for all other constructs. Differences in effect size of interventions on knowledge and other constructs between groups were estimated using matched data, applying either a $t$-test to compare means or a chi-square test to compare proportions (Q10). Intra-group time effect on memorized information was estimated using unmatched data, by applying a paired $t$-test to compare means or a McNemar test to compare proportions. A multiple testing correction was then performed on all test results using the Benjamini-Hochberg method, to ensure that the overall false discovery rate remained below 5\%. All analyses were performed in $\mathrm{R}$ version 3.0.0 or higher, using randomForest for random forest classifier and MatchIt for matching. 
TABLE 6.1: Knowledge questions with correct and incorrect answers

\begin{tabular}{|c|c|c|}
\hline Statements & Answer & \\
\hline A tick is always bigger than a lady bug & incorrect & \\
\hline A tick usually falls out of a tree to bite & incorrect & \\
\hline $\begin{array}{l}\text { A tick can be removed by pulling it } \\
\text { straight up with a pointed tweezers }\end{array}$ & correct & \\
\hline You will always get sick from a tick bite & incorrect & \\
\hline $\begin{array}{l}\text { If you are bitten, it is advisable to remove } \\
\text { a tick within } 48 \mathrm{~h}\end{array}$ & incorrect & \\
\hline $\begin{array}{l}\text { Ticks always bite on so called 'hot spots', } \\
\text { such as arm pits, groins, knee cavity }\end{array}$ & incorrect & \\
\hline $\begin{array}{l}\text { Lyme disease usually starts with a red } \\
\text { circle on the skin }\end{array}$ & correct & \\
\hline What can you do best? & $\begin{array}{l}\text { Situation 1: You will } \\
\text { discover a bitten tick on } \\
\text { your body, within } 24 \mathrm{~h} \\
\text { after you have been in } \\
\text { the green }\end{array}$ & $\begin{array}{l}\text { Situation 2: You will } \\
\text { discover a bitten tick on } \\
\text { your body, more than } \\
24 \mathrm{~h} \text { after you have been } \\
\text { in the green }\end{array}$ \\
\hline Remove tick & correct & correct \\
\hline Visit general practitioner & incorrect & correct \\
\hline Note the date and the site of the bite & correct & correct \\
\hline \multicolumn{3}{|l|}{ Monitor your health } \\
\hline \multicolumn{3}{|l|}{ I don't know } \\
\hline Questions & Correct answers & Incorrect answers \\
\hline $\begin{array}{l}\text { Imagine you have removed a tick. How } \\
\text { long after the bite you should monitor } \\
\text { your health? }\end{array}$ & $\begin{array}{l}\text { Up to } 3 \text { months after the } \\
\text { bite }\end{array}$ & $\begin{array}{l}\text { Up to } 3 \text { weeks after the } \\
\text { bite Up to } 1 \text { year after } \\
\text { the bite }\end{array}$ \\
\hline $\begin{array}{l}\text { Imagine you have removed a tick. On } \\
\text { what symptoms you should look? }\end{array}$ & $\begin{array}{l}\text { Red ring on the skin, } \\
\text { flu-like, symptoms, } \\
\text { painful joints }\end{array}$ & $\begin{array}{l}\text { Bloody nose, diarrhea, } \\
\text { hair loss }\end{array}$ \\
\hline $\begin{array}{l}\text { Imagine you have removed a tick. Which } \\
\text { of the symptoms should you watch out } \\
\text { for to see if you have got Lyme disease? }\end{array}$ & $\begin{array}{l}\text { Flu-like symptoms } \\
\text { Red ring on the skin } \\
\text { around the tick bite } \\
\text { Painful joints }\end{array}$ & $\begin{array}{l}\text { Nose bleed } \\
\text { Diarrhoea } \\
\text { Hair loss }\end{array}$ \\
\hline
\end{tabular}


TABLE 6.2: Percentage correct answers on knowledge questions

\begin{tabular}{|c|c|c|c|c|c|c|c|}
\hline $\begin{array}{l}\text { Number correct } \\
\text { answers out of } 7 \\
\text { knowledge } \\
\text { questions }\end{array}$ & $\begin{array}{l}\text { Control } 1 \\
(t 1) \\
(n= \\
358)\end{array}$ & $\begin{array}{l}\text { Control } 1 \\
(t 2) \\
(n= \\
358)\end{array}$ & $\begin{array}{l}\text { Control } 2 \\
(t 2) \\
(n= \\
361)\end{array}$ & $\begin{array}{l}\text { Movie } \\
(t 1) \\
(n= \\
350)\end{array}$ & $\begin{array}{l}\text { Movie } \\
(t 2) \\
(n= \\
350)\end{array}$ & $\begin{array}{l}\text { Leaflet } \\
(t 1) \\
(n= \\
378)\end{array}$ & $\begin{array}{l}\text { Leaflet } \\
(t 2) \\
(n= \\
378)\end{array}$ \\
\hline 0 & 0.6 & 0.6 & 2.5 & 0.6 & 0.3 & 0.3 & 0.3 \\
\hline 1 & 1.7 & 0.3 & 2.5 & 0.6 & 0.3 & 0 & 0.3 \\
\hline 2 & 4.7 & 3.1 & 6.9 & 0.9 & 3.1 & 2.6 & 3.4 \\
\hline 3 & 20.1 & 16.2 & 17.2 & 2.6 & 5.4 & 6.3 & 9.8 \\
\hline 4 & 30.2 & 28.5 & 31.0 & 13.1 & 25.4 & 18.8 & 25.1 \\
\hline 5 & 29.9 & 33.5 & 29.1 & 27.1 & 31.7 & 32.0 & 36.8 \\
\hline 6 & 12.0 & 16.8 & 10.0 & 42.9 & 30.0 & 25.9 & 22.0 \\
\hline 7 & 0.8 & 1.1 & 0.8 & 12.3 & 3.7 & 14.0 & 2.4 \\
\hline \multicolumn{8}{|l|}{$\begin{array}{l}\text { Number correct } \\
\text { answers out of } 8 \\
\text { 'what to do best } \\
\text { questions' }\end{array}$} \\
\hline 0 & 0 & 0.3 & 0.3 & 0 & 0.3 & 0 & 0 \\
\hline 1 & 8.9 & 6.1 & 8.3 & 2.9 & 3.1 & 2.4 & 2.6 \\
\hline 2 & 0.3 & 1.4 & 1.4 & 0.9 & 0.3 & 0.5 & 0 \\
\hline 3 & 25.4 & 18.7 & 20.5 & 15.1 & 16.0 & 235 & 15.1 \\
\hline 4 & 5.0 & 4.5 & 6.4 & 3.1 & 3.1 & 2.6 & 4.2 \\
\hline 5 & 14.2 & 9.5 & 15.5 & 8.0 & 8.0 & 74 & 14.3 \\
\hline 6 & 10.9 & 10.3 & 11.1 & 10.9 & 9.7 & 13.8 & 11.6 \\
\hline 7 & 26.3 & 31.6 & 26.6 & 26.6 & 30.6 & 25.4 & 28.0 \\
\hline 8 & 8.9 & 17.6 & 10.0 & 32.6 & 28.9 & 24.3 & 24.1 \\
\hline \multicolumn{8}{|l|}{$\begin{array}{l}\text { Recommended } \\
\text { health monitoring } \\
\text { time }\end{array}$} \\
\hline Correct & 26.5 & 32.1 & 25.5 & 69.1 & 50 & 74.3 & 48.4 \\
\hline $\begin{array}{l}\text { Number correctly } \\
\text { recognized } \\
\text { symptoms out of } \\
6 \text { symptoms }\end{array}$ & $\begin{array}{l}\text { Control } 1 \\
(t 1) \\
(n= \\
358)\end{array}$ & $\begin{array}{l}\text { Control } 1 \\
(t 2) \\
(n= \\
358)\end{array}$ & $\begin{array}{l}\text { Control } 2 \\
(t 2) \\
(n= \\
361)\end{array}$ & $\begin{array}{l}\text { Movie } \\
(t 1) \\
(n= \\
350)\end{array}$ & $\begin{array}{l}\text { Movie } \\
(t 2) \\
(n= \\
350)\end{array}$ & $\begin{array}{l}\text { Leaflet } \\
(t 1) \\
(n= \\
378)\end{array}$ & $\begin{array}{l}\text { Leaflet } \\
(t 2) \\
(n= \\
378)\end{array}$ \\
\hline 0 & 0 & 0 & 0 & 0 & 0 & 0 & 0 \\
\hline 1 & 0 & 0 & 0 & 0 & 0 & 0 & 0 \\
\hline 2 & 0.3 & 0.3 & 0 & 0 & 0.3 & 0 & 0.3 \\
\hline 3 & 12.3 & 5.6 & 13.9 & 2 & 4.6 & 1.3 & 3.7 \\
\hline 4 & 27.9 & 21.5 & 25.8 & 21.4 & 22.3 & 23.3 & 24.3 \\
\hline 5 & 28.2 & 31.3 & 33.5 & 28.6 & 36.0 & 39.9 & 34.1 \\
\hline 6 & 31.3 & 41.3 & 26.9 & 48.0 & 36.9 & 35.4 & 37.6 \\
\hline
\end{tabular}

\section{Results}

Table 6.3 shows the baseline characteristics among respondents in all four groups. Although the covariate distributions between groups are largely similar, they do exhibit some differences. For instance, control group 2 has relatively more highly educated respondents, and control group 1 has more respondents from the southern region of the Netherlands. After matching on the propensity score, the balance in covariates between the four groups improved somewhat, in 
part because the balance was already strong before matching.

The sample derived differed slightly in composition (age distribution) from that of the general population: respondents tend to be older than non-respondents. Examination of age stratified results (not presented) shows no systematic influence for any age stratum. We therefore consider the results to be relevant to the general population. In Annex 3 additional results are presented in Table 6.6 the proportions or means (depending on the operationalization of the outcome involved) of all tested outcomes and in Table 6.7 the differences in group mean between control groups.

\section{Knowledge}

Of all respondents (IGs and controls), 83.8\% answered at least 4 out of 7 knowledge statements (Table 6.2) correctly. Knowledge sum scores for respondents who viewed the movie or received the leaflet were significantly better than for controls, at both $t 1$ (immediately post-intervention) $(p<0.01$ and $p<0.01$, respectively) and $t 2$ ( 4 weeks post-intervention) ( $p<0.01, p=0.02$, respectively) (Fig. 6.2). Respondents who viewed the movie had a significantly better knowledge sum score on both measurements ( $p=0.01$ at $t 1, p=0.03$ at $t 2$ ), compared to respondents who received the leaflet. Respondents in both IGs had lower knowledge scores at $t 2$ than at $t 1$ (for both $p \leq 0.01$ ).

Respondents' knowledge of optimal measures in both situations (discovery of tick bite on body within or more than $24 \mathrm{~h}$ after time spent in green space) was significantly better in both IGs than in the control groups, at both $t 1$ (both $p<0.01$ ) and $t 2$ (movie $p<0.01$, leaflet $p=0.05$ ) (Table 6.2 and Fig. 6.3).

Respondents who viewed the movie or received the leaflet had significantly better knowledge of how long they should monitor their health after a tick bite, on both measurements, than did respondents in control groups (both $p<0.01$ ) (Table 6.2 and Fig. 6.4).

Initial LD symptoms (red circle on skin, flu-like symptoms, and painful joints) were significantly better known by IG than control group respondents at $t 1$ (both $p<0.01$ ) (Table 6.2 and Fig. 6.5). Respondents who viewed the movie had significantly more knowledge of symptoms than did respondents in the leaflet group ( $p<0.05$, Fig. 6.5). Additionally, more IG respondents could identify at least one symptom of LD, compared to the control groups.

\section{Perceived anxiety, susceptibility and seriousness}

No significant differences in perceived anxiety and perceived susceptibility were found, with respect to tick bites and $\mathrm{LD}$, between any groups. The respondents perceived LD on average as a very serious disease $(M=6.15)$. For not significant results see Annex 2. 
TABLE 6.3: Baseline characteristics in percentages per group

\begin{tabular}{|c|c|c|c|c|c|}
\hline & & $\begin{array}{l}\% \\
\text { Control } 2 \\
(n=361)\end{array}$ & $\begin{array}{l}\% \\
\text { Control } 1 \\
(n=358)\end{array}$ & $\begin{array}{l}\% \\
\text { Movie } \\
(n=350)\end{array}$ & $\begin{array}{l}\% \\
\text { Leaflet } \\
(n=378)\end{array}$ \\
\hline Gender & $\begin{array}{l}\text { Man } \\
\text { Woman }\end{array}$ & $\begin{array}{l}48.5 \\
51.5\end{array}$ & $\begin{array}{l}43.3 \\
56.7\end{array}$ & $\begin{array}{l}46.6 \\
53.4\end{array}$ & $\begin{array}{l}43.1 \\
56.9\end{array}$ \\
\hline Age & $\begin{array}{l}18-24 \text { years } \\
25-34 \text { years } \\
35-44 \text { years } \\
45-54 \text { years } \\
55-64 \text { years } \\
\geq 65 \text { years }\end{array}$ & $\begin{array}{l}5.8 \\
14.1 \\
23.5 \\
23 \\
18 \\
15.5\end{array}$ & $\begin{array}{l}5.3 \\
7.8 \\
18.7 \\
26.8 \\
24 \\
17.3\end{array}$ & $\begin{array}{l}3.4 \\
8 \\
26 \\
22.3 \\
18.6 \\
21.7\end{array}$ & $\begin{array}{l}3.7 \\
10.1 \\
24.1 \\
20.9 \\
19.8 \\
21.4\end{array}$ \\
\hline Education & $\begin{array}{l}\text { High } \\
\text { Middle } \\
\text { Low }\end{array}$ & $\begin{array}{l}54.3 \\
31.3 \\
14.4\end{array}$ & $\begin{array}{l}42.7 \\
35.5 \\
21.8\end{array}$ & $\begin{array}{l}42.9 \\
36 \\
21.1\end{array}$ & $\begin{array}{l}45.8 \\
36 \\
18.3\end{array}$ \\
\hline $\begin{array}{l}\text { Frequency of walking, } \\
\text { running or mountain } \\
\text { biking }\end{array}$ & $\begin{array}{l}\text { Least } 1 \text { time per week } \\
1 \text { to } 3 \text { times per month } \\
1 \text { to } 11 \text { times per year } \\
\text { Never }\end{array}$ & $\begin{array}{l}43.2 \\
21.9 \\
22.2 \\
12.7\end{array}$ & $\begin{array}{l}39.1 \\
19.3 \\
20.7 \\
20.9\end{array}$ & $\begin{array}{l}37.7 \\
23.4 \\
20.9 \\
18\end{array}$ & $\begin{array}{l}38.9 \\
22 \\
23.8 \\
15.3\end{array}$ \\
\hline Frequency of gardening & $\begin{array}{l}\text { Least } 1 \text { time per week } \\
1 \text { to } 3 \text { times per month } \\
1 \text { to } 11 \text { times per year } \\
\text { Never }\end{array}$ & $\begin{array}{l}35.5 \\
25.2 \\
17.2 \\
22.2\end{array}$ & $\begin{array}{l}34.4 \\
24.3 \\
12.8 \\
28.5\end{array}$ & $\begin{array}{l}41.4 \\
20.9 \\
15.7 \\
22\end{array}$ & $\begin{array}{l}39.7 \\
23.8 \\
15.6 \\
20.9\end{array}$ \\
\hline Frequency of camping & $\begin{array}{l}\text { Least } 1 \text { time per week } \\
1 \text { to } 3 \text { times per month } \\
1 \text { to } 11 \text { times per year } \\
\text { Never }\end{array}$ & $\begin{array}{l}1.4 \\
1.1 \\
39.6 \\
57.9\end{array}$ & $\begin{array}{l}1.1 \\
2 \\
27.7 \\
69.3\end{array}$ & $\begin{array}{l}0.6 \\
0.6 \\
27.4 \\
71.4\end{array}$ & $\begin{array}{l}0.5 \\
1.1 \\
27.2 \\
71.2\end{array}$ \\
\hline $\begin{array}{l}\text { Are you often actively } \\
\text { engaged for your work in } \\
\text { green (i.e. as a ranger or } \\
\text { gardener)? Ever had one } \\
\text { or more tick bites? }\end{array}$ & $\begin{array}{l}\text { No } \\
\text { Yes } \\
\text { No } \\
\text { Yes, } 1 \text { tick bite } \\
\text { Yes, > } 1 \text { tick bites } \\
\text { Don't know }\end{array}$ & $\begin{array}{l}96.1 \\
3.9 \\
67.6 \\
14.1 \\
13.6 \\
4.7\end{array}$ & $\begin{array}{l}94.7 \\
5.3 \\
69 \\
13.7 \\
14.2 \\
3.1\end{array}$ & $\begin{array}{l}94.6 \\
5.4 \\
70.9 \\
13.1 \\
12 \\
4\end{array}$ & $\begin{array}{l}96.3 \\
3.7 \\
72.2 \\
14.8 \\
11.1 \\
1.9\end{array}$ \\
\hline $\begin{array}{l}\text { Has anyone in your } \\
\text { immediate environment } \\
\text { (such as children, partner, } \\
\text { family, friends, colleagues) } \\
\text { once one or more tick } \\
\text { bites? }\end{array}$ & $\begin{array}{l}\text { No } \\
\text { Yes, in my area it has } \\
\text { happened once } \\
\text { Yes, in my area it has } \\
\text { happened more than once } \\
\text { Don't know }\end{array}$ & $\begin{array}{l}35.2 \\
24.4 \\
33.2 \\
7.2\end{array}$ & $\begin{array}{l}37.2 \\
20.4 \\
35.5 \\
7\end{array}$ & $\begin{array}{l}40 \\
22.6 \\
27.7 \\
9.7\end{array}$ & $\begin{array}{l}37.3 \\
26.5 \\
28.8 \\
7.4\end{array}$ \\
\hline $\begin{array}{l}\text { Have you ever had Lyme } \\
\text { disease? }\end{array}$ & $\begin{array}{l}\text { No } \\
\text { Yes, I have (had) Lyme } \\
\text { Disease (once) } \\
\text { Yes, I have (had) Lyme } \\
\text { Disease more than once } \\
\text { Don't know } \\
\text { No }\end{array}$ & $\begin{array}{l}96.1 \\
0.8 \\
0.6 \\
2.5 \\
69.8\end{array}$ & $\begin{array}{l}97.5 \\
1.7 \\
0.3 \\
0.6 \\
74.6\end{array}$ & $\begin{array}{l}97.4 \\
2 \\
0.3 \\
0.3 \\
71.7\end{array}$ & $\begin{array}{l}98.1 \\
1.3 \\
0.3 \\
0.3 \\
75.7\end{array}$ \\
\hline
\end{tabular}


Table 6.3: Baseline characteristics in percentages per group (continued)

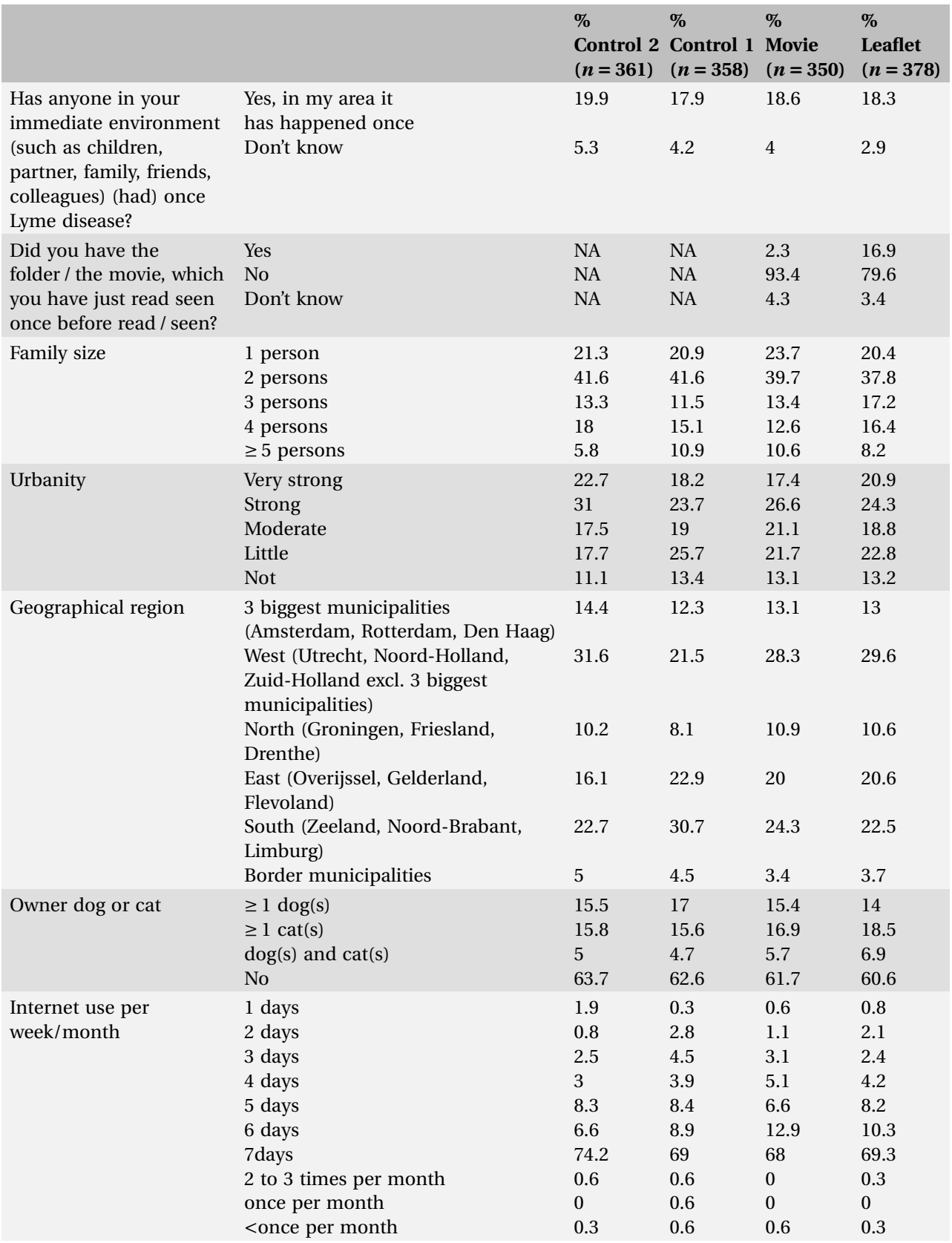




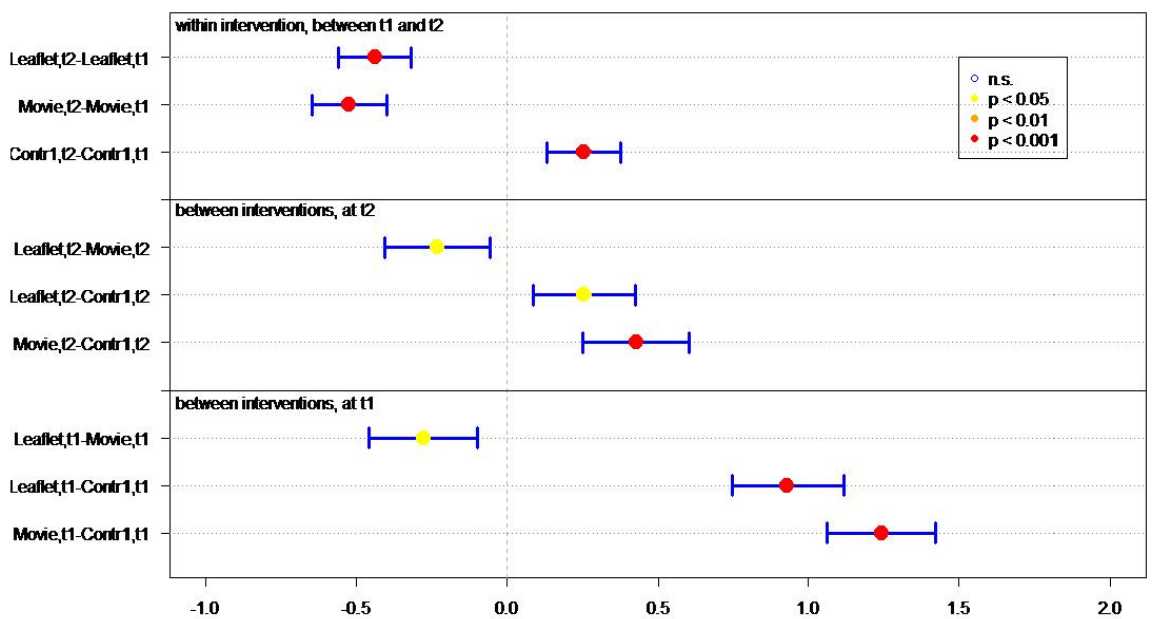

FigURE 6.2: Differences in mean sumscores on knowledge per group (leaflet, movie or control) on $t 1$ (immediately after intervention) and $t 2$ (after 1 month)

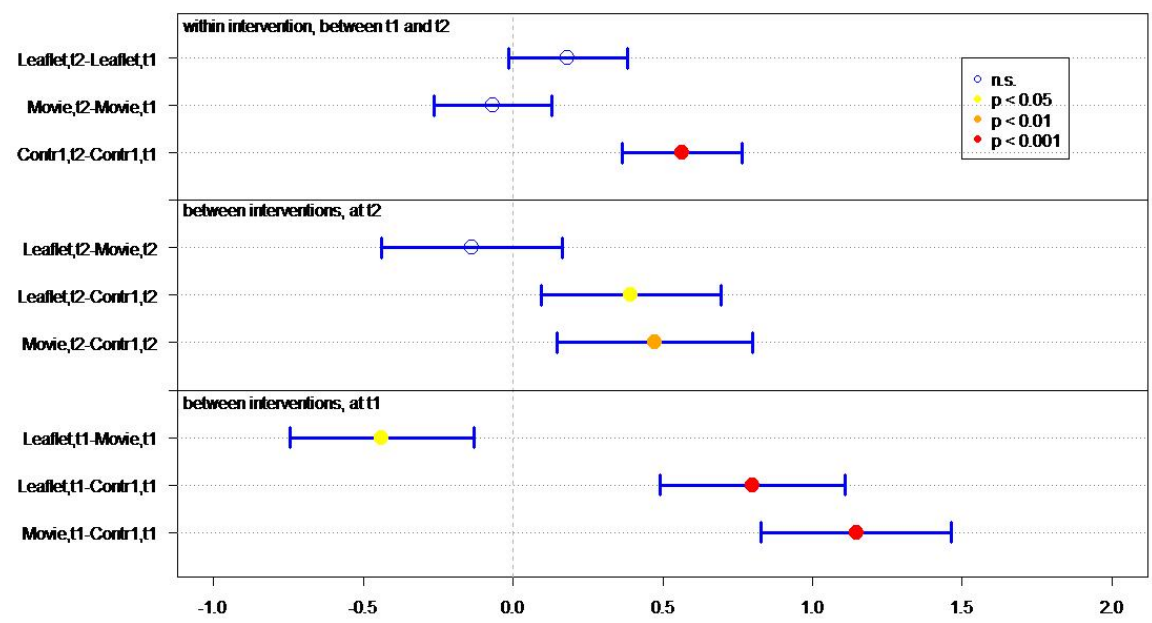

FIGURE 6.3: Differences in mean sumscores on knowledge about behavior in case of tick bite per group (leaflet, movie or control) on $t 1$ (immediately after intervention) and $t 2$ (after 1 month) 


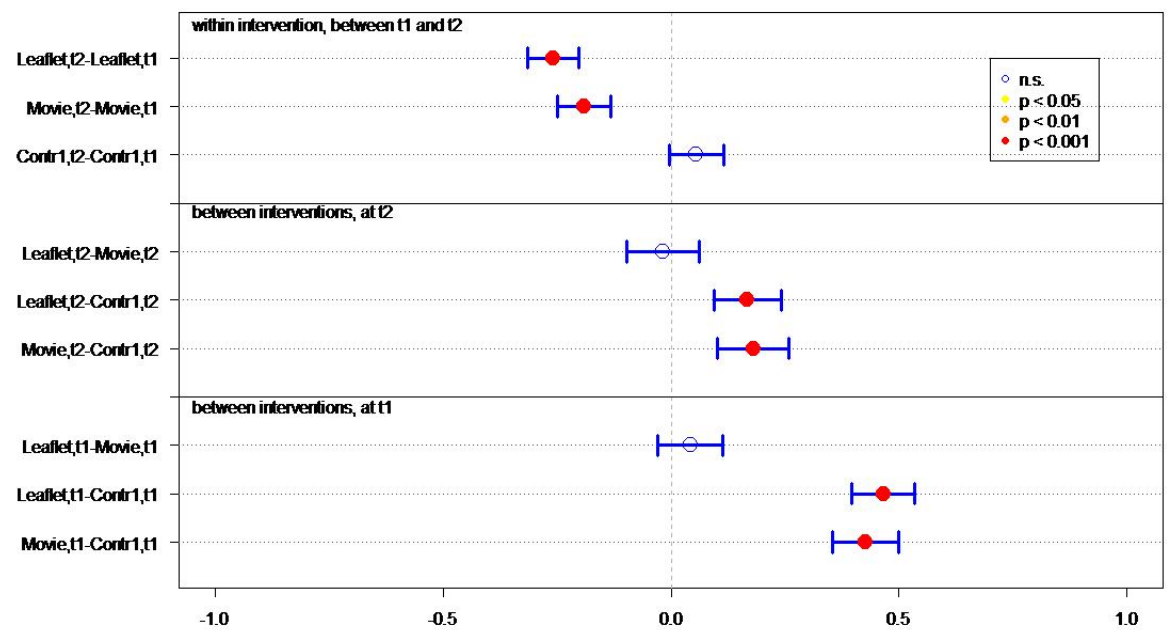

FIGURE 6.4: Differences in knowledge about health monitoring time per group (leaflet, movie or control) on $t 1$ (immediately after intervention) and $t 2$ (after 1 month)

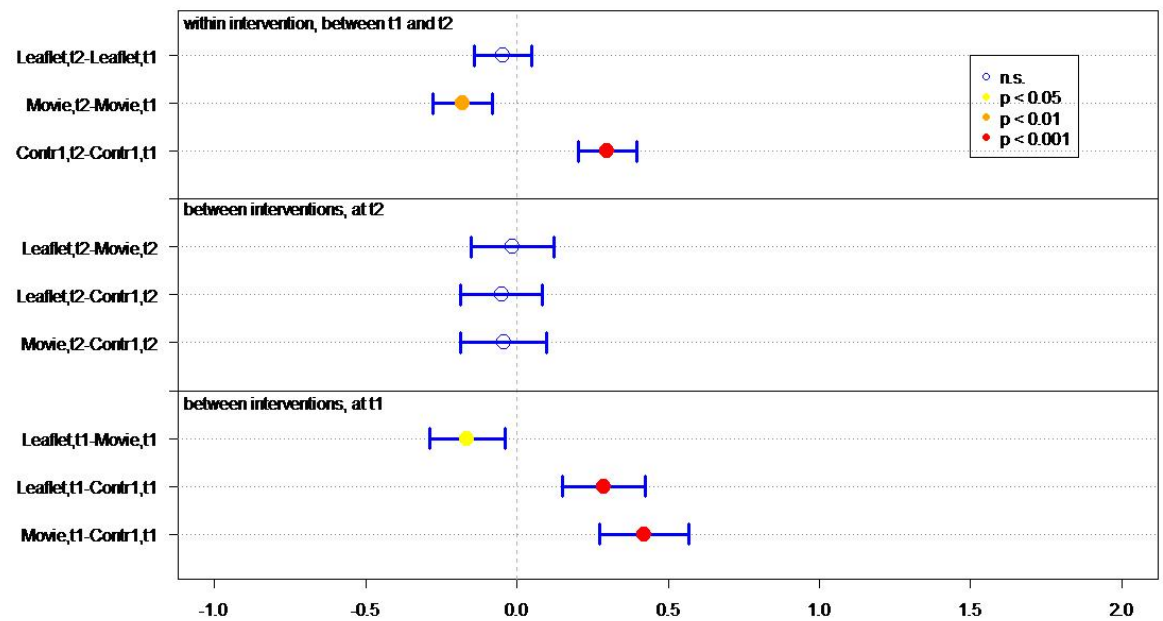

FIGURE 6.5: Differences in recognizing symptoms per group (leaflet, movie or control) on $t 1$ (immediately after intervention) and $t 2$ (after 1 month) 


\section{Self-efficacy and response efficacy}

The self-efficacy and response efficacy of respondents (both IG and control group respondents) is high (Table 6.4); the mean score for self- efficacy in the IGs was 5.42 and 5.28 in the control groups (scale 1-7). At $t 1$, the self-efficacy of IG respondents is higher than of control group respondents (movie $p=0.02$, leaflet $p<0.01$, Fig. 6.6)

TABLE 6.4: Mean Likert-scores of self-efficacy and response efficacy of measures (answer scales: $1=$ strongly disagree $-7=$ strongly agree)

\begin{tabular}{|c|c|c|c|c|c|c|c|}
\hline & C2 & $\begin{array}{l}C 1 \\
t 1\end{array}$ & $\begin{array}{l}C 1 \\
t 2\end{array}$ & $\begin{array}{l}\text { Movie } \\
t 1\end{array}$ & $\begin{array}{l}\text { Movie } \\
\text { t2 }\end{array}$ & $\begin{array}{l}\text { Leaflet } \\
t 1\end{array}$ & $\begin{array}{l}\text { Leaflet } \\
t 2\end{array}$ \\
\hline $\begin{array}{l}\text { I manage to recognize a tick on my } \\
\text { body }\end{array}$ & 5.49 & 5.43 & 5.62 & 5.59 & 5.77 & 5.52 & 5.69 \\
\hline $\begin{array}{l}\text { I manage to do a tick check after } \\
\text { every visit to the green }\end{array}$ & 4.52 & 4.62 & 4.72 & 4.77 & 4.76 & 4.79 & 4.87 \\
\hline $\begin{array}{l}\text { I manage to use a pointed } \\
\text { tweezers (or any other kind of tick } \\
\text { remover) to remove a tick }\end{array}$ & 5.04 & 5.03 & 5.26 & 5.47 & 5.36 & 5.47 & 5.4 \\
\hline $\begin{array}{l}\text { I manage to record the place and } \\
\text { the date of the tick bite }\end{array}$ & 5.5 & 5.39 & 5.66 & 5.82 & 5.82 & 5.81 & 5.85 \\
\hline $\begin{array}{l}\text { I manage to visit the } \mathrm{GP}^{\mathrm{a}} \text { if a tick } \\
\text { is more than } 24 \mathrm{~h} \text { in the skin }\end{array}$ & 5.66 & 5.53 & 5.75 & 5.74 & 5.91 & 5.97 & 5.99 \\
\hline $\begin{array}{l}\text { Do you think recognition of a tick } \\
\text { helps to prevent } L D^{b} \text { ? }\end{array}$ & 5.57 & 5.71 & 5.75 & 5.84 & 5.79 & 6 & 5.88 \\
\hline $\begin{array}{l}\text { Do you think tick check after each } \\
\text { visit to the green helps to prevent } \\
\mathrm{LD}^{\mathrm{b}} \text { ? }\end{array}$ & 5.9 & 5.7 & 5.66 & 5.73 & 5.65 & 5.93 & 5.83 \\
\hline $\begin{array}{l}\text { Do you think removing } \\
\text { immediately a tick with a pointed } \\
\text { tweezers helps to prevent } \mathrm{LD}^{\mathrm{b}} \text { ? }\end{array}$ & 5.19 & 5.36 & 5.42 & 5.69 & 5.54 & 5.83 & 5.65 \\
\hline $\begin{array}{l}\text { Do you think recording the place } \\
\text { and date of the tick bite helps to } \\
\text { prevent } L D^{b} \text { ? }\end{array}$ & 3.83 & 4.01 & 4.27 & 4.31 & 4.3 & 4.43 & 4.37 \\
\hline $\begin{array}{l}\text { Do you think visiting the } \mathrm{GP}^{\mathrm{a}} \text { with } \\
\text { a tick more than } 24 \mathrm{~h} \text { in the skin } \\
\text { helps to prevent } \mathrm{LD}^{\mathrm{b}} \text { ? }\end{array}$ & 4.75 & 5 & 5.03 & 4.93 & 5.06 & 5.25 & 5.26 \\
\hline
\end{tabular}

Taken together, all respondents scored highest $(M=5.79)$ on seeing a GP within $24 \mathrm{~h}$ if a tick had bitten into their skin and least high $(M=4.72)$ on selfefficacy for performing a tick check after every visit to a possibly tick infested area.

The response efficacy of respondents in the leaflet group is significantly higher $(p<0.01)$, at $t 1$, than of the control group respondents (Fig. 6.7). In general, all respondents rated 'recognition of a tick' as the most effective measure for preventing $\mathrm{LD}(M=5.79)$, and 'recording the place and date of the tick bite' as the least effective measure $(M=4.22)$. 


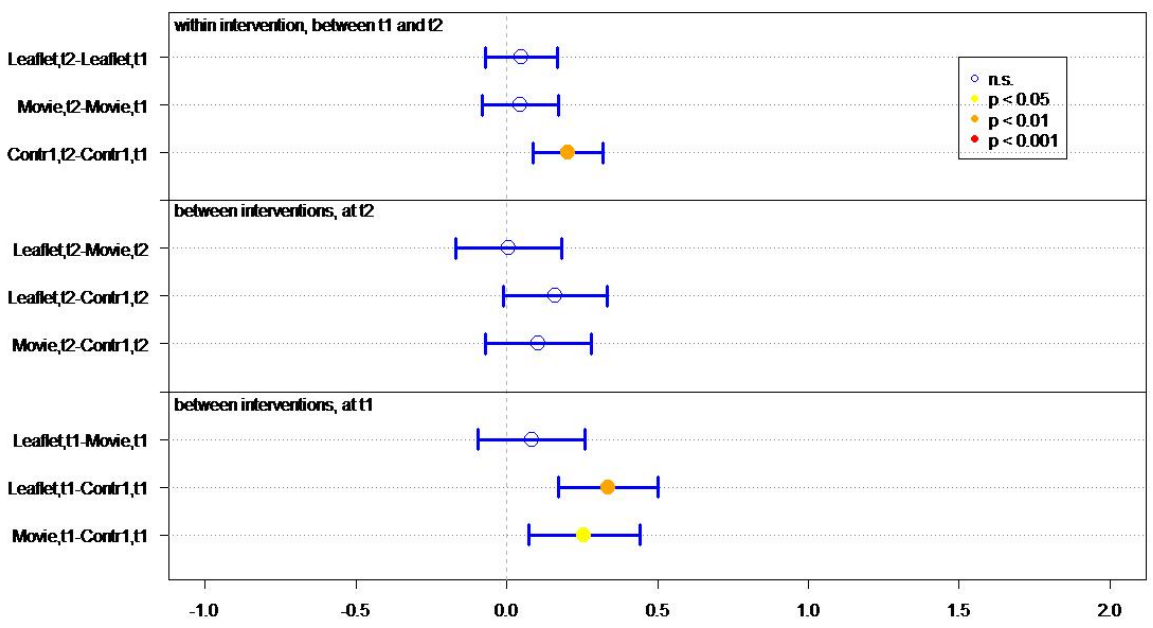

FIGURE 6.6: Differences in mean Likert scores on self efficacy per group (leaflet, movie or control) on $t 1$ (immediately after intervention) and $t 2$ (after 1 month)

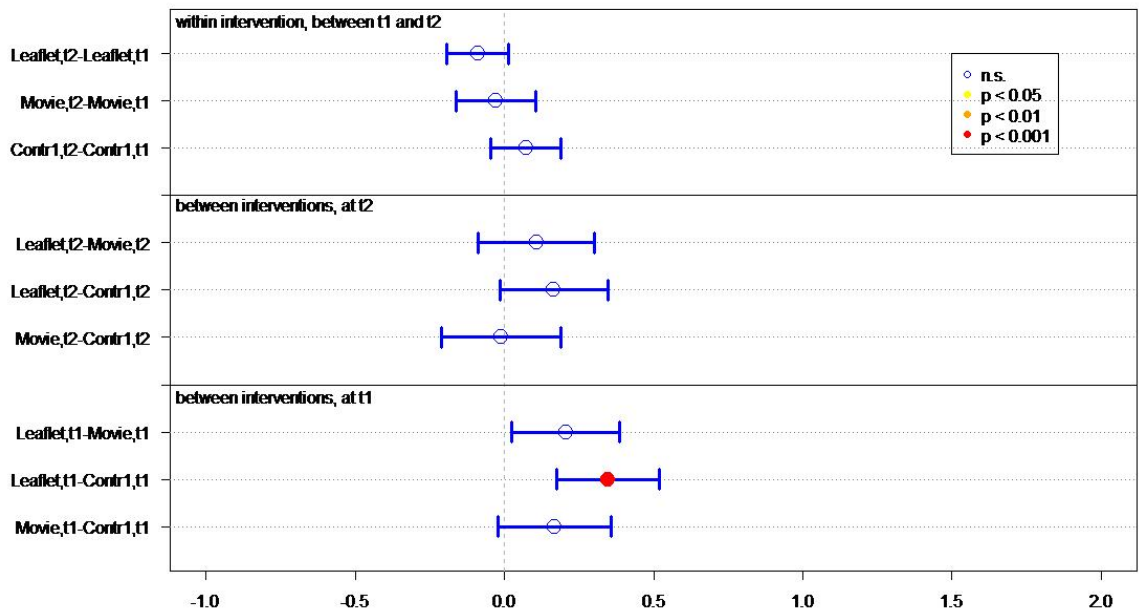

FIGURE 6.7: Differences in mean Likert scores on perceived efficacy per group (leaflet, movie or control) on $t 1$ (immediately after intervention) and $t 2$ (after 1 month) 


\section{Intention}

At $t 1$, significantly more IG respondents $(p<0.01)$ expressed the intention of immediately removing a tick after discovery, recording place and date of tick bite, and visiting a GP if the tick remained on the skin for more than $24 \mathrm{~h}$, compared to control group respondents (Fig. 6.8).

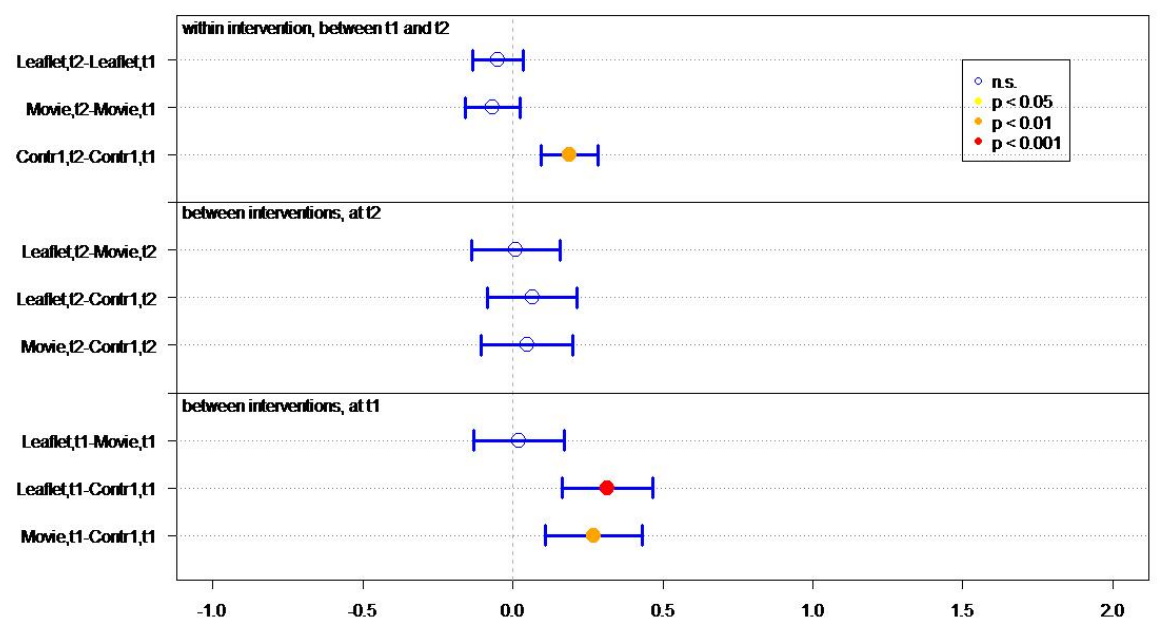

FIGURE 6.8: Differences in mean Likert scores on intention per group (leaflet, movie or control) on $t 1$ (immediately after intervention) and $t 2$ (after 1 month)

\section{Behaviors}

At $t 1$, the protective behavior of the respondents (such as checking on ticks, tick removal, recording date and place of tick bite, and visiting a GP) was the same in all groups.

\section{Lasting effects}

At $t 2,1$ month after $t 1$, the sum score on knowledge and the question 'How long after the bite should you monitor your health?' decreased significantly in both IGs (Figs. 6.2 and 6.4). Furthermore the knowledge on symptoms decreased significantly in the movie group (Fig. 6.5). About $20 \%$ of respondents has reported a tick bite themselves or to someone else during the month between $t 1$ and $t 2$. These respondents visited nature more often than respondents who had not reported a tick bite between $t 1$ and $t 2$ (99\% versus $80 \%$ ). Respondents in IGs who reported a tick bite at $t 1$ as well as at $t 2$, reported more often to take some tick bite prevention measures (like recording of date and place of a tick bite (movie 
and leafet group) and tick checks (movie group) at $t 2$ (question concerned performed behavior during last month) than at $t 1$ (question concerned behavior performed during last year). But they reported less often to take other tick bite prevention measures (like immediate tick removal (movie and leaflet group) and tick checks (leaflet group) (Table 6.5).

TABLE 6.5: Mean Likert scores of taking preventive measures of respondents who reported a tick bite at $t 1$ and $t 2$ (answer scale 1-7)

\begin{tabular}{|c|c|c|c|c|c|c|}
\hline Preventive measures & $\begin{array}{l}\text { Control } 1 \\
(t 1) \\
(n=48)\end{array}$ & $\begin{array}{l}\text { Control } 1 \\
(t 2) \\
(n=48)\end{array}$ & $\begin{array}{l}\text { Movie } \\
(t I) \\
(n=39)\end{array}$ & $\begin{array}{l}\text { Movie } \\
(t 2) \\
(n=39)\end{array}$ & $\begin{array}{l}\text { Leaflet } \\
(t 1) \\
(n=46)\end{array}$ & $\begin{array}{l}\text { Leaflet } \\
(t 2) \\
(n=46)\end{array}$ \\
\hline Tick check & 4.31 & 4.44 & 3.49 & 4.15 & 4.83 & 4.18 \\
\hline Tick removal & 4.23 & 4.6 & 4.13 & 3.77 & 4.61 & 4.52 \\
\hline Note date and site of bite & 2.91 & 3.47 & 3.11 & 3.2 & 2.8 & 2.83 \\
\hline Visit general practitioner & 1.97 & 1.55 & 1.81 & 1.81 & 2.19 & 1.6 \\
\hline
\end{tabular}

\section{Appreciation}

The appreciation of the interventions differed only on the length of time spent. Respondents who received the leaflet were significantly $(p<0.01)$ more satisfied with length of time spent, compared to respondents who viewed the movie.

\section{Effect of questionnaire}

Repeated completion of the questionnaire had a positive effect on knowledge and intention. Respondents in $C 1$, who filled out the questionnaire twice, achieved a significant better knowledge sum score $(p<0.001$, Fig. 6.2$)$, knew significantly better what to do if a tick bite is discovered on the body $(p<0.001$, Fig. 6.3) - both within and after $24 \mathrm{~h}$ of time spent in green space - recognized significant more LD symptoms at $t 2$ than at $t 1$ and had significant more frequently the intention to perform protective behavior $(p<0.001$, Fig. 6.5). This underlines the assigned effect of repeatedly filling in the questionnaire, notwithstanding the effect of public exposure to information on ticks and LD (C2).

\section{Discussion}

The aim of the current study was to evaluate and compare the effects of a newly developed movie and a leaflet for preventing tick bites and LD. We conclude that all respondents in this representative sample of the Dutch population possessed solid knowledge of ticks and LD at baseline: more than $80 \%$ answered at least 4 out of 7 knowledge statements correctly. This may be the positive effect of the annual nationwide 'Week of the Tick' campaign, launched over a decade ago. 
Nonetheless, overall knowledge scores in both IGs increased significantly, compared to the control group. This is comparable with the results of Lawless and colleagues, who described that knowledge increased significantly in the group who received an instructional video [100]. This finding is relevant since others have demonstrated that increased knowledge seems to positively influence protective behavior [67]. However, research in LD-endemic areas has shown that, despite adequate knowledge of LD symptoms and transmission, many people have not adopted behaviors to reduce their infection risk [46, 70]. These findings suggest that (like many other protective health behaviors, ranging from washing hands to using condoms to stop STI transmission) lack of knowledge is only one reason for poor uptake of protective behavior.

The self-efficacy of IG-respondents was higher versus the control group respondents and also the response efficacy in the leaflet group. This is an important and promising effect of the leaflet and the movie because self-efficacy and response efficacy are essential determinants in taking appropriate actions. Floyd showed in his meta-analysis of the literature on the PMT that coping variables like self-efficacy and response efficacy were strongly related to intention and behavior $[61,4]$. Other researchers also conclude in their studies that 'a belief' in the response efficacy and in the own ability to perform the measures is the primary goal of sustainable LD and tick prevention programs [67, 46, 145, 74].

Significantly more respondents (both IGs) also expressed the intention of taking more easily implementable preventive measures, e.g., immediately removing a tick, recording place and date of tick bite, and visiting the GP if the tick remained on the skin more than $24 \mathrm{~h}$ post-bite. This effect is promising, since many interventions only have effect on knowledge and attitudes [113].

Finally, none of both interventions had a lasting positive effect on knowledge after 1 month. Lasting effects of the interventions on behavior were not analysed statiscally because the time periods differed too much ( 1 year versus 1 month). The RIVM is currently assessing the effect of our 'Tick bite' mobile app, which contains extra information and features that complement the leaflet and movie. Repeated use of this app may lead to lasting effects in behavior changes.

The main comment on the movie was the length $(5 \mathrm{~min})$. We have already addressed this by splitting the movie in two short parts $(1.5 \mathrm{~min})$ : one part is about checking for ticks and one about removing ticks.

The second control group was added in order to analyze the effect of repeated questionnaire completion and distinguish it from public exposure to information on ticks and LD via mass media. We found an assigned effect for repeated questionnaire completion, notwithstanding the effect of public exposure to information on ticks and LD.

The present study has some limitations. The respondents are members of an online panel. This implies that all respondents in this study have internet access. Since internet access is extremely high $(97 \%)$ in the Netherlands, we assume that this will not adversely affect the representativeness of this study [159].

Furthermore, members of an online panel are probably a certain selection 
of people, but the respondents are not selected on the fact that they are interested in ticks and LD. So it is not plausible that this will reduce the representativeness of the results. As usual in web-based research, we used data based on self-reported health risk behaviors. This is often associated with social desirability. Crutzen et al. demonstrated that three longitudinal studies revealed no meaningful associations between social desirability and self-reported health risk behaviors in web-based research [48]. Hence, we view the Internet as an appropriate medium to collect self-reports on health risk behaviors.

Knowingly, no prior (pre-test) measurements were taken because another measurement pre-intervention would entail respondents filling out the questionnaire twice in quick succession. Viewing the interventions while able to remember the pre-test measurement questions, which may have influenced their posttest measurement answers (e.g., due to recall or assessment reactivity).

Respondents at $t 2$ were slightly older than non-respondents. However, a sensitivity analysis suggests that indications and the significance of this study's intervention effects are unlikely to change with a fully representative age distribution, although treatment effects may differ slightly in actual magnitude.

\section{Conclusion}

Despite the limitations, we conclude that respondents appreciate the leaflet and movie, and both interventions increased knowledge, self-efficacy, and intention with regard to ticks and $\mathrm{LD}$. While the movie is more effective in furthering knowledge, the leaflet is better for increasing the response efficacy. Since there were no lasting effects of interventions on behavior measured, repeated exposure to them, or additional intervention efforts, are needed. Both online intervention tools present two advantages over written ones: they are available anywhere and anytime, and repeated exposure is easier to achieve. This information is still only available online, however, and the public would have to visit the website and find the movie and the leaflet themselves.

\section{Annex 1: Questionaire}

Questions 1-7 were excluded in the measurements at $t 2$. Question 7 was excluded for the controlgroups.

\section{Introduction}

Welcome to the Study group

The following questions are about ticks and Lyme disease.

It is important to us that you answer all the questions, even if you sometimes find them difficult and that some questions are similar to each other. Cross the 
answer that is most true for you. There are no 'right' or 'wrong' answers. This is about your answers and your experiences. For this reason we ask that you answer the questions yourself without looking at the internet or asking anyone else what they think.

The outcomes will be treated in strict confidence, processed anonymously and will be used in this study only. Participation is voluntary and you may stop at any time without giving a reason.

We wish you every success in answering these questions and thank you in advance for your time and trouble.

Please use the buttons on the screen and not the browser buttons. Please answer the question on the screen by clicking on the box in front of the answer. Filling in the questionnaire takes about 10 minutes.

1. How often do you take part in the activities below? When we talk about green spaces we mean being outdoors in nature areas such as woods, heathland, dunes or a park.

\begin{tabular}{|l|l|l|l|l|}
\hline & $\begin{array}{l}\text { Minimum of once a } \\
\text { week }\end{array}$ & $\begin{array}{l}1-3 \\
\text { times } \\
\text { a } \\
\text { month }\end{array}$ & $\begin{array}{l}1-11 \\
\text { times } \\
\text { a year }\end{array}$ & Never \\
\hline $\begin{array}{l}\text { Walking, running or } \\
\text { mountain biking in green } \\
\text { spaces }\end{array}$ & & & & \\
\hline Gardening & & & & \\
\hline Camping & & & & \\
\hline
\end{tabular}

2. Does your job involve you actively working in green spaces (e.g. forester or gardener)?

When we talk about green spaces we mean being outdoors in nature areas such as woods, heathland, dunes or a park.

$\square$ No

$\square$ Yes

3. Have you ever had one or more tick bites?

$\square$ No

$\square$ Yes, I have had one tick bite

Yes, I have had more than one tick bite

I can't remember

4. Has anyone in your direct social network (such as children, partner, family, friends, colleagues) ever had one or more tick bites? 
$\square$ No

$\square$ Yes, it has happened once in my social network

$\square$ Yes, it has happened a few times in my social network

I I can't remember

5. Have you ever had Lyme disease?

$\square$ No

$\square$ Yes, I have Lyme disease, or have had it once

$\square$ Yes, I have had Lyme disease more than once

I can't remember

6. Has anyone in your direct social network (i.e. children, partner, family, friends, colleagues) ever had Lyme disease?

$\square$ No

$\square$ Yes, it has happened once in my social network

$\square$ Yes, it has happened a few times in my social network

I can't remember

We are now going to show you a film about tick bites. When the film has finished a button will appear. Click on it to go to the next question. You can start the film by clicking on it. The film lasts for 5 minutes.

Or:

We are now going to show you a leaflet about tick bites. Please read the leaflet very carefully. It can be read by scrolling downwards. You can only move on to the next question when the 'next' button appears at the bottom of the screen. This takes about 3 minutes.

7. Have you ever seen/read the film/leaflet you have just seen/read before?

$\square$ yes

$\square$ no

I can't remember

8. You are now going to see a number of statements. Please read them and indicate if you think the statement is 'true' or 'false'. If you do not know the answer please mark 'I don't know'. 


\begin{tabular}{|l|l|l|l|}
\hline & true & false & $\begin{array}{l}\text { I don't } \\
\text { know }\end{array}$ \\
\hline A tick is always larger than a ladybird. & & & \\
\hline A tick usually falls from a tree in order to bite. & & & \\
\hline $\begin{array}{l}\text { Your can remove a tick by pulling it directly } \\
\text { upwards with pointed tweezers. }\end{array}$ & & & \\
\hline A tick bite always makes you ill. & & & \\
\hline $\begin{array}{l}\text { If you are bitten it is advised to remove the tick } \\
\text { within } 48 \text { hours. }\end{array}$ & & & \\
\hline $\begin{array}{l}\text { Ticks only bite in so-called warm areas, e.g. in } \\
\text { the armpit, groin or behind the knee. }\end{array}$ & & & \\
\hline $\begin{array}{l}\text { In Lyme disease a red ring usually appears on } \\
\text { the skin. }\end{array}$ & & & \\
\hline
\end{tabular}

9. Mark the box that indicates the best course of action to take in the following situations. Please do this for Situation 1 and Situation 2. These are followed by a number of actions. Please mark what you think are the best course/s of action. It is possible to mark more than one box.

\begin{tabular}{|l|l|l|}
\hline & $\begin{array}{l}\text { Situation 1. You find a } \\
\text { tick attached to your } \\
\text { body within 24 hours of } \\
\text { being in an area } \\
\text { infested by ticks. }\end{array}$ & $\begin{array}{l}\text { Situation 2. You find a tick } \\
\text { attached to your body } \\
\text { more than 24 hours after } \\
\text { being in an area possibly } \\
\text { infested by ticks. }\end{array}$ \\
\hline Remove the tick & & \\
\hline $\begin{array}{l}\text { Go to your general } \\
\text { practitioner (GP) }\end{array}$ & & \\
\hline $\begin{array}{l}\text { Note down the date } \\
\text { and place of the } \\
\text { bite in your diary }\end{array}$ & & \\
\hline Monitor your health & & \\
\hline I don't know & & \\
\hline
\end{tabular}

10. Imagine you have removed a tick. For how long after you have been bitten should you monitor your health?

up to 3 weeks after the bite

$\square$ up to 3 months after the bite

$\square$ up to 1 year after the bite

I don't know

11. Imagine you have removed a tick. Which of the symptoms below should you watch out for to see if you have got Lyme disease? (More than one answer is possible)

Nose bleed

Flu-like symptoms 
Painful joints

口 Diarrhoea

$\square$ Red ring on the skin around the tick bite

$\square$ Hair loss

$\square$ I don't know

12. Please indicate to what extent you agree or disagree with the statements below?

\begin{tabular}{|l|l|l|l|l|l|l|l|}
\hline & $\begin{array}{l}1- \\
\text { strongly } \\
\text { disagree }\end{array}$ & 2 & 3 & $\begin{array}{l}4- \\
\text { neutral }\end{array}$ & 5 & 6 & $\begin{array}{l}7- \\
\text { strongly } \\
\text { agree }\end{array}$ \\
\hline $\begin{array}{l}\text { I am frightened of a } \\
\text { tick bite. }\end{array}$ & & & & & & & \\
\hline $\begin{array}{l}\text { I am frightened of } \\
\text { getting a red ring on } \\
\text { my skin. }\end{array}$ & & & & & & & \\
\hline $\begin{array}{l}\text { I am frightened of } \\
\text { Lyme disease. }\end{array}$ & & & & & & & \\
\hline $\begin{array}{l}\text { If you get a tick bite, } \\
\text { this is serious. }\end{array}$ & & & & & & & \\
\hline $\begin{array}{l}\text { If you get a red ring on } \\
\text { your skin after a tick } \\
\text { bite, this is serious. }\end{array}$ & & & & & & & \\
\hline $\begin{array}{l}\text { If you get Lyme disease, } \\
\text { this is serious. }\end{array}$ & & & & & & & \\
\hline
\end{tabular}

13. In your opinion, how big is the risk that you will be bitten by a tick in the coming year? If you think the risk is very high then answer a 7. If you think the risk is very low then answer a 1. Of course you can answer any number between 1 and 7.

$$
\begin{aligned}
& \square 1 \text { - very low } \\
& \square 2 \\
& \square 3 \\
& \square 4 \text { - neutral } \\
& \square 5 \\
& \square 6 \\
& \square 7 \text { - very high }
\end{aligned}
$$

14. In your opinion, what is the risk that you will get Lyme disease in the coming year? If you think the risk is very high then answer a 7. If you think the risk is very low then answer a 1. Of course you can answer any number between 1 and 7 . 
1 - very small

2

$\square 3$

4 - neutral

$\square 5$

$\square 6$

$\square 7$ - very high

15. Imagine that you are going to take one of the precautions below to prevent getting Lyme disease. From a practical point of view, to what extent do you think that you would really succeed in taking these precautions? When we talk about green spaces we mean being outdoors in nature areas such as woods, heathland, dunes or a park.

\begin{tabular}{|c|c|c|c|c|c|c|c|}
\hline & $\begin{array}{l}1- \\
\text { strongly } \\
\text { disagree }\end{array}$ & 2 & 3 & $\begin{array}{l}4- \\
\text { neutral }\end{array}$ & 5 & 6 & $\begin{array}{l}\text { - } \\
\text { strongly } \\
\text { agree }\end{array}$ \\
\hline $\begin{array}{l}\text { I would be able to } \\
\text { recognise a tick on my } \\
\text { body. }\end{array}$ & & & & & & & \\
\hline $\begin{array}{l}\text { I would be able to } \\
\text { check my body for tick } \\
\text { bites after every trip to } \\
\text { a green space. }\end{array}$ & & & & & & & \\
\hline $\begin{array}{l}\text { I would be able to } \\
\text { remove a tick } \\
\text { immediately with } \\
\text { pointed tweezers (or } \\
\text { other type of tick } \\
\text { remover). }\end{array}$ & & & & & & & \\
\hline $\begin{array}{l}\text { I would be able to note } \\
\text { down the place of the } \\
\text { tick bite on my body } \\
\text { and the date in my } \\
\text { diary. }\end{array}$ & & & & & & & \\
\hline $\begin{array}{l}\text { I would be able to go to } \\
\text { the GP if I had a tick on } \\
\text { my skin for over } 24 \\
\text { hours. }\end{array}$ & & & & & & & \\
\hline
\end{tabular}

16. The following questions concern measures to prevent Lyme disease. Please indicate how much you think that these measures would help? When we talk about green spaces we mean being outdoors in nature areas such as woods, heathland, dunes or a park. 


\begin{tabular}{|c|c|c|c|c|c|c|c|}
\hline & $\begin{array}{l}1- \\
\text { certainly } \\
\text { does not } \\
\text { help }\end{array}$ & 2 & 3 & $\begin{array}{l}- \\
\text { neutral }\end{array}$ & 5 & 6 & $\begin{array}{l}7- \\
\text { certainly } \\
\text { does help }\end{array}$ \\
\hline $\begin{array}{l}\text { Do you think that } \\
\text { recognising a tick } \\
\text { when checking the } \\
\text { body helps to } \\
\text { prevent Lyme } \\
\text { disease? }\end{array}$ & & & & & & & \\
\hline $\begin{array}{l}\text { Do you think that } \\
\text { checking for ticks } \\
\text { after every visit to a } \\
\text { green space helps to } \\
\text { prevent Lyme } \\
\text { disease? }\end{array}$ & & & & & & & \\
\hline $\begin{array}{l}\text { Do you think that } \\
\text { removing a tick } \\
\text { immediately with } \\
\text { pointed tweezers or } \\
\text { other type of tick } \\
\text { remover helps to } \\
\text { prevent Lyme } \\
\text { disease? }\end{array}$ & & & & & & & \\
\hline $\begin{array}{l}\text { Do you think that } \\
\text { noting down the } \\
\text { place and date of } \\
\text { the tick bite helps to } \\
\text { prevent Lyme } \\
\text { disease? }\end{array}$ & & & & & & & \\
\hline $\begin{array}{l}\text { Do you think that } \\
\text { going to the GP if } \\
\text { you have had a tick } \\
\text { on your skin for } \\
\text { longer than } 24 \text { hours } \\
\text { helps to prevent } \\
\text { Lyme disease? }\end{array}$ & & & & & & & \\
\hline
\end{tabular}

17. The following questions concern the way the people around you deal with tick bites and Lyme disease. When we talk about green spaces we mean being outdoors in nature areas such as woods, heathland, dunes or a park. 


\begin{tabular}{|c|c|c|c|c|c|c|c|c|}
\hline & $\begin{array}{l}1- \\
\text { strongly } \\
\text { disagree }\end{array}$ & 2 & 3 & \begin{tabular}{l|}
$4-$ \\
neut- \\
ral
\end{tabular} & 5 & 6 & $\begin{array}{l}7- \\
\text { strongly } \\
\text { agree }\end{array}$ & $\begin{array}{l}\text { I } \\
\text { don't } \\
\text { know }\end{array}$ \\
\hline $\begin{array}{l}\text { People who are } \\
\text { important to me check } \\
\text { their body after every } \\
\text { visit to a green space to } \\
\text { prevent Lyme disease. }\end{array}$ & & & & & & & & \\
\hline $\begin{array}{l}\text { People who are } \\
\text { important to me think } \\
\text { it is important that I } \\
\text { check my body for ticks } \\
\text { after every visit to a } \\
\text { green space. }\end{array}$ & & & & & & & & \\
\hline $\begin{array}{l}\text { People who are } \\
\text { important to me would } \\
\text { remove a tick } \\
\text { immediately after they } \\
\text { discovered it on their } \\
\text { body. }\end{array}$ & & & & & & & & \\
\hline $\begin{array}{l}\text { People who are } \\
\text { important to me think } \\
\text { it is important that I } \\
\text { remove a tick as soon I } \\
\text { find it on my body. }\end{array}$ & & & & & & & & \\
\hline $\begin{array}{l}\text { People who are } \\
\text { important to me would } \\
\text { note down the place of } \\
\text { the tick bite on their } \\
\text { body and the date. }\end{array}$ & & & & & & & & \\
\hline $\begin{array}{l}\text { People who are } \\
\text { important to me think } \\
\text { it important that I note } \\
\text { down the place of the } \\
\text { tick bite on my body } \\
\text { and the date. }\end{array}$ & & & & & & & & \\
\hline $\begin{array}{l}\text { People who are } \\
\text { important to me would } \\
\text { go to the GP if a tick } \\
\text { had been stuck on their } \\
\text { skin for more than } 24 \\
\text { hours. }\end{array}$ & & & & & & & & \\
\hline $\begin{array}{l}\text { People who are } \\
\text { important to me think } \\
\text { that it important that I } \\
\text { go to the GP if a tick } \\
\text { had been stuck on my } \\
\text { skin for more than } 24 \\
\text { hours. }\end{array}$ & & & & & & & & \\
\hline
\end{tabular}


18. Imagine that you want to go to an area where there could be ticks ('green space'). Please indicate below what you would be intending to do. When we talk about green spaces we mean being outdoors in nature areas such as woods, heathland, dunes or a park.

\begin{tabular}{|c|c|c|c|c|c|c|c|}
\hline & $\begin{array}{l}1- \\
\text { strongly } \\
\text { disagree }\end{array}$ & 2 & 3 & $\begin{array}{l}4- \\
\text { neutral }\end{array}$ & 5 & 6 & $\begin{array}{l}7- \\
\text { strongly } \\
\text { agree }\end{array}$ \\
\hline $\begin{array}{l}\text { I intend to check my } \\
\text { body for ticks after } \\
\text { every visit to a green } \\
\text { space. }\end{array}$ & & & & & & & \\
\hline $\begin{array}{l}\text { If I find a tick on my } \\
\text { body I intend to } \\
\text { remove it immediately. }\end{array}$ & & & & & & & \\
\hline $\begin{array}{l}\text { If I find a tick on my or } \\
\text { someone else's body I } \\
\text { intend to write down } \\
\text { the place of the bite on } \\
\text { the body and the date. }\end{array}$ & & & & & & & \\
\hline $\begin{array}{l}\text { If I have a tick on my } \\
\text { skin for more than } 24 \\
\text { hours I plan to go to } \\
\text { the GP. }\end{array}$ & & & & & & & \\
\hline
\end{tabular}

The following questions concern the measures you take to prevent Lyme disease. When we talk about green spaces we mean being outdoors in nature areas such as woods, heathland, dunes or a park.

19. How often over the past year/month ( $t 2)$ have you checked yourself or someone else for tick bites after visiting a green space?

$\square 1$ - never after visiting a green space

$\square 2$

口 3

$\square 4$

$\square 5$

$\square 6$

$\square$ - every time after visiting a green space

$\square$ I have not visited a green space at all

20. How often over the past year/month ( $t 2)$ have you immediately removed a tick from your own or someone else's skin after discovering a tick bite?

1 - never after a tick bite 
$\square 6$

7 - every time after a tick bite

$\square$ I have not found any tick bites over the past year/month ( $t 2)$

21. How often over the past/ year month ( $t 2)$ after a tick bite have you noted down the place on the body and the date of the bite?

$\square 1$ - never after a tick bite

$\square 2$

$\square 3$

口 4

$\square 5$

$\square 6$

$\square$ - every time after a tick bite

$\square$ I have not found any tick bites over the past year

22. How often over the past year/month ( $t 2)$ have you been to the GP with a tick that has been on the skin for longer than 24 hours?

$\square 1$ - never after a tick bite

$\square 2$

$\square 3$

$\square 4$

$\square 5$

$\square 6$

$\square$ - every time after a tick bite

$\square$ Over the past year/month ( $t 2$ ) I have not found a tick bite that has been on the skin for longer than 24 hours.

I go to the GP for every tick bite, even if it has been on the skin for less than 24 hours.

23. Finally, a few questions about the film/leaflet that you have seen/read. 


\begin{tabular}{|c|c|c|c|c|c|c|c|}
\hline & $\begin{array}{l}1- \\
\text { strongly } \\
\text { disagree }\end{array}$ & 2 & 3 & $\begin{array}{l}4- \\
\text { neutral }\end{array}$ & 5 & 6 & $\begin{array}{l}7- \\
\text { strongly } \\
\text { agree }\end{array}$ \\
\hline $\begin{array}{l}\text { I thought the film/leaflet } \\
\text { was logical }\end{array}$ & & & & & & & \\
\hline $\begin{array}{l}\text { I thought the film/leaflet } \\
\text { was the right length }\end{array}$ & & & & & & & \\
\hline $\begin{array}{l}\text { I feel that I understood } \\
\text { the film/leaflet very well }\end{array}$ & & & & & & & \\
\hline $\begin{array}{l}\text { I think I that would need } \\
\text { help from someone else } \\
\text { to understand the } \\
\text { film/leaflet properly }\end{array}$ & & & & & & & \\
\hline $\begin{array}{l}\text { I think that a lot of } \\
\text { people would find the } \\
\text { film/leaflet useful }\end{array}$ & & & & & & & \\
\hline
\end{tabular}

Your help with this study is much appreciated. To finish, we would like to know what you think of this study. Please give your answers as if you were rating a report. 1 means a very poor report and 10 means a very good report. Of course you can give any number in between.

24. Please indicate on a scale of 1 to 10 how enjoyable or how unenjoyable you found taking part in this study Rate a 1 if you think that taking part in this study was not at all enjoyable and a 10 if you think it was very enjoyable.

$\square 1$

$\square 2$

$\square 3$

$\square 4$

$\square 5$

$\square 6$

a 7

$\square 8$

$\square 9$

10

口 Don't know

$\square$ No report

25. You have rated this study with an $\mathrm{x}$. Please explain in a little more detail why you rated it as such. 


\section{Annex 2: Additional figures not significant results}
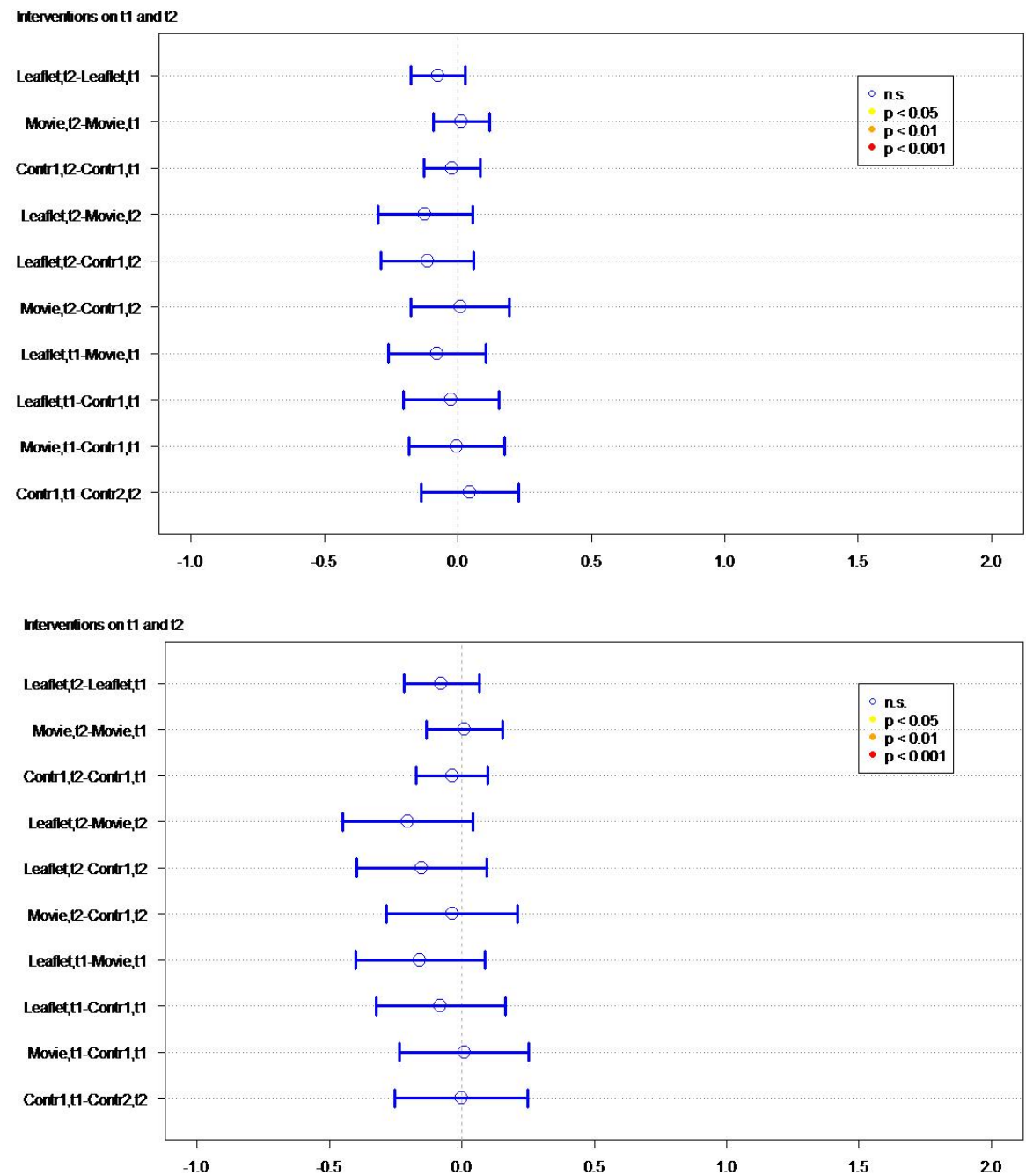

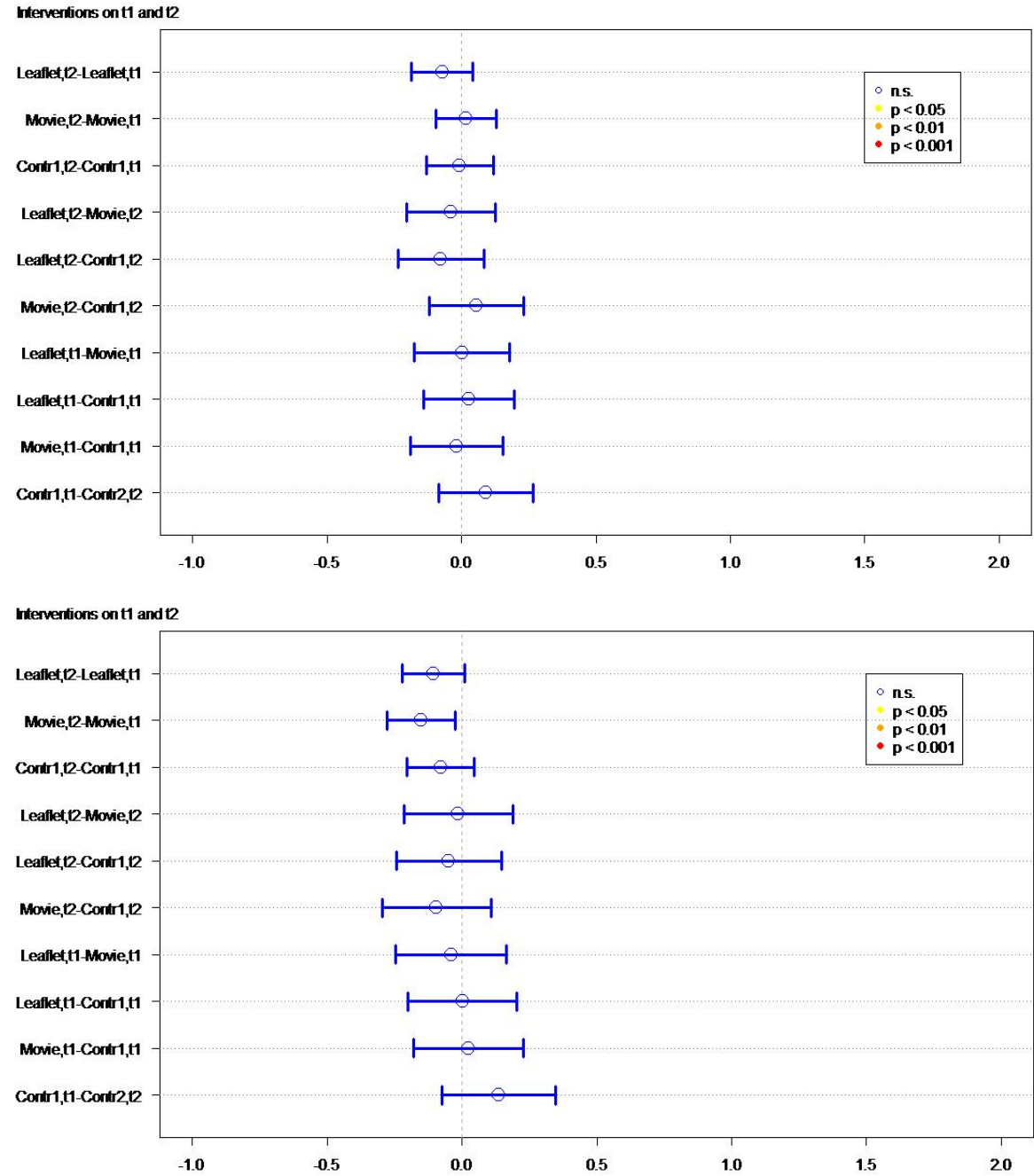


\section{Annex 3: Tables}

TABLE 6.6: The means or proportions of all tested outcomes

\begin{tabular}{|c|c|c|c|c|c|c|c|c|}
\hline Outcomes & $\begin{array}{l}\text { Control2 } \\
t 2\end{array}$ & $\begin{array}{l}\text { Control1 } \\
t 1\end{array}$ & $\begin{array}{l}\text { Control1 } \\
t 2\end{array}$ & $\begin{array}{l}\text { Movie } \\
t 1\end{array}$ & $\begin{array}{l}\text { Movie } \\
t 2\end{array}$ & $\begin{array}{l}\text { Leaflet } \\
t 1\end{array}$ & $\begin{array}{l}\text { Leaflet } \\
t 2\end{array}$ & Overall \\
\hline $\begin{array}{l}\text { Sum scores on } \\
\text { knowledge }\end{array}$ & 4.03 & 4.2 & 4.45 & 5.41 & 4.89 & 5.13 & 4.69 & 4.69 \\
\hline $\begin{array}{l}\text { Sum scores on behavior } \\
\text { in case of tick bite }\end{array}$ & 5.08 & 4.98 & 5.54 & 6.14 & 6.07 & 5.77 & 5.95 & 5.65 \\
\hline $\begin{array}{l}\text { Fraction of correct } \\
\text { answers on health } \\
\text { monitoring time }\end{array}$ & 0.25 & 0.27 & 0.32 & 0.69 & 0.5 & 0.74 & 0.48 & 0.47 \\
\hline $\begin{array}{l}\text { Sum scores on } \\
\text { recognizing symptoms }\end{array}$ & 4.73 & 4.78 & 5.08 & 5.23 & 5.05 & 5.1 & 5.05 & 5 \\
\hline $\begin{array}{l}\text { Likert scores on } \\
\text { perceived severity } \\
\text { overall }\end{array}$ & 4.45 & 4.51 & 4.49 & 4.51 & 4.53 & 4.46 & 4.39 & 4.48 \\
\hline Likert scores on anxiety & 3.87 & 3.87 & 3.84 & 3.89 & 3.9 & 3.76 & 3.69 & 3.83 \\
\hline $\begin{array}{l}\text { Likert scores on } \\
\text { seriousness }\end{array}$ & 5.03 & 5.15 & 5.14 & 5.14 & 5.15 & 5.17 & 5.1 & 5.12 \\
\hline $\begin{array}{l}\text { Likert scores on } \\
\text { susceptibility }\end{array}$ & 2.89 & 3.04 & 2.96 & 3.03 & 2.88 & 3.03 & 2.92 & 2.96 \\
\hline $\begin{array}{l}\text { Likert scores on } \\
\text { self-efficacy }\end{array}$ & 5.24 & 5.2 & 5.4 & 5.48 & 5.52 & 5.51 & 5.56 & 5.42 \\
\hline $\begin{array}{l}\text { Likert scores on } \\
\text { perceived efficacy }\end{array}$ & 4.95 & 5.16 & 5.23 & 5.3 & 5.27 & 5.49 & 5.4 & 5.26 \\
\hline $\begin{array}{l}\text { Likert scores on } \\
\text { intention }\end{array}$ & 5.56 & 5.66 & 5.85 & 5.96 & 5.9 & 5.97 & 5.92 & 5.83 \\
\hline
\end{tabular}

TABLE 6.7: Test results for differences in group mean between Control group 1 at $t 1$ and Control group 2 at $t 2$

\begin{tabular}{|llll} 
Outcome & $\begin{array}{l}\text { Difference } \\
\text { (Cont1, t1-Cont2, } \boldsymbol{t} \text { 2) }\end{array}$ & $\begin{array}{l}\text { Confidence } \\
\text { Interval }\end{array}$ & $\boldsymbol{p}$-value \\
\hline Sum scores on knowledge & 0.202 & $(-0.001-0.405)$ & 0.08 \\
\hline Sum scores on behavior in case of tick bite & -0.016 & $(-0.353-0.321)$ & 0.88 \\
\hline Sum scores on recognizing symptoms & 0.045 & $(-0.117-0.207)$ & 0.80 \\
\hline Likert scores on perceived severity overall & 0.034 & $(-0.148-0.216)$ & 0.88 \\
\hline Likert scores on anxiety & -0.033 & $(-0.281-0.215)$ & 0.87 \\
\hline Likert scores on seriousness & 0.101 & $(-0.075-0.278)$ & 0.43 \\
\hline Likert scores on susceptibility & 0.186 & $(-0.027-0.398)$ & 0.32 \\
\hline Likert scores on self-efficacy & 0.024 & $(-0.152-0.201)$ & 0.98 \\
\hline Likert scores on perceived efficacy & 0.237 & $(0.043-0.432)$ & 0.06 \\
\hline Likert scores on intention & 0.089 & $(-0.077-0.255)$ & 0.52 \\
\hline $\begin{array}{l}\text { Fraction of correct answers on health } \\
\text { monitoring time }\end{array}$ & 0.019 & $(-0.053-0.091)$ & 0.89
\end{tabular}




\section{Chapter 7}

\section{Education on tick bite and Lyme borreliosis prevention, aimed at schoolchildren in the Netherlands: comparing the effects of an online educational video game versus a leaflet or no intervention}

Published as:

Beaujean DJ, Gassner F, Wong A, van Steenbergen JE, Crutzen R, Ruwaard D. Education on tick bite and Lyme borreliosis prevention, aimed at schoolchildren in the Netherlands: comparing the effects of an online educational video game versus a leaflet or no intervention. BMC Public Health 2016 Nov 16;16(1):1163. 


\section{Abstract}

Background: Lyme disease or Lyme borreliosis (LB) is the most common tickborne disease both in the United States and Europe. Children, in particular, are at high risk of contracting LB. Since child-specific educational tools on ticks, tick bites and LB are lacking, we developed an online educational video game. In this study, we compared the effectiveness of said online educational video game versus a newly developed leaflet aimed to improve prevention of tick bites and LB among Dutch schoolchildren.

Methods: A total of 887 children, aged 9-13 years and attending the two final years of primary schooling, were recruited from 25 primary schools in June and July 2012. They were assigned through cluster randomization to one of three intervention groups: 'game' (22.4\%), 'leaflet' (35.6\%) or 'control' (41.9\%). Prior to and directly following intervention, the children were asked to complete a short questionnaire. The main outcome measures were knowledge, perception (perceived susceptibility and importance) and preventive behavior in relation to tick bites and LB. Generalized linear mixed models were used to analyze the data.

Results: In the game group, the leaflet group and the control group, knowledge about ticks and tick bites improved significantly. The game was also an effective tool for improving preventive behavior; the frequency of checking for ticks increased significantly. However, there were no significant differences in knowledge improvement between the interventions. The game outperformed the leaflet in terms of improving preventive behavior, whereas the frequency of tick checks increased significantly. But this frequency didn't increase more than in the control group.

Conclusions: The positive knowledge effects observed in the control group suggests the presence of a mere measurement effect related to completion of the questionnaire. The game did not outperform the leaflet or control group on all outcome measures. Therefore, the game may be of value as a complementary role, in addition to other media, in child-specific public health education programs on ticks and LB. This trial was retrospectively registered on October 21 , 2016 (trial registration number: ISRCTN15142369).

\section{Background}

Lyme borreliosis (LB), also known as Lyme disease, is caused by different Borrelia species from the Borrelia burgdorferi sensu lato group, which in Europe is transmitted by the tick Ixodes ricinus. The most common clinical manifestation of LB is erythema migrans (EM), a characteristic rash expanding from the site of the tick bite, which may appear some days to weeks following infection, and is 
sometimes accompanied by systemic flu-like symptoms. Late and more serious LB can present as a multisystemic disease with skin, neurological, cardiac and musculoskeletal manifestations (such as arthritis) [35].

Lyme disease or LB is the most commonly reported tick-borne disease in both the United States (US) and Europe. Since recording of LB began in 1991 by the Institution of Nationally Notifiable Diseases Surveillance System in the US, there has been a consistent increase in the number of annually reported cases. In 2014, it was the fifth most common notifiable disease in the US. In that year, over 25,000 confirmed cases and 8,000 probable cases were reported to the Centers for Disease Control and Prevention (CDC), although recent data suggest that an estimated 300,000 people in the US are diagnosed with LB annually [35]. Despite substantial efforts to control LB in recent decades, it is still the most prevalent tick-borne disease in the temperate regions of the northern hemisphere. Incidence rates in Europe are lower in northern Europe compared to the southern parts of Central Europe, ranging from less than one case to around 350 per 100,000 population [136]. These numbers are likely an underestimate since case reporting is inconsistent and many infections go undiagnosed [74, 124].

In the Netherlands, a repeated retrospective study among general practitioners (GPs) has shown a continuing and strong increase in consultations for tick bites between 1994 (33,000) and 2009 (93,000) [81]. In 2007, more than one million people in the Netherlands ( $8 \%$ of the total population) suffered a tick bite. This poses a progressive threat to public health. Rizzolli, Stanek and Bacon found that, in Europe, children aged 5-14 years are at the highest risk of contracting LB since their daily life and play routines make them more prone to tick bites [136, 157, 9]. The incidence of tick bites in Dutch children aged 10-19 years was 10,866 per 100,000 population, in the most recent retrospective crosssectional survey in 2007. This incidence exceeded that year's mean incidence of 7,198 tick bites per 100,000 inhabitants among all ages [81]. The Dutch data accords with findings of a LB seroprevalence survey conducted among German children, indicating children as a distinct and vulnerable risk group [56].

Strategies to prevent tick bites and LB have targeted the environment and vertebrate hosts of deer ticks. Other strategies include the avoidance of tickinfested areas, the use of protective clothing (i.e., wearing long-sleeved shirts and trousers, aimed to decrease the area of exposed skin), routine checks of one's body for ticks, and the use of tick repellents on either the skin or clothing. Although numerous prevention strategies are available, which differ in terms of costs, acceptability and effectiveness, uptake of behavioral strategies has been universally poor. Research in endemic areas has demonstrated that despite adequate knowledge about its symptoms and transmission, many people do not actively attempt to reduce their risk of infection [17, 46, 74]. Wearing protective clothing and using insect repellent skin products are less accepted measures, while checking the body and removing ticks are deemed to be more acceptable by the general public in the Netherlands [17]. Corapi concluded in his study that new prevention strategies should aim to increase people's confidence in their 
ability to carry out preventive behaviors, raise awareness of desirable outcomes, and aid in the realization that the necessary skills and resources are available for preventive measures to be taken [46]. Earlier we found that only $18 \%$ of the children were routinely checked for ticks by their parents [18]. De Vries et al. concluded, in their analysis of the determinants of tick inspection by parents, that education programs should clearly indicate how the need for tick inspection should be communicated to children [54]. Therefore, there is an unmet need for educational tools on ticks, tick bites and LB prevention aimed specifically at children. Since online video games are popular among children, both boys and girls, this medium is a potential medium to reach children with information about tick bites and LB [133]. Almost all children between 6 and 12 years play online video games [116]. Previous studies have demonstrated that educational video games improve young people's knowledge, skills, attitudes and behaviors in relation to health [105, 176, 123]. Educational video games are experiential, creating a platform for active learning [154]. Rather than a didactic presentation found in e.g. a leaflet, which requires memorization or assimilation of out-of-context facts, educational video games promote 'situated learning' in which players discover and learn through exploration and experimentation [6, 147]. By helping players see 'the big picture', educational video games may help players make meaningful connections between events, for instance: playing in nature, incur a tick bite, failing to perform a tick check and subsequently becoming ill, versus always performing a tick check after playing in nature and staying healthy. This may increase the likelihood that knowledge and skills attained in the game world will be retained and applied in the real world [154].

The Dutch National Institute for Public Health and the Environment (RIVM) has produced several educational tools on tick bites and LB directed at adults (including a website, a leaflet and a movie), but no tools aimed specifically at children. As part of this study we developed, for the first time, an online educational video game available on the website www.teekcontrol.nl. We investigated the effects of this game on knowledge, perception and behavior in relation to ticks and tick bites. We compared the effectiveness of the game with that of a leaflet, containing the same take-home messages, and a control group in which children received no additional information.

\section{Methods}

\section{Study design \& subjects}

In a pre-intervention study conducted in February-March 2012 ( $t 1$ ), municipal health services (MHS) in the Netherlands contacted primary schools to recruit children (9-13 years, mixed gender and ethnicity) by telephone, e-mail, or advertisement in MHS newsletters. In total, 1,447 children from 40 schools participated in this study by completing a specifically developed and pretested com- 
pact paper questionnaire [18]. This pre-intervention study aimed to examine the knowledge, perceived threat, and perceived importance of protective behaviour in relation to tick bites and their potential consequences. Seventy percent of the children had a good knowledge of ticks and the potential consequences of tick bites. Knowing persons who personally got ill after a tick-bite was associated with a good knowledge score and leads to higher susceptibility and better appreciation of the need for body checks. Perceived severity was associated with a good knowledge score and with knowing persons who got ill after a tick-bite. Based on the results of this study, we concluded that it seemed to be useful to focus in future health education regarding ticks and tick-borne diseases on children besides parents.

In June and July 2012 (t2), study participants were recruited by contacting children of the two final grades (grade 7 and 8) from the 40 primary schools who had participated in the pre-intervention survey (Table 7.1). Twenty-five out of the 40 schools involved in the pre-intervention study at $t 1$, participated again at t2. We have no information about the reasons for those schools that were lost to follow-up. Children of the 25 schools were randomly assigned per class to either the intervention groups 'game' or 'leaflet', or to the control group. To ensure that schools were spread out evenly across the Netherlands a cluster randomization sampling design was used. The Netherlands was divided into regions, which allowed sampling of schools per region and then random selection of classes per school.

Children either: played the game individually on a personal computer (game group); read a leaflet containing similar information as the game (leaflet group); or received no information (control group). Directly following the intervention $(t 2)$, the children completed questionnaire 2 (Annex 1). Ninety percent of the children (887/981) who participated in the pre-intervention study at $t 1$, participated again at $t 2$. Absence due to illness was the most important reason for loss to follow-up. Since the children completed the questionnaire anonymously at $t 1$, they were grouped per class to enable comparative analysis of $t 1$ and $t 2$. Questionnaire 2 at $t 2$ included the same questions as the questionnaire at $t 1$ (pre-intervention study) complemented with questions about the appreciation of the intervention for the intervention groups.

\section{Intervention materials}

We developed an online educational video game www.teekcontrol.nl, based on the results of the pre-intervention study [18]. The scenario of the online educational video game www.teekcontrol.nl is that the player drives around in one's own neighborhood (selected by entering their postal code) and is then faced with different fictive risky situations for tick bites. An example of such a risky situation is children playing in nature and picking flowers in the bushes. The player has to chase tick bite cases across a map as quickly as possible, and while doing so emit warnings that encourage people to check for ticks. The faster 
TABLE 7.1: Study design

\begin{tabular}{|c|c|c|c|c|c|c|}
\hline \multirow[t]{2}{*}{ Date } & \multicolumn{2}{|c|}{ Total number } & \multicolumn{4}{|c|}{ Total number included in analysis } \\
\hline & Schools & Children & Schools & Children & & \\
\hline $\begin{array}{l}t 1^{*} \\
\text { February-March } 2012 \\
\text { Questionnaire } 1\end{array}$ & 40 & 1447 & 25 & $\begin{array}{l}981 \\
\text { Game } \\
\text { group }^{* *} \\
254\end{array}$ & $\begin{array}{l}\text { Leaflet } \\
\text { group }^{* *} \\
328\end{array}$ & $\begin{array}{l}\text { Control }{ }^{* *} \\
\text { group } \\
399\end{array}$ \\
\hline $\begin{array}{l}t 2 \\
\text { June-July } 2012 \\
\text { Questionnaire } 2\end{array}$ & 25 & 887 & 25 & $\begin{array}{l}887 \\
\text { Game } \\
199 \\
(78.3 \%)\end{array}$ & $\begin{array}{l}\text { Leaflet } \\
316 \\
(96.3 \%)\end{array}$ & $\begin{array}{l}\text { Control } \\
372 \\
(93.2 \%)\end{array}$ \\
\hline
\end{tabular}

${ }^{*}$ Pre-intervention study [18]

** Only $t 1$ participants whose school also participated at $t 2$ were included for analysis

the warning is emitted, the more points they earn. It is possible to play the video game individually, or in a league to become the best tick controller in town. At the end of the game, the children obtain their total score. They get the opportunity to inform their own parents (or responsible adult / guardian / carer) of their game results by sending an automatically generated e-mail about the score. This e-mail also includes information on ticks and LB for the parents. In addition, it is possible to share an automatically generated message via Facebook, Twitter and Hyves (the latter was a now defunct Dutch social network site), indicating you have played the game.

The leaflet was also specifically developed by RIVM for this study and explains to children in simple language and clear pictures what ticks look like, where and how they live, where they bite on the body and when it is important for them to ask parents to (help self-)check for ticks (Annex 2). The core lessons of the leaflet and the game are the same, bar the mode of delivery.

In a similar vein to the pre-intervention study [18], the game and the leaflet focus on determinants of preventive behavior in accordance with the Protection Motivation Theory [120, 42]. This theory posits that a 'threat appraisal' is formed by an individual based on the perceived likelihood of a particular event (denominated here as 'perceived susceptibility') and its perceived severity. In the game we tried to simulate a threat appraisal by allowing the player to drive in one's own neighborhood and making them face different risky situations with potential exposure to ticks. During the game, new risky situations appear in the game-field. The specific characteristics of these risky situations are also described point by point next to the game-field, thereby allowing players to recognize these situations in reality too. This is the first objective of the game: to teach children to identify risky situations with potential exposure to ticks.

The second objective is to teach children the right coping appraisal. From the pre-intervention study at $t 1$ it is known that only $18 \%$ of the children were, at that 
time point, routinely checked for ticks by their parents after 'high-risk outings'. In the game, we tried to influence this coping appraisal by stimulating the players to alert others about the need to perform a tick check as soon as possible after a visit to an area with a high tick concentration. The faster the player reaches a tick bite situation and then emits 'the tick check alert', the more points that are earned. Herewith, the right coping appraisal (i.e., request a tick check from a parent after having been in an area with a high potential for exposure to ticks) is rewarded in the game [84]. In the leaflet these two lessons are elaborated in text and pictures (Annex 2).

\section{Questionnaires}

The developed questionnaires were pretested among a sample of primary schoolchildren similar to our target group, and amended slightly as a result. Since our subjects are primary schoolchildren, the questions have to be limited in number and easily understood by children. Answers were presented as two or three options, text was limited to short sentences, and images were used when possible. We included the following constructs: knowledge (assessed by asking 7 questions on tick ecology, basic prevention, and tick bites); perceived susceptibility (asking the respondents whether they think they could personally become ill after a tick bite); an additional proxy for perceived susceptibility (asking whether the respondent personally knows someone who became ill after a tick bite); perceived importance of preventive behavior as a proxy for response efficacy (asking whether the respondent thinks tick-checks are important), and actual preventive behavior (asking for the frequency of tick checks performed by the respondent's parent(s)).

Furthermore, children were asked whether they had been given previous classroom lectures on ticks. Teachers handed out the questionnaires, which were completed in the classroom, and they were returned to RIVM by mail.

This general survey among a sample of healthy children from the general population did not require formal medical ethical approval according to Dutch law [33].

\section{Analyses}

We analyzed whether the game and the leaflet affect knowledge, perception and behavior in relation to ticks, tick bites and LB compared to the control group. Table 7.2 summarizes the design for this evaluation.

Our main interest was any intervention effect for the game group, $y_{G 2}-y_{G 1}$, and for the leaflet group, $y_{L 2}-y_{L 1}$. Any observed difference $y_{C 2}-y_{C 1}$ in the control group was used to determine whether there are learning effects and therefore mere measurement effects of only completing the questionnaires. In the presence of learning effects we considered a differences-in-differences (DID) 
TABLE 7.2: Study design

\begin{tabular}{|lll|} 
Game & $\boldsymbol{t} \mathbf{1}^{*}$ & $\boldsymbol{t} 2$ \\
Leaflet & $y_{G 1}$ & $y_{G 2}$ \\
Control & $y_{L 1}$ & $y_{L 2}$ \\
$y_{C 1}$ & $y_{C 2}$ \\
\hline
\end{tabular}

* Pre-intervention study [18]

$Y_{G 1}$ and $Y_{G 2}=$ intervention effect of game on $t 1$ and $t 2$, respectively

$Y_{L 1}$ and $Y_{L 2}=$ intervention effect of leaflet on $t 1$ and $t 2$, respectively

$Y_{C 1}$ and $Y_{C 2}=$ effect in control group on $t 1$ and $t 2$, respectively

design $^{1}$, by adjusting the differences $y_{G 2}-y_{G 1}$ and $y_{L 2}-y_{L 1}$ for the difference $y_{C 2}-y_{C 1}$. This gives us an estimate for the intervention effects that is adjusted for learning effects.

For our statistical analysis, we included only children whose school participated both at $t 1$ and $t 2$. This selection of individuals makes it more plausible that any differences that may arise are the result of the difference in interventions, rather than any school-specific effects. From the pre-intervention study we concluded that substantial differences in knowledge of ticks exist between schools and therefore children [18].

Generalized linear mixed models (GLMM) were applied to analyze the intervention effects, whilst taking into account that the data are clustered [110]. Clusters are present in our data on two levels. First, children within the same class are likely to have a similar knowledge level, and therefore knowledge scores within classes are likely to be correlated. Second, the knowledge level of a child at $t 2$ depends on the initial knowledge level of this child at $t 1$.

We chose to dichotomize our responses, and used a GLMM assuming a Bernoulli distribution and logit link (i.e., logistic regression with random effects $)^{2}$. The knowledge level response was operationalized as a binary variable, by considering a minimum of 6 out of 7 questions correctly answered as sufficient, and insufficient otherwise (reference category) ${ }^{3}$. For the other responses, we defined the classes as follows: knowing other persons with Lyme - 'yes' versus 'no'/'don't know' (reference), becoming ill after a tick bite (susceptibility) - 'yes' versus 'no'/'don't know' (reference), importance of checking 'very'/'somewhat' versus 'not important' (reference), and frequency of checks 'very often'/'sometimes' versus 'not at all' (reference). For the questions related to knowing other persons with Lyme, and becoming ill after a tick bite, 'no' and

\footnotetext{
${ }^{1}$ This is not a 'traditional' DID design in the sense that individual children could not be identified. Rather, schools were identifiable, so the DID design was applicable on a grouped level (i.e., schools).

${ }^{2}$ This was done for simplification purposes. The statistical software R was used in this study. We were not aware of any (non-Bayesian) package supporting the modelling of a response with three or more classes, whilst taking into account multiple random effects.

${ }^{3}$ The reason why this bar was set so high was that children scored that high at the knowledge level in the study at $t 1[18]$.
} 
'don't know' were pooled together because they both reflect, to varying degrees, the fact that respondents could not confirm the question. For the importance and frequency of checks, the categorization was chosen to see whether the intervention affected the proportion of individuals that take the risk of Lyme disease serious.

To address the sensitivity of our findings to this categorization, we also performed the analysis using an alternative categorization: becoming ill after a tick bite - 'yes' versus 'no' (leaving 'don't know' out), knowing other persons with Lyme - 'yes' versus 'no', importance of checking - 'very' versus 'somewhat'/'not important', and frequency of checks - 'very often' versus 'sometimes' /'not at all'. In most cases, we found that the results did not alter - with the exception of the check frequency, which will be discussed in the results below.

Three types of GLMM models were applied: (1) a model to estimate treatment effects in $t 2$ versus $t 1$, (2) a model to estimate the difference in intervention effects between the game and leaflet groups, and (3) a model to estimate the intervention effects conditional on the covariate values ('knowing somebody with Lyme', and 'having had classroom lecture on ticks'). The rationale behind these models is as follows. In Model 1, we examined whether there exists any intervention effect at all for each group, without taking potential confounding into account. The assumption is made here that if a true effect exists, then this should already become apparent in this model because confounding over time (e.g., children might know more persons with Lyme disease in $t 2$ than in $t 1$ ) within a group is relatively modest. And if such an effect is found, we applied Model 2 to determine whether this effect remained after adjusting for confounding over time, and whether this effect was sustained between groups after adjusting for differences in confounders between groups (e.g., one group might have had more classroom lectures on ticks than another). In particular, we were interested whether the game and leaflet groups performed better than the control group, and whether the game and leaflet groups performed differently from each other. Furthermore, based on an effect in Model 1, one might wonder whether this effect differs between subpopulations (e.g., the effect may be smaller for children who received classroom lectures on ticks), and if this difference exists, whether the difference varies by intervention group. To further describe these models, we introduce some mathematical notation. First, we define the intervention group $Z$ as the group having been exposed to a specific intervention; $Z$ can either be the game group, leaflet group or control group (i.e., no intervention at all). Let $Z_{i j}$ be the group to which individual $i$ in class $j$ belongs. Furthermore, let $p_{i j}$ be the probability of a success (e.g., a high knowledge score), $T_{i j}$ the point of time and $x_{i j k}$ the $k^{\text {th }}$ covariate respectively. $T_{i j}=0$ refers to the baseline measurement, where all individuals are unexposed (because the leaflet was developed specifically for this study and not available anywhere). $T_{i j}>0$ refers to the time points in which the game and leaflet groups become exposed to the intervention, but the control group remains unexposed. $T_{i j}$ can be either 1 or 2 . Note that we did not consider random effects on individual level in 
these models, for simplicity. It was not feasible to include models that take into account such random effects. Between-class variation was considered more important than between-person variation based on examination of the data.

\section{Model 1: Treatment effects $t 2$ versus $t 1$}

$$
\log \left(\frac{p_{i j}}{1-p_{i j}}\right)=\left(\alpha_{0}+a_{0 j}\right)+\left(\alpha_{1}+a_{1 j}\right) T_{i j},
$$

where $a_{0 j}$ and $a_{1 j}$ are a random intercept and random slope for classes, respectively. $\alpha_{1}$ provides the intervention effect for an individual (which can be interpreted as changes in $p_{i j}$ on a logit scale per individual between $t 2$ and $t 1$ ). This model was fitted separately per intervention group $Z$, and for all outcomes.

\section{Model 2: Differences in intervention effects between intervention groups}

$$
\begin{aligned}
\log \left(\frac{p_{i j}}{1-p_{i j}}\right)= & \left(\beta_{0}+b_{0 j}\right)+\left(\beta_{1}+b_{1 j}\right) T_{i j}+\beta_{2} Z_{i j}+\beta_{3} G_{i j} T_{i j} \\
& +\sum_{k} \beta_{k} x_{i j k}+\sum_{k} \beta_{k+m} x_{i j k} T_{i j} .
\end{aligned}
$$

Here, $\beta_{1}$ provides the intervention effect for the reference group (game group), $\beta_{2}$ the difference between intervention groups at baseline, and $\beta_{3}$ the difference in intervention effects between intervention groups at $t$. Here, we are mainly interested in $\beta_{3} . \beta_{k}$ and $\beta_{k+m}$ represent the influence of confounding covariate $k$, but are not of interest. This model was fitted across all intervention groups. This model was considered for all outcomes. Covariates used were 'knowing somebody with Lyme', and 'having followed classes on tick bites'.

\section{Model 3: Conditional intervention effects}

$$
\log \left(\frac{p_{i j}}{1-p_{i j}}\right)=\left(\gamma_{0}+c_{0 j}\right)+\left(\gamma_{1}+\gamma_{1 j}\right) T_{i j}+\sum_{k} \gamma_{k} x_{i j k}+\sum_{k} \gamma_{k+m} x_{i j k} T_{i j} .
$$

Here, $\gamma_{k+m}$, gives the intervention effect conditional on $x_{k}$. This model is fitted separately per intervention group $Z$. This model was considered for all outcomes. Covariates that were considered are 'knowing somebody with Lyme', and 'having had classroom lecture on ticks'. 
TABLE 7.3: Descriptive statistics and effects per intervention group over time, based on Model 1

\begin{tabular}{|c|c|c|c|c|c|c|c|c|c|}
\hline & \multicolumn{3}{|l|}{$t 1$} & \multicolumn{3}{|l|}{$t 2$} & \multicolumn{3}{|c|}{ Difference $t 2-t 1$} \\
\hline & $\begin{array}{l}\text { Game } \\
(n=254)\end{array}$ & $\begin{array}{l}\text { Leaflet } \\
(n=328)\end{array}$ & $\begin{array}{l}\text { Control } \\
(n=399)\end{array}$ & $\begin{array}{l}\text { Game } \\
(n=199)\end{array}$ & $\begin{array}{l}\text { Leaflet } \\
(n=316)\end{array}$ & $\begin{array}{l}\text { Control } \\
(n=372)\end{array}$ & $\begin{array}{l}\text { Game } \\
(n=199)\end{array}$ & $\begin{array}{l}\text { Leaflet } \\
(n=316)\end{array}$ & $\begin{array}{l}\text { Control } \\
(n=372)\end{array}$ \\
\hline $\begin{array}{l}\text { \% of respondents with a } \\
\text { knowledge score } \geq 6 / 7 \\
\text { (knowledge items correct) }\end{array}$ & 70.0 & 72.3 & 69.2 & 88.0 & 95.6 & 85.8 & $\begin{array}{l}18.0 \\
p<0.001\end{array}$ & $\begin{array}{l}23.3 \\
p<0.001\end{array}$ & $\begin{array}{l}16.6 \\
p<0.001\end{array}$ \\
\hline $\begin{array}{l}\text { \% of respondents that } \\
\text { perceived that they are } \\
\text { personally susceptible for } \\
\text { illness after a tick bite } \\
\text { (1st item for perceived } \\
\text { susceptibility) }\end{array}$ & 68.1 & 67.7 & 71.0 & 78.9 & 71.1 & 60.4 & $\begin{array}{l}10.8 \\
p=0.08\end{array}$ & $\begin{array}{l}3.4 \\
p=0.29\end{array}$ & $\begin{array}{l}-10.6 \\
p=0.05\end{array}$ \\
\hline $\begin{array}{l}\% \text { of respondents that } \\
\text { personally knows } \\
\text { someone with illness after } \\
\text { tick bite ( } 2 \text { nd item for } \\
\text { perceived susceptibility) }\end{array}$ & 20.2 & 26.2 & 30.0 & 20.3 & 33.5 & 30.2 & $\begin{array}{l}0.1 \\
p=0.97\end{array}$ & $\begin{array}{l}7.3 \\
p=0.18\end{array}$ & $\begin{array}{l}0.2 \\
p=0.81\end{array}$ \\
\hline $\begin{array}{l}\text { \% of respondents that } \\
\text { regards tick checks as } \\
\text { 'somewhat' or 'very } \\
\text { important' }\end{array}$ & 90.9 & 91.5 & 94.5 & 94.9 & 91.8 & 96.1 & $\begin{array}{l}4.0 \\
p=0.35\end{array}$ & $\begin{array}{l}0.3 \\
p=0.77\end{array}$ & $\begin{array}{l}1.6 \\
p=0.66\end{array}$ \\
\hline $\begin{array}{l}\% \text { of respondents checked } \\
\text { for tick bites occasionally } \\
\text { or every time after } \\
\text { playing in green areas }\end{array}$ & 55.1 & 67.1 & 76.4 & 68.5 & 67.3 & 82.7 & $\begin{array}{l}13.4 \\
p=0.02\end{array}$ & $\begin{array}{l}0.2 \\
p=0.98\end{array}$ & $\begin{array}{l}6.3 \\
p=0.24\end{array}$ \\
\hline
\end{tabular}

In bold: statistically significant values 


\section{Results}

Table 7.3 shows the descriptive statistics for each outcome variable at $t 1$ and $t 2$. At $t 1$, most respondents in all groups find tick checks important, ranging from 90.9 to $94.5 \%$. All respondents had a high knowledge score ( $\geq 6 / 7$ knowledge items correct), ranging from $69.2 \%$ to $72.3 \%$. The differences across groups at $t 1$ are relatively small, with the exception of the percentage of respondents checking for tick bites; this ranged from $55.1 \%$ in the game group to $76.4 \%$ in the control group. The percentages are higher across nearly all outcome variables (depicted in the last three columns of Table 7.3), although the increase for the knowledge score is substantially higher $(16.6 \%$ to $23.3 \%$ across all intervention groups). Using Model 1, we tested whether these treatment effects were significant. The respondents in the two intervention groups and the control group had a significant better knowledge ( $\geq 6 / 7$ questions answered correctly) at $t 2$ than at $t 1$ ( $p<0.001)$. Three questions seem to be relatively difficult, namely estimating tick size $(78.3 \%$ to $84.7 \%$ correct), knowing the location of ticks in vegetation (61.6\% to $72.8 \%)$, and knowing where ticks bite (71.3\% to $79.6 \%)$ (Annex 3). Unsurprisingly, these items showed the biggest intervention effects, since these are also the items where the largest gain could be achieved. These differences were found to be statistically significant (based on Model 1). Also statistically significant were improvements in knowledge for estimation of tick size in the leaflet group (12.9\%), and knowing where on the body ticks bite for the game and leaflet group $(12.1 \%$ and $17.1 \%$, respectively).

Furthermore, the frequency of reported tick checks increased significantly in the game group ( $p=0.02$ ).In sensitivity analysis (using 'very often checking' versus 'no/sometimes checking' definition) this effect was no longer significant. Other outcomes were not analyzed further in Model 2 and 3, since in Model 1 no other intervention effects were identified.

To identify any differences in intervention effects between the groups, we estimated Model 2 (Table 7.4). This was only done for the knowledge and the tick-check frequency outcomes, since there were no significant effects found for the outcomes perceived susceptibility and tick-check importance (Table 7.3). In Model 2 we adjusted the knowledge outcome (based on sum score) and the tick check frequency for the confounders 'knowing somebody with Lyme' and 'having had a classroom lecture on ticks'. The parameter estimates that are of interest are $t 2$ and the interactions $t 2 \times$ leaflet and $t 2 \times$ control.

For knowledge (based on sum score) the main effect $t 2$ is significant but the interaction $t 2 \times$ control is not significant, which suggests that the increase in knowledge purely comes from a learning effect. In Annex 4 these interactions are presented for the three knowledge questions that demonstrated the biggest effects. The interaction $t 2 \times$ control is positive and significant for preferred location in vegetation and bite site on body, suggesting that the game intervention increased participants' knowledge for these two items more compared to the control group. This interaction is not significant for tick size, which suggests that 
the increase in knowledge on tick size purely comes from the aforementioned learning effect.

The interaction $t 2 \times$ leaflet is only positive and significant for the tick size outcome, which suggests that the leaflet performs better than the game in terms of informing the respondents on that aspect. Since $t 2 \times$ control is not significant for this outcome, it seems that the leaflet group performed better than both the game and control group.

For tick-check frequency, the interaction $t 2 \times$ leaflet is positive and significant (Table 7.4), suggesting the game improved the tick-check frequency more than the leaflet. The interaction $t 2 \times$ control is not significant, however, which suggests that the increase in tick-check frequency is a learning effect.

Finally, in a third model we analyzed whether the intervention effects on knowledge and on tick-check frequency might be influenced by the confounders 'Knowing somebody with Lyme' and 'Having had classroom lecture on ticks' [18]. These were not significant for all outcome variables, suggesting that they may only affect knowledge level and tick-check frequency in general, but not the effects of the interventions (Annexes 5 and 6).

TABLE 7.4: Differences in intervention effects on knowledge and tick check frequency between intervention groups and control group after adjusting for confounders (knowing somebody with Lyme and having had lectures on ticks), based on Model 2

\begin{tabular}{|c|c|c|c|c|c|c|}
\hline & \multicolumn{3}{|c|}{ Knowledge } & \multicolumn{3}{|c|}{ Tick check frequency } \\
\hline & $\bar{\beta}$ & S.E. & $p$-value & $\overline{\boldsymbol{\beta}^{*}}$ & S.E. & $p$-value \\
\hline (Intercept) & 0.522 & 0.265 & 0.049 & -0.034 & 0.241 & 0.886 \\
\hline$t 2$ (reference: $t 1$ ) & 1.430 & 0.310 & 0.000 & 0.599 & 0.252 & 0.017 \\
\hline Leaflet (reference: game) & 0.232 & 0.337 & 0.499 & 0.624 & 0.305 & 0.052 \\
\hline Control group (reference: game) & 0.032 & 0.330 & 0.924 & 1.040 & 0.305 & 0.002 \\
\hline Knowing somebody with Lyme & 0.604 & 0.178 & 0.001 & 0.710 & 0.178 & 0.000 \\
\hline Having had lectures on ticks & 0.535 & 0.184 & 0.004 & 0.215 & 0.176 & 0.222 \\
\hline$t 2 \times$ Leaflet & 0.735 & 0.409 & 0.072 & -0.601 & 0.291 & 0.039 \\
\hline$t 2 \times$ Control & -0.532 & 0.335 & 0.112 & -0.347 & 0.298 & 0.244 \\
\hline$t 2 \times$ Knowing somebody with Lyme & -0.022 & 0.316 & 0.946 & -0.270 & 0.253 & 0.286 \\
\hline$t 2 \times$ Having had lectures on ticks & -0.380 & 0.289 & 0.188 & 0.035 & 0.241 & 0.883 \\
\hline
\end{tabular}

In bold: statistically significant values

*Beta refers to the regression coefficient from the GLMM model. If for a given covariate Beta is greater (smaller) than zero, and the corresponding $p$-value is significant, then the covariate is positively (negatively) associated with the outcome (either knowledge or tick check frequency). If the Beta is not significant, then no evidence of an association between covariate and outcome was found. 


\section{Discussion}

We can conclude from the results of this study that both the game and the leaflet interventions had a positive effect on the children in terms of improving the prevention of tick bites and LB. This is in line with a recent study of Shadick et al. who showed that a short in-class LD education program based on social learning theory impacted a child's knowledge, attitude, and preventive behavior [146]

Model 1 showed the effects of the interventions. Although the knowledge level of the children was already high before, at the pre-intervention measurement $(t 1)$, overall knowledge improved significantly for all three groups (i.e., game, leaflet, control). In addition, the frequency of checks for ticks increased significantly in the game group.

In terms of knowledge improvement, it appears the leaflet performs better than the game in informing children about the typical size of ticks. This can probably be explained by the presentation of the tick size: in the game, the tick was pictured as a humorous illustration of a small black spider, while in the leaflet it was an image of a tick drawn to real size. In retrospect, we realized that the children in the game group were therefore informed incorrectly about the size of a tick. This is a pitfall of developing computer games (for children); it has to be educational and veracious, but at the same time it has to be sufficiently attractive and entertaining to be able to compete with other games and retain the player's attention to complete the game. As Thompson stated in his paper about the role of educational video games in obesity prevention: "this game genre has the formidable task of achieving a balance between 'fun-ness' (i.e., components that entertain, such as animation, storyline, sound effects) and 'serious-ness' (i.e., the components that promote behavior change, such as goal setting, problem solving)" [169]. This is linked to the current debate on how enjoyable games for health should be in order to be effective. On the one hand, it has been argued that health games (or, more broadly, educational games) will not be effective if they provide insufficient enjoyment; precisely because of this, fundamentally they do not differ from entertainment games in terms of game type, design, or dissemination strategy. On the other hand, it has been argued that educational games should not compete with entertainment games in terms of enjoyment, but instead with its analogous alternative (e.g., school curricula, behavior change interventions delivered in other settings) [51]. In the future the game can be improved by using an image of a tick drawn to real size.

In terms of tick checks, it appeared that at the pre-intervention measurement $(t 1)$, only $18 \%$ of the children were routinely checked by their parents after potential exposure to ticks [18]. In the game group the frequency of tick checks increased significantly; the percentage of respondents that checked or were checked for tick bites occasionally or every time after playing in green areas increased from $55.1 \%$ to $68.5 \%(13.4 \%, p=0.02)$. Since the percentage of respondents checking for tick bites was lowest in the game group, there also the largest gain could be achieved. In the sensitivity analysis, using the definitions 
'checking very often' versus 'no checking/checking sometimes', this effect was no longer statistically significant. This suggests that the game had a clear effect on the children who did not check before the game, but did not influence (positively nor negatively) those who already checked sometimes or frequently.

Model 2 showed the differences in intervention effects between the intervention groups and the control group after adjustment for the confounders 'knowing somebody with Lyme' and 'having had lectures on ticks'. With this model we could not demonstrate significant differences in knowledge improvement between the game, the leaflet or the control groups. The game was better than the leaflet in improving preventive behavior, but no better than the control. These positive effects observed in the control group suggest the existence of a 'learning effect' of completing the questionnaire. Children may improve their knowledge and behavior by simply completing the questionnaire, and possible looking up the correct answers afterwards (by looking on the internet, or discussing the questions in the classroom with the teacher and/or other children or their parents). Evidence indicates that receiving a questionnaire about a behavior increases the likelihood that the person will perform that behavior. This is known as the mere measurement effect [65] and suggests that even a simple questionnaire can result in changes in knowledge and preventive behavior (frequency of ticks checks). In response to this effect, we think it would be a promising idea to add a 'ticks and Lyme quiz' to the available tools for public health education (in schools).

Papastergiou concluded in her literature review about the potential of computer and video games for health education that computer gaming is more appealing than, and at least as effective as, conventional instructional media in positively influencing health-related knowledge, attitudes and behaviors. She suggested that this perhaps indicates that games should be viewed as a complement to other media within health education programs [123].

This study has some noteworthy restrictions. It should be noted that only children attending the two final years (grade 7 and 8) of primary school participated in this study. Thus, we can only derive conclusions for the effect of the online educational game in the age range 9-13 years. Future research could investigate the potential effects of the game on children of other age groups.

A limitation of the study at hand is that the baseline measurement $(t 1)$ was conducted two months before participants were exposed to the actual interventions. Changes might have happened in this period between measurement and exposure. However, we do not expect these changes to affect differences between groups, as only after this period participants were randomized to the different intervention groups. Nevertheless, in future studies it would be warranted to conduct baseline measurement just before actual exposure to the intervention. In this study, schoolchildren were allocated randomly to the game, leaflet or control groups. In real life, children can often decide themselves which educational tool they choose. Some children like to play a game, while others may prefer to read a leaflet. We asked the children what they feel the preferred method for 
education on tick bites should be. In all groups, a video game was most popular, followed by explanation by a teacher. Therefore, it is feasible that some of the children played the game or read the leaflet against their preference. This might have reduced the effects of the tools. This fits in with the conclusion of Schulz et al. that the best kind of intervention may depend on personal preferences, so called 'preference-based tailoring' [142].

Finally, the intervention in this study was aimed at children and therefore we asked the children, and not the parents, pre-intervention and post-intervention whether their parents performed a tick check. A survey of the parents of the participants could potentially have enriched the study, to determine the influence of the children on their parents' knowledge, perception and preventive behavior regarding ticks and tick bites.

\section{Conclusion}

This is the first online educational video game on ticks and tick bites. The game is effective in improving knowledge and preventive behavior regarding ticks and tick bites. However, it did not outperform the leaflet or control groups on all outcome measures. The positive effects observed in the control group suggest the existence of a mere measurement effect related to completion of the study questionnaire. Nevertheless, the educational video game can play a complementary role to other media within the health education program on ticks and LD aimed at children

\section{Annex 1: Questionnaire}

In the pre-intervention study at $t 1$, questions 1-13 were asked. At $t 2$, questions 1-24 were asked in the game group, 1-23 in the leaflet group, and questions 1-13 and 22 in the control group.

What is your first name?

Girl / boy

What age are you?

In which class are you?

1. Did you ever receive classroom lectures about ticks?
(a) Yes
(b) No

2. What does a tick look like?

(a) Image: Silhouette of an ant

(b) Image: Silhouette of a tick 
(c) I don't know

3. What is the real size of a tick that could bite you?
(a) Image: poppy-seed size black dot
(b) Image: pea size black dot
(c) I don't know

4. At what sort of place would you expect to encounter ticks?
(a) Color image of path in a forest
(b) Color image of sand-covered playground
(c) I don't know

5. Why should you watch out for ticks?
(a) Ticks make you itch
(b) Ticks can make you ill
(c) I don't know

6. At what place do ticks prefer to live?
(a) Up in the trees
(b) Near the ground in brushes and tall grass
(c) I don't know

7. What can you do to prevent tick bites?
(a) Wash carefully to rinse off ticks
(b) Check your clothes and body with an adult and pull out attached ticks
(c) I don't know

8. Which picture shows best where ticks prefer to bite?
(a) Image: child body contours with arrows pointing at nose, chest, hands and toes
(b) Image: child body contours with a rows pointing at ears, armpits crotch and knees
(c) I don't know

9. Do you think that you could personally become ill after a tick bite?
(a) Yes
(b) No
(c) I don't know 
10. Do you consider it important to be checked for tick bites after playing in an area where ticks may live?
(a) Not important
(b) Somewhat important
(c) Very important

11. Do you know someone who has become ill after a tick bite?
(a) Yes
(b) No
(c) I don't know

12. Did you ever do a body inspection for tick bites with your parent or carer?
(a) Never
(b) Occasionally
(c) Every time after a visit to an area where ticks may live

13. Did you ever had a tick bite?
(a) Never
(b) Once
(c) More than once

14. How often did you play the game 'Teekcontrol'?
(a) Never
(b) Once
(c) More than once

15. Did you like the game / leaflet?
(a) The game is not amusing
(b) The game is a bit of amusing
(c) Yes, the game is amusing

16. Is the game / leaflet difficult to play/read?
(a) Difficult
(b) Bit difficult, bit easy
(c) Easy

17. Does it take long time to play the game / read the leaflet? 

(a) Too long
(b) Just long enough
(c) Too short

18. Did you sent the e-mail to your parents / carers at the end of the game?
(a) Yes
(b) No
(c) I don't know

19. Did you send the game to your friends or family?
(a) Yes
(b) No
(c) I don't know

20. If you have send it, how did you do that? (multiple answers possible)
(a) Via E-mail
(b) Via Hyves
(c) Via Facebook
(d) Via Twitter
(e) Via conversation

21. Do you like to play the game / read the leafet (again), for example at home?
(a) Yes
(b) No
(c) I don't know

22. How do you prefer to learn about ticks?
(a) Through game
(b) Through teacher at school
(c) Through leaflet
(d) Through parents/carers

23. What did you learn from the game 'Teekcontrol' / leaflet?

24. Give the game a score between 0 (very bad) and 10 (very good) 


\section{Annex 2: Leaflet}

\section{Waar leeft de teek?}

Teken zitten in het groen. Dus vooral in hoog gras en tussen blaadjes op de grond onder bomen en struiken. Ze zitten vooral in het bos, maar ook in duin, park, hei en tuin. Als je een plantje met een teek erop aanraakt, kunnen ze op je lijf overstappen, en je dan bijten. Van een tekenbeet merk je meestal niets, maar als hij te laat ontdekt wordt kun je er soms ziek van worden.

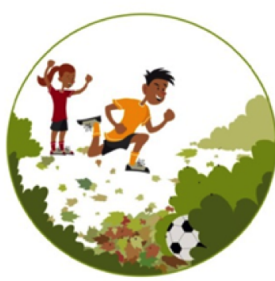

Gelukkig zitten teken niet overal: ze zitten niet op straat, in kort gras, in het zand en in huis.

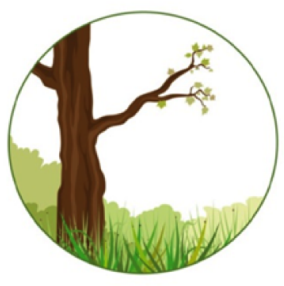

Hoe ziet een teek er uit?

Teken lijken op een klein plat zwart of bruin spinnetje.

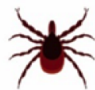

In het echt zijn teken héél klein, zoals een klein moedervlekje. Ze worden pas groter en rond als ze een paar dagen bloed hebben gedronken. Je moet dus goed zoeken om ze op tijd op je huid te vinden.

Ware grootte: .

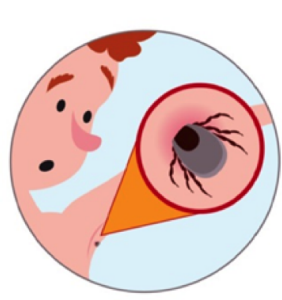

\section{Een tekencontrole doen}

$\checkmark$ Na het spelen in het groen: vraag je je ouders of een andere volwassene dezelfde dag een tekencontrole te doen

$\checkmark$ Een tekenbeet doet geen pijn en zit soms goed verstopt

$\checkmark$ Laat een vastgebeten teek zo snel mogelijk uit je huid trekken wat jij weet over de teek, en wanneer je samen een tekencontrole moet doen. Kijk op de website:

www.rivm.nl/tekenbeet 
Annex 3: Descriptive statistics for 7 knowledge questions per intervention at $t 1$ and $t 2$

\begin{tabular}{|c|c|c|c|c|c|c|c|c|c|}
\hline \multirow[b]{2}{*}{ Knowledge item } & \multicolumn{3}{|c|}{$t 1$} & \multicolumn{3}{|c|}{$t 2$} & \multicolumn{3}{|c|}{ Difference $t 2-t 1$} \\
\hline & $\begin{array}{l}\text { Game } \\
(n=254)\end{array}$ & $\begin{array}{l}\text { Leaflet } \\
(n=328)\end{array}$ & $\begin{array}{l}\text { Control } \\
(n=399)\end{array}$ & $\begin{array}{l}\text { Game } \\
(n=199)\end{array}$ & $\begin{array}{l}\text { Leaflet } \\
(n=316)\end{array}$ & $\begin{array}{l}\text { Control } \\
(n=372)\end{array}$ & $\begin{array}{l}\text { Game } \\
(n=199)\end{array}$ & $\begin{array}{l}\text { Leaflet } \\
(n=316)\end{array}$ & $\begin{array}{l}\text { Control } \\
(n=372)\end{array}$ \\
\hline $\begin{array}{l}\text { Recognising a tick } \\
\text { (\% correct) }\end{array}$ & 88.6 & 89.3 & 83.4 & 98.5 & 98.4 & 93.0 & 9.9 & 9.1 & 9.6 \\
\hline $\begin{array}{l}\text { Estimating tick size } \\
\text { (\% correct) }\end{array}$ & 78.3 & 84.2 & 84.7 & 83.4 & 97.1 & 90.8 & 5.1 & 12.9 & 6.1 \\
\hline $\begin{array}{l}\text { Recognising a typical tick } \\
\text { area (\% correct) }\end{array}$ & 96.8 & 99.1 & 98.7 & 99.5 & 99.7 & 99.7 & 2.7 & 0.6 & 1.0 \\
\hline $\begin{array}{l}\text { Being aware of potential } \\
\text { tick bite consequence } \\
\text { (\% correct) }\end{array}$ & 93.7 & 93.0 & 94.5 & 98.0 & 99.7 & 98.7 & 4.3 & 6.7 & 4.2 \\
\hline $\begin{array}{l}\text { Knowing tick position in } \\
\text { vegetation (\% correct) }\end{array}$ & 72.8 & 65.5 & 61.6 & 91.0 & 91.8 & 68.3 & 18.2 & 26.3 & 6.7 \\
\hline $\begin{array}{l}\text { Knowing how to remove } \\
\text { ticks (\% correct) }\end{array}$ & 86.9 & 85.4 & 83.5 & 96.4 & 96.5 & 94.3 & 9.5 & 11.1 & 10.8 \\
\hline $\begin{array}{l}\text { Knowing where on the body } \\
\text { ticks bite (\% correct) }\end{array}$ & 71.3 & 76.8 & 79.6 & 83.4 & 93.9 & 81.2 & 12.1 & 17.1 & 1.6 \\
\hline
\end{tabular}

In bold: statistically significant differences 
Annex 4: Comparison of differences in intervention effects for the three knowledge questions with the biggest effects, after adjusting for confounders (knowing somebody with Lyme and having had lectures on ticks), based on Model 2

\begin{tabular}{|c|c|c|c|c|c|c|c|c|c|}
\hline & \multicolumn{3}{|c|}{ Tick size } & \multicolumn{3}{|c|}{ Preferred location } & \multicolumn{3}{|c|}{ Preferred bite site } \\
\hline & $\begin{array}{l}\text { Value } \\
\text {. }\end{array}$ & S.E. & $p$-value & Value & S.E. & $p$-value & $\begin{array}{l}\text { Value } \\
\text {. }\end{array}$ & S.E. & $p$-value \\
\hline (Intercept) & 1.050 & 0.275 & 0.000 & 0.709 & 0.235 & 0.003 & 0.626 & 0.309 & 0.043 \\
\hline$t 2$ (reference: $t 1$ ) & 0.562 & 0.306 & 0.066 & 1.570 & 0.319 & 0.000 & 1.130 & 0.290 & 0.000 \\
\hline Leaflet (reference: game) & 0.508 & 0.357 & 0.168 & -0.227 & 0.296 & 0.451 & 0.421 & 0.393 & 0.295 \\
\hline Control group (reference: game) & 0.578 & 0.352 & 0.114 & -0.321 & 0.290 & 0.280 & 0.551 & 0.389 & 0.171 \\
\hline Knowing somebody with Lyme & 0.248 & 0.212 & 0.244 & 0.394 & 0.165 & 0.017 & 0.480 & 0.197 & 0.015 \\
\hline Having had lectures on ticks & 0.445 & 0.228 & 0.051 & 0.111 & 0.171 & 0.515 & 0.675 & 0.215 & 0.002 \\
\hline$t 2 \times$ Leaflet & 1.310 & 0.443 & 0.003 & 0.334 & 0.375 & 0.373 & 0.514 & 0.372 & 0.167 \\
\hline$t 2 \times$ Control & 0.063 & 0.345 & 0.855 & -1.160 & 0.331 & 0.000 & -0.929 & 0.318 & 0.004 \\
\hline$t 2 \times$ Knowing somebody with Lyme & 0.473 & 0.387 & 0.221 & -0.221 & 0.258 & 0.392 & -0.143 & 0.305 & 0.639 \\
\hline$t 2 \times$ Having had lectures on ticks & -0.567 & 0.341 & 0.096 & -0.186 & 0.253 & 0.462 & -0.623 & 0.299 & 0.037 \\
\hline
\end{tabular}

In bold: statistically significant values $p<0.05$ 
Annex 5: Conditional treatment effects on knowledge, after adjusting for confounders (knowing somebody with Lyme and having had lectures on ticks), based on Model 3

\begin{tabular}{|c|c|c|c|c|c|c|c|c|c|}
\hline & \multicolumn{3}{|c|}{ Game } & \multicolumn{3}{|c|}{ Leaflet } & \multicolumn{3}{|c|}{ Control } \\
\hline & Value & S.E. & $p$-value & $\begin{array}{l}\text { Value } \\
\text { Val }\end{array}$ & S.E. & $p$-value & Value & S.E. & $p$-value \\
\hline (Intercept) & 0.461 & 0.383 & 0.228 & 0.883 & 0.238 & 0.000 & 0.498 & 0.166 & 0.003 \\
\hline$t 2-t 1$ & 1.560 & 0.430 & 0.000 & 2.330 & 0.431 & 0.000 & 0.887 & 0.259 & 0.001 \\
\hline Knowing somebody with Lyme & 0.588 & 0.389 & 0.132 & 0.468 & 0.296 & 0.115 & 0.736 & 0.264 & 0.005 \\
\hline Having had classroom lecture on ticks & 0.844 & 0.382 & 0.028 & 0.098 & 0.300 & 0.745 & 0.575 & 0.285 & 0.044 \\
\hline$t 2-t 1$ : Knowing somebody with Lyme & 0.022 & 0.751 & 0.976 & 0.229 & 0.695 & 0.742 & -0.143 & 0.422 & 0.735 \\
\hline$t 2-t 1$ : Clasrooms lectures on ticks & -0.885 & 0.605 & 0.144 & -0.424 & 0.604 & 0.483 & -0.196 & 0.412 & 0.634 \\
\hline
\end{tabular}

In bold: statistically significant values $p<0.05$ 
Annex 6: Conditional treatment effects on tick check frequency, after adjusting for confounders (knowing somebody with Lyme and having had lectures on ticks), based on Model 3

\begin{tabular}{|c|c|c|c|c|c|c|c|c|c|}
\hline & \multicolumn{3}{|c|}{ Game } & \multicolumn{3}{|c|}{ Leaflet } & \multicolumn{3}{|c|}{ Control } \\
\hline & Value & S.E. & $p$-value & Value & S.E. & $p$-value & Value & S.E. & $p$-value \\
\hline (Intercept) & 0.461 & 0.382 & 0.228 & 0.886 & 0.238 & 0.002 & 0.498 & 0.166 & 0.003 \\
\hline$t 2-t 1$ & 1.555 & 0.433 & 0.000 & 2.340 & 0.433 & 0.000 & 0.887 & 0.259 & 0.001 \\
\hline Knowing somebody with Lyme & 0.588 & 0.389 & 0.131 & 0.466 & 0.296 & 0.115 & 0.736 & 0.264 & 0.005 \\
\hline Having had classroom lecture on ticks & 0.844 & 0.381 & 0.027 & 0.094 & 0.299 & 0.753 & 0.575 & 0.285 & 0.044 \\
\hline$t 2-t 1$ : Knowing somebody with Lyme & 0.035 & 0.750 & 0.962 & 0.225 & 0.695 & 0.746 & -0.143 & 0.422 & 0.735 \\
\hline$t 2-t 1$ : Clasrooms lectures on ticks & -0.881 & 0.605 & 0.146 & -0.464 & 0.604 & 0.443 & -0.196 & 0.412 & 0.634 \\
\hline
\end{tabular}

In bold: statistically significant values $p<0.05$ 


\section{Chapter 8}

\section{Prevention of tick bites: an evaluation of a smartphone app}

\section{Submitted:}

Beaujean DJ, Antonise-Kamp L, Crutzen R, van Steenbergen JE, Ruwaard D. Prevention of tick bites: an evaluation of a smartphone app. 


\section{Abstract}

Background: Lyme borreliosis (LB) is the most common reported tick-borne infection in Europe, and involves transmission of Borrelia by ticks. Because a vaccine is not available and effective measures for controlling tick populations are insufficient, LB control is focused on preventive measures to avoid tick bites. To inform citizens about the risk of ticks, motivate them to check for tick bites, and encourage them to remove any attached tick as quickly as possible, a mobile app called 'Tekenbeet' (Dutch for 'tick bite') was released.

Objective: The aim of this study was to evaluate the usage and user satisfaction of the 'Tekenbeet' app and to investigate whether it affects users' knowledge, perceived severity, perceived susceptibility, self-efficacy, response efficacy, current behavior and intention to comply with preventive measures.

Methods: The usage of the app was evaluated with data obtained from Google Analytics. A survey among the Dutch general adult population with two data collection periods evaluated the usage, user satisfaction and its influence on abovementioned outcomes. The usage of the app was also evaluated with data obtained from Google Analytics.

Results: Data obtained from Google Analytics showed the app was downloaded almost 40,000 in the 20 months following the launch. The 'tick radar' and 'tick diary' screens were viewed most often. In addition, a total of 554 respondents completed an online survey. The mean user satisfaction score for the app was 7.44 (on a scale of 1-10) and $90.9 \%$ of respondents would recommend the app to others. On average, survey respondents who downloaded the app $(n=243)$ recorded significantly more often higher knowledge scores (OR 3.37; 95\% CI 2.025.09 ) and had a higher intention to comply with preventive measures (OR 2.47; 95\% CI 1.22-5.85) compared to respondents who did not download the app ( $n=$ $311)$.

Conclusions: The 'Tekenbeet' app is a frequently used, well-appreciated and effective educational tool to increase public knowledge of ticks and tick bites. It also increases the intention to apply preventive measures. The use of smartphones and apps is now commonplace; the 'Tekenbeet' app feeds into this trend and thereby offers a modern day alternative to established formats such as an information leaflet and information provision on the Internet.

\section{Introduction}

Lyme borreliosis (LB) is caused by different Borrelia species, which in Europe are transmitted by the tick Ixodes ricinus. The most common clinical symptom of 
LB is erythema migrans (EM), a characteristic rash expanding from the site of the tick bite, which may appear several days to weeks following infection, and is sometimes accompanied by systemic flu-like symptoms. Progressive LB can develop into a multi-systemic disease with skin, neurological, cardiac and musculoskeletal manifestations [156]. In Western Europe there have been a multitude of ecological changes over the last decades; a huge increase in afforestation, a much stronger growth of vegetation due to increased use of fertilizing agents and a rise in CO2 concentrations, more rainfall and increased humidity levels [63]. This has resulted in improved living conditions for ticks. In the Netherlands, there has been a continuing and strong increase in general practitioner consultations for both tick bites and EM, from 191 to 564 per 100,000 inhabitants between the years 1994 and 2009 [88, 106, 152]. More than one million people ( $8 \%$ of the total Dutch population) sustain a tick bite each year, making LB a serious threat to public health $[81,173]$. Hence there is a genuine need to inform and educate the public about the risks associated with tick bites, especially since the first case of tick-borne encephalitis recently has been diagnosed in the Netherlands.

At present, a vaccine is not available and effective measures for controlling tick populations are not sufficient or are still in the experimental phase. Therefore, a reduction in LB incidence should be focused on preventive behavioral measures for avoidance of tick bites and hence achieving prevention of Borrelia transmission [185, 171, 153]. These behavioral measures consist of the use of protective clothing and/or using repellants initially, then subsequently checking for, and immediately removing any attached ticks after spending time in tick habitats. Conducting such behavioral measures has been found to be an effective and cost-efficient method for LB prevention [52]. The Dutch National Institute for Public Health and the Environment (RIVM) provides information on public health topics for professionals and the general public. This includes a national guideline on the prevention and control of LB for professionals and several educational materials for the general public [135]. An annual media campaign called 'de week van de teek' ('Tick-bite Prevention Week') aims to inform the general public about the health risks associated with tick bites.

Current evidence on the relationship between knowledge on ticks and the application of preventive behavior is conflicting. Gould et al. have found a significant positive correlation between knowledge and protective behavior [67]. However, research by Corapi, in areas where LB is endemic, demonstrated that many people fail to show behavior changes aimed at reducing their risk of LB infection, despite having adequate knowledge about its symptoms and transmission [67, 46]. This suggests that (acquired) knowledge may influence the intention to change behavior, but it does not necessarily guarantee a sustained change in habit. Moreover, a message is best received if it is tailor-made and presented at the optimal moment [113]. One of the tools that can possibly meet this requirement is mobile health technology (mHealth). Traditionally, health information has been presented in paper format, via leaflets or posters. These are not readily accessible in times of need, for example if a person is hiking in a 
tick-rich environment. mHealth can make this information more accessible, by making it available on a smartphone, something people have with them most of the time $[113,15]$. This study aimed to evaluate a dedicated tick-related smartphone application. Questions to be answered included: what is the usage and user satisfaction of the app and what are the effects of this kind of mHealth technology on user knowledge, perceived severity, perceived susceptibility, selfefficacy, response efficacy, and intention to comply with measures to prevent tick bites and LB?

\section{Methods}

\section{The 'Tekenbeet' mobile app}

We have previously studied how to design an electronic health intervention for prevention of tick bites and LB by using end-user profiling and a value-based design [15, 177]. This previous study resulted in a set of requirements that not only specify what the technology should do (functionalities), but also how it should be implemented. These requirements were best suited to a mobile app. The app called 'Tekenbeet' (Dutch for 'tick bite') is a smartphone application aimed at supporting the public in dealing with exposure to ticks and tick bites. The app is aimed at the prevention of tick bites and LB by providing relevant information, including instructions on the correct way to check for, and remove ticks; and providing intelligence on tick activity in the Netherlands ('tick radar'). Furthermore, the app also offers the option for users to document any tick bites sustained, allows reminders to be set to check one's skin for up to several weeks post-bite, and includes a tick activity alarm, based on 'tick radar', that sends the user a notification when a selected tick activity level is reached. A more detailed explanation of the app's functionality can be found in Figure 8.1.

The freely available Android-based 'Tekenbeet' app was developed by RIVM and available from April 2014. It was achieved in partnership with several stakeholders such as national nature and recreational organizations, Association of Community Health Services Netherlands, Scouting Netherlands, and several universities. Originally, the app was only available for Android phones since this was the most popular operating system in the Netherlands. Due to popular demand, in July 2014 the app became available for iOS as well. The app can be downloaded for Android smartphones at: https://play.google.com/store/ apps/details?id=nl.ddt.tick\&hl=nl and for iPhones at: https://itunes . apple.com/nl/app/tekenbeet/id894584051?mt=8.

On-the-spot Internet access is not required for most components of the app, apart from the 'tick radar', which assures that most of the app's functionality is available anywhere. Screenshots of the app are shown below. Figures $8.2 \mathrm{a}$ and $8.2 \mathrm{~b}$ show the screens with tick information and the 'tick radar' screen, respectively. 


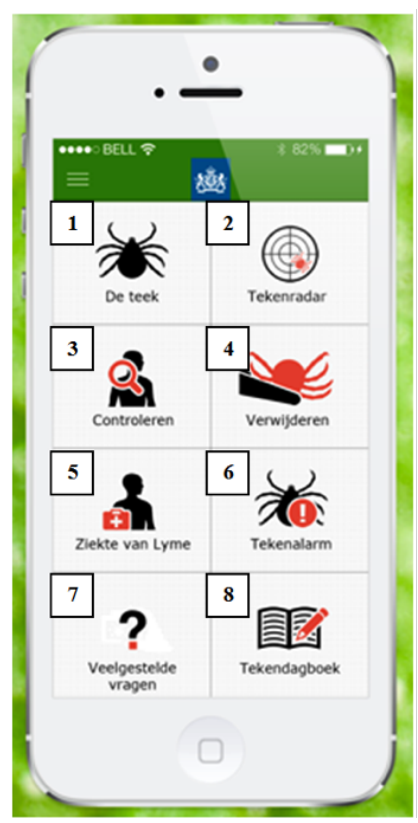

The main screen of the app contains 8 buttons which are connected to information screens.

1. 'De teek' (Tick info) provides information about ticks in general.

2. 'Tekenradar' (Tick radar) gives users an update on the current tick activity in the Netherlands.

3. 'Controleren' (Tick checks) provides information about the correct way to check for ticks and tick bites.

4. 'Verwijderen' (Tick removal) provides information about the correct way to remove ticks.

5. 'Ziekte van Lyme' (Lyme disease) provides information on Lyme disease.

6. 'Tekenalarm' (Tick alarm) gives the opportunity to set reminders to check the skin for up to several weeks post-bite, and includes a radar-based tick activity alarm that sends the user a notification when a selected tick activity level is reached.

7. 'Veelgestelde vragen' (FAQ) provides a set of frequently asked questions with their answers.

8. 'Tekendagboek' (Tick diary) provides a 'diary' which offers end users the option to document any tick bites they may have incurred. Date entries can then be referred to for skin checks in subsequent weeks.

FIGURE 8.1: An overview of the functionality of the 'Tekenbeet' app 


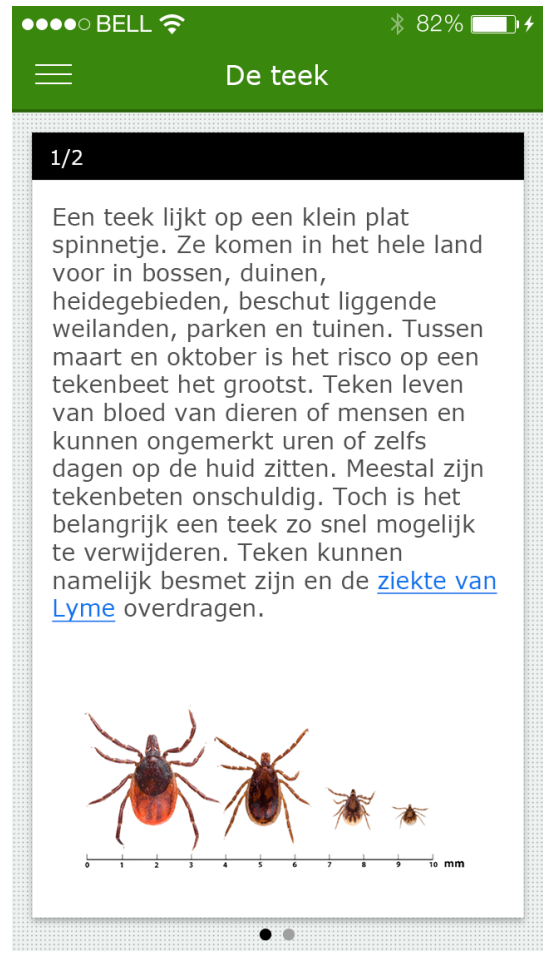

(A) Tick information screen about the appearance of ticks, their habitat, and how they can cause Lyme disease.

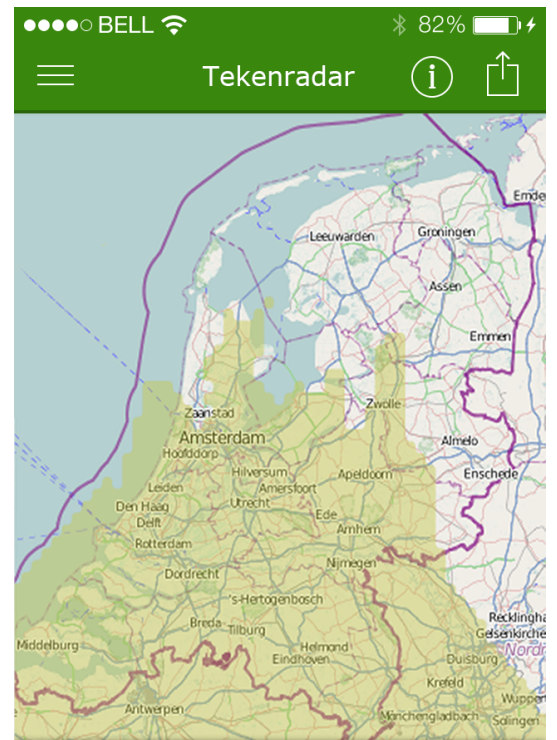

Kies Datum voorspelling

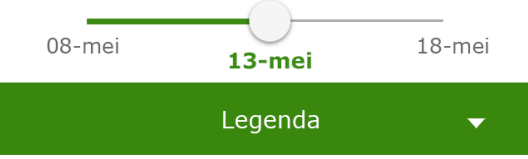

(B) Tick radar screens show the current activity of ticks (nymphs) in the Netherlands and a ten day forecast. Light green implies a small risk for tick bites and white a minimal risk.

FIGURE 8.2: Examples of screenshots of the 'Tekenbeet' app 


\section{Pilot test}

Before the final version of the app became available in the app stores, a pilot test was carried out among 10 participants. Test users included an expert tick biologist $(n=1)$ and experts in communication $(n=2)$, whilst others were member of the general public $(n=7)$. While being observed by two researchers, each participant received a list of tasks to perform with the app, such as 'You are going for a walk in the woods tomorrow and would like to know the risk of a tick bite. Find out the risk level'. While performing the tasks using the app, participants were encouraged to give live critical feedback (a so-called think aloud procedure). Besides these tasks, more general questions were asked such as 'Which functionalities do you expect to find in this app?', and 'When would you like to use this app?'. This resulted in a list of comments, addressed before the final app version was finalized, such as 'please show more pictures of ticks and tick bites', which was solved by adding more pictures, and 'it would be nice to view the video in full screen mode', which was solved by creating a full screen video option in the app.

\section{Google Analytics to evaluate usage of the 'Tekenbeet' app}

Usage statistics such as number of downloads, popularity of the different screen types, and amount of returning users were recorded using Google Analytics [50] and provided app data at the aggregate level.

\section{Survey to evaluate usage, user satisfaction, and the effect of the 'Tekenbeet' app}

\section{Study design and participant recruitment}

A survey with two questionnaires, one per time point, was carried out in order to evaluate usage, user satisfaction and the effect of the mobile 'Tekenbeet' app. According to Dutch law, this general Internet-based survey involving healthy volunteers from the general population requires no formal medical ethical approval. During the first data collection period (Questionnaire 1), respondents were recruited through several channels. To fill out the questionnaire, it was not necessary for respondents to have downloaded the app or to even be aware of its availability; anyone willing to participate could do so. A call for participants for this study was posted on the RIVM website (http://www.rivm.nl/tekenbeet), which attracts around 220,000 unique visitors annually, who are most likely interested in information on ticks and LB. Therefore this group of visitors represents a large part of the target group on which this mobile app is focused, and from which it is important to get relevant results. In addition, several other external websites from our stakeholders such as national nature organizations, Scouting Netherlands and the Foundation Tick Bite Diseases advertised this call for participants. Furthermore, several organizations included a call in their subscriber 
newsletters. After filling out Questionnaire 1, respondents who were willing to fill out a second questionnaire (Questionnaire 2) a few weeks later, could leave their e-mail address. To increase response rates, participants could win one of 50 gift certificates with a value of 10 Euro if they filled out both questionnaires.

The first questionnaire (questionnaire 1) could be filled out from 18th July till $1^{\text {st }}$ October 2014; the second questionnaire (Questionnaire 2) from 6th till 30th October 2014. The first questionnaire had a much longer inclusion time compared to the second, which was due to the inclusion methods. During the first questionnaire, respondents were passively recruited. During the second questionnaire, respondents who indicated that they were willing to participate left their e-mail address at the end of the first questionnaire and could therefore be contacted directly. It was important to collect the data before the end of the tick season (end of October) to ensure the content of the questionnaire was still relevant. It was not the goal to randomly allocate the respondents over the two groups (i.e. those who did and those who did not download the app), since it was impossible to force respondents to refrain from downloading the app as it is publicly available. Therefore respondents were assigned to a group based on their willingness to download the app or not. After agreeing to fill out the questionnaire, respondents were asked if they were willing to download the app if they did not already have the app. Respondents who already had the app or were voluntarily willing to download the app were included in the experimental group (the group of people who already downloaded the app or did so in the beginning of the first questionnaire). Respondents who were not willing to download the app or did not have a smartphone were included in the control group (the group of people who did not download the app).

\section{Questionnaires}

The questionnaires (Annex 1) both consisted of two parts; the first part intended to evaluate usage and user satisfaction of the app, which was only intended for those in the experimental ('downloaders') group. The second part was filled out by respondents in both the experimental and the control group, and intended to evaluate the effects of having the app, or not, on determinants such as knowledge, perceived severity and susceptibility, self-efficacy, response efficacy and intention to comply with measures to prevent tick bites and LB. The different utilities of the app correspond with these determinants. During the first questionnaire, respondents in the experimental group who had only just downloaded the app were asked to take some time to explore the app. Respondents in the experimental group who already downloaded the app before participating in this survey were assumed to have familiarized themselves with the app's content.

To evaluate usage and user satisfaction, experimental group respondents were asked to give feedback on the app (Questionnaire 1). This involved questions about usefulness of different elements of the app, how many times the app was used (if downloaded prior to participation in the survey), and whether one 
would recommend the app to others. In the second questionnaire (Questionnaire 2), questions about usage and user satisfaction were asked again to assess the captivating effect of the app. This time the questions were about ongoing usage and user satisfaction since respondents had access to the app for a longer period of time.

For the effectiveness evaluation, the effects of the app on respondents' knowledge, perceived severity, perceived susceptibility, self-efficacy, response efficacy, and intention regarding the prevention of tick bites and LB were assessed. These determinants were derived from the Protection Motivation Theory (PMT) and the Health Belief Model (HBM) and correspond to our previous evaluation studies of an educational game, leaflet and movie on ticks [46, 113, 120, 42]. Different components of the app are expected to influence the following psychosocial determinants: the information on ticks and LB is expected to influence knowledge and perceived severity, information on checking and removing ticks is expected to influence response efficacy and self-efficacy and intention, and tick radar information is expected to influence perceived susceptibility. The questionnaire was developed further on the basis of an existing questionnaire already used in a study to evaluate the effect of a movie and a leaflet on prevention of tick bites and LB in the Netherlands [16]. In this questionnaire, different psychosocial determinants were based on parts of the PMT and the HBM [120, 42]. The PMT proposes that intention to protect oneself against a health threat is based on the threat appraisal and the coping appraisal, which each depend on two factors. The appraisal of a health threat, which is also part of the HBM, consists of perceived severity (How severe are the consequences of the disease?) and perceived vulnerability (How probable is it that I will contract the disease?). The coping appraisal consists of response efficacy (How effective is the recommended behavior in avoiding the negative consequences?) and self-efficacy (To what extent am I able to perform the recommended behavior successfully?) [120].

In this questionnaire, level of knowledge was measured with eight true/false questions (e.g. 'Ticks usually fall out of trees to bite.'). The other psychosocial determinants were measured on a 7-point Likert scale, ranging from 1 (totally disagree) to 7 (totally agree). Response efficacy was measured with five questions (e.g. 'Checking for ticks after every outdoor visit will help prevent LB.'), self-efficacy with five questions (e.g. 'I am capable of recognizing a tick on my body.'), intention with four questions (e.g. 'I am planning to check my skin for ticks after every outdoor visit.'), perceived susceptibility with two questions (e.g. 'How likely do you think it is that you will be diagnosed with LB within the next year?'), and perceived severity with three questions (e.g. 'If I were to sustain a tick bite, I would be worried about the possible consequences.'). Personal demographics were recorded, including gender, age, and level of education achieved. In addition, questions about everyday use of mobile apps, amount of time spent outdoors (increased risk of tick bites), and having children aged 0-17 years in the home (increased tick awareness) were asked. 


\section{Statistical analyses}

Data from Questionnaires 1 and 2 were analyzed using SPSS 22 for Windows. To assess user satisfaction, means (standard deviation (SD)) and proportions were used. The study population was described using means (SD) and proportions. Sum scores were calculated for questions on knowledge. If psychosocial items showed sufficient internal consistency, they were measuring the same construct, and were therefore assembled into a single construct. Since Cronbach's alpha is an inadequate estimate for both validity and reliability, omega was used to assess the internal structure of the items in each scale [49]. Perceived severity was assessed by means of 3 items $(\Omega=0.90$, 95\% CI $0.88-0.92)$, perceived susceptibility by means of 2 items $(\Omega=0.56,95 \%$ CI $0.46-0.64)$, self-efficacy by means of 5 items $(\Omega=0.72,95 \%$ CI $0.67-0.77)$, response efficacy by means of 5 items $(\Omega=0.80,95 \%$ CI $0.77-0.84)$, and intention by means of 4 items $(\Omega=0.69,95 \%$ CI 0.63-0.75). The full text of all items can be found in Annex 2.

After dichotomization of the items on the 7-point scale, odds ratios (ORs) with $95 \%$ confidence intervals (CI) were calculated, with a $p$-value from a Chisquare test, to find associations between psychosocial determinants and the two groups. Multivariate logistic regression analyses, adjusted for gender, having children aged 0-17 years in the home, and having experience of tick bites, was used to calculate adjusted ORs. Associations between the different determinants were corrected for multiple testing using the Benjamini-Hochberg method [19].

\section{Results}

\section{Usage of the 'Tekenbeet' app according to Google Analytics}

Google Analytics was accessed to gain insight in user statistics. Since the launch in April and July 2014 respectively, until December $1^{\text {st }} 2015$, the Android version of the app had been downloaded 25,783 times ( $62.9 \%$ of total downloads), and the iOS version had been downloaded 15,221 times (37.1\% of total downloads). There were several peak moments when the app was downloaded considerably more frequently. These coincided with certain media events about ticks and tick bites, such as the introduction of the app itself, television shows, 'Tick Bite Prevention Week', and tweets and Facebook messages about the app. Figure 8.3 shows a download timeline between $1^{\text {st }}$ March and $31^{\text {st }}$ May 2015. During the colder months (October-March) when ticks are less active, the amount of downloads was lowest (data not shown).

As of December $1^{\text {st }}, 2015$, measured from the initial app publication date of April 2014, Google Analytics showed that $67.5 \%$ of the Android app users was a returning user, meaning they accessed the app at least twice. Users viewed the tick bite screen most often (this is the start screen of the app), followed by the tick radar, the tick diary screen, and the tick alarm screen. An overview of popularity of the different screens can be found in Table 8.1. 


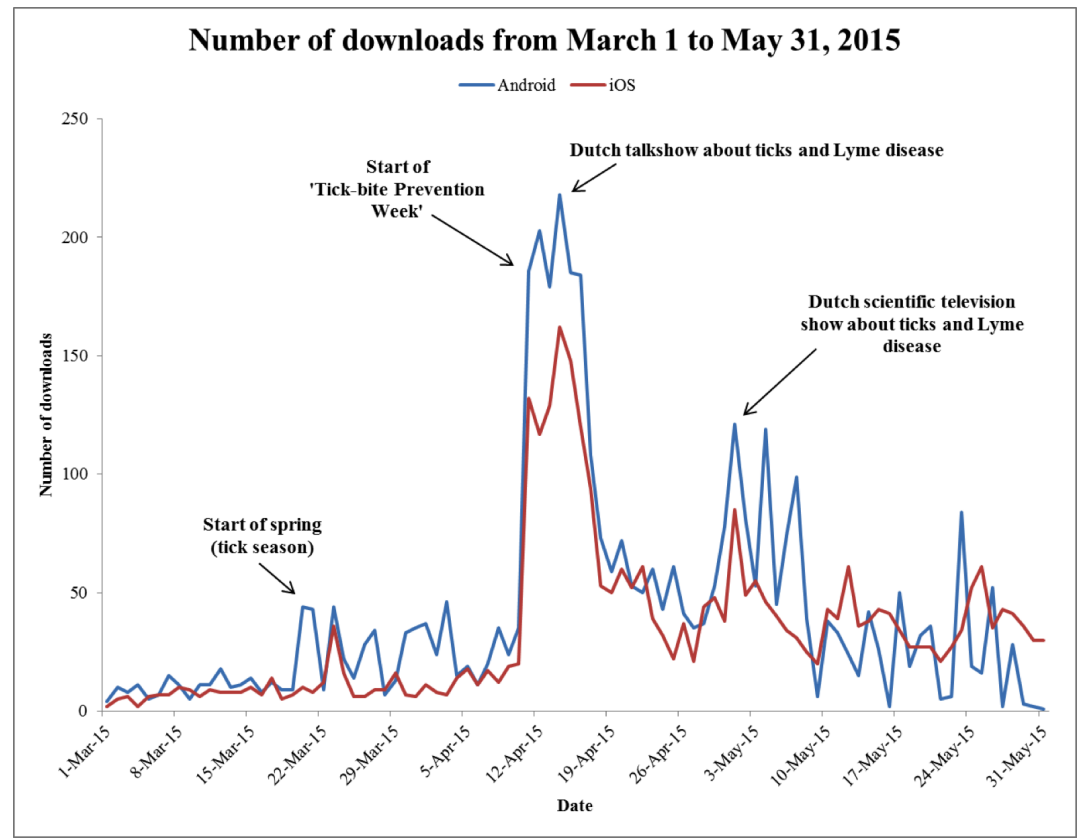

FIgURE 8.3: Overview of Android and iOS downloads between March and May 2015

\section{Usage, user satisfaction and the effects of the 'Tekenbeet' app ac- cording to the survey}

\section{Response}

A total of 812 respondents started filling out the questionnaire, while 258 did not finish the complete questionnaire, resulting in 554 complete questionnaires. Most respondents were recruited during the first few weeks of the inclusion period. Of the 554 respondents, 340 gave details of their e-mail address. On 6th October 2014 they received an invitation e-mail requesting completion of the second questionnaire. A reminder e-mail was sent on 16th October. Seventy percent of the invitees (238 out of 340 ) completed the second questionnaire (Figure 8.4).

\section{Respondents}

Sixty-three point four percent $(n=351 / 554)$ of the respondents was female and the mean age was 46.6 years (SD: 13.5). Sixty-two point three percent ( $n=345 / 554$ ) had a high educational level (defined as higher education or university), and $33.9 \%$ ( $n=188 / 554)$ had children aged 0-17 living at home. Eighty-seven point five percent ( $n=485 / 554$ ) had tick bite experience them- 


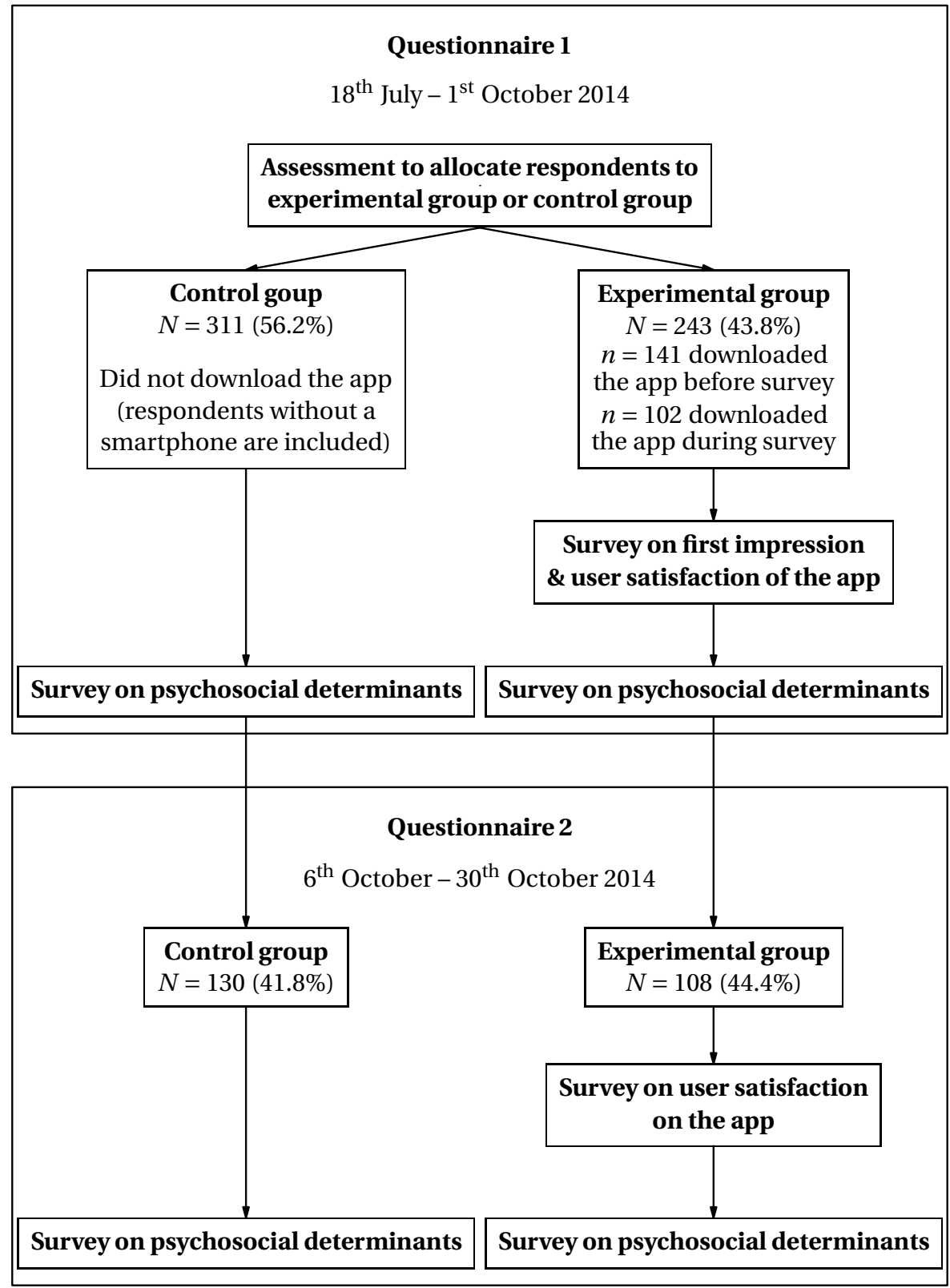

FIGURE 8.4: Flowchart depicting response rates of participants in the survey 
TABLE 8.1: An overview of popularity of the different screens

\begin{tabular}{|c|c|c|c|}
\hline Screen Name & $\begin{array}{l}\text { Number } \\
\text { screen } \\
\text { views }\end{array}$ & $\begin{array}{l}\text { Number } \\
\text { unique } \\
\text { screen } \\
\text { views }\end{array}$ & $\begin{array}{l}\text { Average } \\
\text { time on } \\
\text { screen in } \\
\text { minutes }\end{array}$ \\
\hline Tekenbeet ('Tick bite') & 93,268 & 75,734 & $0: 20$ \\
\hline Tekenradar ('Tick radar’) & 38,636 & 29,348 & $0: 54$ \\
\hline Tekendagboek ('Tick diary’) & 25,245 & 13,355 & $0: 39$ \\
\hline Tekenalarm ('Tick alarm') & 24,372 & 19,312 & $0: 30$ \\
\hline De teek ('Tick info') & 18,921 & 15,354 & $0: 42$ \\
\hline Controleren ('Tick check') & 16,039 & 14,146 & $0: 43$ \\
\hline Verwijderen ('Tick removal') & 15,549 & 13,698 & $1: 00$ \\
\hline Ziekte van Lyme ('Lyme disease') & 12,742 & 10,511 & $0: 46$ \\
\hline Veelgestelde vragen ('FAQ') & 8,759 & 7,587 & $2: 10$ \\
\hline Teek herkennen ('Tick identification') & 3,778 & 3,219 & $0: 42$ \\
\hline Total & 258,238 & 203,051 & $0: 39$ \\
\hline
\end{tabular}

The rating for the 'Tekenbeet' app in the Google Play Store (based on 250 ratings, as of December $\left.1^{\text {st }} 2015\right)$, was 4.1 out of 5 . According to the rating information found on the iOS App Store (based on 26 ratings, as of December $1^{\text {st }} 2015$ ), its rating was $4+$. These numbers provide a measure of popularity/appreciation of the app.

selves or through someone they knew, whereas $56.5 \%(n=313 / 554)$ had LB experience themselves or trough someone they knew. Twenty point four percent ( $n=113 / 554$ ) had a profession that involved working outdoors. Most of the respondents, $88.7 \%(n=490 / 546)$, indicated that in the three months prior to filling out the questionnaire they sometimes or always checked for tick bites following potential exposure.

When comparing the experimental group (i.e. those who downloaded the app) to the control group (respondents who did not download the app), the experimental group contained significantly more male respondents, more respondents who had children aged 0-17 living at home, and more people who had experienced a tick bite themselves or knew someone who had. Table 8.2 presents an overview of the demographics and how they were distributed within the two groups.

\section{Usage and user satisfaction of the app}

Just over eight percent $(8.3 \% ; n=46 / 554)$ of the respondents indicated that they did not own an app-enabled mobile phone. Therefore, these respondents were excluded in the questions about app usage and user satisfaction. Fortyfive point one percent $(n=229 / 508)$ of the respondents who owned a mobile phone indicated they were aware of availability of the 'Tekenbeet' app and $27.8 \%$ ( $n=141 / 508$ ) had already downloaded the app prior to the survey. An overview 
TABLE 8.2: Demographics of respondents

\begin{tabular}{|c|c|c|c|c|c|c|}
\hline Characteristics & $\begin{array}{l}\text { Total } \\
(N=554) \\
\%(n / N)\end{array}$ & $\begin{array}{l}\text { Control group } \\
(N=311) \\
\%(n / N)\end{array}$ & $\begin{array}{l}\text { Experimental } \\
\text { group } \\
(N=243) \\
\%(n / N)\end{array}$ & $\begin{array}{l}\text { Odds } \\
\text { ratio }\end{array}$ & $95 \% \mathrm{CI}$ & $\begin{array}{l}p \text { - } \\
\text { value }\end{array}$ \\
\hline \multicolumn{7}{|l|}{ PERSONAL DATA } \\
\hline Mean age [years (SD)] & $46.6(13.5)$ & $46.4(14.1)$ & $46.9(12.6)$ & & & 0.37 \\
\hline \multicolumn{7}{|l|}{ Gender } \\
\hline Male & $36.6(203 / 554)$ & $31.5(98 / 311)$ & $43.2(105 / 243)$ & Ref. & & \\
\hline Female & $63.4(351 / 554)$ & $68.5(213 / 311)$ & $56.8(138 / 243)$ & 0.61 & $0.43-0.86$ & 0.005 \\
\hline \multicolumn{7}{|l|}{ Educational level } \\
\hline Lower education & $37.7(209 / 554)$ & $38.9(121 / 311)$ & $36.2(88 / 243)$ & Ref. & & \\
\hline Higher education & $62.3(345 / 554)$ & $61.1(190 / 311)$ & $63.8(155 / 243)$ & 1.12 & $0.79-1.59$ & 0.52 \\
\hline \multicolumn{7}{|c|}{ Children (aged 0-17) living at home } \\
\hline No & $66.1(366 / 554)$ & $70.7(220 / 311)$ & $60.1(146 / 243)$ & Ref. & & \\
\hline Yes & $33.9(188 / 554)$ & $29.3(91 / 311)$ & $39.9(97 / 243)$ & 1.60 & $1.13-2.29$ & 0.009 \\
\hline \multicolumn{7}{|l|}{ PROFESSIONAL DATA } \\
\hline \multicolumn{7}{|c|}{ Being outdoors professionally } \\
\hline No & $79.6(441 / 554)$ & $79.7(248 / 311)$ & $79.4(193 / 243)$ & Ref. & & \\
\hline Yes & $20.4(113 / 554)$ & $20.3(63 / 311)$ & $20.6(50 / 243)$ & 1.02 & $0.67-1.55$ & 0.93 \\
\hline
\end{tabular}

TICK/LYME EXPERIENCE

Either they themselves or someone they know has incurred a tick bite

$\begin{array}{lllllll}\text { No } & 12.5(69 / 554) & 15.1(47 / 311) & 9.1(22 / 243) & \text { Ref. } & & \\ \text { Yes } & 87.5(485 / 554) & 84.9(264 / 311) & 90.9(221 / 243) & 1.79 & 1.05-3.06 & 0.03\end{array}$

Having had LB themselves or know someone who has

$\begin{array}{lllllll}\text { No } & 43.5(241 / 554) & 43.4(135 / 311) & 43.6(106 / 243) & \text { Ref. } & & \\ \text { Yes } & 56.5(313 / 554) & 56.6(176 / 311) & 56.4(137 / 243) & 0.99 & 0.71-1.39 & 0.96\end{array}$

Past behavior (checked for tick bites in the past three months) ${ }^{\text {a }}$

$\begin{array}{lllllll}\text { Never } & 10.3(56 / 546) & 12.5(38 / 304) & 7.4(18 / 242) & \text { Ref. } & & \\ \text { Sometimes/always } & 88.7(490 / 546) & 87.5(266 / 304) & 92.6(224 / 242) & 1.78 & 0.99-3.20 & 0.05\end{array}$

a Eight people indicated not to have been in green areas in the past three months and were therefore not included in the analyses. 
of how often these respondents used the app in the recent past (ranging from one to ten weeks) can be found in Figure 8.5. Thirty-one point one percent ( $n=158 / 508$ ) were planning to download the app. When these participants were asked to download the app at that moment, $64.6 \%(n=102 / 158)$ of them did so. In total, $43.9 \%$ ( $n=243 / 554)$ had the 'Tekenbeet' app on their mobile phone at the moment of the first questionnaire.

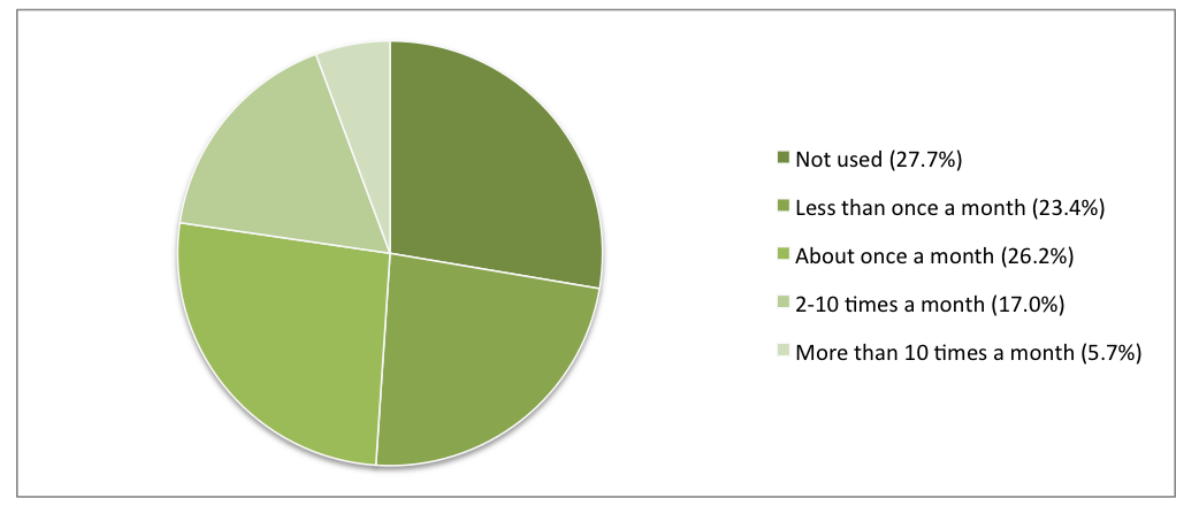

FIGURE 8.5: Overview of recent usage of the 'Tekenbeet' app

The mean score on user satisfaction (1-10) was 7.44 (SD 1.22). When asked whether they felt 'attracted' to the app, on a scale of 1 (not at all attracted) to 7 (very much attracted), the mean score was 5.62 (SD 1.21). Over ninety percent of respondents $(90.9 \%, n=221 / 243)$ indicated they would recommend the app to others. Timing of app download - i.e. prior to or during the questionnaire - did not influence these results. Respondents were asked which section of the app they thought was most useful and which part was least useful (see Table 8.3 for data).

TABLE 8.3: Usefulness of different sections of the 'Tekenbeet' app

\begin{tabular}{|lll|}
\hline Section & $\begin{array}{l}\text { Most useful } \\
\mathbf{\%}(\boldsymbol{n} / \boldsymbol{N})\end{array}$ & $\begin{array}{l}\text { Least useful } \\
\mathbf{\%}(\boldsymbol{n} / \boldsymbol{N})\end{array}$ \\
\hline Information about removing ticks & $39.1(95 / 243)$ & $4.1(10 / 243)$ \\
\hline Tick radar & $35.4(86 / 243)$ & $20.2(49 / 243)$ \\
\hline Information about LB & $26.3(64 / 243)$ & $4.5(11 / 243)$ \\
\hline Information about checking for ticks & $24.7(60 / 243)$ & $3.3(8 / 243)$ \\
\hline Tick diary & $24.3(59 / 243)$ & $16.5(40 / 243)$ \\
\hline Information about ticks & $22.2(54 / 243)$ & $4.5(11 / 243)$ \\
\hline Tick alarm & $22.2(54 / 243)$ & $12.3(30 / 243)$ \\
\hline Frequently asked questions & $19.3(47 / 243)$ & $5.3(13 / 243)$ \\
\hline a It was possible to indicate multiple sections as most or least useful.
\end{tabular}


Most participants, $78.2 \%$ ( $n=190 / 243$ ), indicated that they thought information in the app was presented as expected. In Questionnaire 2, user satisfaction (range from 1 to 10) mean score was 7.35 (SD 0.96). A near identical score to Questionnaire 1 was achieved for recommendation of the app to others in Questionnaire 2, at $90.6 \%(n=87 / 96)$. More than half of the respondents in Questionnaire $2(53.1 \% ; n=60 / 113)$ indicated that they used the app 1-3 times since they downloaded it.

\section{Effects of the app (Questionnaire 1)}

Table 8.4 presents an overview of the results of the univariate analyses of the determinants according to Questionnaire 1 ; ninety-three point five percent ( $n=$ $518 / 554$ ) of the respondents had a positive intention to check for and remove ticks. Respondents in the experimental group scored significantly more often high on knowledge compared to respondents in the control group (OR 3.37; 95\% CI 2.15-5.28); the same applied for self-efficacy (OR 2.67; 95\% CI 1.29-5.55). The experimental group more often had a more positive intention to comply with measures to prevent tick bites and LB when compared to the control group (OR 2.47; 95\% CI 1.14-5.36); a similar impact was observed for response efficacy (OR 1.74; 95\% CI 1.02-2.99). There was no significant difference between the two groups in current behavior, perceived susceptibility and severity scores.

Multivariate logistic regression analyses showed that gender, having children aged 0-17 years in the home, and having experience with a tick bite, had only a very minimal effect on the significance of the relationship between the determinants and the two groups for both intention and knowledge. However, response efficacy and self-efficacy were no longer significantly different in both groups. The results of the multivariate analyses can be found in Table 8.5.

\section{Effects of the app (Questionnaire 2)}

In the second questionnaire, univariate analyses showed no significant differences between the two groups for any determinant. An overview of results in Questionnaire 2 can be found in Table 8.6.

\section{Results of Questionnaire 1 compared to Questionnaire 2}

By comparing the results of Questionnaire 1 to the results of Questionnaire 2, it shows response efficacy was higher during Questionnaire 2 for both the experimental group (5.88 versus 5.67) and the control group (5.68 versus 5.46). Results can be found in Tables 8.7 and 8.8 . 
TABLE 8.4: Univariate analyses of determinants in Questionnaire 1

\begin{tabular}{|c|c|c|c|c|c|c|}
\hline \multirow[b]{2}{*}{$\begin{array}{l}\text { Variables, } \\
\%(n / N)\end{array}$} & \multirow[b]{2}{*}{$\begin{array}{l}\text { Total } \\
(N=554) \\
\%(n / N)\end{array}$} & \multirow[b]{2}{*}{$\begin{array}{l}\text { Control } \\
\text { group } \\
(N=311) \\
\%(n / N)\end{array}$} & \multirow[b]{2}{*}{$\begin{array}{l}\text { Experimental } \\
\text { group } \\
(N=243) \\
\%(n / N)\end{array}$} & \multicolumn{3}{|c|}{ Univariate analysis } \\
\hline & & & & $\begin{array}{l}\text { Odds } \\
\text { ratio }\end{array}$ & 95\% CI & $p$-value \\
\hline \multicolumn{7}{|c|}{ Knowledge (scale range $1-8$ ) } \\
\hline Low & $23.5(130 / 554)$ & $32.2(100 / 311)$ & $12.3(30 / 243)$ & Ref. & & \\
\hline High & $76.5(424 / 554)$ & $67.8(211 / 311)$ & $87.7(213 / 243)$ & 3.37 & $2.15-5.28$ & $<.001$ \\
\hline \multicolumn{7}{|c|}{ Perceived severity (scale range $1-7$ ) } \\
\hline Negative & $53.8(298 / 554)$ & $52.1(162 / 311)$ & $56.0(136 / 243)$ & Ref. & & \\
\hline Positive & $46.2(256 / 554)$ & $47.9(149 / 311)$ & $44.0(107 / 243)$ & 0.86 & $0.61-1.20$ & 0.36 \\
\hline \multicolumn{7}{|c|}{ Perceived susceptibility 1 (scale range 1-7) } \\
\hline Negative & $48.0(266 / 554)$ & $46.6(145 / 311)$ & $49.8(121 / 243)$ & Ref. & & \\
\hline Positive & $52.0(288 / 554)$ & $53.4(166 / 311)$ & $50.2(122 / 243)$ & 0.88 & $0.63-1.23$ & 0.46 \\
\hline \multicolumn{7}{|c|}{ Perceived susceptibility 2 (scale range $1-7$ ) } \\
\hline Negative & $82.7(458 / 554)$ & $80.1(249 / 311)$ & $86.0(209 / 243)$ & Ref. & & \\
\hline Positive & $17.3(96 / 554)$ & $19.9(62 / 311)$ & $14.0(34 / 243)$ & 0.65 & $0.41-1.03$ & 0.07 \\
\hline \multicolumn{7}{|c|}{ Response efficacy (scale range $1-7$ ) } \\
\hline Negative & $12.3(68 / 554)$ & $14.8(46 / 311)$ & $9.1(22 / 243)$ & Ref. & & \\
\hline Positive & $87.7(486 / 554)$ & $85.2(265 / 311)$ & $90.9(221 / 243)$ & 1.74 & $1.02-2.99$ & 0.04 \\
\hline \multicolumn{7}{|c|}{ Self-efficacy (scale range $1-7$ ) } \\
\hline Negative & $7.6(42 / 554)$ & $10.3(32 / 311)$ & $4.1(10 / 243)$ & Ref. & & \\
\hline Positive & $92.4(512 / 554)$ & $89.7(279 / 311)$ & $95.9(233 / 243)$ & 2.67 & $1.29-5.55$ & 0.01 \\
\hline \multicolumn{7}{|c|}{ Intention (scale range $1-7$ ) } \\
\hline Negative & $6.5(36 / 554)$ & $8.7(27 / 311)$ & $3.7(9 / 243)$ & Ref. & & \\
\hline Positive & $93.5(518 / 554)$ & $91.3(284 / 311)$ & $96.3(234 / 243)$ & 2.47 & $1.14-5.36$ & 0.02 \\
\hline
\end{tabular}


TABLE 8.5: Multivariate analyses of determinants in Questionnaire 1 (corrected for gender, having children aged 0-17 years in the home, and having experience with a tick bite.)

\begin{tabular}{|c|c|c|c|c|}
\hline Variables, $n / N(\%)$ & Odds ratio & $95 \% \mathrm{CI}$ & $p$-value & $\begin{array}{l}\text { Transformed } \\
p \text {-value }\end{array}$ \\
\hline \multicolumn{5}{|c|}{ Knowledge (scale range $1-8$ ) } \\
\hline Low (1-4) & Ref. & & & \\
\hline High (5-8) & 3.21 & $2.02-5.09$ & $<0.001$ & 0.01 \\
\hline \multicolumn{5}{|c|}{ Perceived severity (scale range $1-7$ ) } \\
\hline Negative (1-4) & Ref. & & & \\
\hline Positive (5-7) & 0.94 & $0.67-1.34$ & 0.743 & 0.74 \\
\hline \multicolumn{5}{|c|}{ Perceived susceptibility 1 (scale range $1-7$ ) } \\
\hline Negative (1-4) & Ref. & & & \\
\hline Positive (5-7) & 0.77 & $0.54-1.09$ & 0.142 & 0.19 \\
\hline \multicolumn{5}{|c|}{ Perceived susceptibility 2 (scale range $1-7$ ) } \\
\hline Negative (1-4) & Ref. & & & \\
\hline Positive (5-7) & 0.67 & $0.42-1.07$ & 0.092 & 0.15 \\
\hline \multicolumn{5}{|c|}{ Self-efficacy (scale range $1-7$ ) } \\
\hline Negative (1-4) & Ref. & & & \\
\hline Positive (5-7) & 2.56 & $1.22-5.37$ & 0.013 & 0.05 \\
\hline \multicolumn{5}{|c|}{ Response efficacy (scale range 1-7) } \\
\hline Negative (1-4) & Ref. & & & \\
\hline Positive (5-7) & 1.65 & $0.96-2.86$ & 0.072 & 0.14 \\
\hline \multicolumn{5}{|c|}{ Intention (scale range $1-7$ ) } \\
\hline Negative (1-4) & Ref. & & & \\
\hline Positive (5-7) & 2.67 & $1.22-5.85$ & 0.014 & 0.04 \\
\hline
\end{tabular}


TABLE 8.6: Univariate analyses of determinants in Questionnaire 2

\begin{tabular}{|c|c|c|c|c|c|c|}
\hline \multirow[b]{2}{*}{ Variables } & \multirow[b]{2}{*}{$\begin{array}{l}\text { Total } \\
(N=238) \\
\%(n / N)\end{array}$} & \multirow[b]{2}{*}{$\begin{array}{l}\text { Control group } \\
(N=130) \\
\% n / N\end{array}$} & \multirow[b]{2}{*}{$\begin{array}{l}\text { Experimental } \\
\text { group } \\
(N=108) \\
\% n / N\end{array}$} & \multicolumn{3}{|c|}{ Univariate analysis } \\
\hline & & & & $\begin{array}{l}\text { Odds } \\
\text { ratio }\end{array}$ & 95\% CI & $p$-value \\
\hline \multicolumn{7}{|c|}{ Knowledge (scale range $1-8)^{a}$} \\
\hline Low & $22.7(54 / 238)$ & $26.9(35 / 130)$ & $17.6(19 / 108)$ & Ref. & & \\
\hline High & $77.3(184 / 238)$ & $73.1(95 / 130)$ & $82.4(89 / 108)$ & 1.73 & $0.92-3.24$ & 0.09 \\
\hline \multicolumn{7}{|c|}{ Perceived severity (scale range $1-7)^{b}$} \\
\hline Negative & $51.4(119 / 226)$ & $53.7(65 / 121)$ & $51.4(54 / 105)$ & Ref. & & \\
\hline Positive & $47.3(107 / 226)$ & $46.3(56 / 121)$ & $48.6(51 / 105)$ & 1.10 & $0.65-1.85$ & 0.731 \\
\hline \multicolumn{7}{|c|}{ Perceived susceptibility 1 (scale range $1-7)^{b}$} \\
\hline Negative & $44.5(106 / 238)$ & $45.4(59 / 130)$ & $43.5(47 / 108)$ & Ref. & & \\
\hline Positive & $55.5(132 / 238)$ & $54.6(70 / 130)$ & $56.5(61 / 108)$ & 1.08 & $0.65-1.80$ & 0.77 \\
\hline \multicolumn{7}{|c|}{ Perceived susceptibility 2 (scale range $1-7)^{b}$} \\
\hline Negative & $87.3(145 / 166)$ & $87.4(76 / 87)$ & $87.3(69 / 79)$ & Ref. & & \\
\hline Positive & $12.7(21 / 166)$ & $12.6(11 / 87)$ & $12.7(10 / 79)$ & 1.00 & $0.40-2.50$ & 0.998 \\
\hline \multicolumn{7}{|c|}{ Self-efficacy (scale range $1-7)^{b}$} \\
\hline Negative & $4.2(10 / 238)$ & $5.4(7 / 130)$ & $2.8(3 / 108)$ & Ref. & & \\
\hline Positive & $95.8(228 / 238)$ & $94.6(123 / 130)$ & $97.2(105 / 108)$ & 1.99 & $0.50-7.90$ & 0.32 \\
\hline \multicolumn{7}{|c|}{ Response efficacy (scale range $1-7)^{b}$} \\
\hline Negative & $8.8(21 / 238)$ & $9.2(12 / 130)$ & $8.3(9 / 108)$ & Ref. & & \\
\hline Positive & $91.2(217 / 238)$ & $90.8(118 / 130)$ & $91.7(99 / 108)$ & 1.12 & $0.45-2.76$ & 0.81 \\
\hline \multicolumn{7}{|c|}{ Intention (scale range $1-7)^{b}$} \\
\hline Negative & $5.5(13 / 238)$ & $6.9(9 / 130)$ & $3.7(4 / 108)$ & Ref. & & \\
\hline Positive & $94.5(225 / 238)$ & $93.1(121 / 130)$ & $96.3(104 / 108)$ & 1.93 & $0.60-6.46$ & 0.28 \\
\hline
\end{tabular}

TABLE 8.7: Determinants in Questionnaire 1 and 2 for the experimental group ${ }^{\mathrm{a}}$

\begin{tabular}{|llll} 
& $\begin{array}{l}\text { Questionnaire 1 } \\
(\boldsymbol{N = 1 0 8 )} \\
\text { Mean (SD) }\end{array}$ & $\begin{array}{l}\text { Questionnaire 2 } \\
(\boldsymbol{N = 1 0 8 )} \\
\text { Mean (SD) }\end{array}$ & $p$-value \\
\hline Knowledge (scale range 1-8) & $6.05(1.44)$ & $6.04(1.50)$ & 0.94 \\
\hline Perceived severity (scale range 1-7) & $3.99(1.63)$ & $3.95(1.56)$ & 0.69 \\
\hline Perceived susceptibility 1 (scale range 1-7) & $4.65(1.74)$ & $4.63(1.67)$ & 0.87 \\
\hline Perceived susceptibility 2 (scale range 1-7) & $2.65(1.39)$ & $2.82(1.46)$ & 0.14 \\
\hline Self-efficacy (scale range 1-7) & $5.94(0.81)$ & $6.04(0.79)$ & 0.12 \\
\hline Response efficacy (scale range 1-7) & $5.67(1.20)$ & $5.88(1.09)$ & 0.03 \\
\hline Intention (scale range 1-7) & $6.14(0.96)$ & $6.27(0.87)$ & 0.06
\end{tabular}

a Only data of respondents who completed both questionnaires have been taken into account. 
TABLE 8.8: Determinants in Questionnaire 1 and 2 for the control group ${ }^{\mathrm{a}}$

\begin{tabular}{|c|c|c|c|}
\hline & $\begin{array}{l}\text { Questionnaire } 1 \\
(N=130) \\
\text { Mean (SD) }\end{array}$ & $\begin{array}{l}\text { Questionnaire } 2 \\
(N=130) \\
\text { Mean (SD) }\end{array}$ & $p$-value \\
\hline Knowledge (scale range $1-8$ ) & $5.29(1.61)$ & $5.40(1.52)$ & 0.39 \\
\hline Perceived severity (scale range $1-7$ ) & $4.04(1.66)$ & $4.04(1.66)$ & 0.98 \\
\hline Perceived susceptibility 1 (scale range $1-7$ ) & $4.82(1.78)$ & $4.81(1.65)$ & 0.90 \\
\hline Perceived susceptibility 2 (scale range $1-7$ ) & $2.85(1.58)$ & $2.71(1.49)$ & 0.32 \\
\hline Self-efficacy (scale range 1-7) & $5.69(1.14)$ & $5.79(0.97)$ & 0.14 \\
\hline Response efficacy (scale range 1-7) & $5.46(1.24)$ & $5.68(1.17)$ & 0.02 \\
\hline Intention (scale range $1-7$ ) & $6.01(1.10)$ & $6.06(1.00)$ & 0.41 \\
\hline
\end{tabular}

\section{Discussion}

The aim of this study was to evaluate the usage and user satisfaction of the 'Tekenbeet' app and to investigate whether the app affects users' knowledge, perceived severity, perceived susceptibility, self-efficacy, response efficacy, current behavior and intention to comply with measures to prevent tick bites and LB.

\section{Usage}

Since its launch 2 years ago, the 'Tekenbeet' app has been downloaded over 41,000 times. Even when compared with other non-tick related apps published by the Dutch government, this number is high. According to data obtained from Google Analytics, more than half of the downloads was by a returning user, meaning they accessed the app at least twice. The survey shows almost $50 \%$ of the respondents used the app at least once a month, which supports the Google Analytics data. Compared to other apps, the 'Tekenbeet' app is a so-called 'seasonal app'; customers tend to use it during the tick season between March and October, when there is a more acute need for information about ticks and LB, which is reflected in the increased downloads during the tick season. There are two other Dutch apps available in app stores that focus on ticks and tick bites: 'Teek!' (Dutch translation of 'Tick!') is an app developed by the Public Health Service Zeeland; and 'Teek Away' (Dutch translation of 'Tick Away', a wordplay on the English word takeaway) produced by the organization 'Nature and Environment Overijssel'. Both apps are rated 3.5 out of 5 by users on the Google Play Store and each has been downloaded between 1,000 and 5,000 times (data Google Play Store). If we compare these two other Dutch tick-focused apps to the 'Tekenbeet' app, there are clear differences. 'Tekenbeet' offers a more interactive experience, such as instruction videos and a tick alarm that can be set to a tick-related activity by the end-user. More importantly, unlike the other apps, 
the 'Tekenbeet' app also functions when there is no Internet connectivity and can therefore be used anytime and anywhere. This can be particularly useful for outdoor activities when there is a lack of Internet connection and potentially a high risk of incurring a tick bite.

\section{User satisfaction}

Our survey data shows that most users felt 'attracted' to the app and would recommend it to others; with a mean score of 7.44 on a scale of 1 to 10 , user satisfaction was high. This is reflected by the rating of the app in the Google Play Store. This is slightly higher compared to the average medical app [121]. It is clear there were some conflicting opinions regarding its most useful content. Google Analytics shows that the tick radar had the most screen views. However, in the survey the tick radar was appreciated and not appreciated in near equal measures. The appreciation suggests that people may find it useful to make an assessment of the tick risk based on the tick radar data. From the comments made by survey participants, we deduct that disapproval can be explained by the fact that you cannot zoom in on the tick radar map (it can only give a national overview), and it therefore for some lacks a sufficiently detailed display of activity in a specific geographic region that the user wishes to explore. In the survey, the screen with information about removing ticks was rated 'most useful', but as per Google Analytics, this screen was 6th in terms of most screen views. This may be explained by the fact that the information on this screen is only useful in the event of an actual tick bite.

\section{Effects}

Based on our survey results, we conclude that the 'Tekenbeet' app is an effective educational tool to increase public knowledge, and to meet the intention to improve preventive behavior regarding ticks and tick bites. Knowledge was high in both the downloader and non-downloader groups, which is consistent with other findings concerning other media used for educational purposes [16], although app users were slightly more knowledgeable. This might be explained by the fact that they could look up certain answers on the knowledge questions in the app, or because they were aware of the risks of tick bites and were therefore keener to download the app. However, respondents who did not download the app could potentially have looked up the answers too via different sources such as websites. The outcomes for the knowledge aspect might explain why intention to take preventive measures was also higher in the experimental group, since knowledge is a known determinant that has a positive influence on intention [67].

Our previous research has shown that a movie and leaflet for prevention of tick bites and LB are effective educational tools for improving knowledge, and that these types of media help to increase the intention - at least in the short- 
term - to take preventive measures concerning tick bites and LB [16]. However, these improvements in knowledge and intention could no longer be detected during the second measurement, which meant an enduring effect of information provided through a leaflet or movie was lacking. To consult a leaflet or movie as a consumer, you need to have the leaflet at hand or know where to find the movie online. However, the 'Tekenbeet' app is readily available once downloaded (with only the tick radar requiring live Internet connection), which may help users to keep consulting it repeatedly over a longer period. This could mean it can have a 'perpetuating short-term effect' rather than the one-off short-term effect we have seen with the movie and the leaflet. It is a challenge to also reach people who are less intrinsically interested in this subject and make them aware of the availability of the app. One option would be to promote the app on notice boards at places with a higher tick bite risk, such as visitor centers in national parks, camp sites, or at outdoor festivals. Furthermore, promoting the app in other educational materials, such as the RIVM's website, leaflet and the online movie about ticks and LB, or in publications by other organizations, may increase awareness of the availability of the app. After all, an app store may not be the natural place one looks for information on ticks.

\section{Limitations and future research}

Remarkably, almost half of the respondents indicated that they were aware of the availability of the 'Tekenbeet' app before participating in the survey. An invitation to participate in the survey was posted on websites with a special interest in nature or ticks and LB, which was also the place where the app was promoted in the months prior to the survey. This may explain why so many respondents were aware of the availability of the app. However, being aware of the availability of the app due to promotion does not necessarily mean someone is willing to download the app. This can be explained by many reasons such as not having a smartphone or simply not being interested in having an app on this subject. Furthermore, almost a third of the respondents who started filling out Questionnaire 1 did not complete it, most of them quit after only one or two questions. These factors may have introduced selection bias, but due to this kind of inclusion method, a non-response study was not possible. This recruitment method was chosen to increase the likelihood that native tick-interested people participated in the study, and only native app-interested people would fill out the questions about the app, since these people are precisely the target group of the mobile app. Clearly, the recruitment method used in this study does not provide a representative sample of the Dutch population. However, we were mainly interested in the usage and the effects of the app on the different determinants of people who, in real life, would also use this app. To reduce selection bias, in the multivariate analyses we corrected for gender, having children aged 0-17 years in the home, and having experience of tick bites. In the study population there was an overrepresentation of women and people with a higher education level. 
However, this phenomenon is seen more often when respondents are recruited through websites or social media [119].

People had the option to download the app if they were willing to do so. They were not divided into two groups beforehand, and this may have contributed to selection bias. However, in this study, we were mostly interested in respondents that showed an unforced interest in ticks/LB and/or in downloading the app. At the end of each questionnaire, respondents could leave comments. This resulted in some useful recommendations to improve its user-friendliness. For example, the inclusion of a functionality to make it possible to send tick diary data to someone else if approved by the user, such as parents or one's general practitioner. This could be an improvement, especially for teachers or supervisors at children's nature clubs. Furthermore, the tick radar function in the app was considered 'least useful' by $20.2 \%$ of respondents, mostly due to the unavailability of a zoom function. These feedback results may be acted upon to make improvements to future updated versions of the app. The introduction of a zoom option for the tick radar is currently being considered.

\section{Conclusion}

In conclusion, the 'Tekenbeet' app is a frequently used and well-appreciated educational tool to increase the public's knowledge concerning ticks and tick bites. It appears to be a useful addition to the current range of educational tools, and helps to increase self-efficacy to perform preventive measures (check for and remove ticks), and the user's intention to apply these measures. The difference in increase in knowledge, self-efficacy and intention between the experimental and the control group does seem to diminish over time. However, one of the advantages of mHealth is that it can be used anytime and anywhere the information is needed, which may reduce the need for long-term knowledge retention. The use of smartphones and apps is now commonplace; the 'Tekenbeet' app feeds into this trend and offers a modern day interactive alternative to other educational tools. 


\section{Annex 1: Questionaires}

\section{Questionnaire 1: Research on ticks and Lyme disease}

Part 1: questions regarding your knowledge on ticks and Lyme disease

1. You are now going to see eight statements. Please read them and indicate if you think the statement is 'true' or 'false'. If you do not know the answer please mark 'I don't know'.

\begin{tabular}{|l|l|l|l|}
\hline & true & false & $\begin{array}{l}\text { I don't } \\
\text { know }\end{array}$ \\
\hline A tick usually falls from a tree in order to bite. & & & \\
\hline $\begin{array}{l}\text { You can remove a tick by pulling it directly } \\
\text { upwards with pointed tweezers. }\end{array}$ & & & \\
\hline A tick bite always makes you ill. & & & \\
\hline $\begin{array}{l}\text { Ticks mostly bite in so-called 'warm areas', e.g. } \\
\text { armpits, groin, or behind the knee. }\end{array}$ & & & \\
\hline $\begin{array}{l}\text { After removing a tick, you should monitor your } \\
\text { health for up to a week maximum. }\end{array}$ & & & \\
\hline $\begin{array}{l}\text { If part of a tick remains in the skin, this is } \\
\text { dangerous. }\end{array}$ & & & \\
\hline $\begin{array}{l}\text { In Lyme disease a red ring usually appears on } \\
\text { the skin. }\end{array}$ & & & \\
\hline $\begin{array}{l}\text { Over half of all ticks is infected with the } \\
\text { bacterium responsible for Lyme disease. }\end{array}$ & & & \\
\hline
\end{tabular}

Part 2: questions regarding app use. Below, we ask questions about your experience regarding app use in general and the RIVM app 'Tekenbeet' in particular. Please note: this study only focusses on the RIVM app 'Tekenbeet', and does not focus on other apps regarding ticks, such as 'Teek' or 'Teek away'.

2. Which brand of mobile phone do you use?

No mobile phone $\Rightarrow$ go to question 23

$\square$ iPhone

$\square$ Samsung

$\square$ HTC

口 LG

$\square$ Other:

3. Do you ever download apps on your mobile phone (excluding messaging services such as WhatsApp Messenger, e-mail, and calendar)? 
$\square$ Yes

No $\Rightarrow$ go to question 5

4. How often do you download apps on your mobile phone (excluding messaging services such as WhatsApp Messenger, e-mail and calendar)?

$\square$ Less than once a month

- 1-2 times in 6 months

-3 -5 times in 6 months

- 1-3 times a month

- 1-2 times a week

-3-4 times a week

-5-6 times a week

$\square$ Every day

5. How often do you use apps on your mobile phone (excluding messaging services such as WhatsApp Messenger, e-mail and calendar)?

$\square$ Less than once a month

- 1-2 times in 6 months

-3-5 times in 6 months

-1-3 times a month

-1-2 times a week

-3-4 times a week

-5-6 times a week

$\square$ Every day

6. Are you familiar with the RIVM app 'Tekenbeet' about ticks and Lyme disease?

$\square$ Yes

$\square$ No

7. Did you download the app 'Tekenbeet' on your mobile phone, or are you planning to do so?

No, I did not download or plan to download the app $\Rightarrow$ go to question 24

$\square$ Yes, I am planning to download the app

$\square$ Yes, I downloaded the app 
8. Why did you not download the app 'Tekenbeet' or do you not intend to do so? $\Rightarrow$ go to question 24

9. Did you use the app 'Tekenbeet' in the recent past?

$\square$ No

Less than once a month

about once a month

口 2-10 times a month

$\square$ More than 10 times a month

We ask you to download the app 'Tekenbeet' on your phone. You can find this app in the Google Play Store or in the App Store.

10. Did you manage to download the app 'Tekenbeet'?

$\square$ Yes

$\square$ No $\Rightarrow$ go to question 24

Part 3: Questions regarding the content of the app 'Tekenbeet'. Below we ask you for your opinion regarding the app 'Tekenbeet'.

11. How would you rate the app (1-10)?

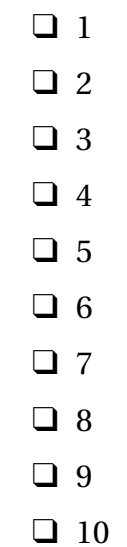

12.

\begin{tabular}{|l|l|l|l|l|l|l|l|}
\hline & $\begin{array}{l}1- \\
\text { not } \\
\text { at all }\end{array}$ & 2 & 3 & 4 & 5 & 6 & $\begin{array}{l}7- \\
\text { very } \\
\text { much }\end{array}$ \\
\hline Do you feel addressed by the app & & & & & & & \\
\hline
\end{tabular}

13. Would you recommend the app to friends or family? 
$\square$ Yes $\Rightarrow$ go to question 14

No $\Rightarrow$ go to question 15

14. Why would you recommend the app to friends or family? $\Rightarrow$ go to question 16

15. Why would you not recommend the app to friends or family?

16. What would you like to change about the app?

17. Which part(s) of the app do you consider most useful? (more than one answer is possible)

All parts are evenly useful

$\square$ 'the tick'

口 'tick radar'

$\square$ 'to control'

$\square$ 'to remove'

$\square$ 'Lyme disease'

口 'tick alert'

$\square$ 'frequently asked questions'

口 'tick diary'

18. Which part(s) of the app do you consider least useful? (more than one answer is possible)

$\square$ All parts are evenly useful

$\square$ 'the tick'

$\square$ 'tick radar'

$\square$ 'to control'

$\square$ 'to remove'

$\square$ 'Lyme disease'

$\square$ 'tick alert'

$\square$ 'frequently asked questions'

$\square$ 'tick diary'

19. Does the app provide the information you are looking for?

Yes $\Rightarrow$ go to question 21

$\square$ Partially

$\square$ No 
20. What kind of information would you like to find in the app?

21. In what manner would you prefer to receive information about ticks and Lyme disease?

$\square$ Through a leaflet

$\square$ Through a website

$\square$ Through an app

$\square$ Through a movie

$\square$ Other:

22. You are now going to see eight statements. Please read them and indicate if you think the statement is 'true' or 'false'. If you do not know the answer please mark 'I don't know'. We are aware you have already answered these questions in the beginning of the questionnaire, but it is important that you answer them once again.

\begin{tabular}{|l|l|l|l|}
\hline & true & false & $\begin{array}{l}\text { I don't } \\
\text { know }\end{array}$ \\
\hline A tick usually falls from a tree in order to bite. & & & \\
\hline $\begin{array}{l}\text { You can remove a tick by pulling it directly } \\
\text { upwards with pointed tweezers. }\end{array}$ & & & \\
\hline A tick bite always makes you ill. & & & \\
\hline $\begin{array}{l}\text { Ticks mostly bite in so-called 'warm areas', e.g. } \\
\text { armpits, groin, or behind the knee. }\end{array}$ & & & \\
\hline $\begin{array}{l}\text { After removing a tick, you should monitor your } \\
\text { health for up to a week. }\end{array}$ & & & \\
\hline $\begin{array}{l}\text { If part of a tick remains in the skin, this is } \\
\text { dangerous. }\end{array}$ & & & \\
\hline $\begin{array}{l}\text { In Lyme disease a red ring usually appears on } \\
\text { the skin. }\end{array}$ & & & \\
\hline $\begin{array}{l}\text { Over half of all ticks is infected with the } \\
\text { bacterium responsible for Lyme disease. }\end{array}$ & & & \\
\hline
\end{tabular}

Part 4: Questions regarding your personal situation. Below, we will ask you some questions regarding your personal and family situation.

23. What is your year of birth?

24. What is your gender?

a Male

$\square$ Female

25. What is the highest level of education you have completed?

None (did not finish primary school) 
Primary school (basisschool, special-needs primary school)

- Lower vocational education or Prepratory Vocational Education (e.g. Ambachtsschool, Huishoudschool, LTS, LEAO, LHNO, VMBO)

- Secondary school (e.g. MAVO, (M)ULO, MBO-kort, VMBO-t)

- Secondary vocational education (e.g. training programs for baker or hairdresser, MBO-lang, MTS, UTS, MEAO, BOL, BBL, INAS)

$\square$ Higher secondary education or preparatory scientific education (e.g. HAVO, VWO, Atheneum, Gymnasium, HBS, MMS)

$\square$ Higher professional education (e.g. kweekschool, HBO, HTS, HEAO, HBO-V, kandidaats wetenschappelijk onderwijs)

$\square$ Academic education (university)

$\square$ Other,

26. Do you own a dog or a cat?
$\square$ No
$\square$ Yes, (a) $\operatorname{dog}(\mathrm{s})$
$\square$ Yes, (a) cat(s)
$\square$ Yes, both

27. Do you have children living at your home (age $0-17)$ ?

$\square$ Yes

$\square$ No

28. How often are your kids active in green spaces? When we talk about green spaces we mean being outdoors in nature areas such as woods, heathland, dunes or a park.

Less than once a month $\Rightarrow$ go to question 32

$\square$ Every month

$\square$ Every week $\Rightarrow$ go to question 30

$\square$ Daily $\Rightarrow$ go to question 31

29. On a monthly basis, how many hours does your child on average spend in green spaces? When we talk about green spaces we mean being outdoors in nature areas such as woods, heathland, dunes or a park. $\Rightarrow$ go to question 32

30. On a weekly basis, how many hours does your child on average spend in green spaces? When we talk about green spaces we mean being outdoors in nature areas such as woods, heathland, dunes or a park. $\Rightarrow$ go to question 32 
31. On a daily basis, how many hours does your child on average spend in green spaces? When we talk about green spaces we mean being outdoors in nature areas such as woods, heathland, dunes or a park.

32. How often are you active in green spaces? When we talk about green spaces we mean being outdoors in nature areas such as woods, heathland, dunes or a park.

Less than once a month $\Rightarrow$ go to question 36

$\square$ Every month

$\square$ Every week $\Rightarrow$ go to question 34

$\square$ Daily $\Rightarrow$ go to question 35

33. On a monthly basis, how many hours do you on average spend in green spaces? When we talk about green spaces we mean being outdoors in nature areas such as woods, heathland, dunes or a park.

34. On a weekly basis, how many hours do you on average spend in green spaces? When we talk about green spaces we mean being outdoors in nature areas such as woods, heathland, dunes or a park. .................... $\Rightarrow$ go to question 36

35. On a daily basis, how many hours do you on average spend in green spaces? When we talk about green spaces we mean being outdoors in nature areas such as woods, heathland, dunes or a park.

36. Does your job involve you actively working in green spaces? (e.g. forester or gardener) When we talk about green spaces we mean being outdoors in nature areas such as woods, heathland, dunes or a park.

$\square$ Yes

No $\Rightarrow$ go to question 41

37. On average, how much time do you spend working in green spaces? When we talk about green spaces we mean being outdoors in nature areas such as woods, heathland, dunes or a park.

Less than once a month $\Rightarrow$ go to question 41

Every month

Every week $\Rightarrow$ go to question 39

$\square$ Daily $\Rightarrow$ go to question 40

38. On a monthly basis, how many hours do you on average spend in green spaces professionally? When we talk about green spaces we mean being outdoors in nature areas such as woods, heathland, dunes or a park. $\Rightarrow$ go to question 41 
39. On a weekly basis, how many hours do you on average spend in green spaces professionally? When we talk about green spaces we mean being outdoors in nature areas such as woods, heathland, dunes or a park. $\Rightarrow$ go to question 41

40. On a daily basis, how many hours do you on average spend in green spaces professionally? When we talk about green spaces we mean being outdoors in nature areas such as woods, heathland, dunes or a park.

Part 5: questions regarding ticks and Lyme disease Below, we will ask you questions regarding ticks and Lyme disease.

41. Have you or anyone in your direct social network (such as children, partner, family, friends) ever had one or more tick bites?

$\square$ Yes

$\square$ No

I can't remember

42. Have you or anyone in your direct social network (such as children, partner, family, friends) ever had Lyme disease?

$\square$ Yes

No $\Rightarrow$ go to question 44

I can't remember $\Rightarrow$ go to question 44

43. Who diagnosed Lyme disease? (In case you know more cases of Lyme disease, assume the first case that comes to mind)

General practitioner

$\square$ A medical specialist

$\square$ Other,

I don't know

44. How often over the past year have you checked yourself or someone else for tick bites after visiting a green space? When we talk about green spaces we mean being outdoors in nature areas such as woods, heathland, dunes or a park.

Never after visiting a green space

$\square$ Sometimes after visiting a green space

$\square$ Every time after visiting a green space

$\square$ I have not visited a green space 
45. How often over the past year have you immediately removed a tick from your own or someone else's skin after discovering a tick bite? When we talk about green spaces we mean being outdoors in nature areas such as woods, heathland, dunes or a park.

Never after visiting a green space

Sometimes after visiting a green space

Every time after visiting a green space

I have not discovered a tick bite

46. Imagine that you are going to take one of the precautions below to prevent getting Lyme disease. From a practical point of view, to what extent do you think that you would really succeed in taking these precautions? When we talk about green spaces we mean being outdoors in nature areas such as woods, heathland, dunes or a park.

\begin{tabular}{|l|l|l|l|l|l|l|l|}
\hline & $\begin{array}{l}1- \\
\text { strongly } \\
\text { dis- } \\
\text { agree }\end{array}$ & 2 & 3 & 4 & 5 & 6 & $\begin{array}{l}7- \\
\text { strongly } \\
\text { agree }\end{array}$ \\
\hline $\begin{array}{l}\text { I would be able to recognise } \\
\text { a tick on my body. }\end{array}$ & & & & & & & \\
\hline $\begin{array}{l}\text { I would be able to check my } \\
\text { body for tick bites after every } \\
\text { trip to a green space. }\end{array}$ & & & & & & & \\
\hline $\begin{array}{l}\text { I would be able to remove a } \\
\text { tick immediately with } \\
\text { pointed tweezers (or other } \\
\text { type of tick remover). }\end{array}$ & & & & & & & \\
\hline $\begin{array}{l}\text { I would be able to note down } \\
\text { the place of the tick bite on } \\
\text { my body and the date. }\end{array}$ & & & & & & & \\
\hline $\begin{array}{l}\text { I would be able to go to the } \\
\text { GP if I had a tick on my skin } \\
\text { for over 24 hours. }\end{array}$ & & & & & & & \\
\hline
\end{tabular}

47. The following statements concern measures to prevent Lyme disease. Please indicate how much you think that these measures would help. When we talk about green spaces we mean being outdoors in nature areas such as woods, heathland, dunes or a park. 


\begin{tabular}{|l|l|l|l|l|l|l|l|}
\hline & $\begin{array}{l}1- \\
\text { strongly } \\
\text { dis- } \\
\text { agree }\end{array}$ & 2 & 3 & 4 & 5 & 6 & $\begin{array}{l}7- \\
\text { strongly } \\
\text { agree }\end{array}$ \\
\hline $\begin{array}{l}\text { Recognising a tick when } \\
\text { checking the body helps to } \\
\text { prevent Lyme disease }\end{array}$ & & & & & & & \\
\hline $\begin{array}{l}\text { Checking for ticks after every } \\
\text { visit to a green space helps to } \\
\text { prevent Lyme disease. }\end{array}$ & & & & & & & \\
\hline $\begin{array}{l}\text { Removing a tick immediately } \\
\text { with pointed tweezers or other } \\
\text { type of tick remover helps to } \\
\text { prevent Lyme disease. }\end{array}$ & & & & & & & \\
\hline $\begin{array}{l}\text { Noting down the place and } \\
\text { date of the tick bite helps to } \\
\text { prevent Lyme disease. }\end{array}$ & & & & & & & \\
\hline $\begin{array}{l}\text { Going to the GP if you have } \\
\text { had a tick on your skin for } \\
\text { longer than 24 hours helps to } \\
\text { prevent Lyme disease. }\end{array}$ & & & & & & & \\
\hline
\end{tabular}

48. Imagine that you would want to go to an area where there could be ticks ('green spaces'). Please indicate below what you intend to do. When we talk about green spaces we mean being outdoors in nature areas such as woods, heathland, dunes or a park.

\begin{tabular}{|l|l|l|l|l|l|l|l|}
\hline & $\begin{array}{l}1- \\
\text { strongly } \\
\text { dis- } \\
\text { agree }\end{array}$ & 2 & 3 & 4 & 5 & 6 & $\begin{array}{l}7- \\
\text { strongly } \\
\text { agree }\end{array}$ \\
\hline $\begin{array}{l}\text { I intend to check my body for } \\
\text { ticks after every visit to a green } \\
\text { space. }\end{array}$ & & & & & & & \\
\hline $\begin{array}{l}\text { If I find a tick on my body I } \\
\text { intend to remove it } \\
\text { immediately. }\end{array}$ & & & & & & & \\
\hline $\begin{array}{l}\text { If I find a tick on my or } \\
\text { someone else's body I intend } \\
\text { to write down the place of the } \\
\text { bite on the body and the date. }\end{array}$ & & & & & & & \\
\hline $\begin{array}{l}\text { If I have a tick on my skin for } \\
\text { more than 24 hours I plan to } \\
\text { go to the GP. }\end{array}$ & & & & & & & \\
\hline
\end{tabular}

49. The following questions concern your expectations regarding tick bites in the coming year. 


\begin{tabular}{|l|l|l|l|l|l|l|l|}
\hline & $\begin{array}{l}1- \\
\text { very } \\
\text { low }\end{array}$ & 2 & 3 & 4 & 5 & 6 & $\begin{array}{l}7- \\
\text { very } \\
\text { high }\end{array}$ \\
\hline $\begin{array}{l}\text { In your opinion, how big is the } \\
\text { risk that you will be bitten by a } \\
\text { tick in the coming year? }\end{array}$ & & & & & & & \\
\hline $\begin{array}{l}\text { In your opinion, how big is the } \\
\text { risk that you will get Lyme } \\
\text { disease in the coming year? }\end{array}$ & & & & & & & \\
\hline
\end{tabular}

50. The following questions concern your expectations regarding the consequences of tick bites.

\begin{tabular}{|c|c|c|c|c|c|c|c|}
\hline & $\begin{array}{l}1- \\
\text { strongly } \\
\text { dis- } \\
\text { agree }\end{array}$ & 2 & 3 & 4 & 5 & 6 & $\begin{array}{l}7- \\
\text { strongly } \\
\text { agree }\end{array}$ \\
\hline $\begin{array}{l}\text { If I would have a tick bite, I } \\
\text { would worry about the } \\
\text { possible consequences. }\end{array}$ & & & & & & & \\
\hline $\begin{array}{l}\text { If I get a tick bite, I expect } \\
\text { serious health consequences. }\end{array}$ & & & & & & & \\
\hline $\begin{array}{l}\text { If I would have a tick bite, I } \\
\text { expect long term } \\
\text { consequences. }\end{array}$ & & & & & & & \\
\hline $\begin{array}{l}\text { I am frightened of ticks or } \\
\text { Lyme disease by all the media } \\
\text { attention around this subject. }\end{array}$ & & & & & & & \\
\hline
\end{tabular}

51. Do you have any comments?

Thank you for filling in the questionnaire! We would like to ask you to fill in a second (short) questionnaire again within 2-3 months. If you are willing to participate in the second questionnaire, you can leave your e-mail address below. Among participants filling out both questionnaires, 50 gift certificates (10 Euro each) will be raffled. Off course you may use the app as often as you like.

E-mail address:

\section{Questionnaire 2: Research on ticks and Lyme disease}

Questionnaire 2 contained some of the questions that were also asked during questionnaire $1(11,13,14,15,16,21,22,41,42,43,44,45,47,46,48,49,50)$. Questions concerning behavior in the past year in questionnaire 1 were replaced by questions concerning behavior in the past three months in questionnaire 2 . Questions regarding use of the app 'Tekenbeet' were excluded for the control group. In addition, the following questions were added to questionnaire 2: 
1. Are you familiar with the RIVM app 'Tekenbeet' about ticks and Lyme disease?

$\square$ No

$\square$ Yes, but I did not download the app

$\square$ Yes, I downloaded the app

2. When did you download the RIVM app 'Tekenbeet'

$\square$ About 1 day ago

$\square$ About 1 week ago

$\square$ About 2 weeks ago

$\square$ About 3 weeks ago

$\square$ About 4 weeks ago

$\square$ Longer than 4 weeks ago

3. Did you use the RIVM app 'Tekenbeet' after you downloaded it?

$\square$ No

Yes, 1-3 times

- Yes, 4-6 times

- Yes, 7-9 times

$\square$ Yes, more than 9 times

4. How would you rate the RIVM app 'Tekenbeet' (1-10)?

$\square 1$

$\square 2$

$\square 3$

口 4

口 5

$\square 6$

$\square 7$

$\square 8$

口 9

- 10

5. Do you currently have Lyme disease?

$\square$ Yes

口 No 


\section{Annex 2: Internal consistency of different psychosocial determinants, and their corresponding items}

\begin{tabular}{|c|c|c|}
\hline & $\begin{array}{l}\text { Nr. of } \\
\text { items }\end{array}$ & $\begin{array}{l}\text { Internal } \\
\text { consistency } \\
(\text { Omega } \\
\text { total })\end{array}$ \\
\hline $\begin{array}{l}\text { Perceived severity } \\
\text { 1. If I were to sustain a tick bite, I would be worried about } \\
\text { the possible consequences } \\
\text { 2. If I were to sustain a tick bite, I would expect this to have a } \\
\text { serious impact on my health. } \\
\text { 3. If I were to sustain a tick bite, I would expect to suffer from } \\
\text { the consequences for quite a long time. }\end{array}$ & 3 & $\Omega=0.90$ \\
\hline $\begin{array}{l}\text { Perceived susceptibility } \\
1 . \text { How do you assess the chance that you will be bitten by a } \\
\text { tick in the next year? } \\
\text { 2. How likely do you think it is that you will be diagnosed } \\
\text { with Lyme Disease in the next year }\end{array}$ & 2 & $\Omega=0.56$ \\
\hline $\begin{array}{l}\text { Self-efficacy } \\
\text { 1. I am capable of recognizing a tick on my body. } \\
\text { 2. I am capable of checking my skin for tick bites after I have } \\
\text { ventured outdoors } \\
\text { 3. I am capable of removing a tick from my skin using } \\
\text { pointed tweezers (or a different kind of tick remover). } \\
\text { 4. I am capable of writing down place and date that the tick } \\
\text { bite occurred. } \\
\text { 5. I am capable to visit a GP if a tick has been on my body for } \\
\text { over } 24 \text { hours. }\end{array}$ & 5 & $\Omega=0.72$ \\
\hline Response efficacy & 5 & $\Omega=0.80$ \\
\hline
\end{tabular}

1. Recognizing a tick when checking your body will help preventing Lyme disease.

2. Checking for ticks after every outdoor venture will help preventing Lyme disease

3. Removing a tick immediately using pointed tweezers (or a different kind of tick remover) will help prevent Lyme disease.

4. Writing down place and date when the tick bite occurred will help prevent Lyme disease.

5. Visiting a GP if a tick has been stuck on the skin for over 24 hours will help prevent Lyme disease.

Intention
1. I am planning to check my skin for ticks after every
outdoor venture.
2. If I discover a tick bite on my body, I am planning to
remove the tick immediately.
3. If I discover a tick bite on my body, I am planning to note
the place of the bite and the date it occurred.
4. I am planning to visit a GP if a tick has been stuck on my
skin for over 24 hours.




\section{Part III}

\section{Reflections and current thoughts}


称 


\section{Chapter 9}

\section{Increase in ticks and Lyme borreliosis, yet research into its prevention on the wane}

Published as:

Beaujean DJ, Crutzen R, Kengen C, van Steenbergen JE, Ruwaard D. Increase in ticks and Lyme borreliosis, yet research into its prevention on the wane. Vector Borne Zoonotic Dis, 2016 May;16(5):349-351. 
There is increased concern about the upward incidence of Lyme borreliosis (LB) in Europe, the United States, Asia, and Northern Africa [136, 39, 182]. However, effective measures to control tick populations or vaccines for LB are not yet available. Therefore, behavioral measures including performing routine body checks, using protective clothing and the application of tick repellents are of great importance. Unfortunately, acceptance and uptake of many of these preventive behaviors is currently low. Hence, effective health education and health communication aimed at promoting the uptake of preventive behaviors regarding tick bites and LB are urgently needed [17].

In this journal, Mowbray published a systematic review of educational and communicational interventions to prevent tick-borne disease covering the period 1995-2010 [113]. Mowbray included nine studies, of which the most recent one was published in 2008. Based on the limited number and low quality of studies available at the time, Mowbray recommended that more research should be conducted. Focus should be directed at improving evidence-based insights regarding the promotion of preventive behaviors among those members of the general public that exposed a greater risk of contracting LB. We fully agree with Mowbray's stance and conducted a systematic review on the same topic in May 2015, covering the period 1995-May 2015. Following a literature search, a total of nine studies were included. Surprisingly, our review yielded exactly the same studies as already included in the review by Mowbray. This means no studies were published in the seven years following 2008 on the topic of education and communication interventions to prevent tick borne diseases.

This raises the question why no new studies were conducted in recent years concerning educational and communicational interventions to prevent tickborne disease. In contrast, the annual number of publications concerning ticks and LB in general had increased from 1995 to 2015. To illustrate this, when searching PubMed for articles that include the key terms 'ticks' and 'LB', the number of articles retrieved increased from 112 in 1995 to 394 in 2010, followed by 659 in 2014. However, it might be that some unpublished results or rejected proposals exist and these would be missed by searching for publically available output. Furthermore, it is possible that some studies are still ongoing, and it could take some years before these studies will be published. When considering the reasons for a lack of research output, it could be possible that the lack of studies on tick bites and LB is due to competition from other - possibly deemed more urgent - public health topics such as tobacco, alcohol, and nutrition. Based on the PubMed searches described above, we made a pragmatic assessment of trends over time for different research themes related to ticks and LB. Studies were categorized by year (1995-May 2015) and theme, i.e. vaccines, diagnosis, treatment, based on the article's title. It was noticeable that in the initial years covered, most research concerned the prevalence and incidence of ticks and LB. In the years that followed considerably more studies were published on the topic of co-infections from tick bites and the long term sequelae of LB. The proportion of studies investigating the theme 'diagnosis' decreased from approximately $10 \%$ 
in 1995 to approximately $3 \%$ in the last five years, and research on vaccines and vaccination (circa $4 \%$ ) and treatment (circa $2 \%$ ) remained almost constant. This therefore implies that a reduction in diagnosis research output has not necessarily been due to an increased focus elsewhere, such as LB prevention work. Hopefully, the increased number of publications on tick-borne diseases - mainly on co-infections and the long-term sequelae - will function as leverage in the call for more research on education and communication interventions to prevent tick-borne disease. After all, education and communication on (prevention of) tick bites and tick-borne diseases is also needed for prevention of disease due to co-infection and the long-term sequelae of LB [156].

In this editorial, we again sound the alarm bell, just as Mowbray did a few years ago. As long as there are no effective measures for controlling tick populations and there is no vaccine available, we rely solely on health education and communication efforts to prevent tick bites and LB. Since checking one's body for ticks after every visit to nature is not a universally accepted behavior, further prevention efforts need to be established, implemented and honed on the basis of scientific rigor.

First of all, insight into public perceptions and protective behavior regarding LB is crucial in order to develop a successful prevention program [74]. It is important to design and evaluate interventions with different populations in mind, because of variation in pre-existing levels of knowledge and perceptions about LB [52, 113]. Furthermore, future studies should be of a higher scientific quality: application of reliable and valid data collection methods, such as using standardized assessment tools and trained assessors blinded to the intervention. In addition, Randomized Controlled Trials (RCT's) should be conducted, to measure the actual behavioral change effect of protective measures against LB. Prevention programs targeting tick bites and LB should aim at influencing those determinants related to preventive behaviours, e.g. knowledge, concern about LB, perceived efficacy of wearing protective clothing [17]. To illustrate this, an interactive and practical approach to increase self-efficacy could be applied, such as practicing the search for and removal of a tick on a rubber arm [52], or enabling individuals by providing tools to check for ticks, to remove ticks, and to apply repellent (DEET) to skin, and permethrin to clothing [108]. However, these are just examples; we emphasize the use of the Intervention Mapping protocol for the development of health promotion programs to link determinants of behaviors to appropriate behavior change methods [11]. Intervention Mapping describes the process of health promotion program development in six steps, from recognition of a need or problem to the identification of a solution. With such a systematic approach - whereby each step is based on previous steps - evidence-based health promotion programs can be developed, implemented and evaluated.

We call on researchers and funders to prioritize research in the field of public health interventions for tick bites and LB because, in the words of Benjamin Franklin, "an ounce of prevention is worth a pound of cure". 


\section{Chapter 10}

\section{General discussion}

\section{Partly published as book chapter:}

D.J. Beaujean and H. Sprong. Evidence-based health promotion programmes and tools to prevent tick bites and Lyme borreliosis. In: M.A.H. Braks, S.E. van Wieren, W. Takken and H. Sprong editors, Ecology and prevention of Lyme borreliosis, Wageningen Academic Publishers, 2016. 
Lyme borreliosis (LB) is the most commonly reported tick-borne disease in Europe and North America. As long as there are no effective measures for controlling tick populations in nature and there are no vaccines available, we have to rely primarily on health education to prevent and adequately deal with tick bites and LB. Therefore, it is surprising to see that the number of studies on health education interventions to prevent tick bites and LB is revalitvely small in contrast to published studies in the field of diagnostics and treatment of LB $[113,14]$. On top of that, one might say that by implementing effective educational interventions on ticks and LB, diagnostics and treatment will become less necessary. It is therefore pivotal that time and effort is spent now on prevention of tick bites and LB!

The first objective of this thesis was to gain insight into the general public's knowledge, perceptions and behavior in relation to tick bites and LB. As school children are a distinct and vulnerable risk group for tick bites and LB, we targeted our research specifically towards this group. Children are frequently active in bushy areas with high grass. Moreover, because half of all erythema migrans is situated on the head and neck and can go unnoticed, LB can be more difficult to identify in children and late manifestations can present with non-specific chronic complaints. Therefore, one of the inventory studies and one of the intervention studies was focused specifically on children.

The second objective was to evaluate the effects of four newly developed interventions (a movie, a leaflet, an online educational video game and an application for the mobile phone) in terms of social-cognitive variables and behaviour related to prevention of ticks and LB among the general public and schoolchildren in the Netherlands.

In the following paragraphs, the main research findings regarding these two objectives are described. Subsequently, the theoretical and methodological considerations regarding the studies are examined. Finally, recommendations for public health practice, policy and future research are provided.

\section{Main findings}

\section{Knowledge}

Good knowledge about how to prevent tick bites and LB is scarce among adults in the Netherlands (Chapter 2). Only 35\% of the respondents, for example, had a high knowledge level (four out of five knowledge questions answered correctly), and only a quarter was aware that using repellent skin products can protect against tick bites. Meanwhile, in the study of schoolchildren (Chapter 3), $70 \%$ had a high knowledge level, as they answered six out of seven knowledge questions correctly. 


\section{Perception}

In the study of the general public (Chapter 2), the perception of the severity of the disease was high; almost all (95\%) adult respondents perceived LB as a (very) severe disease. However, only a minority of the respondents (36\%) perceived themselves as quite/very susceptible to LB. This means that the public underestimates the risk, especially given the fact that people in the Netherlands, in particular those who often visit woodland areas, have a considerable risk of being bitten by ticks and developing LB. School children had a more realistic perception of LB than adults; $69 \%$ believed they were susceptible to illness caused by a tick bite (Chapter 3 ). Wearing protective clothing and checking the skin after being outdoors were perceived as the most effective measures for preventing tick bites. The self-efficacy was highest for checking the skin after being outdoors and removing ticks from the skin.

\section{Behavior}

A minority of respondents in our study among the general public (Chapter 2) was used to taking preventive measures, varying from using insect repellent skin products $(6 \%)$, to checking the skin after being outdoors $(32 \%)$ and wearing protective clothing (37\%). A history of tick bites, higher levels of knowledge and moderately high levels of worry were significant predictors of skin checking. Significant predictors of wearing protective clothing were higher knowledge levels, higher levels of worry about LB, higher levels of perceived efficacy of wearing protective clothing, and being unemployed/retired. In the study of school children, half of them reported being checked occasionally for tick bites after having been outside. Nearly one third of the participating children never had a tick check, and only $18 \%$ of them indicated they were checked after every visit to nature. Children with a high level of knowledge and those knowing persons with LB were more likely to be checked often. Similarly, children who considered tick checks as somewhat or very important were checked more frequently by their parents/carers.

\section{Effect of interventions}

In Part I we present the inventory studies on determinants in relation to preventive behavior regarding tick bites and LB among adults (Chapter 2) and school children (Chapter 3), the identification and profiling of at risk groups (Chapter 4) and on the requirements that users have in relation to a mobile phone application (Chapter 5). Based on the results of these inventory studies in Part I (Chapters 2-5), four educational interventions on preventing tick bites and LB were developed: a movie, a leaflet, an online serious game and a mobile app.The content of these four interventions was partly comparable in regard to the information provided on what ticks look like, their preferred habitat and how to check and remove ticks correctly after being outdoors, but the 
app 'Tekenbeet' (Tick bite) offers a more interactive experience, such as instruction videos and a tick alarm that can be set to a tick-related activity by the user. In Part II (Chapters 6, 7 and 8) the effects of these four interventions on the social-cognitive determinants and preventive behaviors in relation to tick bites and LB among the general public and children in the Netherlands were evaluated. The effects of the interventions were comparable: people appreciated the interventions, they learnt quickly from it and some of the interventions motivated them to check their skin for ticks more frequently. None of the interventions was particularly effective, some of the interventions were, in fact, as effective as the control interventions (only filling out a questionnaire). Thus our evidence indicates that simply completing a questionnaire about a behavior increases the likelihood that the person will perform that behavior. This is known as the "mere measurement' effect and suggests that even a simple questionnaire can result in changes in knowledge and preventive behavior (frequency of tick checks).

\section{Theoretical considerations}

In Part I of this thesis, the inventory studies of adults and school children are presented (Chapter 2 and 3), so that a better understanding of their preventive behavior regarding ticks and LB is achieved. One way to increase the chances that public health programmes are successful is to ensure that they are based on psychological theories aimed at explaining/changing behaviour. A number of these theories exist that propose different factors that may drive behavioral change. Although numerous theories exist, many of the components which they are composed of are similar. In the inventory studies the Protection Motivation Theory (PMT) was used [120]. The PMT proposes that the intention to protect oneself depends upon four factors:

1. The perceived severity of a threatened event (LB);

2. The perceived probability of the occurrence, or vulnerability (the perceived vulnerability of the individual to get LB);

3. The efficacy of the recommended preventive behavior (the perceived response efficacy);

4. The perceived self-efficacy (the level of confidence in one's ability to undertake the recommended preventive behavior).

The questionnaires of both the inventory and evaluative studies were focused on the determinants of the above-mentioned PMT and the Health Belief Model (HBM), a widely used psychological model that attempts to explain and predict health behaviors [42]. This resulted in the formulation of questions concerning the following determinants: knowledge, perceived severity, perceived vulnerability, perceived response efficacy, perceived self efficacy, cues to action, perceived benefits and barriers and (intended) preventive behavior. 
The inventory studies in Part I (Chapters 2 and 3) showed that a high level of general knowledge about preventing tick bites and LB is scarce among adults in the Netherlands, but common among school children. Whether higher levels of knowledge positively influence preventive behaviors is uncertain. On the one hand, Gould et al. and Butler et al. demonstrated that higher levels of knowledge seem to positively influence preventive behavior $[67,30]$. On the other hand, research conducted in areas where LB is endemic has demonstrated that, despite having adequate knowledge about its symptoms and transmission, many people do not perform behaviors to reduce their risk of infection [46]. These findings suggest that knowledge is not the decisive determinant of the uptake of preventive behavior. However, to correctly perform the advised preventive behavior, knowledge is certainly essential, as people need to know, for example, how to recognise a tick, how to remove a tick and what the symptoms of LB are. Therefore, we conclude that public health programmes should not focus only on knowledge transfer, but also on the perception of the disease, self-efficacy and the efficacy of measures [114].

Although nearly all adult respondents perceived LB as a (very) severe disease, we can demonstrate that they underestimated their personal risk. The underestimation of risk is found to have been caused by factors such as lack of knowledge. Furthermore, if people underestimate their personal risk they will be less willing to engage in preventive behavior $[31,150]$. This underpins the need to focus on awareness of personal risk in public health programmes. Furthermore, Gould et al. concluded that sustainable LB and tick-borne disease prevention and control programmes should focus on promoting measures which are most likely to be adopted by residents in endemic areas [67]. Based on the levels of perceived self-efficacy of the measures in our study, this means that the interventions should focus on checking the skin after being outdoors and removing ticks from the skin. If other measures were to be targeted, then it would be crucial to also address self-efficacy regarding these measures.

Few people took measures to prevent LB; depending on the particular measure in question, response rates ranged from $6 \%$ to $37 \%$ of the adults (Chapter 2) and $18 \%$ of the children reported they were checked for tick bites after every visit to nature (Chapter 3). In comparison with other studies these percentages are rather low. Studies in the US reported that $66 \%-99 \%$ of the respondents took measures to prevent LB $[67,126,145]$. Heller et al. found that $78 \%$ of the Brazilian respondents wore long trousers when outdoors and Herrington reported that half of the US respondents also did this $[74,76]$. The percentage of respondents checking their skin after being outdoors (32\%) is still comparable with the results of a number of other studies; i.e. Heller et al. reported that $28 \%$ of the Brazilian population checked their skin for ticks [74]. However, the main difference in measure uptake is the lower levels of wearing protective clothing in the Netherlands. This could be caused by the moderate climate of The Netherlands; people like wearing shorts and short sleeved shirts during the few weeks of the year that temperatures are relatively high. Also, the fact that people believe 
that wearing protective clothing in nature is overdone, as reported in Chapter 2 , might be a reason for the low levels of wearing protective clothing. Because these kinds of underlying reasons for non-compliance are difficult to change, we agree with Gould's opinion that sustainable LB and tick-borne disease prevention and control programmes should focus on promoting measures most likely to be adopted by residents in endemic areas [67].

Chapter 3 demonstrated that children with a good knowledge score and children who considered tick checks as somewhat or very important were checked more frequently by their parents/carers, thus it seems useful to focus public health programmes on both children and their parents. Furthermore, as children with a high knowledge level were checked more frequently by their parents, it would be interesting to disentangle cause and effect (whether children influence their parents to perform preventive behavior or parents influence their children). Studies on knowledge transfer that aim to improve health literacy about paediatric infectious disease prevention in families showed that children are able to play an active role in family's health situations [144, 20, 90, 134].

The studies in Chapters 2 and 3 explained the preventive behavior of adults and children regarding ticks and LB through determinant derived from PMT and HBM. The explicit use of these theories helps to improve the uptake of preventive behaviors across a wide range of health topics, from condom use, to smoking cessation, to taking exercise [7]. Designing an intervention on the basis of qualitative interviews with the target population, and a consideration of the determinants of behavior suggested by these theories, as we did in the studies of Part I, is likely to produce the most successful change, as demonstrated by the studies in Mowbray's review [113]. Since the explicit use of psychological theory to inform intervention development is very limited in the literature on interventions to prevent tick bites and LB, this thesis is a notable exception.

But, besides understanding the behavior, it is necessary to translate theoretical methods of behavioral change into practical applications that are used by the target group. This is not only relevant during the translation of methods into practical applications, but also when choosing the delivery channels/vehicles and designing the content, structure and layout of the intervention in general [11]. As the target group of tick bites and LB prevention programmes comprises the entire general public it is necessary to reach both children and adults as well as people with a low or moderate risk and high risk groups (Chapter 4). This has been taken into account when choosing the various delivery channels. For example, as online video games are popular among children, both boys and girls, this medium is a potential medium for reaching children to provide information about tick bites and LB [133]. Almost all children between 6 and 12 years play online video games [116]. As the game was introduced via schools, a large group of children were reached - regardless of their risk of, or interest in, tick bites and LB. This is a big advantage of integration in 'mandatory' school programmes. On the other hand, the mobile app 'Tekenbeet' is an example of an intervention which is primarily aimed at intrinsically tick-interested people 
(who often estimate their risk of tick bites as high), as these people are willing to download an app of this type on their mobile phone. As $94 \%$ of the general public has internet access and $56.7 \%$ use the Internet to search for information on health, the online leaflet and movie are examples of interventions which are accessible to the entire general public [160]. The leaflet is also available in a printed version via Public Health Services (PHS), general practitioners, national nature organisations, Scouting Netherlands and the Dutch Foundation for Lyme patients. Finally, the usage of the leaflet and movie on the internet or the printed leaflet depends, of course, on the interest of the public and their familiarity with it.

In Part II (Chapters 6, 7 and 8) the effects of four different interventions were studied: a movie, a leaflet, a mobile app and an online serious video game. These interventions were all developed, based on the results of the inventory studies in Part I, Chapters 2-5. This is an added-value of our approach and conforms to the principals of the Intervention Mapping approach (IM) [11]. Designing an intervention based on interviews with the target population, and a consideration of the determinants of behavior suggested by psychological theories and empirical evidence, is likely to give the best chance of success, as Mowbray demonstrated in her review. This is the second step of IM and takes place after the objectives of the intervention have been set. Unfortunately, in many other studies it is unclear whether these are based on theories of change behavior [113]. After designing, organising and implementing the intervention, the last phase of IM is to make a plan for the evaluation of the intervention. As demonstrated in Chapters 6, 7 and 8 , all the interventions developed were appreciated and effective to some extent and none of the interventions was outstanding. So, all these educational interventions need to be seen as complementary to each other.

This whole assortment of interventions should be made easily accessible to everyone, as LB has the 12th highest disease burden when compared to the comprehensive DALY estimates for 32 other infectious diseases, largely based upon the 'Burden of Communicable Disease in Europe' (BCoDE) project [1]. The disease burden attributed to LB demonstrates the need for continued prevention and control efforts to be made. Between 2009 and 2014, the analyses of the average annual numbers of ticks per field site per month conducted by the tick monitoring programme of Wageningen University did not indicate a significant change in Ixodes ricinus abundance in the Netherlands. Actually, in 2014, for the first time since the start of the identical GP surveys in 1994 in the Netherlands, there has been observed a decreased incidence in tick bite GP consultations. Whether people decide to consult a physician for a tick bite, rather than remove the tick themselves, may be influenced by having tick bites frequently, public health education and media attention. So we tentatively propose that the decrease in GP consultations for tick bites may reflect the impact of the extensive national media attention on LB each year around springtime, with the national awareness week on tick bites (http: //www.weekvandeteek.nl) to mark the onset of the tick bite season. The National Institute for Public Health and the 
Environment (RIVM), and Wageningen University, together with other stakeholders distributed public health education about the relevance of body checking, prompt tick removal and when to visit a physician. Perhaps the four newly developed intervention tools have also facilitated this development during this period [79]. However, an ongoing focus on this wide variety of educational interventions should be retained to ensure that people simply know where they can find these interventions. Especially online interventions need ongoing attention because, as opposed to a leaflet, these are not physically present in the immediate environment of people. It would be useful to integrate the online serious game 'Teekcontrol' in an educational school programme on ticks and LB.

As none of the interventions was able to establish a long term effect, it is important to keep a continuous focus on education. The 'Tekenbeet' app seems to be the most appropriate tool for this purpose as it makes all information and the movie easily accessible on a mobile phone and can be used when and where it is needed (even without internet access).

Finally, health education is not the only measure which can be taken to tackle the ticks and LB problem. In other fields, like the prevention of traffic accidents, for example, a multidisciplinary approach involving improved infrastructure, better car safety, speed limits, mass media campaigns, and stricter legislation (increased financial penalties) resulted in a substantial and ongoing decrease in the number of accidents since 1973 [166]. A multidisciplinary approach to combat the tick and LB problem, directed at individual behavior, diagnosis, treatment, tick habitats, wildlife control and applying pesticides is needed. Individuals, industry and government have equal responsibility for this and need to unite to tackle this problem.

\section{Methodological reflections}

\section{Use of psychological theory}

The studies in Chapters 2 and 3 explained the preventive behavior of adults and children through the PMT and the HBM. However, alongside the PMT and the HBM, there is a plethora of theories to explain and change behaviors. Several attempts have been made to build an integrative theory, and some have even striven for a Theory of Everything. Theory is used to understand behavior, which is one of the aims of health psychology and a prerequisite for changing behavior [125]. And so, with any problem that needs to be tackled, it is important to decide which approaches from which theories are useful. The choice made in this thesis was to use the PMT and the HBM. However, it could be that insight from other psychological theories has added value on top of these theories. 


\section{Target group and recruitment methods}

The risk of tick exposure is greatest in the woods and in the edge area between lawns and woods; however, ticks can also be carried by animals onto lawns and gardens and into houses by pets. Campers, hikers, scouts, outdoor workers, and others may be exposed to infected ticks in wooded, brushy, and grassy places. People who spend time in heavily wooded areas where infected ticks are common are at higher risk of exposure. Almost every member of the general Dutch population is part of the target group for education on ticks and LB. Therefore, public campaigns in many countries aimed at preventing tick bites and LB use the strategy of providing every member of the public with all the relevant preventive measures [132]. In this context, there is mention of the so-called: "prevention paradox', first formally described in 1981 by the epidemiologist Geoffrey Rose [137]. The prevention paradox describes the seemingly contradictory situation where the majority of cases of a disease come from a population at low or moderate risk of that disease, and only a minority of cases come from the high risk population. This is because the number of people at high risk is small. For example, outdoor workers are at a higher risk of exposure to ticks than the general public. Yet, most cases of LB occur in the general public. This situation is paradoxical because it is common and logical to equate high-risk populations with the major disease burden. Greater societal gain will occur by achieving a small reduction in risky behavior within the far larger group of 'risky' outdoor visitors with fewer tick bites than by trying to reduce the number of tick bites among a smaller number of high-risk outdoor workers. The prevention paradox is always a problem which is encountered when governments or organisations attempt to introduce a large scale intervention to improve health. Many public health interventions that aim to improve health have relatively little influence or perceptible benefits on the health of most people. Therefore, for one person to benefit, many people have to change their behavior - even though they may receive no benefit, or even suffer, from the change. Both the general public (children and adults with low/moderate risk) and the high risk groups are served by the various interventions described in this thesis. Of course they are all accessible to everybody, but for example, the game 'Teekcontrol' was developed especially for children and the app 'Tekenbeet' will be downloaded mainly by people who have a high risk of tick bites and LB.

In Chapters 2 and 6, we used a random sample from a representative Internet panel of panel members aged 18 years and older. As the movie and the leaflet described in Chapter 6 are aimed at the general public (and not at a specific high risk target group), these panel members are good representatives of the target group of these interventions. However, to evaluate the mobile app 'Tekenbeet', in Chapter 8, we used a quasi-experimental design. Respondents were recruited through several channels like the RIVM-website (http://www.rivm.nl/tekenbeet) and a number of other external websites from national nature organisations like Scouting Netherlands and the Tick Bite 
Diseases Foundation. They were assigned to a (non-) (intervention) group based on their willingness to download the app or not. This recruitment method via the websites attracts participants who are most likely to be interested in information on ticks and LB. This group, therefore, represents the main target group that the mobile app is focused on (native tick-interested people), and from which it is important to get relevant results. However, since these respondents are intrinsically tick-interested people - and therefore not a representative sample of the general Dutch population - it is conceivable that the results of the evaluation would be more positive. In short, although this was a very efficient recruitment technique, the conclusions about the effects of the app should be judged in that light.

\section{Mere measurement effect}

In all evaluation studies (Chapters 6, 7 and 8) we included a control group to analyse the effects of the interventions at $\mathrm{t} 1$ and $\mathrm{t} 2$. In the evaluation study of the game (Chapter 7), we found that simply by filling out the questionnaire a 'learning effect' was achieved. Evidence indicates that completing a questionnaire about a behavior increases the likelihood that the person will perform that behavior. This is known as the mere measurement effect [65] and suggests that even completing a simple questionnaire can result in changes in knowledge and preventive behavior (frequency of tick checks). In order to distinguish between the mere measurement effect and any exogenous exposure to public information on ticks and LB via mass media, social networks or family, we included a second control group in the evaluation study of the leaflet and the movie (Chapter 6). The results of his second control group showed that repeated completion of the questionnaire had a positive effect on knowledge and intention. This underlines the assigned effect of repeatedly filling in the questionnaire, notwithstanding the effect of public exposure to information on ticks and LB. The effects of interventions on behavior should be interpreted in the light of the presence of this effect.

\section{Measurability of effects}

The effects of the educational tick bite and LB interventions in this thesis are measured by investigating the (intention to) adopt preventive behavior; do those exposed to the interventions (have the intention to) perform the desired preventive behavior? Performing an observational study to measure the behavior would seem to be the ideal method of researching this issue, but this is a complicated and time-consuming research method implying observations of the preventive behavior of people who just have visited wooded areas. This could mean, for example, accompany each person individually to their home to observe their preventive behavior. Therefore, the studies included in this thesis relied on the self-reporting of behavior. One of the difficulties is that self-reporting may reflect actual behavior, but can also be heavily influenced by numerous other 
factors, including the social desirability of reporting good behavior, recall bias, and systematic changes in a participant's understanding of what counts as effective behavior $[140,12,29]$. Whether these difficulties play a role in the studies in this thesis is unclear. In future research, it would be interesting to perform a prospective diary study; after being outdoors participants register daily their preventive behavior in an (online) prepared diary by simply ticking boxes identifying preventive measures. This method can avoid recall bias and any individual interpretations of effective behavior [155]. Another difficulty is deciding on the timeframe to use. On the one hand, if the measurement is taken too early, people are not at risk of tick bites and therefore do not perform preventive behavior (a tick check). The first measurement showed that around half of the respondents were regularly (every week/once a month) physically active in a garden, $37 \%$ visited the woods regularly and $21 \%$ visited open areas regularly. For questions about preventive behavior in the evaluative studies, this was corrected by excluding respondents who have not been in green areas (being outdoors in nature areas such as woods, heathland, dunes or a park) between $t 1$ and $t 2$. On the other hand, if the measurement is taken too late, undertaking the preventive behavior recommended by the intervention might have been forgotten meanwhile.

\section{Recommendations for practice, policy and research}

\section{Practice}

The studies in this thesis demonstrate that all newly developed interventions are effective. PHS, general practitioners, national nature organisations, Scouting Netherlands and the Dutch Foundation for Lyme patients are advised to use this mix of interventions to reach as many people as possible to encourage them to take part in prevention programmes on ticks and LB. These programmes should not only focus on adults, but also on school children. For example, by integrating the game 'Teekcontrol' in a school education programme on ticks and LB, both children and their parents can be reached.

The development of effective interventions on tick bites and LB is a challenge in itself, but the implementation of the interventions is even more important. The development of these interventions was made possible by a one-off subsidy from the Ministry of Health, Welfare and Sport (VWS). However, developing these interventions without any options for their structural implementation is not likely to achieve a sustained impact on public health. In particular, when a prevention programme is aimed at specific measures to prevent a 'seasonal risk' that is only present for a number of months per year, and the interventions have no long lasting effects (Part II, Chapters 6,7,8), intermittent attention is needed. We recommend that the RIVM and PHS maintain ongoing advertising campaigns throughout the entire tick season, every year. Online interventions like online games, movies and apps, are particularly in need of advertising as they are not 
tangible products like a leaflet or a poster, which you easily, by accident, can encounter. Therefore, we recommend that online social media (Twitter, Facebook, Instagram etc) be used, as well as traditional media (newspapers, radio, television) to repeatedly draw attention to these online interventions.

\section{Policy}

In different fields there is a need to adapt current policy. Firstly, there is a need for more research into educational and communicational interventions to prevent tick bites and LB as there is a lack of studies on this topic [113, 14]. This is in contrast to the increasing number of studies on the diagnosis and treatment of LB [14]. Additionally, studies on the effects of the prevention of tick bites and LB on health costs and quality of life are also important. Moreover, as long as there are no effective measures for controlling tick populations in nature and no vaccines are available, we will have to rely on information provision and communication to prevent tick bites and LB.

Furthermore, governments and research funds are advised to fund above all the development of systematic development of prevention programmes based on the principals of intervention mapping. Besides, the provisional funding of the development of an systematicly positive developed prevention programme should be followed by the structural funding of an implementation programme and a costs- and effect evaluation of this implementation.

And finally, it is very important that evidence based guidelines on the prevention of tick bites and LB are available for professionals in public health. These guidelines should focus on measures which are practical and achievable for individuals. As measures like applying pesticides and reducing tick habitat cannot be performed by an individual, and vaccines are not available yet, they should not be included in guidelines, like the CBO guideline [32]. This guideline should focus primarily on educating the public to avoid tick areas, wear protective clothing, use insect repellent and remove ticks promptly. Moreover, it should be considered to complement the CBO guideline with the four newly developed effective intervention tools to change preventive behavior: the app 'Tekenbeet' (Tick bite), the online serious game 'Teekcontrol', the movie and the leaflet.

\section{Future research}

In line with our policy recommendation for principals and research funds related to the funding of research, future research should be focused more on educational and communicational interventions. The more effective the educational and communicational interventions on ticks and LB are, the fewer diagnostics and therapies will be needed. More specifically, in the study of school children, their parents were not included. Although children are a risk group for tick bites and LB, they cannot be held responsible for checking themselves for ticks, this is the responsibility of parents. As children have a high level of knowledge level 
about ticks and LB it would be interesting to explore whether the children can influence their parents' preventive behavior in relation to checking their children for ticks. According to evidence and to our own research findings, in the interventions, it is mainly the preventive measures that the public are most likely to adopt and/or fit with their perceptions that are promoted like checking the body for ticks and removing ticks as quickly as possible. It would be interesting to investigate the barriers that stop other preventive measures from being taken like using insect repellent skin products or wearing protective clothing. Maybe it will give rise to new opportunities in the field of preventive behavior.

And finally, although information on the prevention of tick bites and LB has been provided, there has - so far - been no practical training tool to teach people how to remove ticks. Learning how to perform a complex activity, such as removing ticks, requires training. Recently, a prototype of the 'TekenTrekTrainer' (TickRemovalTrainer) has been developed. With this tool people can be trained to develop their skills by removing 3D-printed ticks from a plastic skin model and thereby increase their self efficacy in removing ticks. This tool has been taken in production recently (limited edition). An evaluation study on the learning effects of practical training with the 'TekenTrekTrainer' would be an innovative addition to all the other evaluation studies on existing interventions aimed at preventing tick bites. 


\section{References}

[1] BCoDE. European Centre for Disease Prevention and Control. http: //ecdc.europa.eu/en/healthtopics/burden_of_communicable diseases/Pages/Tool . aspx. Accessed 29 August 2016.

[2] Citizens initiative on Lyme disease. https://petities.nl/petitions/ burgerinitiatief-de-ziekte-van-lyme/. In Dutch. Accessed $29 \mathrm{Au}-$ gust 2016.

[3] Lyme disease knowledge, attitudes, and behaviors - Connecticut. MMWR Morb Mortal Wkly Rep, 41(28):505-507, 1992. Centers for Disease Control and Prevention (CDC).

[4] C. Aenishaenslin, A. Michel, P. Ravel, L. Gern, F. Milord, J.P. Waaub, and D. Belanger. Factors associated with preventive behaviors regarding Lyme disease in Canada and Switzerland: A comparative study. BMC Public Health, 15:185, 2015.

[5] A. Agresti. Categorical Data Analysis. Hoboken, New Jersey, Wiley, 2nd edition, 2002.

[6] J.R. Anderson, L.M. Reder, and H.A. Simon. Situated learning and education. Educational Researcher, 25(4):5-11, 1996.

[7] C.J. Armitage and M. Conner. Social cognition models and health behavior: A structured review. Psychol Health, 15:173-189, 2000.

[8] British Infection Association. The epidemiology, prevention, investigation and treatment of Lyme borreliosis in Unites Kingdom patients: A position statement by the British Infection Association. J Infect, 62(5):329-338, 2011.

[9] R.M. Bacon, K.J. Kugeler, and P.S. Mead. Surveillance for Lyme disease United States, 1992-2006. MMWR Surveill Summ, 57(10):1-9, 2008.

[10] A. Bannwart. Chronische lymphocytäre Meningitis, entzündliche Polyneuritis und "Rheumatismus": Ein Beitrag zum Problem "Allergie und Nervensystem”. Arch Psych Nervenkrank, 113:248-376, 1941. 
[11] L.K. Bartholomew, G.S. Parcel, G. Kok, N.H. Gottlieb, and M.E. Fernández. Planning Health Promotion Programs: an Intervention Mapping Approach. John Wiley And Sons Ltd, San Francisco CA, Jossey-Bass, 3rd edition, 2011.

[12] R.F. Baumeister, K.D. Vohs, and D.C. Funder. Psychology as the science of self-reports and finger movements: Whatever happened to actual behavior? Perspectives on Psychological Science, 2(4):396-403, 2007.

[13] B.R. Bayles, G. Evans, and B.F. Allan. Knowledge and prevention of tickborne diseases vary across an urban-to-rural human land-use gradient. Ticks Tick-borne Dis, 4(4):352-358, 2013.

[14] D. Beaujean, R. Crutzen, C. Kengen, J. van Steenbergen, and D. Ruwaard. Increase in ticks and Lyme borreliosis, yet research into its prevention on the wane. Vector Borne Zoonotic Dis, 16(5):349-351, 2016.

[15] D. Beaujean, L. van Velsen, J.E.W.C. van Gemert-Pijnen, A. Maat, J.E. van Steenbergen, and R. Crutzen. Using risk group profiles as a lightweight qualitative approach for intervention development: an example of prevention of tick bites and Lyme disease. JMIR Res Protoc, 2(2):e45, 2013.

[16] D.J. Beaujean, R. Crutzen, F. Gassner, C. Ameling, A. Wong, van Steenbergen J.E., and D. Ruwaard. Comparing the effect of a leaflet and a movie in preventing tick bites and Lyme disease in the Netherlands. BMC Public Health, 16:495, 2016.

[17] D.J.M.A. Beaujean, M. Bults, J.E. van Steenbergen, and H.A.C.M. Voeten. Study on public perceptions and protective behaviors regarding Lyme disease among the general public in the Netherlands: implications for prevention programs. BMC Public Health, page 225, 2013.

[18] D.J.M.A. Beaujean, F. Gassner, A. Wong, J.E. van Steenbergen, and R. Crutzen. Determinants and protective behaviors regarding tick bites among school children in the Netherlands: a cross-sectional study. BMC Public Health, 13:1148, 2013.

[19] Y. Benjamini and Y. Hochberg. Controlling the false discovery rate: A practical and powerful approach to multiple testing. Journal of the Royal Statistical Society Series B (Methodological), 57(1):289-300, 1995.

[20] P.D. Bhore, C.P. Bhore, and S. Powar. Child-to-parent education: a pilot study. Indian J Lepr, 64(1):51-57, 1992.

[21] P.M. Bingham, S.L. Galetta, B. Athreya, and J. Sladky. Neurologic manifestations in children with Lyme disease. Pediatrics, 96:1053-1056, 1995. 
[22] S.E. Boslaugh, M.W. Kreuter, R.A. Nicholson, and K. Naleid. Comparing demographic, health status and psychosocial strategiesof audience segmentation to promote physical activity. Health Educ Res, 20(4):430-438, 2005.

[23] V. Braun and V. Clarke. Using thematic analysis in psychology. Qualitative Research in Psychology, 3(2):77-101, 2006.

[24] N.T. Brewer, N.D. Weinstein, C.L. Cuite, and J.E. Herrington. Risk perceptions and their relation to risk behavior. Ann Behav Med, 27(2):125-130, 2004.

[25] D.M. Broekhuijsen-van Henten, K.P. Braun, and T.F.W. Wolfs. Clinical presentation of childhood neuroborreliosis; neurological examination may be normal. Arch Dis Child, 95(11):910-914, 2010.

[26] J. Brug, A.R. Aro, A. Oenema, O. de Zwart, J.H. Richardus, and G.D. Bisschop. Sars risk perception, knowledge, precautions, and information sources, the Netherlands. Emerg Infect Dis, 10(8):1486-1489, 2004.

[27] M. Bults, D.J.M.A. Beaujean, O. de Zwart, G. Kok, P. van Empelen, J.E. van Steenbergen, J.H. Richardus, and H.A.C.M. Voeten. Perceived risk, anxiety, and behavioural responses of the general public during the early phase of the Influenza A (H1N1) pandemic in the Netherlands: results of three consecutive online surveys. BMC Publ Health, 11:2, 2011.

[28] W. Burgdorfer, A.G. Barbour, S.F. Hayes, J.L. Benach, E. Grunwaldt, and J.P. Davis. Lyme disease - a tick-borne spirochetosis? Science, 216(4552):13171319, 1982.

[29] T.A. Burke, J.R. McKee, H.C. Wilson, R.M.J. Donahue, A.S. Batenhorst, and D.S. Pathak. A comparison of time-and-motion and self-reporting methods of work measurement. Journal of Nursing Administration, 30(3):118-125, 2000 .

[30] A.D. Butler, T. Sedghi, J.R. Petrini, and R. Ahmadi. Tick-borne disease preventive practices and perceptions in an endemic area. Ticks Tick Borne Dis, 7(2):331-337, 2016.

[31] M.L. Cartter, T.A. Farley, H.A. Ardito, and J.L. Hadler. Lyme disease prevention-knowledge, beliefs, and behaviors among high school students in an endemic area. Conn Med, 53(6):354-356, 1989.

[32] CBO-guideline Lyme disease. http://www.nvvg.nl/images/stories/ Richtlijn_lymeziekte_definitief_18_juli_2013.pdf. In Dutch. Accessed 29 August 2016. 
[33] Central committee on research involving human subjects: Manual for the review of medical research involving human subjects. CMMO. http:// www. ccmo.nl/en. Accessed 29 August 2016.

[34] Confirmed Lyme disease cases by age and sex - United States, 2001-2010. Centers for Disease Control Prevention (CDC). http://www.cdc.gov/ lyme/stats/chartstables/incidencebyagesex.html. WebCite Cache ID 6KagJf3ne. Accessed 23 October 2013.

[35] Data and statistics. Centers for Disease Control Prevention (CDC). http: //www.cdc.gov/lyme/stats/index.html. Accessed 21 March 2016.

[36] How many people get Lyme disease? Centers for Disease Control and Prevention (CDC). http://www.cdc.gov/lyme/stats/humancases . html. Accessed 29 August 2016.

[37] Lyme disease graphs. Centers for Disease Control Prevention (CDC). http: //www.cdc.gov/lyme/stats/chartstables/incidencebyagesex. html. Accessed 29 August 2016.

[38] Preventing Tick Bites on People. Centers for Disease Control and Prevention (CDC). http://www.cdc.gov/lyme/prev/on_people.html. Accessed 29 August 2016.

[39] Reported Cases of Lyme Disease by Year, United States, 1995-2014. Centers for Disease Control Prevention (CDC). http://www.cdc.gov/lyme/ stats/chartstables/casesbyyear.html. Last modified 2015 March 1. Accessed 9 November 2015.

[40] Signs and Symptoms of Untreated Lyme Disease. Centers for Disease Control and Prevention (CDC). http://www.cdc.gov/lyme/signs_ symptoms/index.html. Accessed 29 August 2016.

[41] L. Chambers and S. Sullivan. Reflections on Canada's public health enterprise in the 21st century. Healthc Pap, pages 22-30, 2007.

[42] V.L. Champion and C.S. Skinner. The health belief model. In K. Glanz, B.K. Rimer, and K. Viswanath, editors, Health behavior and health education: theory, research, and practice, pages 45-65. Jossey Bass, San Francisco, CA, 2008.

[43] H.J. Christen, F. Hanefeld, H. Eiffert, and R. Thomsen. Epidemiology and clinical manifestations of Lyme borreliosis in childhood. a prospective multicentre study with special regard to neuroborreliosis. Acta Paediatr Suppl, 82(386):1-75, 1993.

[44] R.P. Clark and L.T. Hu. Prevention of Lyme disease and other tick borne infections. Infect Dis Clin North Am, 22(3):381-396, 2008. 
[45] A. Cooper. The inmates are running the asylum: why high-tech products drive us crazy and how to restore the sanity. SAMS Publishing, 1999.

[46] K.M. Corapi, M.I. White, C.B. Phillips, L.H. Daltroy, N.A. Shadick, and M.H. Liang. Strategies for primary and secondary prevention of Lyme disease. Nature Clinical Practice, 3(1):20-25, 2007.

[47] J. Coumou, T. van der Poll, P. Speelman, and J.W.R. Hovius. Tired of Lyme borreliosis. Lyme borreliosis in the Netherlands. Neth J Med, 69(3):101-111, 2011 .

[48] R. Crutzen and A.S. Göritz. Social desirability and self-reported health risk behaviors in web-based research: three longitudinal studies. BMC Public Health, 10:720, 2010.

[49] R. Crutzen and G.Y. Peters. Scale quality: alpha is an inadequate estimate and factor-analytic evidence is needed first of all. Health Psychol Rev, pages 1-14, 2015.

[50] R. Crutzen, J.L. Roosjen, and J. Poelman. Using google analytics as a process evaluation method for internet-delivered interventions: an example on sexual health. Health promotion international, 28(1):36-42, 2013.

[51] R. Crutzen, J. van 't Riet, and C.E. Short. Enjoyment: a conceptual exploration and overview of experimental evidence in the context of games for health. Games for Health Journal, 5(1):15-20, 2016.

[52] L.H. Daltroy, C. Phillips, R. Lew, E. Wright, N.A. Shadick, and M.H. Liang. A controlled trial of a novel primary prevention program for Lyme disease and other tick-borne illnesses. Health Educ Behav, 34(3):531-542, June 2007.

[53] E.L. de Mik, W. van Pelt, B. Docters-van Leeuwen, A. van der Veen, J.F. Schellekens, and M.W. Borgdorff. The geographical distribution of tick bites and erythema migrans in general practice in the Netherlands. Int J Epidemiol, 26(2):451-457, 1997.

[54] H. de Vries and S. van Dillen. Prevention of Lyme disease in Dutch children: analysis of determinants of tick inspection by parents. Prev Med, 35:160-165, 2002.

[55] O. de Zwart, I.K. Veldhuijzen, G. Elam, A.R. Aro, T. Abraham, G.D. Bishop, J.H. Richardus, and J. Brug. Avian influenza riks perception, Europe and Asia. Emerg Infect Dis, 13:290-293, 2007.

[56] M. Dehnert, V. Fingerle, C. Klier, T. Talaska, M. Schlaud, G. Krause, H. Wilking, and G. Poggensee. Seropositivity of Lyme borreliosis and associatedrisk factors: a population-based study in children and adolescents in Germany (KiGGS). PLoS One, 7(8):e41321, 2012. 
[57] S. den Boon, J.F. Schellekens, L.M. Schouls, A.W. Suijkerbuijk, B. Docters van Leeuwen, and W. van Pelt. Verdubbeling van het aantal consulten voor tekenbeten en Lyme-borreliose in de huisartsenpraktijk in Nederland. Ned Tijdschr Geneeskd, 148(14):665-670, 2004. in Dutch.

[58] S.W. Dubrey, A. Bhatia, S. Woodham, and R. Rakowicz. Lyme disease in the United Kingdom. Postgrad Med J, 90:33-42, 2014.

[59] R. Eisen, J.J. Piesman, E. Zielinski-Gutierrez, and L. Eisen. What do we need to know about disease ecology to prevent Lyme disease in the northeastern United States? J Med Entomol, 49(2):11-22, 2012.

[60] H.M. Feder, B.J.B. Johnson, S. O’Connell, E.D. Shapiro, A.C. Steere, G.P. Wormser, and the Ad Hoc International Lyme Disease Group. A critical appraisal of "chronic Lyme disease”. N Engl J Med, 357:1422-1430, 2007.

[61] D.L. Floyd, S. Prentice-Dunn, and R.W. Rogers. A meta-analysis of research on protection motivation theory. J of Applied Social Psychology, 30:407-429, 2000 .

[62] C.L. Fritz. Emerging tick-borne diseases. Vet Clin North Am Small Anim Pract, 39(2):265-278, 2009.

[63] R. Fuchs, M. Herold, P.H. Verburg, and J.G.P.W. Clevers. A high-resolution and harmonized model approach for reconstructing and analysing historic land changes in Europe. Biogeosciences, 10(3):1543-1559, 2013.

[64] K.M. Gebbie, L. Rosenstock, and L.M. Hernandez, editors. Who will keep the public healthy? Educating public health professionals for the 21st century. National Academy Press, Washington, D.C, 2003.

[65] G. Godin, P. Sheeran, M. Conner, G. Delage, M. Germain, A. BélangerGravel, and H. Naccache. Which survey questions change behavior? Randomized controlled trial of mere measurement interventions. Health Psychol, 29(6):636-644, 2010.

[66] J.D. Gould and C. Lewis. Designing for usability: key principles and what designers think. Commun ACM, 28:300-311, 1985.

[67] L.H. Gould, R.S. Nelson, K.S. Griffith, Hayes. E.B., J Piesman, P.S. Mead, and M.L. Cartter. Knowledge, attitudes, and behaviours regarding Lyme disease prevention among Connecticut residents 1999-2004. Vector Borne Zoonotic Dis, 8(6):769-776, 2008.

[68] J.S. Gray. The ecology of ticks transmitting Lyme borreliosis. Exp Appl Acarol 1998, 22:249-258, 1998. 
[69] J.S. Gray, O. Kahl, J.N. Robertson, M. Daniel, A. Estrada-Pena, G. Gettinby, T.G. Jaenson, P. Jensen, F. Jongejan, E. Korenberg, K. Kurtenbach, and P. Zeman. Lyme borreliosis habitat assessment. Zentralbl Bakteriol, 287:211228, 1998.

[70] W. Hallman, N. Weinstein, Kadakia. S., and C. Chess. Precautions taken against Lyme disease at three recreational parks in endemic areas of New Jersey. Environ Behav, 27:437-453, 1995.

[71] K. Hansen and A.M. Lebech. The clinical and epidemiological profile of Lyme neuroborreliosis in Denmark 1985-1990. a prospective study of 187 patients with Borrelia burgdorferi s.l. specific intrathecal antibody production. Brain, 15:399-423, 1992.

[72] R.P. Hawkings, M. Kreuter, K. Resnicow, M. Fishbein, and A. Dijkstra. Understanding tailoring in communicating about health. Health Educ Res, 23(3):454-466, 2008.

[73] G.W. Hazeu, C. Schuiling, G.J. Dortland, J. Oldengarm, and H.A. Gijsbertse. Landelijk grondgebruiksbestand nederland versie 6 (LGN6): Vervaardiging, nauwkeurigheid en gebruik. Technical report, Alterra, 2010. In Dutch. http: //edepot . wur.nl/137531. Accessed 29 August 2016.

[74] J.E. Heller, E. Benito-Garcia, N.E. Maher, L.B. Chibnik, C.P. Maher, and N.A. Shadick. Behavioral and attitudes survey about Lyme disease among a brazilian population in the endemic area of Martha's Vineyard, Massachusetts. J Immigr Minor Health, 12(3):377-383, 2010.

[75] J.E. Heller, E. Benito-Garcia, N.E. Maher, L.B. Chibnik, C.P. Maher, and N.A. Shadick. Behavioral and attitudes survey about Lyme disease among a Brazilian population in the endemic area of Martha's Vineyard, Massachusetts. J Immigr Minor Health, 12(3):377-383, 2019.

[76] J.E. Herrington. Risk perceptions regarding ticks and Lyme disease: a national survey. Am J Prev Med, 26(2):135-140, 2004.

[77] P. Heyman, C. Cochez, A. Hofhuis, J. van der Giessen, H. Sprong, S.R. Porter, B. Losson, C. Saegerman, O. Donoso-Mantke, M. Niedrig, and A. Papa. A clear and present danger: tick-borne diseases in Europe. Expert Rev Anti Infect Ther, 8(1):33-50, Jan 2010.

[78] R. Hjetland, K. Eliassen, M. Lindbæk, R. Nilsen, N. Grude, and E. Ulvestad. Tick bites in healthy adults from western Norway: occurrence, risk factors, and outcomes. Ticks Tick Borne Dis, 4(4):304-310, 2013.

[79] A. Hofhuis, S. Bennema, M. Harms, A.J. van Vliet, W. Takken, C.C. van den Wijngaard, and W. van Pelt. Decrease in tick bite consultations and stabilization of early Lyme borreliosis in the Netherlands in 2014 after 15 years of continuous increase. BMC Public Health, 16(1):425, 2016. 
[80] A. Hofhuis, M. Harms, S. Bennema, C.C. van den Wijngaard, and W. van Pelt. Physician reported incidence of early and late Lyme borreliosis. Parasit Vectors, 8:161, 2015.

[81] A. Hofhuis, M. Harms, C. van den Wijngaard, H. Sprong, and W. van Pelta. Continuing increase of tick bites and Lyme disease between 1994 and 2009. Ticks and Tick-borne Dis, 6(1):69-74, 2015.

[82] A Hofhuis, M.G. Harms, J.W.B. van der Giessen, H. Sprong, D.W. Notermans, and W. van Pelt. Ziekte van Lyme in Nederland 1994-2009: Aantal huisartsconsulten blijft toenemen. Is voorlichting en curatief beleid genoeg? Infectieziekten Bulletin, 21(3):84-87, 2010. In Dutch.

[83] A. Hofhuis, J.W. van der Giessen, F.H. Borgsteede, P.R. Wielinga, D.W. Notermans, and W. van Pelt. Lyme borreliosis in the Netherlands: strong increase in GP consultations and hospital admissions in past 10 years. Euro Surveill, 11(25):pii=2978, 2006.

[84] W. Hofmann, M. Friese, and R.W. Wiers. Impulsive versus reflective influences on health behavior: a theoretical framework and empirical review. Health Psychology Review, 2(2):111-137, 2008.

[85] Y. Hong, D.V. Dahlke, M. Ory, A. Hochhalter, J. Reynolds, and N.P. Purcell. Designing iCanFit: a mobile-enabled Web application to promote physical activity for older cancer survivors. JMIR Res Protoc, 2(1):e12, 2013.

[86] J.W.R. Hovius and H. Sprong. Combatting Lyme disease. Ned Tijdschr Geneeskd, 158:A7986, 2014.

[87] K.E. Hovius, S.T.G. Rijpkema, P. Westers, B.A.M. van der Zeijst, A.J.A.M. van Asten, and D.J. Houwers. A serological study of cohorts of young dogs, naturally exposed to Ixodes ricinus ticks, indicates seasonal reinfection by Borrelia burgdorferi sensu lato. Vet Q, 21(1):16-20, 1999.

[88] Z. Hubalek. Epidemiology of Lyme borreliosis. Current problems in dermatology, 37:310-50, 2009.

[89] Z. Hubalek and J. Halouzka. Distribution of borrelia burgdorferi sensu lato genomic groups in Europe, a review. Eur J Epidemiol, 13(8):951-957, 1997.

[90] M.S. Jacob, D. Amar, A. Christopher, and J.S. Keystone. Transmission of health information on leprosy from children to their families in an urban centre. Lepr Rev., 65(3):272-278, 1994.

[91] J.J.W.M. Jacobs, G.T. Noordhoek, J.M.M. Brouwers, P.R. Wielinga, J.P.A.M. Jacobs, and A.H. Brandenburg. Kleine kans op lymeborreliose na een tekenbeet op ameland: onderzoek in een huisartsenpraktijk. Ned Tijdschr Geneeskd, 152:2022-2026, 2008. 
[92] L. Kazbare, H. van Trijp, and J.K. Eskildsen. A-priori and post-hoc segmentation in the design of healthy eating campaigns. J Marketing Communications, 16:1-2, 2010.

[93] S.M. Kelders. Understanding adherence to web-based interventions. PhD thesis, University of Twente, 2012. http://doc .utwente.nl/81967/. Accessed 29 August 2016.

[94] J.D. Klein, S.C. Eppes, and P. Hunt. Environmental and life-style risk factors for Lyme disease in children. Clin Pediatr (Phila), 35(7):359-363, 1996.

[95] G. Kok. Planmatige ontwikkeling van op theorieën en evidentie gebaseerde gezondheidsbevordering, met als voorbeeld de ziekte van Lyme. Infectieziektenbulletin, 17(3):102-103, 2006.

[96] F. Konings, B. Beljaars, M. Boverhof, S. van Dam, G. van Dijk, R. ter Schegget, and P. Verhoeven. Instrument risico inventarisatie infectieziektebestrijding, herziene versie 2008. Technical report, GGD West-Brabant, Breda, 2008. In Dutch.

[97] P. Krebs, J.O. Prochaska, and J.S. Rossi. A meta-analysis of computertailored interventions for health behavior change. Prev Med, pages 214$221,2010$.

[98] M. Kwan, G. Faulkner, and S. Bray. Evaluation of active transition, a website-delivered physical activity intervention for university students: pilot study. JMIR Res Protoc, 2(1):e16, 2013.

[99] R.S. Lane, S.A. Manweiler, H.A. Stubbs, E.T. Lennette, J.E. Madigan, and P.E. Lavoie. Risk factors for Lyme disease in a small rural community in northern California. Am J Epidemiol, 136(11):1358-1368, 1992.

[100] K.A. Lawless, S.W. Brown, and M. Cartter. Applying educational psychology and instructional technology to health care isues: Combating Lyme disease. Int J Instr Media, 24:287-297, 1997.

[101] LCI-richtlijn Lymeziekte. RIVM. http://www.rivm.nl/richtlijnlyme. In Dutch. Accessed 29 August 2016.

[102] B.K. Lee, J. Lessler, and E.A. Stuart. Improving propensity score weighting using machine learning. Stat Med, 29(3):337-346, 2010.

[103] C. Lefebvre. Integrating cell phones and mobile technologies into public health practice: a social marketing perspective. Health Promot Pract, 10:490-494, 2009.

[104] C. LeRouge, J. Ma, S. Sneha, and K. Tolle. User profiles and personas in the design and development of consumer health technologies. Int J Med Inform, pages e251-268, 2013. 
[105] D.A. Lieberman. Management of chronic pediatric diseases with interactive health games: theory and research findings. J Ambul Care Manage, 24(1):26-38, 2001.

[106] E. Lindgren, T.G. Jaenson, and Organization WH. Lyme borreliosis in Europe: influences of climate and climate change, epidemiology, ecology and adaptation measures. http://www.euro.who.int/_data/ assets/pdf_file/0006/96819/E89522.pdf?ua=1, WHO Regional Office for Europe. Copenhagen, 2006. Accessed 29 August 2016.

[107] A. Maat and F. Koning. Teek it or leave it? Onderzoek van GGD WestBrabant naar preventieve maatregelen tegen tekenbeten [Tick it or leave it? An investigation of the area health authority of West-Brabant of preventive measures against tick bites]. Infectieziekten Bulletin, 21:221-223, 2010.

[108] R. Malouin, P. Winch, E. Leontsini, G. Glass, D. Simon, E.B. Hayes, and B.S. Schwartz. Longitudinal evaluation of an educational intervention for preventing tick bites in an area with endemic Lyme disease in Baltimore County, Maryland. Am J Epidemiol, 157(11):1039-1051, 2003.

[109] A. Marcu, D. Uzzell, and J. Barnett. Making sense of unfamiliar risks in the countryside: the case of Lyme disease. Health Place, pages 843-850, 2011.

[110] G. Molenberghs and G. Verbeke. Models for discrete longitudinal data. New York: Springer-Verlag, 2000.

[111] T. Morrissey. The affordable care act's public health workforce provisions: opportunitiesand challenges. http://www.apha.org, 2011. https://www.apha.org/ /media/files/pdf/topics/aca/apha_ workforce.ashx. Accessed 29 August 2016.

[112] A.S.M. Mosa, I. Yoo, and L. Sheets. A systematic review of healthcare applications for smartphones. BMC Med Inform Decis Mak, page 67, 2012.

[113] F. Mowbray, R. Amlôt, and G.J. Rubin. Ticking all the boxes? a systematic review of education and communication interventions to prevent tickborne disease. Vector Borne Zoonotic Dis, 12(9):817-825, 2012.

[114] F. Mowbray, R. Amlôt, and G.J. Rubin. Predictors of protective behavior against ticks in the UK: a mixed methods study. Ticks Tick Borne Dis, 5(4):392-400, 2014.

[115] K.E. Muessig, E.C. Pike, S. Legrand, and L.B. Hightow-Weidman. Mobile phone applications for the care and prevention of HIV and other sexually transmitted diseases: a review. J Med Internet Res, 15(1):e1, 2013.

[116] Next level - Dossier over online spelletjes voor kinderen mijn kind online. http://mijnkindonline.nl/publicaties/onderzoeksrapporten/ next-level, 2009. In Dutch. Accessed 29 August 2016. 
[117] N. Nijland. Grounding eHealth: towards a holistic framework for sustainable eHealth technologies. $\mathrm{PhD}$ thesis, University of Twente, Enschede, 2011. http://doc.utwente.nl/75576/. Accessed 29 August 2016.

[118] S.M. Noar, C.N. Benac, and M.S. Harris. Does tailoring matter? metaanalytic review of tailored print health behavior change interventions. Psychol Bull, 133(4):673-693, 2007.

[119] M.T. Nolte, M.J. Shauver, and K.C. Chung. Analysis of four recruitment methods for obtaining normative data through a web-based questionnaire: a pilot study. Hand, 10(3):529-534, 2015.

[120] P. Norman, H. Boer, and E.R. Seydel. Predicting health behaviour. In M. Conner and P. Norman, editors, Protection Motivation Theory, pages 81-126. Open University Press, Berkshire, UK, 2005.

[121] V. Obiodu and E. Obiodu. Review of the top 500 medical apps in a European android market. Journal of Mobile Technology in Medicine, 1(4):22-37, 2012.

[122] H. Oinas-Kukkonen and M. Harjumaa. Persuasive systems design: key issues, process model and system features. Comm Assoc Inform Syst, 24:Article 28, 2009.

[123] M. Papastergiou. Exploring the potential of computer and video games for health and physical education: A literature review. Computers and Education, 53(3):603-622, 2009.

[124] C. Perronne. Lyme and associated tick-borne diseases: global challenges in the context of a public health threat. Front Cell Infect Microbiol, 4:74, 2014.

[125] G.-J.Y. Peters and R. Crutzen. Pragmatic nihilism: How a theory of nothing can help health psychology progress. Submitted.

[126] C.B. Phillips, M.H. Liang, O. Sangha, E.A. Wright, A.H. Fossel, R.A. Lew, K.K. Fossel, and N.A. Shadick. Lyme disease and preventive behaviors in residents of Nantucket Island, Massachusetts. Am J Prev Med, 20(3):219224, 2001.

[127] J. Piesman, T.N. Mather, R.J. Sinsky, and A. Spielman. Duration of tick attachment and Borrelia burgdorferi transmission. J Clin Microbiol, 25(3):557-558, 1987.

[128] D.W. Pitches. Removal of ticks: a review of the literature. Euro Surveill, 11(33):pii=3027, 2006.

[129] G.A. Poland. Prevention of Lyme disease: a review of the evidence. Mayo Clin Proc, 76:13-24, 2001. 
[130] C. Pope and N. Mays, editors. Qualitative research in health care. Blackwell Publishing Ltd, Oxford, 3rd edition, 2006.

[131] J. Pruitt and T. Adlin. The persona lifecycle: keeping people in mind throughout product design. Morgan Kaufmann Publishers, Amsterdam, 2006.

[132] C.P. Quine, J. Barnett, A.D. Dobson, A. Marcu, M. Marzano, D. Moseley, L. O’Brien, S.E. Randolph, J.L. Taylor, and D. Uzzell. Frameworks for risk communication and disease management: the case of Lyme disease and countryside users. Philos Trans R Soc Lond B Biol Sci, 366(1573):2010-2022, 2011 .

[133] V. Rideout, U. Foehr, and D. Roberts. Generation M2: Media in the lives of 8- to 18 year olds. http://www.kff.org/entmedia/mh012010pkg.cfm, 2010. Accessed 29 August 2016.

[134] R.N. Rimal and J.A. Flora. Bidirectional familial influences in dietary behavior: test of a model of campaign influences. Commun Res, 24(4):610-637, 1998.

[135] Tekenbeten en Lyme. http://rivm.nl/Onderwerpen/T/Tekenbeten_ en_lyme. In Dutch. Accessed 16 December 2015.

[136] A. Rizzoli, H.C. Hauffe, G. Carpi, G.I. Vourc'h, M. Neteler, and R. Rosà. Lyme borreliosis in Europe. Euro Surveill, 16(27):pii=19906, 2011. http: //www . eurosurveillance. org/ViewArticle. aspx?ArticleId=19906. Accessed 29 August 2016.

[137] G. Rose. Strategy of prevention: lessons from cardiovascular disease. $\mathrm{Br}$ Med J (Clin Res Ed), 282(6279):1847-1851, 1981.

[138] P.R. Rosenbaum. Observational Studies. Springer Verlag New York, Inc., 2nd edition, 2002. ISBN 0-387-98967-6.

[139] K.L. Schmid, S.E. Rivers, A.E. Latimer, and P. Salovey. Targeting or tailoring? Mark Health Serv, 28(1):32-37, 2008.

[140] K.E.E. Schroder, M.P. Carey, and P.A. Vanable. Methodological challenges in research on sexual risk behavior: II. accuracy of self-reports. Annals of Behavioral Medicine, 26(2):104-123.

[141] T.J. Schuijt, J.W. Hovius, T. van der Poll, A.P. van Dam, and E. Fikrig. Lyme borreliosis vaccination: the facts, the challenge, the future. Trends Parasitol, 27(1):40-47, 2011.

[142] D.N. Schulz, S.P. Kremers, C. Vandelanotte, M.J.G. van Adrichem, F. Schneider, M.J.J.M. Candel, and H. de Vries. Effects of a web-based 
tailored multiple-lifestyle intervention for adults: A two-year randomized controlled trial comparing sequential and simultaneous delivery modes. $J$ Med Internet Res, 16(1):e26, 2014.

[143] B.S. Schwartz, J.L. Sanchez, M.L. Sanders, and R.F. DeFraites. Tick avoidance behaviors associated with a decreased risk of anti-tick salivary gland protein antibody seropositivity in military personnel exposed to Amblyomma americanum in Arkansas. Am J Trop Med Hyg, 55(4):410-416, 1996.

[144] I. Sedighi, S. Nouri, T. Sadrosadat, R. Nemati, and M. Shahbazi. Can children enhance their family's health knowledge? An infectious disease prevention program. Iran J Pediatr., 22(4):493-498, 2012.

[145] N.A. Shadick, L.H. Daltroy, C.B. Phillips, U.S. Liang, and M.H. Liang. Determinants of tick-avoidance behaviors in an endemic area for Lyme disease. Am J Prev Med, 13(4):265-270, 1997.

[146] N.A. Shadick, M.J. Zibit, E. Nardone, A. Jr DeMaria, C.K. Iannaccone, and J. Cui. A school-based intervention to increase Lyme disease preventive measures among elementary school-aged children. Vector Borne Zoonotic Dis, 16(8):507-515, 2016.

[147] D.W. Shaffer, K.R. Squire, R. Halverson, and J.P. Gee. Video games and the future of learning. Phi Delta Kappan, 87(2):104-111, 2005.

[148] B.H. Skogman, S. Croner, M. Nordwall, M. Eknefelt, J. Ernerudh, and P. Forsberg. Lyme neuroborreliosis in children. a prospective study of clinical features, prognosis, and outcome. Pediatr Infect Dis J, 27:1089-1094, 2008.

[149] M.D. Slater. Theory and method in health audience segmentation. J Health Commun, 1(3):267-283, 1996.

[150] P. Slovic. Perception of risk. Science, 236(4799):280-285, 1987.

[151] G.D. Smith, P.E. Wileyto, R.B. Hopkins, B. Cherry, and J.P. Maher. Risk factors for Lyme disease in Chester County, Pennsylvania. public. Public Health Rep, 116(1):146-156, 2001.

[152] R. Smith, J. Takkinen, and Editorial team. Lyme borreliosis: Europe wide coordinated surveillance and action needed? Euro Surveill, 11(25):pii=2977, 2006.

[153] H. Sprong, J. Trentelman, I. Seemann, L. Grubhoffer, R.O.M. Rego, O. Hajdušek, P. Kopáček, R. Šíma, A.M. Nijhof, J. Anguita, P. Winter, B. Rotter, S. Havlíková, B. Klempa, T.P. Schetters, and J.W.R Hovius. ANTIDotE: antitick vaccines to prevent tick-borne diseases in Europe. Parasit Vectors, 7:77, 2014 . 
[154] K. Squire. From content to context: videogames as designed experience. Educational Researcher, 35(8):19-29, 2006.

[155] C. Stalgaitis and S.N. Glick. The use of web-based diaries in sexual, risk behavior research: a systematic review. Sex Transm Infect., 90(5):374-381, 2014.

[156] G. Stanek, V. Fingerle, K.P. Hunfeld, B. Jaulhac, R. Kaiser, A Krause, W. Kristoferitsch, S O’Connell, K. Ornstein, F. Strle, and J. Gray. Lyme borreliosis: clinical case definitions for diagnosis and management in Europe. Clin Microbiol Infect, 17(1):69-79, 2011.

[157] G. Stanek, G.P. Wormser, J. Gray, and F. Strle. Lyme borreliosis. Lancet, 379:461-473, 2012.

[158] L.K. Staten, A.S. Birnbaum, J.B. Jobe, and J.P. Elder. A typology of middle school girls: audience segmentation related to physicalactivity. Health Educ Behav, 33(1):66-80, 2006.

[159] ICT gebruik van personen naar persoonskenmerken, 2005-2013. Statistics Netherlands. http://statline.cbs.nl/Statweb/publication/ ?DM=SLNL\&PA=71098ned\&D1=33-133\&D2=0-2\&D3=a\&VW=T. In Dutch. Accessed 29 August 2016.

[160] Internet; toegang, gebruik en faciliteiten. Statistics Netherlands. http://statline.cbs.nl/Statweb/publication/?DM=SLNL\&PA= 83429ned\&D1 $=0-69 \& D 2=0,3-6 \& D 3=0 \& D 4=a \& V W=T$. In Dutch. Accessed 29 August 2016.

[161] Nabijheid voorzieningen; afstand locatie, wijk- en buurtcijfers 20062012. Statistics Netherlands. http://statline.cbs.nl/StatWeb/ publication $/$ ?VW $=T \& D M=S L N L \& P A=80306$ ned\&D $1=60-63 \& D 2=0,6592$, $6594 \& D 3=56 \& H D=130627-1220 \& H D R=T \& S T B=G 1$, G2. In Dutch. Accessed 29 August 2016.

[162] A.C. Steere, J. Coburn, and L. Glickstein. The emergence of Lyme disease. J Clin Invest, 113(8):1093-1101, 2004.

[163] L. Stjernberg and J. Berglund. Risk of acquiring tick bites in south-eastern Sweden. Scand J Infect Dis, 34(11):840-844, 2002.

[164] L. Stjernberg and J. Berglund. Detecting ticks on light versus dark clothing. Scand J Infect Dis, 37(5):361-364, 2005.

[165] E.A. Stuart. Matching methods for causal inference: A review and a look forward. forward. Stat Sci, 25(1):1-21, 2010.

[166] http://www.swov.nl. Accessed 29 August 2016. 
[167] R Development Core Team. R: A language and environment for statistical computing. Vienna, Austria, R Foundation for Statistical Computing, 2011. http://www.R-project.org/. Accessed 29 August 2016.

[168] S. Teece and I. Crawford. Towards evidence based emergency medicine: best BETs from the Manchester Royal Infirmary. How to remove a tick. Emerg Med J, 19(4):323-324, 2002.

[169] D. Thompson. What serious games can offer child obesity prevention. JMIR serious games, 2(2):e8, 2014.

[170] H. Tilson and B. Berkowitz. The public health enterprise: examining our twenty-first-century policy challenges. Health Aff (Millwood), 25(4):900910, 2006.

[171] A.J. Ullmann, T.M. Russell, M.C. Dolan, M. Williams, A. Hojgaard, Weiner Z.P., and B.J. Johnson. Evaluation of borrelia burgdorferi BbHtrA protease as a vaccine candidate for lyme borreliosis in mice. PloS one, 10(6):e0128868, 2015.

[172] A.P. van Dam, H. Kuiper, K. Vos, A. Widjojokusumo, B.M. de Jongh, L. Spanjaard, A.C. Ramselaar, M.D. Kramer, and J. Dankert. Different genospecies of Borrelia burgdorferi are associeted with distinct clinical manifestations of Lyme borreliosis. Clin Infect Dis, 17(4):708-717, 1993.

[173] C.C. van den Wijngaard, A. Hofhuis, M.G. Harms, J.A. Haagsma, A. Wong, G.A. de Wit, A.H. Havelaar, A.K. Lugné, A.W. Suijkerbuijk, and W. van Pelt. The burden of Lyme borreliosis expressed in disability-adjusted life years. Eur J Public Health, 25(6):1071-1078, 2015.

[174] J.E.W.C van Gemert-Pijnen, N. Nijland, M. van Limburg, H.C. Ossebaard, S.M. Kelders, G. Eysenbach, and E.R. Seydel. A holistic framework to improve the uptake and impact of eHealth technologies. J Med Internet Res, 13:e111, 2011.

[175] M. van Limburg, J.E.W.C. van Gemert-Pijnen, N. Nijland, H.C. Ossebaard, R.M. Hendrix, and E.R. Seydel. Why business modeling is crucial in the development of eHealth technologies. J Med Internet Res, 13(e124), 2011.

[176] J. van 't Riet, R. Crutzen, and A.S. Lu. How effective, are active videogames among the young and the old? adding meta-analyses to two recent systematic reviews. Games for Health Journal, 3(5):311-318, 2014.

[177] L. van Velsen, D.J. Beaujean, J. Wentzel, J. van Steenbergen, and J.E. van Gemert-Pijnen. Developing requirements for a mobile app to support citizens in dealing with ticks and tick bites via end-user profiling. Health informatics J, pages 24-35, 2015. 
[178] L. van Velsen, L. van Gemert-Pijnen, N. Nijland, D. Beaujean, and J. Steenbergen. Personas: the linking pin in holistic design for eHealth. In eTELEMED 2012: Fourth international conference on eHealth, telemedicine, and social medicine, pages 128-133, Valencia, Spain, 31-02-2012 - 04-022012 2012. http://doc . utwente.nl/82319/. Accessed 29 August 2016.

[179] L. van Velsen, J. Wentzel, and J.E. van Gemert-Pijnen. Designing eHealth that matters via a multidisciplinary requirements development approach. JMIR Res Protoc, 2(1):e21, 2013.

[180] M. Vazquez, C. Muehlenbein, M. Cartter, E.B. Hayes, S. Ertel, and E.D. Shapiro. Effectiveness of personal protective measures to prevent Lyme disease. Emerg Infect Dis, 14(2):210-216, 2008.

[181] V. Voncken-Brewster, A. Moser, T. van der Weijden, Z. Nagykaldi, H. de Vries, and H. Tange. Usability evaluation of an online, tailored selfmanagement intervention for chronic obstructive pulmonary disease patients incorporating behavior changetechniques. JMIR Res Protoc, 2(1):e3, 2013.

[182] World Health Organization (WHO). Lyme borreliosis (Lyme disease). http: //www. who.int/ith/diseases/lyme/en/. Accessed 9 Nov 2015.

[183] World Health Organization (WHO). mHealth. New horizons for health through mobile technologies, volume 3 of Global Observatory for eHealth Series. WHO, Geneva, Switzerland, 2011. http://whqlibdoc.who.int/ publications/2011/9789241564250_eng.pdf. Accessed 29 August 2016.

[184] P.R. Wielinga, C. Gaasenbeek, M. Fonville, A. de Boer, A. de Vries, W. Dimmers, G. Akkerhuis Op Jagers, L.M. Schouls, F. Borgsteede, and J.W. van der Giessen. Longitudinal analysis of tick densities and Borrelia, Anaplasma, and Ehrlichia infections of Ixodes ricinus ticks in different habitat areas in the Netherlands. Appl Environ Microbiol, 72(12):7594-7601, 2006.

[185] G.P. Wormser, R.J. Dattwyler, E.D. Shapiro, J.J. Halperin, A.C. Steere, M.S. Klempner, P.J. Krause, F. Bakken, J.S. Strle, and G. Stanek. Clinical assessment, treatment, and prevention of Lyme disease, human granulocytic anaplasmosis, and babesiosis: clinical practice guidelines by the Infectious Diseases Society of America. Clinical infectious diseases: an official publication of the Infectious Diseases Society of America, 43(9):1089-1134, 2006.

[186] Nationale Atlas Volksgezondheid. http://www.zorgatlas.nl. Accessed 29 August 2016. 


\section{Valorization addendum}

The studies presented in this thesis have implications for society and the economy, in addition to its scientific relevance. As is explained in this thesis, Lyme borreliosis (LB) is the most commonly reported tick-borne disease in North Eastern USA and Europe. In 2014, Dutch general practitioners (GPs) assessed approximately 82,000 patients with tick bites and erythema migrans (EM) was diagnosed in 23,500 of them. LB has the 12th highest disease burden when compared to the comprehensive disability-adjusted life years (DALY) estimates for 32 other infectious diseases. This disease burden attributed to LB demonstrates the need for continued prevention and control efforts. Furthermore, preventive measures like avoiding tick areas, wearing protective clothing, using insect repellent are effective, cheap, safe, and easy to apply. These measures to reduce the risk of tick exposure (primary prevention measures) or checking the body for ticks (secondary prevention) are well-known, but universally the uptake is poor. We therefore investigated the social-cognitive variables associated with people's motivation to take preventive measures against ticks. Based on these results we developed four new intervention tools to inform about ticks and LB and to promote preventive measures: a leaflet, a movie, an online educational video game,

and a mobile app. This has led to intervention tools that are well appreciated by the public and also effective to improve their (intention to engage in) preventive behavior. The leaflet and the movie are free and available for anyone on www.rivm.nl/tekenbeet, the game via www.teekcontrol.nl, and the app in the Google Play Store and the App Store. The site www.rivm.nl/tekenbeet attracts around 220,000 unique visitors annually. It appears that the game and the app are very popular, since the game has been played more than 35,000 times since the launch in 2012 and the app has been downloaded more than 60,000 times since 2014.

The developed intervention tools can be called innovative, as these are the first theory- and evidence-based online educational video game and mobile app on ticks and LB in the Netherlands. Since the daily use of these tools is transparent via Google Analytics, the effects of the media-attention you pay to these tools on the use of it is also transparent. This is in contrast with a leaflet for example; once it is downloaded you don't have insight in the use and dissemination of it anymore. This impact assessment of media attention is very motivating and 
stimulating to the employees of the internal department of communication of the RIVM.

To disseminate the findings of the studies included in this thesis among professionals and the public at large, the results are presented at several (inter-)national congresses, published in (inter-)national scientific and public journals and discussed on national radio and television broadcastings (e.g. www.nporadio1.nl/vroege-vogels/onderwerpen/188262-teken-vroeg-dit-jaar and jeugdjournaal.nl/artikel/356039-game-over-teken-gemaakt.html). Furthermore, Chapter 1 (Introduction) and Chapter 10 (Discussion) of this thesis are compiled as Chapter 22: 'Evidence-based health promotion programmes and tools to prevent tick bites and Lyme borreliosis' in volume 4 of the Ecology and Control of Vector-borne diseases series 'Ecology and prevention of Lyme borreliosis'. And last but not least, each year around springtime, the national awareness week on tick bites (www.weekvandeteek.nl) is organized to mark the onset of the tick bite season. The RIVM and Wageningen University, together with other stakeholders distribute public health education about the relevance of body checking, prompt tick removal, and when to visit a physician. The results of the studies in this thesis are incorporated in this campaign yearly.

Between 2009 and 2014, the analyses of the average annual number of ticks per square metre per month conducted by the tick monitoring programme of Wageningen University did not indicate a significant change in tick abundance in the Netherlands. However, for the first time since the start of the identical GP surveys in 1994 in the Netherlands, there has been observed a decreased incidence in tick bite GP consultations in 2014. Whether people decide not to consult a physician for a tick bite, may be influenced by public health education and media attention. Possibly, the decrease in GP consultations for tick bites may reflect the impact of the four newly developed intervention tools. The studies in this thesis demonstrate that all newly developed interventions are effective. Public Health Services (PHS), GPs, national nature organisations, Scouting Netherlands and the Dutch Foundation for Lyme patients are advised to promote this mix of interventions to reach as many people as possible to encourage them to take part in prevention programmes on ticks and LB. These programmes should not only focus on adults, but also on school children. For example, by integrating the game 'Teekcontrol' in a school education programme on ticks and LB, both children and their parents can be reached. The development of effective interventions on tick bites and LB is a challenge in itself, but the implementation of the interventions is even more important. The development of these interventions was made possible by a one-off subsidy from the Ministry of Health, Welfare and Sport (VWS). However, developing these interventions without any options for their structural implementation is not likely to achieve a sustained impact on public health. In particular, when a prevention programme is aimed at specific measures to prevent a 'seasonal risk' that is only present for a number of months per year, and the interventions have no long lasting effects, intermittent attention is needed. We recommend that the RIVM and PHS maintain 
ongoing advertising campaigns throughout the entire tick season, every year. Online interventions like online games, movies and apps, are particularly in need of advertising as they are not tangible products like a leaflet or a poster, which you can easily, even inadvertently encounter. Therefore, we recommend that online social media (Twitter, Facebook, Instagram etc.) be used, as well as traditional media (newspapers, radio, television) to repeatedly draw attention to these online interventions. Furthermore, governments and research funds are advised to fund above all the systematic development of prevention programmes based on the principals of intervention mapping. Besides, the provisional funding of the development of a systematically positive developed prevention programme should be followed by the structural funding of an implementation programme and a cost- and effect evaluation of this implementation.

Finally, it is very important that evidence based guidelines on the prevention of tick bites and LB are available for professionals in public health. These guidelines should focus on measures which are practical and achievable for individuals. As measures like applying pesticides and reducing tick habitat cannot be performed by an individual, and vaccines are not available yet, they should not be included in guidelines, like the CBO guideline. This guideline should focus primarily on educating the public to avoid tick areas, wear protective clothing, use insect repellent, check for ticks and remove ticks promptly. Moreover, it should be considered to complement the CBO guideline with the four newly developed effective intervention tools to change preventive behavior: the app 'Tekenbeet' (Tick bite), the online serious game 'Teekcontrol', the movie and the leaflet. 


\section{Summary}

Lyme disease (LD) is the most commonly reported tick-borne infection in Europe and North America. As long as there are no effective measures to control tick populations in nature and no vaccine is available, we have to rely on health education to prevent and adequately deal with tick bites and Lyme borreliosis (LB). Here we summarize the results of our research into the knowledge, attitude and behavior of adults and school-aged children concerning the prevention of tick bites and LD in the Netherlands (Part I, Chapters 2-5) as well as the effects of a leaflet, a movie, an educational game and a mobile phone application on behavior and other related determinants among both adults and children (Part II, Chapters 6-8) to ultimately reflect on these findings (Part III, Chapters 9-10).

In Chapter 2, results of research into the knowledge, attitude and behavior of adults in relation to the prevention of tick bites and LD are described. From a representative internet panel, approximately one-third of the 362 respondents (35\%) demonstrated a sound knowledge of ticks and LD; they correctly answered at least four of the five questions. The majority (95\%) of respondents were of the opinion that $\mathrm{LD}$ is a (very) serious disease, and the minority $(36 \%)$ of the respondents felt that they themselves were (very) susceptible to contracting LD. The respondents were more prepared to self-check for ticks and, when applicable, to remove a tick when bitten after being outdoors rather than wear protective clothing or to apply insect repellent. The percentage of respondents who took preventive measures varied from $6 \%$ for the use of insect repellent to $37 \%$ for wearing protective clothing. Significantly more self-checks for ticks were performed by people who had experienced a tick bite themselves, had more knowledge or a moderate to severe wariness of ticks and LD. Respondents who wore protective clothing significantly more frequently, were more often not in employment or retired, had more knowledge of ticks and LD, were more wary of ticks and $\mathrm{LD}$ and were inclined to trust the effects of protective clothing. Future tick and LD prevention programs should be aimed at increasing the public's knowledge of ticks and LD, influencing people's perception, and stressing the positive effect of preventive measures.

Chapter 3 describes a similar study to the one reported in Chapter 2, but this time involving schoolchildren. In total, 1,447 schoolchildren aged between 9 and 13 years from forty different primary schools based throughout the Netherlands 
participated in the study. The majority of participating children (70\%) correctly answered at least six out of seven knowledge questions on ticks and LD. The vast majority of the children $(93 \%)$ felt that tick-checks were very or somewhat important. However, only $18 \%$ of the children were routinely checked for ticks by their parents or carers. Children who had more knowledge of ticks and LD and children who knew someone who had LD were checked more often by their parents. Those children who live in arboraceous areas were also checked more often.

Chapter 4 focuses on identifying at-risk groups for tick bites and LD, and to profile these at-risk groups. Knowledge of these profiles and insight into people's motives allow health organizations to fine-tune their communication strategies to the characteristics of these at-risk groups, for example by only propagating preventive advice which will most likely be heeded by specific at-risk groups. By means of a procedure developed by the Public Health Services (PHS) WestBrabant, two prominent at-risk groups have been identified. Subsequently, 25 in-depth interviews were conducted with members of these groups. Based on their answers, the at-risk groups could be further categorized into 'Nature lovers' who do or do not check for tick bites, and 'Parents' who do or do not check their children for tick bites. Each group had their own attitude in relation to ticks and LD and exhibited associated behavior. Having (in)direct experience of tick bites and/or LD proved to be the most important determinant for following preventive advice. Information provision should be aimed at motivating (self-) checking for tick bites instead of the prevention of tick bites (such as wearing body-covering clothing). In addition, it is of key importance that regional PHS teach the public how to remove ticks of different sizes, using different types of tick pliers or tweezers. The profiles of the at-risk groups can be utilized to develop intervention tools which can help citizens to manage tick-associated risks and tick bites.

Chapter 5 reports on the wishes and requirements that users have in relation to a mobile phone application (app) regarding measures to prevent ticks, tick bites and LD. Firstly, we identified organizational stakeholders and end users. Subsequently, we organized a focus group discussion with these stakeholders and 25 in-depth interviews with the end users. From this it transpired that the app should first motivate users to self-check for ticks after a visit to a high-risk area. The app should also contain a tick radar, to allow users to see where the ticks are most prevalent. Furthermore, stakeholders wanted a reminder function to be available, which alerts the user to self-check after a visit to nature and also allows the option to record a tick bite. Our experiences in this study confirm the importance of carefully drawing up an inventory of wishes and requirements of the end users and the context of how the app will be used, to allow targeted advice concerning prevention. Here, we have shown how this can be achieved. In conclusion, this study showed the importance of developing persuasive technology aimed at optimizing the compliance to advice. 
In order to inform the Dutch population about preventive measures concerning ticks and LD, we developed a leaflet and a movie. The aim of the study covered in Chapter 6 was to evaluate the effect of these two educational products in relation to knowledge, perceived severity and risk, self-efficacy, response efficacy, intention and behavior. In addition, we assessed whether the public valued the leaflet and movie. Sixteen hundred and seventy-seven respondents (aged 18 and over) from a representative internet panel participated in the study. We applied a four-group randomized control design to compare the effectiveness of the leaflet and the movie with a control group and an extra follow-up group. All respondents had a good level of knowledge of ticks and LD following the interventions. Both those respondents who watched the movie and the respondents who had read the leaflet knew more about ticks and LD compared to the control group participants; and they were better informed about appropriate preventive measures. Furthermore, they showed greater intention to take preventive measures in the future when compared to respondents in the control group. Although the respective respondents rated the leaflet and the movie in equal measure, the latter group felt that the 5-minute long movie was too lengthy. A long-term effect could not be demonstrated for either the leaflet or the movie. These results showed that both the leaflet and the movie are valued as effective educational products to enhance the public's knowledge of ticks and LD, self-efficacy, and the intention to take preventive measures. Nevertheless, to achieve long-term effects, more action is required.

Children are an at-risk group for tick bites and LD. Since the Dutch National Institute for Public Health and the Environment (RIVM) had so far not developed any public information medium specifically aimed at children, we developed an online educational game. Chapter 7 describes the study in which the effectiveness of a leaflet detailing ticks and LD is compared to the effectiveness of the aforementioned game amongst schoolchildren. In total, 887 schoolchildren aged between nine and thirteen years from 25 different primary schools participated. The pupils were divided, per class, into two intervention groups and one control group: 'game' (22.4\%), 'leaflet' $(35.6 \%)$ or control $(41.9 \%)$. Prior to and immediately after the intervention, the children completed a short questionnaire. Knowledge of ticks and LD increased in all groups. The children who had played the game and those in the control group, were checked for ticks more often by their parents/carers when compared to the children in the leaflet group. This indicates the presence of a mere measurement effect, which is obtained simply by completing a questionnaire. Since the game did not achieve a significantly better effect than the leaflet or no intervention, we would anticipate the game to have a supplementary role in addition to other information provision products used for public health interventions aimed at children.

In order to educate the Dutch public on the risks of ticks and to motivate them to self-check when they return from being outdoors, and - if applicable - to remove a tick as soon as possible, an app was devised for a mobile phone, named 'Tekenbeet' (Dutch for tick bite). The app content was based on the results of 
the studies reported on in Chapters 2, 4 and 5. In Chapter 8 we describe a study reporting the effect of this 'Tekenbeet' app on the behavior of adults in relation to ticks and LD. Data on the use of the app was extracted from Google Analytics. In addition, we conducted a survey amongst the Dutch public (aged 18 years and over) on the use, appreciation and the effect of the app.

Data provided by Google Analytics showed that the the app was downloaded nearly 50,000 times in the 20 months following the launch in April 2014. The tick radar and the tick diary were the most viewed sections of the app. A total of 554 respondents were involved in the online survey, of which 238 completed a second follow-up survey. The survey consisted of questions concerning the use of the app, what people know about ticks and LD, and how they manage (prevention of) tick bites. The mean satisfaction score was 7.44 (on a scale of 1 to 10 ), and $90.9 \%$ of the respondents indicated that they would recommend the app to others. On average, when compared to those who had not downloaded the app ( $n=311)$, respondents who had downloaded the app $(n=243)$ scored higher on knowledge and intention to take preventive measures.

Based on the results of this study, we can conclude that the 'Tekenbeet' app is used often, is well-appreciated, and effective to increase users' knowledge of ticks and prevention of tick bites. It is a practical addition to the existing public health products, and enhances the self-efficacy to take preventive measures (checking for and removal of ticks). Furthermore, the app increases the intention to take preventive measures, although these effects are not sustained long-term. However, one of the advantages of mobile technology is that it can be used anywhere when required, which could be beneficial in acquiring a long-term effect.

The use of apps for mobile phones is popular. The 'Tekenbeet' app fits this trend and offers a modern alternative to more traditional media for information provision such as a leaflet or information on a website.

In Chapter 9 we describe a literature review in which we included interventional studies on ticks and LD from between the period 1995 to May 2015. In 2012, Mowbray published a similar literature review study covering the period 1995 to 2010. At that time, she recommended to conduct more studies focused on enhancing evidence-based insight into the provision of information on preventive measures concerning ticks and LD. Unfortunately, we could not identify any more studies than those included in the study by Mowbray in 2010. Therefore, we again raise the issue of a need for more interventional studies, just like Mowbray did a few years ago. As long as there are no effective measures to control tick populations in nature and no vaccine is available, we have to rely on information provision and communication to prevent tick bites and LD. We would encourage researchers and grant providers to prioritize studies into public health interventions concerning ticks and LD, since, in the words of Benjamin Franklin: "An ounce of prevention is worth a pound of cure".

The results of the presented studies are discussed and integrated from a theoretical as well as methodological perspective in Chapter 10. In addition, implications for practice, policy and future research are provided. 


\section{Samenvatting}

Lyme borreliosis (LB) is de meest gerapporteerde teekgerelateerde infectieziekte in Europa en Noord Amerika. Zo lang er geen effectieve maatregelen bestaan om tekenpopulaties in de natuur te beheersen en er geen vaccin beschikbaar is, moeten we vertrouwen op gezondheidsvoorlichting om tekenbeten en LB te voorkomen. Hier vatten we de resultaten samen van ons onderzoek naar de kennis, de attitude en het gedrag van volwassenen en schoolkinderen ten aanzien van de preventie van tekenbeten en LB in Nederland (deel I, hoofdstuk 2-5). Daarnaast bevat het onderzoek naar de effecten van een folder, een film, een serious game en een applicatie voor de mobiele telefoon over teken en LB op het gedrag en andere gerelateerde determinanten van volwassenen en kinderen (deel II, hoofdstuk 6-8). Tot slot reflecteren we op de resultaten van de onderzoeken (deel III, hoofdstuk 9 en 10).

In hoofdstuk 2 is de kennis, attitude en het gedrag van volwassenen ten aanzien van de preventie van teken en LB onderzocht. Van een representatief internetpanel had ongeveer eenderde van de respondenten $(35 \%)$ een goede kennis over teken en LB: zij beantwoordden minstens 4 van de 5 vragen goed. De meerderheid (95\%) van de respondenten vond LB een (zeer) ernstige ziekte, en een minderheid (36\%) achtte zichzelf (zeer) vatbaar om LB te krijgen. De respondenten waren meer bereid om een tekencontrole te doen en indien van toepassing een teek te verwijderen na een verblijf in de natuur, dan om beschermende kleding te dragen of insectenwerende middelen te gebruiken. Het percentage respondenten dat preventieve maatregelen nam, varieerde van $6 \%$ voor het gebruik van insectenwerende middelen tot $37 \%$ voor het dragen van beschermende kleding. Personen die zelf een tekenbeet meegemaakt hadden, meer kennis hadden of een gematigde tot grote angst hadden voor teken en LB, deden significant vaker een tekencontrole. Respondenten die significant vaker beschermende kleding droegen, waren vaker werkloos/gepensioneerd, hadden meer kennis over teken en LB, meer angst voor teken en LB en vertrouwden meer op het effect van beschermende kleding. In de toekomst moeten programma's ter preventie van teken en LB zich richten op het vergroten van de kennis over teken en LB, het beïnvloeden van de perceptie en het positieve effect van preventieve maatregelen. 
Hoofdstuk 3 beschrijft een vergelijkbare studie als hoofdstuk 2, maar dan onder schoolkinderen. In totaal deden 1447 schoolkinderen tussen de 9 en 13 jaar van 40 basisscholen verspreid over het land mee aan het onderzoek. De meerderheid van de kinderen $(70 \%)$ beantwoordde ten minste zes van de zeven kennisvragen over teken en LB correct. De overgrote meerderheid van de kinderen (93\%) vond een tekencontrole heel of een beetje belangrijk. Slechts $18 \%$ van de kinderen werd routinematig op teken gecontroleerd door hun ouders of verzorgers. Kinderen die meer kennis hadden over teken en LB en kinderen die iemand kenden met LB, werden vaker gecontroleerd door hun ouders. Kinderen die in bosrijke gebieden wonen, werden vaker gecontroleerd. Het lijkt zinvol om voorlichting over teken en LB ook specifiek op kinderen te richten.

Hoofdstuk 4 is gericht op de identificatie van risicogroepen voor tekenbeten en LB en de profilering van deze risicogroepen. Hiervoor is een kwalitatieve aanpak gehanteerd, grotendeels bestaand uit diepte-interviews. Een dergelijke aanpak is er niet zozeer op gericht om generaliseerbare uitspraken te doen over menselijk gedrag in het algemeen, maar is geschikt om subgroepen te identificeren binnen een populatie, en om de verschillende beweegredenen voor menselijk gedrag te achterhalen. Met deze profielen en inzicht in hun beweegredenen kunnen gezondheidsorganisaties hun communicatie afstemmen op de karakteristieken van deze risicogroepen, bijvoorbeeld door alleen preventieve adviezen te propageren die hoogstwaarschijnlijk zullen worden opgevolgd door de risicogroep.

Door middel van een procedure ontwikkeld door de GGD West-Brabant zijn twee prominente risicogroepen geïdentificeerd. Vervolgens zijn 25 diepte-interviews gehouden met leden van deze groepen. Op basis van hun antwoorden konden de twee risicogroepen verder onderscheiden worden in 'Natuurliefhebbers' die wel of niet controleren op tekenbeten, en 'Ouders' die hun kinderen wel of niet controleren op tekenbeten. Elke groep had een eigen houding ten opzichte van teken en LB en vertoonde daarbij horend gedrag. Het hebben van (indirecte) ervaring met tekenbeten en/of LB bleek de belangrijkste voorspeller te zijn van het opvolgen van preventief advies. Voorlichting moet zich richten op het stimuleren van controleren op tekenbeten in plaats van het voorkomen van tekenbeten (bijvoorbeeld door het dragen van lichaamsbedekkende kleding). Daarnaast is het van belang dat GGD'en mensen leren hoe ze teken van verschillende grootte moeten verwijderen met behulp van verschillende soorten tekentangen of een pincet.

De profielen van de risicogroepen kunnen worden gebruikt om voorlichtingsinterventies te ontwikkelen die de Nederlandse bevolking helpen met het omgaan met teken en tekenbeten.

Hoofdstuk 5 gaat over de wensen en eisen die gebruikers hebben ten aanzien van een applicatie (app) voor de mobiele telefoon met betrekking tot maatregelen ter preventie van teken en LB. Allereerst zijn organisatorische stakeholders en eindgebruikers geïdentificeerd. Daarna is een focusgroepdiscussie gehouden met deze stakeholders en 25 diepte-interviews met de eindgebruikers. Hieruit 
bleek dat de app allereerst gebruikers moet motiveren om zichzelf te controleren op teken na een bezoek aan een risicogebied. De app moet ook een tekenradar bevatten zodat gebruikers kunnen zien waar de teken actief zijn. Verder wilde men een herinnering kunnen instellen dat men zich moet controleren op teken na een bezoek aan de natuur en een mogelijkheid om een tekenbeet te documenteren. De ervaringen met dit onderzoek bevestigen het belang van een zorgvuldige inventarisering van de wensen en eisen van de eindgebruikers en hun context van het gebruik ten behoeve van het op maat maken van adviezen over preventie. Tot slot toont dit onderzoek het belang van de ontwikkeling van persuasieve technologie aan met het oog op het optimaliseren van de naleving van de adviezen.

Om de Nederlandse bevolking te informeren over de maatregelen ter preventie van teken en LB is een folder en een film ontwikkeld. Het doel van de studie in hoofdstuk 6 was om te evalueren wat het effect van deze twee voorlichtingsprodukten, op het gebied van kennis, ervaren ernst en gevoeligheid, eigeneffectiviteit, respons effectiviteit, intentie en gedrag was. Daarnaast is onderzocht of het publiek de folder en de film waardeerde. 1677 respondenten (vanaf 18 jaar) van een representatief internetpanel deden mee aan het onderzoek. Er is een vier-groepen-gerandomiseerd-controle-design toegepast om het effect van de folder en de film te vergelijken met een controlegroep en een extra follow-upcontrolegroep. Alle respondenten bleken na de interventies een goede kennis te hebben van teken en LB. Zowel respondenten die de film zagen als respondenten die de folder kregen, wisten meer over teken en LB dan de respondenten in de controlegroep, en ze waren beter op de hoogte van de juiste preventiemaatregelen. Bovendien hadden zij een grotere intentie om in de toekomst preventieve maatregelen te nemen, dan de respondenten in de controlegroep. Hoewel de respondenten zowel de folder als de film goed waardeerden, vonden ze de 5minuten-film te lang duren. Er kon geen lang termijneffect worden aangetoond van de folder of de film. Deze resultaten tonen aan dat zowel de folder als de film gewaardeerde als effectieve voorlichtingsprodukten zijn om de kennis over teken en LB, de eigen-effectiviteit en de intentie tot het nemen van preventieve maatregelen te vergroten. Echter om effecten op de lange termijn te bereiken, is meer actie nodig.

Kinderen zijn een risicogroep voor tekenbeten en LB. Aangezien het RIVM tot nu toe geen voorlichtingsprodukten had die speciaal gericht waren op kinderen, is een online serious game ontwikkeld. Hoofdstuk 7 beschrijft een studie waarin het effect van een folder over teken en LB wordt vergeleken met het effect van deze game onder schoolkinderen. In totaal deden 887 schoolkinderen tussen de negen en dertien jaar van 25 basisscholen mee. De leerlingen werden per klas verdeeld over de drie interventiegroepen: 'game' (22,4\%), 'folder' $(35,6 \%)$ of controle $(41,9 \%)$. Voorafgaand en onmiddellijk na de interventie vulden de kinderen een korte vragenlijst in. De kennis over teken en LB nam in alle groepen toe. De kinderen die de game hadden gespeeld, waren net als de kinderen in de controlegroep vaker gecontroleerd door hun ouders/verzorgers, dan de kinderen 
die de folder kregen. Dit wijst erop dat er sprake lijkt te zijn van een zogenaamd 'mere measurement effect', een blootstellingseffect enkel door het invullen van een vragenlijst. Aangezien de game niet overwegend een beter effect had dan de folder of de controle, moet de game worden gezien als een aanvulling op andere produkten in een voorlichtingsprogramma over teken en LB gericht op kinderen.

Om de Nederlandse bevolking te informeren over de risico's van teken en hen te motiveren om een tekencontrole te doen als ze in de natuur zijn geweest, en indien van toepassing de teek zo snel mogelijk te verwijderen, is op basis van de studies in hoofdstuk 2, 4 en 5 een applicatie (app) voor de mobiele telefoon ontwikkeld, genaamd: 'Tekenbeet'. Hoofdstuk 8 beschrijft een studie naar het effect van deze app 'Tekenbeet' op het gedrag van volwassenen ten aanzien van teken en LB. Data over het gebruik en de downloads van de app zijn uit Google Analytics gehaald. Daarnaast is een enquete gedaan onder de Nederlandse bevolking (vanaf 18 jaar) over het gebruik, de waardering en het effect van de app. Uit de gegevens van Google Analytics bleek dat de app bijna 50.000 keer was gedownload in de 20 maanden na de lancering in april 2014. De tekenradar en het tekendagboek waren de meest bekeken onderdelen van de app. Er deden 554 respondenten mee aan de online enquete, waarvan er 238 ook nog een tweede keer meededen. De enquete bestond uit vragen over het gebruik van de app, wat mensen weten over teken en Lyme en hoe ze omgaan met (de preventie van) tekenbeten. De gemiddelde tevredenheidsscore was 7,44 (op een schaal van 1-10), $90,9 \%$ van de respondenten gaf aan de app aan anderen aan te bevelen. Respondenten die de app hadden gedownload $(n=243)$ hadden gemiddeld een hogere kennisscore en een grotere intentie om preventieve maatregelen te nemen dan respondenten die de app niet hadden gedownload $(n=311)$. Op basis van deze studie kan worden geconcludeerd dat de app 'Tekenbeet' vaak wordt gebruikt, goed wordt gewaardeerd en effectief is om de kennis over teken en de preventie van tekenbeten te vergroten. Het is een nuttige aanvulling op de andere voorlichtingsprodukten, en vergroot de eigen-effectiviteit tot het nemen van preventieve maatregelen (controleren op en verwijderen van teken). Bovendien vergroot de app de intentie tot het nemen van preventieve maatregelen. Deze effecten blijven niet bestaan over langere tijd. Echter een van de voordelen van mobiele technologie is dat het gebruikt kan worden wanneer en waar het nodig is, wat mogelijk kan bijdragen aan een langdurig effect. Het gebruik van applicaties voor de mobiele telefoon is populair. De app 'Tekenbeet' past binnen deze trend en biedt een modern alternatief voor meer traditionele voorlichtingsmiddelen zoals een folder of informatie op een website.

Hoofdstuk 9 beschrijft een literatuurstudie naar interventiestudies op het terrein van teken en LB, uitgevoerd tussen 1995 en mei 2015. In 2012, publiceerde Mowbray een vergelijkbare literatuurstudie over de periode 1995 tot 2010. Zij deed toen de aanbeveling om meer onderzoek te doen dat gericht is op het vergroten van de evidence-based inzichten in de voorlichting over preventieve maatregelen ten aanzien van teken en LB. Helaas zijn in de onderhavige literatuurstudie niet meer studies geïncludeerd dan Mowbray deed in 2010. Daarom 
wordt opnieuw de alarmklok geluid, net als Mowbray een aantal jaren geleden ook deed. Zolang er geen effectieve maatregelen zijn om de tekenpopulatie in de natuur onder controle te krijgen en er geen vaccin beschikbaar is, kan er alleen worden vertrouwd op voorlichting en communicatie over maatregelen ter preventie van teken en LB. Dit is een oproep aan onderzoekers en subsidiegevers om prioriteit te geven aan onderzoek naar public health interventies ten aanzien van teken en LB want, zoals Benjamin Franklin zei: "An ounce of prevention is worth a pound of cure", oftewel: voorkomen is beter dan genezen.

Tot slot worden in hoofdstuk 10 de bevindingen van alle onderzoeken in dit proefschrift besproken en geïntegreerd vanuit een theoretisch en een methodologisch perspectief. Tevens worden de implicaties ervan voor de praktijk, het beleid en toekomstig onderzoek gegeven. 


\section{Dankwoord}

Wat was het geweldig om de afgelopen jaren met zoveel fijne collega's samen te werken! Dit dankwoord had dus ook best helemaal aan het begin van dit boekje kunnen staan. Je wilt immers starten met de belangrijkste boodschap.

Ik begin met het bedanken van de drie heren mét en ván de puntjes op de i: Dirk, Rik en Jim.

Allereerst mijn promotor: Dirk Ruwaard. We maakten samen een vliegende start. Het plan was er al en we zochten 'alleen nog' een promotor. Jij was meteen heel enthousiast, Dirk. Jij leerde mij dat een plan fijn is, maar dat een rode draad, een planning en een raamwerk onmisbaar zijn. Jij hebt de structuur en de scope van het proefschrift steeds zeer secuur bewaakt.

Vervolgens Rik Crutzen, mijn copromotor. Ik ken niemand die zo snel reageert op mijn mailtjes als jij. Soms leek het er zelfs op dat ik al antwoord had, voordat ik mijn mail had verstuurd ;-) Bewonderenswaardig! Wat hebben we prettig en efficiënt samengewerkt.

En dan Jim van Steenbergen, mijn andere copromotor. Mede dankzij de vogelgriepepidemie van 2003 leerden wij elkaar kennen. Na een open sollicitatie mocht ik bij jou op sollicitatiegesprek komen bij toen nog de Landelijke Coördinatiestructuur Infectieziektebestrijding op de Adriaen van Ostadelaan in Utrecht. Merel was destijds amper zes weken en jij keek er helemaal niet vreemd van op dat ik haar in de Maxi Cosi had meegenomen. Inmiddels wisselen we ongemerkt, soms zelfs tijdens een en dezelfde afspraak, onze 'petten' van copromotor, baas/bazin, collega, vriend/vriendin en weer terug. Dat vind ik héél bijzonder. Veel dank voor bijna vijftien jaar vriendschap, Jim.

De leescommissie, Christiaan Hoebe, Nanne de Vries, Bart van den Borne, Joppe Hovius en Willem Takken, bedank ik voor het beoordelen van mijn manuscript en de bereidheid om aanwezig te zijn tijdens de verdediging daarvan in Maastricht.

Aura Timen, hoofd van de Landelijke Coördinatie Infectieziektebestrijding (LCI) en dus mijn baas, jou wil ik heel graag bedanken voor de mogelijkheid die je mij de afgelopen vijf jaar hebt geboden om aan mijn onderzoek te werken. Jij hebt me geleerd om te gaan met de stress die de combinatie van afdelingshoofd zijn en promotieonderzoek doen met zich meebrengt. Op jouw advies maakte ik met mezelf afspraken over wanneer ik wél en vooral ook wanneer ik 
níet aan het onderzoek zou werken. Dat zorgde ervoor dat ik ook regelmatig en zonder schuldgevoel van een vrij weekend kon genieten. Ik hoop dat we nog lang kunnen samenwerken. Bijzonder dat jij ook in de corona zit, Aura.

Marloes ten Buuren-Bults, vooral het eerste en tweede jaar hebben we met veel plezier samengewerkt. Voornamelijk aan artikelen voor jouw proefschrift, maar ook aan een artikel in mijn boekje. Als paranimf bij jouw promotie heb ik de kunst afgekeken.

Lex van Velsen, samen zijn we gestart met het SOR-project 'e-public health'. Later kwamen daar nog allerlei leuke projectjes (o.a. Twipi) bij. Ik bedank jou heul erg voor je eHealth (techno)logische kijk op communicatie. We blijven gewoon projecten verzinnen waarin we kunnen samenwerken, toch?

Evelien Belfroid, samen met Laura kampioen e-mailtjes schrijven over de Tekenbeet-app. Maar het resultaat mag er zijn! Jouw boekje is inmiddels ook bijna klaar. Ik wens je heel veel succes met de afronding ervan.

Fedor Gassner, we hebben twee jaar met heel veel plezier samengewerkt. 'Hora est' heb ik vaak tegen jou gezegd, als de deadline weer eens onverwacht snel genaderd was. Zo meteen gaat de pedel dat tegen míj zeggen. Hoe bijzonder is het dat jij, dé tekenspecialist van Nederland, nu een van mijn (para-)nimfen bent ;-)

Laura Antonise-Kamp, samen met Evelien kampioen e-mailtjes schrijven over de Tekenbeet-app. Wat kunnen wij heerlijk samenwerken. Niet alleen aan het app-onderzoek, maar ook aan 'het kippenetiket-onderzoek' en het project 'Extra vaccinaties op maat'. Hopelijk blijven we nog heel lang collega's.

Cindy Kengen: de resultaten van jouw afstudeeronderzoek vormden de basis van jouw eerste en mijn laatste publicatie in dit boekje. Zo zie je waar de ervaring van je vader met tekenbeten op het tankstation toe heeft geleid ;-)

Hein Sprong: mede dankzij jouw inzet was er geld om dit onderzoek uit te voeren. Dank daarvoor en natuurlijk voor je altijd bemoedigende woorden en alle hulp bij het schrijven van het boekhoofdstuk.

Albert Wong en Caroline Ameling: wat een fijne collega's zijn jullie! Alle statistische analyses in dit boekje hebben we samen bedacht en uitgevoerd. Behalve de vele, vele prettige en voor mij zeer leerzame discussies over data-analyses vond ik onze gesprekjes over 'het leven' ook heel fijn.

En dan mijn eigen afdeling: 'Team Richtlijnontwikkeling \& Implementatie'. Wat ben ik trots op jullie! En wat hebben we veel gedaan de afgelopen jaren: richtlijnenboeken, quizzen, filmpjes, infographics, Twipi, serious games, apps en nog veel meer. En dan nog al die leuke ZON-, SOR-, SPR-, Innovatie- en Libelleprojecten. Met als klap op de vuurpijl: ons eigen Glazen Huis bij het RIVM afgelopen december. Ik bof maar dat jullie (bijna) altijd minstens zo enthousiast zijn als ik. Vanaf nu heb ik weer alle tijd voor jullie.

Sabine de Jong: het beste paard van de secretariaatsstal! Zonder jouw nooit aflatend enthousiasme voor mijn agendabeheer had ik het zeker niet gered de afgelopen jaren. Je bent een echte topper.

André Jacobi, bijna tien jaar mijn kamergenoot, eerst in Utrecht en later in 
Bilthoven. Wat hebben wij samen veel meegemaakt en besproken in al die jaren. We hadden 't over álles; natuurlijk over werk, maar zeker ook over kinderen, vakanties, relaties en zelfs (kapotte) auto's...

Alle overige collega's van de LCI: dank jullie wel voor alle fijne jaren. Wat hebben we het goed samen.

Liesbeth Mollema, alias Lars: wat een heerlijke collega ben jij toch. Volgens mij benaderen wij de ideale samenwerking. We praten gewoon allebei tegelijk tijdens een afspraak; hoe efficiënt $(-)$

Alle overige collega's van het CIb en de andere centra van het RIVM: veel dank voor alle collegialiteit. Wat werken we toch bij een mooi instituut met zóveel mogelijkheden!

Nicole Beaujean, mijn oudste zus en eindelijk ook mijn paranimf. Ik had nooit met zó'n gerust en fijn gevoel kunnen werken als jij niet ruim tien jaar de gezellige en toegewijde gouvertante van Thomas, Koen en Merel was geweest!

Gjerrit Meinsma, bedankt voor de consistente en fraaie vormgeving van de 'thesis desis'.

Liefste vrienden en vriendinnen Hans, Paul, Mart, Carla, Ida, Monique, Henriette, Franka, Ineke, Titia, Claar, Marianne, Ellen, Lien, Wendy, Marisca, Roos, Damiet, Karin, Irene en Immy: dank voor onze vriendschap de afgelopen jaren. De gezellige etentjes, wandelingen, logeerweekenden, theater- en saunabezoekjes (mét dompelbad!), carpoolritten, appjes, kaartjes en goede gesprekken waren en zijn onmisbaar voor mij.

Lieve (ex-schoon-)familie, dank voor jullie liefde en begrip. Vanaf nu heb ik weer veel meer tijd.

Lieve zus Geraldine, met wie ik de liefde voor Hippocrates deel, wat fijn dat jij mijn zus bent.

Ubi bene, ibi... mam en pap: dank jullie wel voor ons warme en stabiele nest. Dé basis voor mijn gelukkige leven.

Lieve Thomas, hoewel ik 30 jaar ouder ben, is dit voor mij de eerste keer dat ik promoveer. Jij promoveert sinds je vijfde al bijna elk voetbalseizoen. Wat ben je toch een kanjer!

Lieve Koen, we doen allebei examen dit jaar, hoe bijzonder is dat?! Ik ben erg trots op je.

Lieve Merel, liefste dochter! Wat hebben we ons samen verheugd op dit feest, hè? Een mooie feestjurk en éindelijk... hóge hakken!

En tot slot, lieve Marco, woorden zijn overbodig: 


\section{Publications}

D.J. Beaujean, H.E. Blok, C.M. Vandenbroucke-Grauls, A.J. Weersink, J.A. Raymakers, and J. Verhoef. Surveillance of nosocomial infections in geriatric patients. J Hosp Infect, 36(4):275-284, 1997.

D.J. Beaujean, H.E. Blok, A.J. Weersink, and J. Verhoef. Long-term methicillinresistant Staphylococcus aureus (MRSA) carriage and tagging of patient records: in Utrecht you're not MRSA-positive for life. J Hosp Infect, 39(1):83, 1998.

D.J. Beaujean, A.J. Weersink, H.E. Blok, H.M. Fréay, and J. Verhoef. Determining risk factors for methicillin-resistant Staphylococcus aureus carriage after discharge from hospital. J Hosp Infect, 42(3):213-218, 1999.

J. Verhoef, D. Beaujean, H. Blok, A. Baars, A. Meyler, C. van der Werken, and A. Weersink. A Dutch approach to methicillin-resistant Staphylococcus aureus. Eur J Clin Microbiol Infect Dis, 18(7):461-466, 1999.

D.J. Beaujean, A.J. Weersink, A. Troelstra, and J. Verhoef. A pilot study on infection control in 10 randomly selected European hospitals: results of a questionnaire survey. Infect Control Hosp Epidemiol, 21(8):531-534, 2000.

D. Beaujean, H. Blok, A. Gigengack-Baars, T. Kamp-Hopmans, K. Ballemans, J. Verhoef, and A. Weersink. Five-year surveillance of patients with communicable diseases nursed in isolation. J Hosp Infect, 47(3):210-217, 2001.

D. Beaujean, S. Veltkamp, H. Blok, A. Gigengack-Baars, C. van der Werken, J. Verhoef, and A. Weersink. Comparison of two surveillance methods for detecting nosocomial infections in surgical patients. Eur J Clin Microbiol Infect Dis, 21(6):444-448, 2002.

F. Boukes, Tj. Wiersma, D. Beaujean, R.J.F. Burgmeijer, and A. Timen. Tetanusprofylaxe in de huisartsenpraktijk. Ned Tijdschr Geneeskd, 148(44):21722173, 2004. 
D.J. Beaujean, M.F. Verweij, and J.E. van Steenbergen. Pneumococcal vaccination; arguments for informing parents about the options available. Ned Tijdschr Geneeskd, 149(17):909-911, 2005.

C.M.J.E. Vandenbroucke-Grauls and D.J.M.A. Beaujean. Meticillineresistente Staphylococcus aureus bij veehouders. Ned Tijdschr Geneeskd, 150(31):1710-1712, 2006.

I. van Loo, X. Huijsdens, E. Tiemersma, A. de Neeling, N. van de Sande-Bruinsma, D. Beaujean, A. Voss, and J. Kluytmans. Emergence of methicillin-resistant Staphylococcus aureus of animal origin in humans. Emerg Infect Dis, 13(12):1834-1839, 2007.

D.J.M.A. Beaujean, I.M.S. van Ouwerkerk, A. Timen, R.J.F. Burgmeijer, P.E. Vermeer-de Bondt, and J.E. van Steenbergen. Mogelijke blootstelling aan rabiës in de anamnese: rabiësadvisering in Nederland. Ned Tijdschr Geneeskd, 152(9):473-477, 2008. Erratum in: Ned Tijdschr Geneeskd. 2008;152(12):720.

M. Bults and D.J.M.A. Beaujean. De Mexicaanse griep: reacties van het publiek op de berichtgeving, gemeten met een internetpanel. Ned Tijdschr Geneeskd, 153:1215-1217, 2009.

M. Bults, D.J.M.A. Beaujean, O. de Zwart, G. Kok, P. van Empelen, J.E. van Steenbergen, J.H. Richardus, and H.A.C.M. Voeten. Mexicaanse griep: risicoperceptie bij de bevolking, eigen maatregelen en vertrouwen in overheidsinformatie. Ned Tijdschr Geneeskd, 154:A1686, 2010.

M. Bults, D.J. Beaujean, O. de Zwart, G. Kok, P. van Empelen, J.E. van Steenbergen, J.H. Richardus, and H.A. Voeten. Perceived risk, anxiety, and behavioural responses of the general public during the early phase of the Influenza a $(\mathrm{H} 1 \mathrm{~N} 1)$ pandemic in the Netherlands: results of three consecutive online surveys. BMC Public Health, 11:2, 2011.

J.K. Breteler, J.P. Oudhoff, J.M. Munster, J.G. Aarnoudse, J.E. van Steenbergen, and D.J. Beaujean. Risks, trust and knowledge: determinants of pregnant women's decisions regarding participation in a future Q fever screening and treatment program during a large epidemic in The Netherlands. Prenat Diagn, 31(8):814-820, 2011.

W. van der Weerd, D.R. Timmermans, D.J. Beaujean, J. Oudhoff, and J.E. van Steenbergen. Monitoring the level of government trust, risk perception and intention of the general public to adopt protective measures during the influenza A (H1N1) pandemic in The Netherlands. BMC Public Health, 11:575, 2011. 
M. Bults, D.J. Beaujean, J.H. Richardus, J.E. van Steenbergen, and H.A. Voeten. Pandemic influenza A (H1N1) vaccination in The Netherlands: parental reasoning underlying child vaccination choices. Vaccine, 29(37):6226-6235, 2011.

L. van Velsen, J.E. van Gemert-Pijnen, D.J. Beaujean, J. Wentzel, and J.E. van Steenbergen. Should health organizations use web 2.0 media in times of an infectious disease crisis? An in-depth qualitative study of citizens' information behavior during an EHEC outbreak. J Med Internet Res, 14(6), 2012.

M. Bults, D.J. Beaujean, C.J. Wijkmans, A. Timen, J.H. Richardus, and H.A. Voeten. Why did patients with cardiovascular disease in the Netherlands accept Q fever vaccination? Vaccine, 30(23):3369-3375, 2012.

L. van Velsen, D.J. Beaujean, and J.E. van Gemert-Pijnen. Why mobile health app overload drives us crazy, and how to restore the sanity. BMC Med Inform Decis Mak, 13:23, 2013.

D.J. Beaujean, M. Bults, J.E. van Steenbergen, and H.A. Voeten. Study on public perceptions and protective behaviors regarding Lyme disease among the general public in the Netherlands: implications for prevention programs. BMC Public Health, 13:225, 2013.

D. Beaujean, L. van Velsen, J.E. van Gemert-Pijnen, A. Maat, J.E. van Steenbergen, and R. Crutzen. Using risk group profiles as a lightweight qualitative approach for intervention development: an example of prevention of tick bites and Lyme disease. JMIR Res Protoc, 2(2):e45, 2013.

D.J. Beaujean, F. Gassner, A. Wong, J.E. van Steenbergen, R. Crutzen, and D. Ruwaard. Determinants and protective behaviours regarding tick bites among school children in the Netherlands: a cross-sectional study. BMC Public Health, 13:1148, 2013.

L. van Velsen, D.J. Beaujean, J. Wentzel, J.E. van Steenbergen, and J.E. van Gemert-Pijnen. Developing requirements for a mobile app to support citizens in dealing with ticks and tick bites via end-user profiling. Health Informatics J, 21(1):24-35, 2015.

M. Bults, D. Beaujean, C. Wijkmans, J.H. Richardus, and H. Voeten. Q fever in the Netherlands: public perceptions and behavioral responses in three different epidemiological regions: a follow-up study. BMC Public Health, 14:263, 2014.

R. Crutzen and D. Beaujean. Preventive behaviours regarding tick bites. BMJ, 348:g231, 2014. 
L. van Velsen, D.J. Beaujean, J.E. van Gemert-Pijnen, J.E. van Steenbergen, and A. Timen. Public knowledge and preventive behavior during a large-scale Salmonella outbreak: results from an online survey in the Netherlands. BMC Public Health, 14:100, 2014.

M. Bults, D.J.M.A. Beaujean, J.H. Richardus, and H. Voeten. Perceptions and behavioral responses of the general public during the 2009 Influenza A (H1N1) pandemic. Journal Disaster Medicine and Public Health Preparedness, 9(2):207-219, 2015.

D. Beaujean, R. Crutzen, C. Kengen, J. van Steenbergen, and D. Ruwaard. Increase in ticks and Lyme borreliosis, yet research into its prevention on the wane. Vector Borne Zoonotic Dis, 16(5):349-351, 2016.

D.J. Beaujean, R. Crutzen, F. Gassner, C. Ameling, A. Wong, J.E. van Steenbergen, and D. Ruwaard. Comparing the effect of a leaflet and a movie in preventing tick bites and Lyme disease in The Netherlands. BMC Public Health, 16:495, 2016.

D.J.M.A. Beaujean, F. Gassner, A. Wong, J.E. van Steenbergen, R. Crutzen, and D. Ruwaard. Education on tick bite and Lyme borreliosis prevention, aimed at schoolchildren in the Netherlands: comparing the effects of an online educational video game versus a leaflet or no intervention. BMC Public Health, 16(1):1163, 2016.

D.J. Beaujean and H. Sprong. Evidence-based health promotion programmes and tools to prevent tick bites and Lyme borreliosis. In: M.A.H. Braks, S.E. van Wieren, W. Takken, and H. Sprong, editors, Ecology and prevention of Lyme borreliosis. Wageningen Academic Publishers, 2016. 


\section{Curriculum vitae}

The author of this thesis, Desirée Beaujean (1970), was born in Heerlen, in the south of the Netherlands. After completing her gymnasium studies at the St Bernardinuscollege in Heerlen in 1988, she started studying Health Sciences at the Radboud University Nijmegen. In her second year she switched to the Hogeschool Eindhoven to study a brand-new degree course in Hygiene and Sterilisation Technology, successfully graduating in July 1993. Her final internship in the department of Hospital Hygiene at the University Medical Center of Utrecht (UMCU) led to an employment contract starting in July 1993. She worked for several years as an infection control practitioner in the UMCU and, in 1996, began a part-time course in Health Sciences at Maastricht University, specialising in Health Education. For three years she worked four days a week at the UMCU and travelled for her study every Friday to Maastricht University. In September 1999 she received her degree, on the very day that her first son Thomas was born! Meanwhile, in January 1999, she had taken a place as a junior researcher at the University Utrecht working on an international study examining the link between the development of antibiotic resistance, infection control policies and antibiotic policies in ten European hospitals.

In May 2000 Desirée began a three year investigation into the quality of specialist medical care at the Netherlands Institute for Health Services (Nivel). Since April 2003 she has been employed by the National Coordination Centre for Communicable Disease Control (LCI), which became part of the Centre for Infectious Disease Control of the National Institute for Public Health and the Environment (RIVM) in June 2005. Desirée now heads up the 'Guideline Development and Implementation' department, a department which is responsible for the development and implementation of guidelines on infectious disease control in public health. In January 2017, the National Centre for Hygiene and Safety (LCHV) was integrated in her department. Since 2005, the department has tripled in size. Because of her special interest in health education, Desirée worked part-time from 2012 to 2016 on two research projects. One project examined ways of introducing the use of social media in the course on infectious diseases. This project was financed by the Strategic Research Programme of the RIVM and carried out at the RIVM, in collaboration with University Twente. The other project was focused on improving educational programmes on ticks and Lyme disease and financed 
by the Dutch Ministry of Health, Welfare and Sports. The main results of these two projects are partly bundled in this thesis. In November 2015, Desirée won the RIVM Innovation Price after developing the 'Tick Removal Trainer' and she was 'RIVM-employee of the year' last January. She is currently involved in many projects such as the development of a mobile app with the LCI-guidelines and the citizen science project 'To gather'. 